\title{
IntechOpen
}

\author{
IntechOpen Book Series \\ Biochemistry, Volume 9
}

\section{Chemical Properties of Starch}

Edited by Martins Emeje 



\title{
Chemical Properties of Starch
}

\author{
Edited by Martins Emeje
}



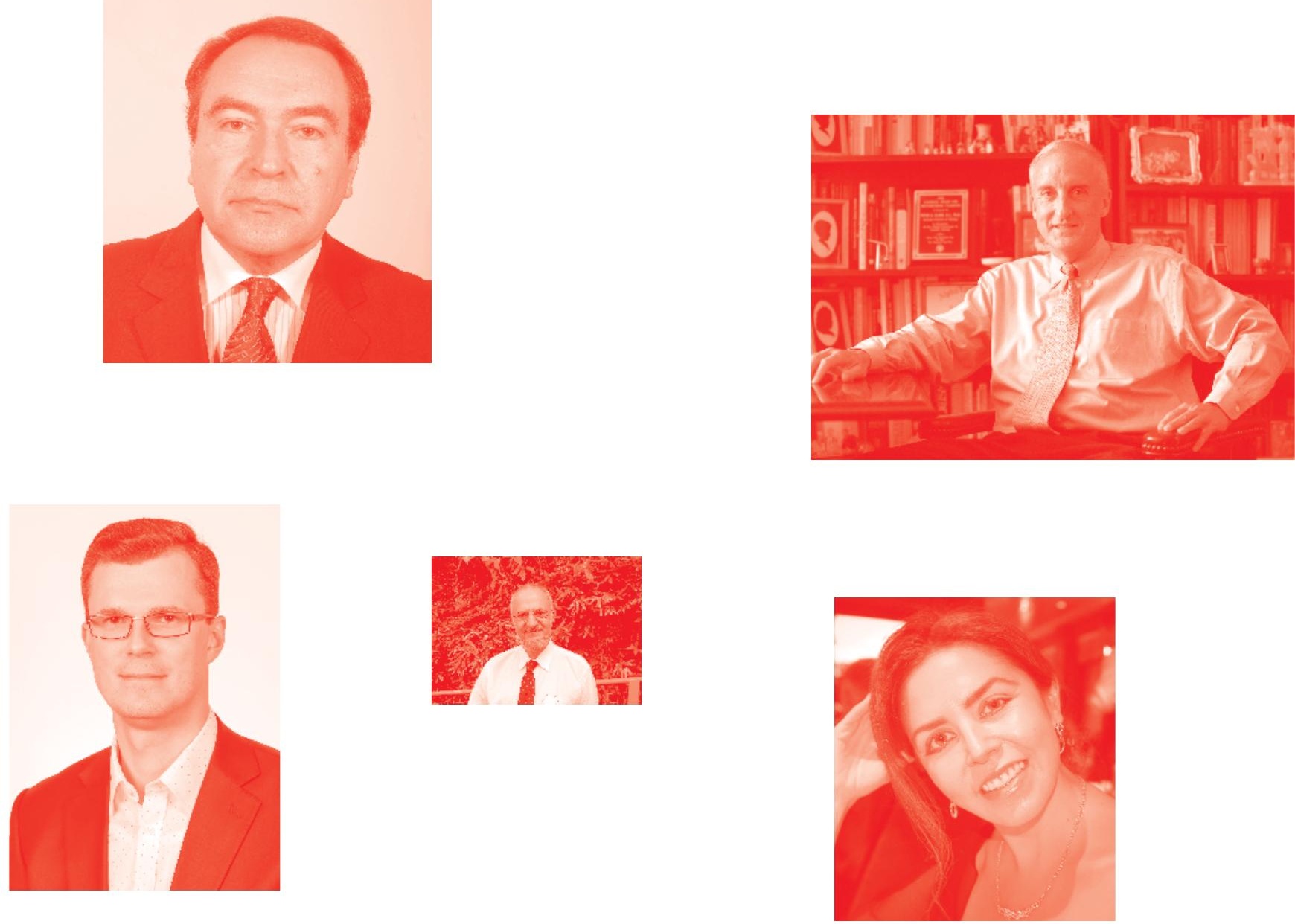

Supporting open minds since 2005
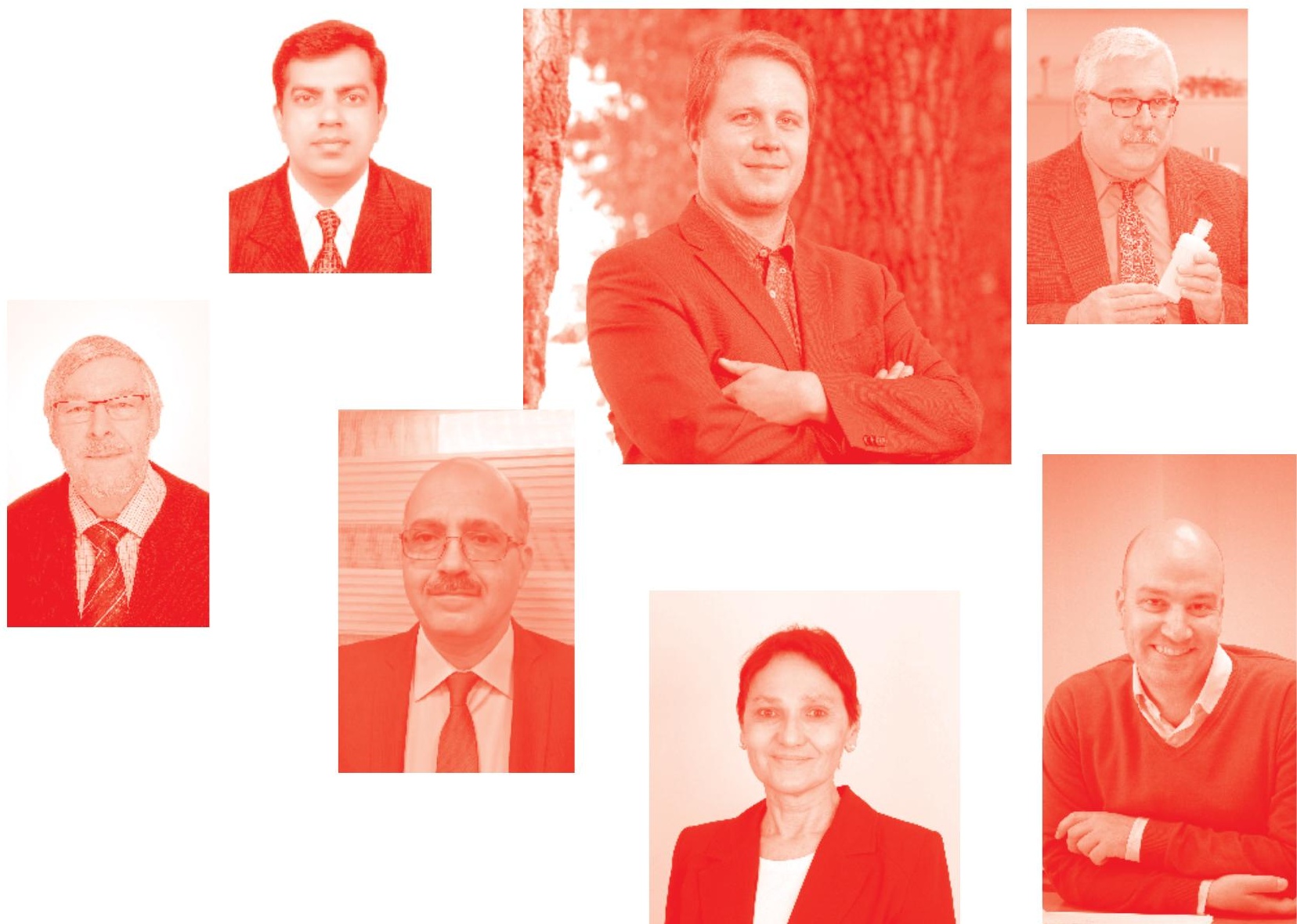
Chemical Properties of Starch

http: //dx. doi. org/10.5772/intechopen. 78119

Edited by Martins Emeje

Part of IntechOpen Book Series: Biochemistry, Volume 9

Book Series Editor: Miroslav Blumenberg

Contributors

Oladapo Adetunji, Haq Nawaz, Rashem Waheed, Mubashir Nawaz, DureShahwar, Henry Omoregie Egharevba, Omolola Fatokun, Ben Amadi, Christian Chibuogwu, Zikora Anyaegbunam, Emesiani Benjamin, Ofoefule Sabinus, William Sullivan, Shyamalima Gogoi, Lee Hoon Ho, Liu Zhongdong, Liu Boxiang, Olobayo Kunle

() The Editor(s) and the Author(s) 2020

The rights of the editor(s) and the author(s) have been asserted in accordance with the Copyright, Designs and Patents Act 1988. All rights to the book as a whole are reserved by INTECHOPEN LIMITED. The book as a whole (compilation) cannot be reproduced, distributed or used for commercial or non-commercial purposes without INTECHOPEN LIMITED's written permission. Enquiries concerning the use of the book should be directed to INTECHOPEN LIMITED rights and permissions department (permissions@intechopen.com).

Violations are liable to prosecution under the governing Copyright Law .

\section{(cc) BY}

Individual chapters of this publication are distributed under the terms of the Creative Commons Attribution 3. 0 Unported License which permits commercial use, distribution and reproduction of the individual chapters, provided the original author(s) and source publication are appropriately acknowledged. If so indicated, certain images may not be included under the Creative Commons license. In such cases users will need to obtain permission from the license holder to reproduce the material. More details and guidelines concerning content reuse and adaptation can be found at http : //www . intechopen . com/copyright-policy. html.

\section{Notice}

Statements and opinions expressed in the chapters are these of the individual contributors and not necessarily those of the editors or publisher. No responsibility is accepted for the accuracy of information contained in the published chapters. The publisher assumes no responsibility for any damage or injury to persons or property arising out of the use of any materials, instructions, methods or ideas contained in the book.

First published in London, United Kingdom, 2020 by IntechOpen

IntechOpen is the global imprint of INTECHOPEN LIMITED, registered in England and Wales, registration number: 11086078, 7th floor, 10 Lower Thames Street, London,

EC3R 6AF, United Kingdom

Printed in Croatia

British Library Cataloguing-in-Publication Data

A catalogue record for this book is available from the British Library

Additional hard and PDF copies can be obtained from orders@intechopen .com

Chemical Properties of Starch

Edited by Martins Emeje

p. $\mathrm{cm}$.

Print ISBN 978-1-83880-115-1

Online ISBN 978-1-83880-116-8

eBook (PDF) ISBN 978-1-78985-697-2

ISSN 2632-@983 


\section{We are IntechOpen, \\ the world's leading publisher of Open Access books}

Built by scientists, for scientists

\section{$4,700+$}

Open access books available

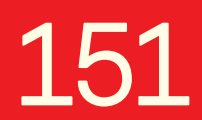

Countries delivered to
$120,000+$

International authors and editors

Our authors are among the

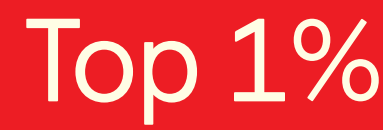

most cited scientists

Contributors from top 500 universities
$135 \mathrm{M}+$

Downloads

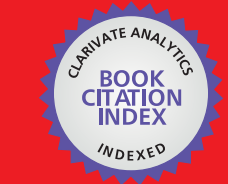

WEB OF SCIENCE ${ }^{\mathrm{MM}}$

Selection of our books indexed in the Book Citation Index in Web of Science ${ }^{\mathrm{TM}}$ Core Collection (BKCI)

\section{Interested in publishing with us? \\ Contact book.department@intechopen.com}

Numbers displayed above are based on latest data collected.

For more information visit www.intechopen.com 



\section{IntechOpen Book Series Biochemistry \\ Volume 9}

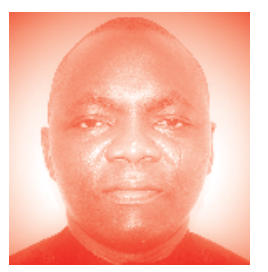

Professor Martins Emeje holds a Bachelor of Pharmacy with distinction from Ahmadu Bello University, Nigeria. He was immediately hired by the National Institute for Pharmaceutical Research and Development. He subsequently obtained a Master of Pharmacy and PhD from University of Nigeria, Nsukka, where he received the best $\mathrm{PhD}$ award. Prof. Emeje's several international fellowships include the prestigious Raman fellowship. He has published over 100 primary scientific articles and patents. Prof. Emeje was the head of the institute's spin-off company (NIPCO) during which the first indigenous phytomedicine was successfully licensed to an indigenous multinational pharmaceutical industry. He holds a professional teaching qualification and is a visiting Professor to Nnamdi Azikiwe University, Awka. Prof. Emeje also holds an advanced postgraduate certificate in project management from Walden University, USA.

\section{Editor of Volume 9:}

Martins Emeje

National Institute for Pharmaceutical Research and Development, Abuja, Nigeria

\section{Book Series Editor: Miroslav Blumenberg}

NYU Langone Medical Center, New York, USA

\section{Scope of the Series}

Biochemistry, the study of chemical transformations occurring within living organisms, impacts all of life sciences, from molecular crystallography and genetics, to ecology, medicine and population biology. Biochemistry studies macromolecules proteins, nucleic acids, carbohydrates and lipids -their building blocks, structures, functions and interactions. Much of biochemistry is devoted to enzymes, proteins that catalyze chemical reactions, enzyme structures, mechanisms of action and their roles within cells. Biochemistry also studies small signaling molecules, coenzymes, inhibitors, vitamins and hormones, which play roles in the life process. Biochemical experimentation, besides coopting the methods of classical chemistry, e.g., chromatography, adopted new techniques, e.g., X-ray diffraction, electron microscopy, NMR, radioisotopes, and developed sophisticated microbial genetic tools, e.g., auxotroph mutants and their revertants, fermentation etc. More recently, biochemistry embraced the 'big data' omics systems. 
Initial biochemical studies have been exclusively analytic: dissecting, purifying and examining individual components of a biological system; in exemplary words of Efraim Racker, (1913 -1991) “Don't waste clean thinking on dirty enzymes." Today however, biochemistry is becoming more agglomerative and comprehensive, setting out to integrate and describe fully a particular biological system. The 'big data' metabolomics can define the complement of small molecules, e.g., in a soil or biofilm sample; proteomics can distinguish all the proteins comprising e.g., serum; metagenomics can identify all the genes in a complex environment e.g., bovine rumen. This Biochemistry Series will address both the current research on biomolecules, and the emerging trends with great promise. 


\section{Contents}

Preface

Section 1

Modification of Starch

Chapter 1

Chemically Modified Starches as Excipients in Pharmaceutical

Dosage Forms

by Oladapo Adewale Adetunji

Chapter 2

Physical and Chemical Modifications in Starch Structure and Reactivity

by Haq Nawaz, Rashem Waheed, Mubashir Nawaz

and Dure Shahwar

Chapter 3

Starch Source and Its Impact on Pharmaceutical Applications by Olobayo O. Kunle

\section{Section 2}

Application of Starch

Chapter 4

Studies on the Property and Application of Starch Sugar Ester Dodecenylsuccinic

by Liu Zhongdong, Liu Boxiang, Wei Guohua, Zhu Xin

and Wang Huabin

Chapter 5

Chemical Properties of Starch and Its Application in the

Food Industry

by Henry Omoregie Egharevba

Chapter 6

Application of Starch and Starch Derivatives in Pharmaceutical Formulation

by Christian Chibuogwu, Ben Amadi, Zikora Anyaegbunam, Benjamin Emesiani and Sabinus Ofoefule 
Section 3

Resistant Starch

Chapter 7

Resistant Starch from Exotic Fruit and Its Functional Properties:

A Review of Recent Research

by Lee-Hoon Ho and Shi-Yun Wong

Chapter 8

Resistant Starch

by William Russell Sullivan

Section 4

Micrometry and Food Starch

Chapter 9

Value of Starch in Indian Traditional Food System

by Shyamalima Gogoi

Chapter 10

Micrometrics and Morphological Properties of Starch

by Omolola Temitope Fatokun 


\section{Preface}

Starch is a natural, cheap, available, renewable, and biodegradable polymer produced by many plants as a source of stored energy. It is the second most abundant biomass in nature. It is found in plant leaves, stems, roots, bulbs, nuts, stalks, crop seeds, and staple crops such as rice, corn, wheat, cassava, and potato. It has wide use in the food, textiles, cosmetics, plastics, adhesives, paper, and pharmaceutical industries. For example, in the food industry starch has a wide range of applications ranging from being a thickener, gelling agent, to being a stabilizer for making snacks, meat products, and fruit juices. It is either used as an extract from the plant in which case it is called "native starch", or it undergoes one or more modifications to reach specific properties and is called "modified starch". Worldwide, the main sources of starch are maize $(82 \%)$, wheat $(8 \%)$, potatoes $(5 \%)$, and cassava (5\%). Nine years ago, the world starch market was estimated to be 70.0 million tons, based on an annual global growth of $2.2 \%$. The value of the output is worth $€ 15$ billion per year. It is worthy to note that, as far back as the first century, Celsus, a Greek physician, had described starch as a wholesome food. Starch was added to rye and wheat breads during the 1890s in Germany and to beer in 1918 in England. The 1930s saw the use of starch as components of salad dressings in mayonnaise. Starch is also used as sweeteners. Acid-catalyzed hydrolysis of starch is used in the improvement of wines in Germany in the 1830s. The leading users of starch are believed to be the brewing, baking powder, and confectionery industries. In fact, the versatility of starch applications is unparalleled. The need for starch continues to increase especially as this biopolymer finds application in other industries including medicine and pharmacy. From serving as a source of food for man, starch has been found to be effective in drying up skin lesions (dermatitis), especially where there are watery exudates. Consequently, starch is a major component of dusting powders, pastes, and ointments meant to provide protective and healing effect on skins. Starch mucilage has also performed well as an emollient and major base in enemas. Because of its ability to form complexes with iodine, starch has been used in treating iodine poisoning. Acute diarrhea has also been effectively prevented or treated with starch-based solutions due to the excellent ability of starch to take up water. In pharmacy, starch appears indispensable. It is used as excipients in several medicines. Its traditional role as a disintegrant or diluent is giving way to the more modern role as drug carrier; the therapeutic effect of the starch-adsorbed, starch-encapsulated, or starch-conjugated drug largely depends on the type of starch. Starch and starch derivatives also play very important roles in environmental management, agriculture, biomedical engineering and textiles, and this appears to be driving the starch industry in the utilisation of raw materials other than maize and potato.

Chemically, starch is a carbohydrate polymer consisting of two inherently incompatible molecules: amylose and amylopectin. Although starch is generally considered inert, the controversy over its inertness rages due to its chemical properties and attendant reactivity. Some have argued that starch has moved from its traditional role as food to being an indispensable medicine. To continually consider starch as an ordinary inert excipient, therefore, is to be oblivious of the influence this important biopolymer plays in various fields of human endeavor; roles which are directly or indirectly related to its chemical properties. Starch is very 
sensitive to acid attack, and this is equally attributed to its chemical properties. The chemical properties of starch as conferred by the presence, amount and/or quality of amylose and amylopectin molecules, granule structure, and the nature and amounts of the lipid and protein molecules vary with the botanical source of the starch. Therefore, what has been discovered about the structural features of one type of starch does not necessarily apply to other types of starch.

Chemical Properties of Starch is a collective project that brings together authors of varying backgrounds, experience, and expertise in starch.

In order to simplify and enable the reader to appreciate the interesting perspectives brought to bear by this team, this book has been organised into four major parts;

\section{Modification of Starch}

\section{Application of Starch}

\section{Resistant Starch}

\section{Micrometry and Food Starch}

This book comprises 10 chapters, arranged in an ordered sequence, starting with the basics of starch; micrometry, i.e. the qualitative and quantitative morphological, chemical, and genetic properties of starch. It continues with starch as food and how the chemical properties influence the delicacies peculiar to the Indian community. Following this are the chapters on resistant starches, which comprehensively examine the benefits of resistant starch to human health by promoting a balanced blood sugar and beneficial gut bacteria. There are also special articles on the modification and applications of starch and starch derivatives as well as the role of starch chemistry on its properties, written by authors based on their practical experience in the industry and academia, making this book a very rich compendium. In general, this book provides the reader with an excellent and rich knowledge of the role the botanical or biological source of starch play in determining its chemical properties and the influence of the chemical properties on starch functionalities and roles in various fields. The book will be useful to pharmacists, agriculturists, chemists, biologists, chemical engineers, and health research scientists. University professors, research professors, researchers, and their undergraduate and postgraduate students will find this multi-authored, multi-dimensional book useful when preparing their thesis on starch-related projects.

Finally, I wish to express my gratitude to the authors for agreeing to share their wealth of experience in their contributions, my excellent Author Service Manager, Marijana, and to my wife, Comfort, who endured my late nights in the course of editing the contributions for this book. 
Section 1

Modification of Starch 



\title{
Chemically Modified Starches as Excipients in Pharmaceutical Dosage Forms
}

\author{
Oladapo Adewale Adetunji
}

\begin{abstract}
Excipients play a great role in ensuring that pharmaceutical dosage form meets the required specifications of quality approved by the relevant authorities. Starches are the most widely used excipients in dosage form development, but their use is enhanced by several modification methods (such as chemical degradation, physical alteration, enzymatic modifications or crystalline-genetic transformation), all aimed at restructuring the starch granules, thus ensuring that the reactive polymers are accessible to reactants. Chemical modification of starch usually follows the pathway of substitution, degradation or cross-linking. The most common approaches to chemical modification of starches for pharmaceutical use include oxidation, esterification and etherification, which are employed to optimize the structural and nutritional properties for targeted applications. The oxidant type, botanical origin of starch, and process conditions are all determinants of how effective the oxidation is. Esterification improves the hydrophobicity of starch usually via acetylation and phosphorylation, while etherification is a derivatization technique that involves the use of various alkylation agents such as dimethyl sulphate, diethyl sulphate, alkylene oxides (epoxides) and alkyl halides. Chemically modified starch enhances thermoplasticity, solubility and flow properties. In conclusion, chemically modified starches have shown excellent potentials and are, thus, incorporated as core excipients in several pharmaceutical drug formulations.
\end{abstract}

Keywords: excipients, modified starches, chemical modification, formulations, polymers

\section{Introduction}

The goal of an ideal oral solid-dosage drug delivery system is to achieve a situation where the desired therapeutic effect is obtained in conformity with official standards. Excipients play a great role in ensuring that the dosage form meets the required specifications of quality by modifying the release, absorption, distribution and elimination profiles of the drug. This assures product efficacy, safety, patient compliance and acceptance. Compressed tablets still account for the most widely used oral solid dosage form due to their compactness, precision of doses and ease of administration and production. The process of tableting requires that all the ingredients are fairly dried, powdered (or granulated) to form uniform particle sizes, with good content uniformity to ensure delivery of the right dose of the active 
pharmaceutical ingredient. Excipients form a larger bulk of the constituent of tablets and the presence of the excipients ensures, amongst other goals, that acceptable physical and mechanical properties of tablets are achieved.

Based on their primary functions, excipients are classified into two categories as follows:

i. Those which principally affect the compressional characteristics of the tablets: diluents (fillers), binders (adhesives), lubricants, glidants, anti-adherents.

ii. Those which principally affect the bio-pharmaceutics, chemical and physical stability: disintegrants, flavourants, sweeteners and colourants.

Ideally, pharmaceutical excipients are expected to be non-toxic, physically and chemically stable, commercially available, pleasant organoleptic properties and economically feasible [1].

This chapter will discuss the different chemical modifications of starch and give documented examples of starches that have been modified and used as excipients in pharmaceutical dosage forms.

\section{Starch}

Starch is one of the most abundant organic chemicals on earth and it is synthesized in the amyloplasts of seeds, grain, roots and tubers of many plants where it serves as the chemical storage form of energy from the sun [2]. It is a carbohydrate consisting of a large number of glucose units joined by glycosidic bonds. It is the most common carbohydrate in the human diet and is contained in large amounts in such staple foods as potatoes, wheat, maize (corn), rice, and cassava [3]. Pure starch is a white, tasteless and odourless powder that is, insoluble in cold water or alcohol. It consists of two types of molecules: the linear helical amylose and the branched amylopectin. Depending on the plant, starch generally contains $20-25 \%$ amylose and $75-80 \%$ amylopectin by weight [4]. The amylose portion is a macromolecule that is, linear in nature, while the amylopectin is the highly branched portion of the starch. Glycogen, the glucose store of animals, is a more branched version of amylopectin.

Starch is the most commonly used excipient in the pharmaceutical industry and this wide application is premised on its availability, low cost, high caloric value, inherent excellent physicochemical properties and the ease of its modification to other derivatives. The versatility of starch in industrial applications is clearly defined by its physicochemical properties; therefore a thorough evaluation of the necessary parameter is important in elucidating its industrial use. The morphology and physicochemical characteristics of starch are typical of its biological origin; hence starch from each plant source will vary somewhat in appearance, composition and properties [2].

The preclusion of the application of starch in its native form in the pharmaceutical industry is based on certain setbacks that have necessitated the need to modify starches to achieve the objective of the formulation scientist in ensuring the production of standard tablets, thereby circumventing the limitations inherent in the use of native starch as pharmaceutical ingredients. Such setbacks that have been linked to the unfavourable properties of native starch include poor solubility, poor flow properties and high hydrophilicity.

Starch has been extensively modified to stabilize the granules during processing. This involves restructuring the starch granules and dispersion of the amylopectin 
polymers within the granules, thus ensuring that the reactive polymers are accessible to the reactants. Consequently, the profile of starch (after modification) is enhanced as an excipient in the drug manufacturing industry. Starch can be modified through chemical degradation, physical alteration, enzymatic modifications or genetic transformation.

\section{Degradation of starch}

Starch degradation proceeds under basic conditions and the extent of degradation depends on the several factors such as the presence or absence of oxygen, concentration of the base used, duration of the reaction and the temperature at which it occurs. Matsunaga and Seib reported the liberation of the proteins and lipids present in wheat starch when exposed to $0.4 \% \mathrm{w} / \mathrm{w}$ dilute aqueous alkali solution at $25^{\circ} \mathrm{C}$. It was documented that the process of degradation was slowed down by the presence of hydroxyl ions [5]. In the presence of oxygen, starch degradation is a slow process that has a direct relationship with the concentration of alkali. However, it is not all parts of starch that undergoes degradation when exposed to alkali conditions. Those parts that are alkali resistant to degradation are sensitive to the presence of acids, thus suggesting that starch has selective degradation, depending on the chemical used.

The reducing end of the macromolecular chain of starch has been suggested to be the point where starch degradation progresses from; hence, the reducing-terminal glucose units, even in branched structures, are split off, indicating that, not only amylose but also amylopectin is alkali labile [6].

Starch can be degraded by pregelatinization. Gelatinization involves the disruption of the crystalline and granular structures of starch when heat and water are applied. The presence of excess water (not less than 90\%w/w) causes the starch granules to swell due to preferential solubility of the amylose molecules in water. When heat is applied and the gelatinization temperature is exceeded, the crystalline region of the starch becomes irreversibly disoriented, eventually leading to lattice disruption. Alabi et al. pregelatinized millet, sorghum and cocoyam starches and the process resulted in better flowability and compressibility than the natural starches. Tramadol tablets prepared with freeze-dried pregelatinized starches generally exhibited higher crushing strength but lower friability than those prepared with the natural starches [7].

\section{Chemical modification of starch in drug formulations}

The biodegradable nature of starch, presence of certain functional groups and the granular structure (macroscopic) have contributed significantly to the chemical modifications that starch is susceptible to. Moreover, the presence and location of hydroxyl groups at C2, C3 and C6 increases this susceptibility to substitution reactions [8]. Figure 1 shows a representation of the different methods of chemical modifications of starch in the pharmaceutical industry.

Chemical modification of starch usually follows the pathway of substitution, degradation or cross-linking, and these methods are employed to optimize the structural and nutritional properties for targeted applications. Enhancement of the thermoplasticity of starch is achieved by chemical modification of starch, thus causing a disorientation of the hydrogen bonds between the hydroxyl groups of the native starch, and disruption of the crystalline nature. Subsequently, the starch is becomes more fluid and the temperature at which it melts become lowered. 


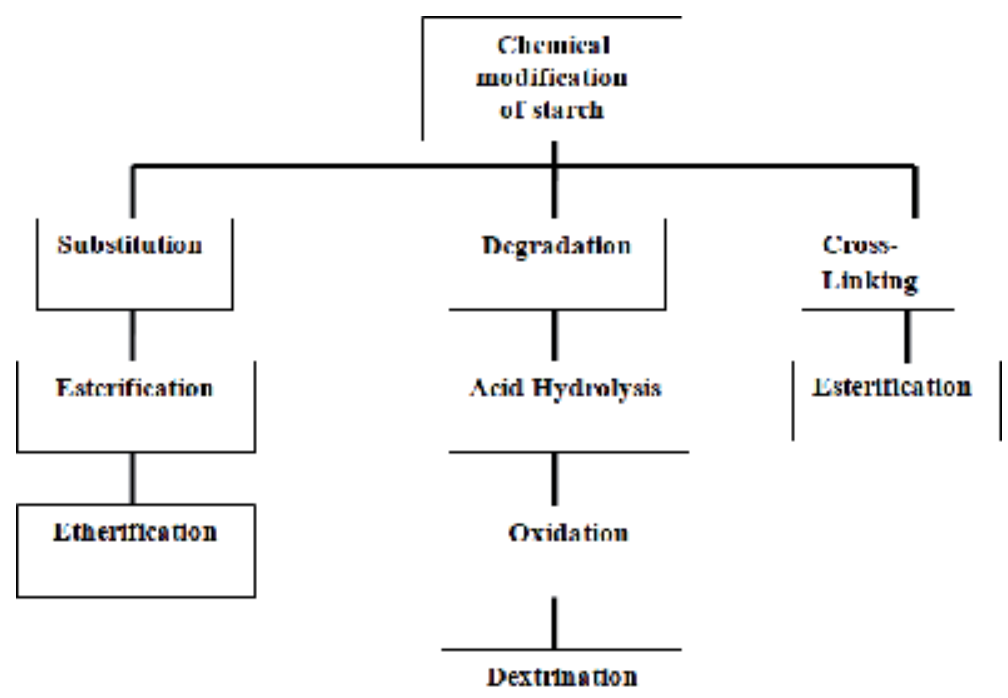

Figure 1.

Methods of chemical modification of starch.

Moreover, the reduction in the number of hydroxyl groups due to the chemical modification increases the hydrophobicity of the starch. The most common approaches to chemical modification of starches for pharmaceutical use include oxidation, hydrolysis, esterification and etherification. However, several approaches that involve a combination of the aforementioned chemical modification methods are also applicable.

Starches can be chemically modified following different pathways:

i. Liquid pathway: here, the chemical modification is carried out in a water medium. The starch is formulated as a suspension (with water as the vehicle) and the chemical modification is carried out until the desired property of the starch is achieved.

ii. Semi-solid pathway: this involves the chemical modification of native starch in form of a paste or gel. The resultant modified starch is usually dried by lyophilisation.

iii. Solid pathway: dry native starch is modified using the liquid form of the derivatization chemical as the medium, usually at a high temperature $\left(\geq 1000^{\circ} \mathrm{C}\right)$.

Generally, the biodegradable nature of starch due to its macroscopic granular structure and presence of several functional groups makes it easily susceptible to modification. The glucose residues of starch are responsible for its chemical reactivity, and as mentioned earlier, the presence of the hydroxyl on the amylose and amylopectin are prone to the oxidation, reduction and hydrogen bond formation that starch undergoes in the process of chemical modification. The occurrence of large-sized grains in the granular structure exposes starch to external factors, thereby enhancing modification. The penetrating ability of the chemical involved in the modification process, into the starch granular surface or the interior also influences the chemical modification of starch. 


\section{Starch modification by oxidation}

Starch modification by oxidation, which is one of the most common modification methods, involves oxidation of primary or secondary hydroxyl groups of the glucose units with formation of aldehyde or carboxyl groups. The oxidized starch has better water solubility and lower viscosity tendency in comparison to the native one [9]. The type of oxidant used, the botanical origin of starch, and the process conditions are all determinants of how effective the oxidation is. Moreover, the oxidation reaction may cause loosening of intermolecular bonds and/or partial depolymerization of the polymer chains [10]. It is worthy of mention that not all methods of oxidation are applicable for use in the pharmaceutical industry. Aerobic oxidation methods are not applicable for use in the pharmaceutical industry, simply due to the unique category of reactions that simply cannot be performed in batches as applicable in most starch oxidation techniques.

Oxidation with hydrogen peroxide appears very promising, especially because of the production of non-toxic residues such as water. However, a limitation of the use of hydrogen peroxide is its low reactivity towards most organic functional groups and the fact that in the presence of the compounds with electrophilic character it behaves as a nucleophile, not exhibiting oxidizing properties [11]. This limitation of hydrogen peroxide can be improved by the use of metal ions as catalysts, subsequently leading to heavy metal contamination of the modified starch.

Oxidation of starch with sodium hypochlorite involves the oxidation of the primary hydroxyl groups to either aldehyde or carboxyl groups. High concentration of the oxidant in an acidic medium has a direct relationship with the progression of oxidation as more of starch is oxidized in the aforementioned conditions. The modification of the hydroxyl group is affected by the protein content of the starting material considering the fact that any reaction on the starch is preceded by oxidation of the proteins. The starch oxidized by sodium hypochlorite is characterized by higher resistance to amylase activity and better stability at higher temperature and is capable of complexing calcium ions while exhibiting the polyelectrolyte properties [8]. Chemical oxidation of starch can also be carried out using sodium periodate. The bonds of the carbon atoms on the second and third positions are cleaved and dialdehyde groups are formed within the starch structure.

Garrido et al. successfully demonstrated the increase in the crystallinity, better water solubility and lower viscosity of cassava starch when modified by oxidation using sodium hypochlorite [12].

\section{Starch modification by esterification}

The hydrophobicity of starch is improved by the process of esterification, subsequently leading to improved thermoplasticity of the starch. Starch forms esters with reagents (organic and inorganic acids, and their derivatives such as chlorides, oxychlorides and acid anhydrides) due to the presence of the hydroxyl groups on each glucose residue, been converted to hydrophobic ester groups.

\subsection{Esterification by acetylation}

This is carried out with the aid of acetic acid or acetic anhydride. The esterification can be carried out in the presence of acetic acid as an activator or with acetic anhydride in the presence of sodium hydroxide as the activator [13]. A high degree of substitution was obtained when potassium carbonate was applied as the activator in the reaction of starch with acetic anhydride [14]. Starch acetates have been 
used extensively in the pharmaceutical industry as binders. In 2011, Singh and Nath demonstrated the potential of acetylated moth bean starch as a carrier for controlled drug delivery of lamivudine tablets [15]. On a micro scale, starches can be acetylated without the presence of a catalyst. The process involves heating the native starch with acetic acid at a temperature between 179 and $181^{\circ} \mathrm{C}$ for a period of 2-4 min, resulting in a homogenous mixture. Tuovinen et al. documented the potential of natural sensitive starch acetate as an excipient in the retinal delivery of calcein; the in-vivo studies revealed that starch acetate nanoparticles, when compared with native starch, were taken up faster by reticuloendothelial cells without significant toxicity [16]. Akin-Ajani et al. also demonstrated the increase in crushing strength and disintegration time but lower friability of acid modified white fonio (Digitaria exilis) and sweet potatoe (Ipomea batatas) starches when incorporated as exo-disintegrants in paracetamol tablet formulations [17].

\subsection{Esterification by phosphorylation}

Phosphorylation of starch enhances the rheological and pasting properties of starch, which improves the flowability of starch when used in tablet formulation as documented by Adetunji and Kolawole [18]. This is as a result of addition of phosphate groups to the C6 position of the glucose residue [19].

Starch phosphate esters containing magnesium, calcium, or aluminum ions are used extensively as disintegrants in the pharmaceutical industry. Monostarch phosphate is obtained by treating starch with potassium or sodium phosphates, while distarch phosphates can be obtained by treating starch with phosphorus oxychloride or sodium trimetaphosphate. The degree of cross-linking of phosphorylated starch determines the swelling ability of the modified starch. At a low degree of cross-linking, starch has high swelling ability but with increasing degree of crosslinking; swelling ability in water decreases, until complete loss of this ability [20].

Zuo et al. documented the use of maleic anhydride in the esterification of corn starch. The esterification led to roughness on the surface of the starch particle with a subsequent increase in particles size. Crystal lattice destruction of the starch during the maleic anhydride esterification also led to improved thermoplasticity and reduction in gelatinization temperature [21]. Phosphorylated starch yielded a better result than native starch when Prosanthi and Rama incorporated it a disintegrant in Ziprasidone tablet formulations [22], while starches from various botanical sources with different amylose contents (way corn, common corn, Hylon V, Hylon VII and potatoe) were phosphorylated at $\mathrm{pH} 9.0$ and 11.0 using reactive extrusion method prior to their use in the formulation of sustained release metoprolol tartrate tablets; these phosphorylated starches produced stronger hydrogels than the corresponding native starch [23]. Chowdary et al. used phosphorylated potatoe starch prepared by the reaction of the native starch with di-sodium hydrogen orthophosphate anhydrous at elevated temperatures as a carrier in solid dispersions for enhancing the dissolution rate of aceclofenac; better results were achieved from the formulations containing the phosphorylated starches [24].

\section{Starch modification by etherification}

Etherification of starch is a derivatization technique that involves the use of various alkylation agents such as dimethyl sulphate, diethyl sulphate, alkylene oxides (epoxides) and alkyl halides. The use of diethyl (or dimethyl) sulphates in starch etherification was documented to have taken place in dimethyl sulfoxide with the addition of aqueous sodium chloride [25]. Starch ethers with branched chains are usually produced through reactions with alkyl halides. 
The use of epoxides in starch etherification can proceed in the absence of sodium hydroxide. According to Cui, the high reactivity of the asymmetrical epoxide group is due to the highly strained three-membered ring with bond angles of $60^{\circ}$ [25]. Etherification of macrogranular starch (containing $\leq 10 \% \mathrm{w} / \mathrm{w}$ moisture) by pressurized hot air can also be carried out using ethylene oxide [26].

Starch etherification involving the introduction of ammonium, amino or imino group yields important industrial derivatives. The use of different amino-alkyl agents, such as 2-diethylaminoethyl chloride, 2,3-(epoxypropyl), trimethylammonuim chloride, (4-chlorobutene-2)-trimethylammonium chloride, etc., in etherification is a major way of producing cationic starches with enhanced gelatinization behavior, pasting properties and solubility [6].

Carboxymethylated starches are derivatives of etherification of starch that are formed when hydrogen atoms are replaced by carboxymethyl functional groups. Carboxymethylated starches have been documented to show low gelatinization temperature and swelling properties and, solubility in cold water than most interesting native starches [27]. Synthesis of carboxymethyled starch involves initial activation of the native starch with aqueous sodium hydroxide in an organic slurry, followed by the reaction with monochloroacetic acid or its sodium salt. The tablet film-coating potential of carboxymethylated mungbean starch was reported by Kittipongpatana et al. as due to the formation of clear, thin film with greater flexibility and strength than that of the native starch [28]. Drug release was better sustained when high amylose sodium carboxymethylated starch matrices were used in the formulation of oral acetaminophen tablets [29].

\title{
8. Conclusion
}

The modification of starch using different approaches such as oxidation, esterification and esterification is well documented in literature. While small scale researches have substantiated the usefulness of modified starches as excellent excipients in the manufacture of different dosage forms due to enhancement of characters such as flow properties of starch, favorable particle size, robust crystallinity etc., it is pertinent to develop more methods of chemically modifying starch that can be scaled-up in the pharmaceutical industry to increase the options that drug formulation scientists can exploit when choosing excipients for drug dosage form designs.

\section{Author details}

\author{
Oladapo Adewale Adetunji \\ Department of Pharmaceutics and Industrial Pharmacy and Centre for \\ Drug Discovery, Development and Production, Faculty of Pharmacy, \\ University of Ibadan, Ibadan, Nigeria
}

*Address all correspondence to: adetunjioladapo@gmail.com

\section{IntechOpen}

(C) 2019 The Author(s). Licensee IntechOpen. This chapter is distributed under the terms of the Creative Commons Attribution License (http://creativecommons.org/licenses/ by/3.0), which permits unrestricted use, distribution, and reproduction in any medium, provided the original work is properly cited. (cc) BY 


\section{References}

[1] Navya A, Suresh JN. Co-processed excipients as a new generation excipients with multifunctional activities: An overview. Indian Journal of Pharmaceutical Science and Research. 2014;(2):231-246

[2] Kolawole SA. Comparison of the physicochemical properties of starch from ginger (Zingiber officinale) and maize (Zea mays). International Journal of Science and Research. 2013;11:2319-7064

[3] Umida-Khodjaeva TB. Food additives as important part of functional food. Journal of Microbiology and Biotechnology. 2013;56:2125-2135

[4] Poon WH. Starch molecules. In: Morrison EB, editor. Introduction to Organic Chemistry. 4th ed. New York: John Wiley and Sons; 2005. pp. 21-63

[5] Matsunaga N, Seib PA. Extraction of wheat starch with aqueous sodium hydroxide. Cereal Chemistry. 1997;74:851

[6] Song L. Chemical modification of starch and preparation of starch based nanocomposites. A dissertation presented to The Graduate Faculty of The University of Akron; 2010

[7] Alabi C, Singh I, Odeku O. Evaluation of natural and pregelatinized forms of three tropical starches as excipients in tramadol tablet formulation. Journal of Pharmaceutical Investigation. 2017;48:1-8. DOI: 10.1007/s40005-017-0325-9

[8] Lewicka K, Slemlon P, Kurcok P. Chemical modification of starch: Microwave effect. International Journal of Polymer Science. 2015:1-10. Article ID: 867697. http://dx.doi. org/10.1155/2015/867697
[9] Lewandowicz G, Mączynski M. Chemical modifications starch. Part 1. Modification potatoes starch. Chemik. 1990;43(1):9-144

[10] Fortuna T, Juszczak L, Pietrzyk S, Wrobel M. Physicochemical properties of oxidized starches of different origin. Polish Journal of Food and Nutrition Sciences. 2002;11(2):21-27

[11] Arts SJHF, Mombarg EJM, VanBekkum H, Seldon RA. Hydrogen peroxide and oxygen in catalytic oxidation of carbohydrates and related compounds. Synthesis. 1997;6:597-613

[12] Garrido LH, Schnitzler E, Zortéa ME, DeSouza-Rocha T, Demiate IM. Physicochemical properties of cassava starch oxidized by sodium hypochlorite. Journal of Food Science and Technology. 2014;51(10):2640-2647

[13] Kakuschke R, Rapthel I, Stoye H, Schmoz G. Process for the manufacture of biodegradable starch esters. WO 1998007755A1. 1998

[14] Volkert B, Lehmann A, Greco T, Nejad MH. A comparison of different synthesis routes for starch acetates and the resulting mechanical properties. Carbohydrate Polymers. 2010;79(3):571-577

[15] Singh AV, Nath L. Evaluation of acetylated moth bean starch as a carrier for controlled drug delivery. International Journal of Biological Macromolecules. 2011;50(2):362-368

[16] Tuovinen L, Ruhanen E, Kinnarinen T, Ronkko S, Pelkonen J, Urtti A, et al. Starch acetate microparticles for drug delivery into retinal pigment epithelium-In vitro study. Journal of Controlled Release. 2004;98(3):407-413 
[17] Akin-Ajani OD, Odeku O.

Evaluation of the disintegrant properties of native and modified forms of fonio and sweet potato starches. Starch/Stärke. 2016;68:169-174

[18] Adetunji OA, Kolawole O. The influence of phosphate modified and pregelatinized plantain (Musa paradisiaca, family: Musaceae) starches as disintegrants in paracetamol tablet formulations. Nigerian Journal of Pharmacy Research. 2018;14(1):15-24

[19] Roznowski J, Fortuna T, Szuba E, Labanowska M. Impact of starch phosphorylation and iron(II) and copper(II) ion enrichment on its physicochemical properties. StarchStarke. 2015;67(11-12):937-948

[20] Seker M, Hannah M. Crosslinking starch at various moisture content by phosphate substitution in an extruder. Carbohydrate Polymers. 2005;59(4):541-544

[21] Zuo Y, Gu J, Yang L, Qiao Z, Tan H, Zhang Y. Synthesis and characterization of maleic anhydride esterified corn starch by the dry method. International Journal of Biological Macromolecules. 2013;62:241-247

[22] Prasanthi NL, Rama Rao N. Starch phosphate: A novel pharmaceutical excipient for tablet formulation. Journal of Pharmacy Research. 2010;3(12):2919

[23] Stephen O, Wang Y, Vervaet C, Remon JP. Starch phosphates prepared by reactive extrusion as a sustained release agent. Carbohydrate Polymers. 2009;75(4):557-566

[24] Chowdary KPR, Enturi V, Sandhya Rani A. Formulation development of Aceclofenac tablets employing starch phosphate-A new modified starch. International Journal of Pharmaceutical Sciences and Research. 2011;2(3):124-129
[25] Yang BY, Montgomery R. Acylation of starch using trifluoroacetic anhydride promoter. Starch/Staerke. 2006;58:520

[26] Cui SW. Food Carbohydrates: Chemistry, Physical Properties, and Applications. Boca Raton, FL, USA: Taylor and Francis/CRC Press; 2005. p. 2005

[27] Noor Fadzlina ZAN, Karim AA, Teng TT. Physicochemical properties of carboxy-methylated sago (Metroxylon sagu) starch. Journal of Food Science. 2005;70:560-567

[28] Kittipongpatana OS, Chaichanasak N, Kanchongkittipoan S, Panturat A, Taekanmark T, Kittipongpatana N. An aqueous filmcoating formulation based on sodium carboxymethyl mungbean starch. Starch/Stärke. 2006;58(11):587-589

[29] Brouillet F, Bataille B, Cartilier L. High amylose sodium carboxymethyl starch matrices for oral, sustained drug-release: Formulation aspects and in vitro drug-release evaluation. International Journal of Pharmaceutics. 2008;356(1-2):52-60 



\title{
Physical and Chemical Modifications in Starch Structure and Reactivity
}

\author{
Haq Nawaz, Rashem Waheed, Mubashir Nawaz \\ and Dure Shahwar
}

\begin{abstract}
Starch is a naturally occurring glucose homo-polysaccharide of nutritional, pharmaceutical, and industrial importance. The complex polymeric structure and poor solubility of native starch in water limits their importance at pharmaceutical and industrial level. The structure, reactivity, and functionality of the native starch can be modified by physical, chemical, enzymatic, and biotechnological methods. Various physical modifications techniques, including the thermal, radio-thermal, freezing and thawing, annealing, high-pressure, ultrasonic, and pulsed electric field treatment, and chemical modifications, including oxidation, etherification, esterification, cationization, cross-linking, and graft polymerization, have been found to change the surface properties, polarity and linearity of the molecular chains, the degree of substitution, the polymeric, granular, and crystalline structure, amylose to amylopectin ratio, solubility, viscosity, pasting, gelatinization, swelling, water absorption, and emulsifying properties of starch. The structural changes have resulted in the improvement of thermal and freeze-thaw stability, viscosity, solubility, water binding capacity, swelling power, gelling ability, and enzymatic digestibility of starch. The exposure of reactive functional groups after physical or chemical modification modifies the reactivity of starch toward water, oil, acids, enzymes, and other chemical species. These modification techniques have led to some revolutionary changes in reactivity, functionality, and application of starch in various fields.
\end{abstract}

Keywords: starch structure, starch reactivity, functional properties, chemical modifications, physical modification

\section{Introduction}

Starch is the most important polysaccharide as well as storage polymer of plants abundantly found in leaves, stem, fruit, seed, tubers, and roots of various plants. Starch is produced in chloroplast and amyloplast of plant cells by photosynthesis, stored as a source of food and energy. It is stored in plant cell during tubers sprouting, germination of seeds and fruit maturation [1, 2]. Major sources of starch included cereals grains such as wheat, barley, rice and corn, the seeds of the legumes such as beans, garden peas, chickpeas, and pulses, the 
tubers such as potato, sweet potato, ginger, turmeric and groundnut and immature fruits and vegetables [3-5].

Starch has great nutritional, pharmaceutical and industrial significance due to its unique physical, chemical and functional and nutritional properties. Starch is a good source of nutrition as it is hydrolyzed into glucose on digestion by $\alpha$-amylase. The metabolic oxidation of glucose provides instant energy which is utilized in various metabolic and other cellular activities [6-8]. Due to the higher concentration of amylose, starch is used as an excipient to activate drugs and act as an encapsulating agent facilitating the deliver the drug to its target organ [9-11]. As a natural polymer, starch is used to replace plastic in the coating of food materials and production edible films in the food industry. It is usually mixed with food components to protect them from mechanical damage, to extend their half-life and to improve their appearance. It is also used as a recyclable component for molds production in the food industry. It is added as a bulking agent in food and pharmaceutical formulations to enhance handling and stability as well as preservation of components texture and to enhance their viscosity [12-14]. Moreover, due to water-resistant nature of amylose, it can form excellent films due to which it has great importance at industrial level [15].

\subsection{Starch structure and composition}

Chemically starch is a homopolymer of $\alpha$-Glucopyranose units with the chemical formula $\left(\mathrm{C}_{6} \mathrm{H}_{10} \mathrm{O}_{5}\right)_{\mathrm{n}}$. Starch is composed of two types of polymer chains known as amylose and amylopectin. Amylose possesses a linear structure with $\alpha 1-4$ glycosidic linkage while amylopectin possesses a branched structure with $\alpha 1-4$ as well as $\alpha 1-6$ glycosidic linkages (Figure 1) [16, 17]. Normally, starch consists of relatively lower amount of amylose (20-30\%) than that of amylopectin (70-80\%). The ratio of amylose and amylopectin affects the starch structure in terms of crystallinity, size of the granules and chemical nature and arrangement of polymers within the granule. The studies have shown that the fine structure of amylopectin plays an important role in the functionality of starch. It is the relative concentration of amylose and amylopectin which determines the physical and functional properties of starch. The starches containing low amylopectin have been found to show the quick onset of gelation as compared to low amylose starches. The starches containing relatively high amylose content have been found to form comparatively hard and rigid gels and strong films while high amylopectin starches are dispersed easily in water and form soft gels and weak films [15, 18-21]. The amylose to amylopectin ratio also influences the nutritional quality of starch that is assessed by its rate of digestion and glycemic index (GI) as an indicator to check the quality of carbohydrates [22].

\subsection{Functional properties of starch}

Based on its compact structure, starch possesses diverse functional properties and applications in biomedical and industrial fields. Due to polymeric and branching nature starch shows relatively less solubility in water and possesses relatively lower ability to absorb water and oil. Starch shows good iodine-binding ability. It also possesses a relatively high viscosity and good swelling power and gelatinization abilities. It also shows good pasting properties with consistency, smoothness, and clarity and can form thin films. Starch shows freeze-thaw and cold storage stabilities which make it a favorable candidate for various food and industrial formulations. Starch is resistant to moderate temperature and pressure but 


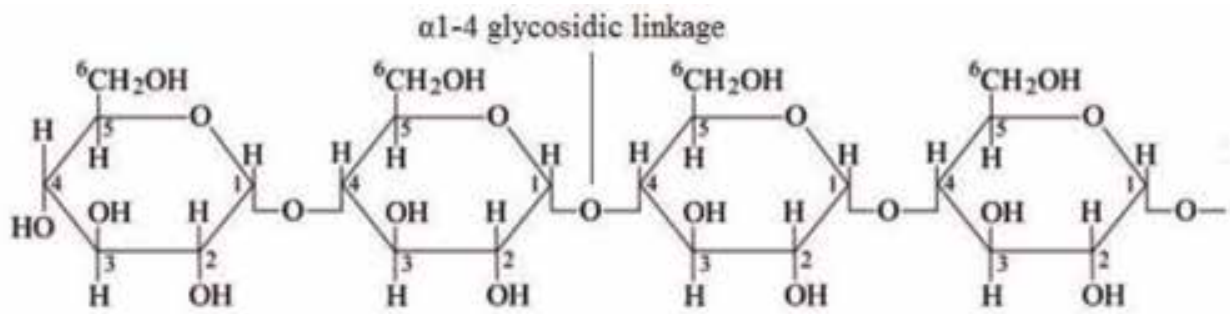

Amylose

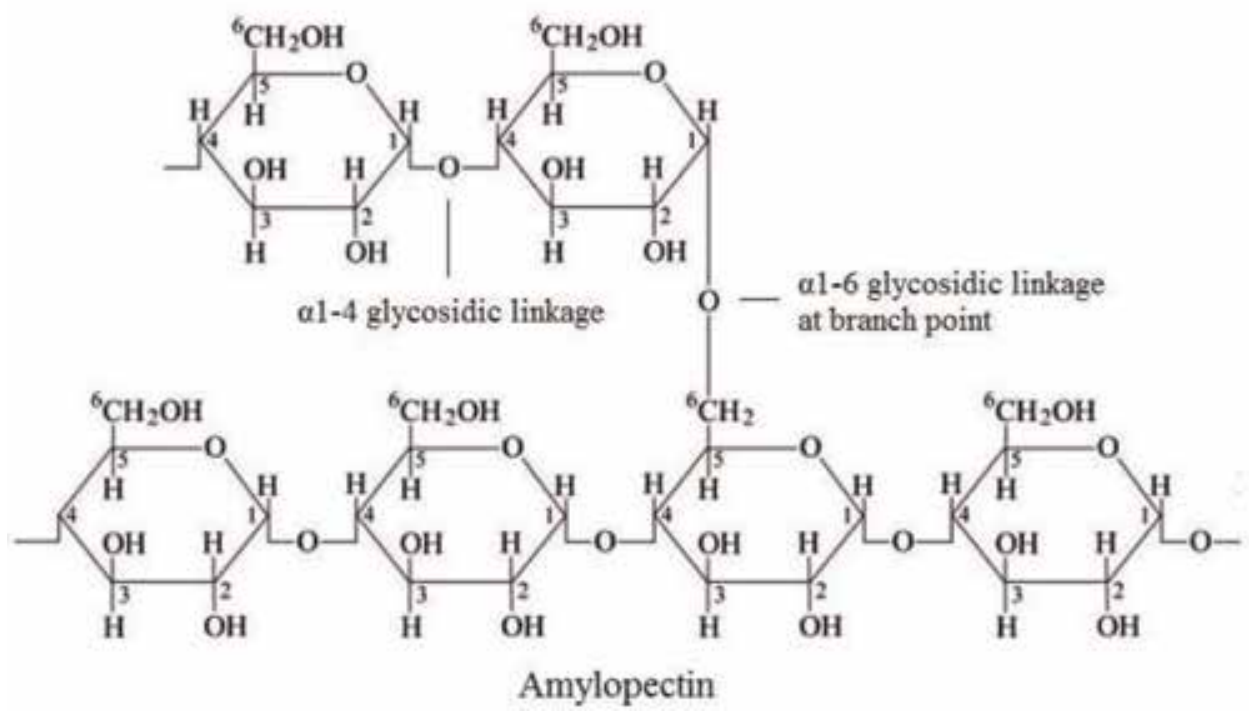

Figure 1.

Structure of amylose and amylopectin in starch.

susceptible to acid and enzyme-catalyzed hydrolysis. However, the native starches show relatively lower values of enzymatic digestibility [18, 23-26]. To increase its nutritional, biomedical and industrial importance, the functional properties of starch can be improved under the influence of various physical and chemical factors.

\subsection{Factors affecting the structure and properties of starch}

The native starches possess a complex granular and crystalline structures which differ in size in various plants $[2,16]$. Several factors have been reported which affect the structural, physical, chemical, and functional properties of starch. Starch is sensitive to very high and very low $\mathrm{pH}$, high temperature, high pressure, and osmotic pressure, light, radiation, mechanical stress, and ultrasound waves. Heating treatment of starch in aqueous medium has been found to cause transition of amorphous form to crystalline starch resulting in gelatinization of starch. The treatment with microwave radiation has been found to affect the crystalline structure and functional properties of starch which is linked with the loss of birefringence and crystallinity due to deformation during modification [27-36]. Interaction of starch with water and oil also affects the properties of starch. The absorption of water results in the breakdown of amylose-amylopectin linkages, loss of 
crystallinity and swelling of starch granules. The swelling of starch granules is reversible at the initial stage but irreversible after a certain period [37]. Freezing at low temperature after gelatinization results in recrystallization of starch granules and increases the resistance and hardness of starch [38].

Along with these physical factors, some chemical factors have been also reported to affect the structure and functions of starch. Various oxidizing agents, hydroxy or carboxy derivatives of hydrocarbons, some carboxylic acids, phosphates, different acid, and base cross-linkers and synthetic polymers, and some cationic molecules are the major chemical factors which have been reported to modify the structure and properties of native starches [39-46]. Starch is also susceptible to acids and enzymatic hydrolysis which results in degradation of amylose and amylopectin and alter the morphology and surface properties of granules leading to the change in functional value of starch [47-49]. These physical and chemical factors have helped improve the functional quality of starch to obtain better results while used in various food and industrial formulations.

\section{Starch modification}

Any changes in the structure of starch molecule caused by various environmental, operational and processing factors are termed as modifications. These modifications may exert either positive or negative effects on the structure and functionality of starch molecules. The native starches obtained from various plants are diverse in their structure and functions. To enhance the structural and functional quality of these starches and achieve better results in various formulations, the researchers suggest some modification in their structure. Several studies have been reported on the improvement of functional quality of starch by physical, chemical or mechanical modifications [23, 43, 45, 48, 50-58]. However, some environmental and processing factors may reduce the functional quality of starch by various modifications during storage and processing [57]. The physical modifications are comparatively safe and preferable over chemical modifications as the later involve the changes in the chemical structure of the molecule which limit its use in most of the formulations.

\subsection{Physical modification of starch}

Physical modifications involve the changes in the morphology and threedimensional structure of starch under the influence of some physical factors such as milling, moisture, temperature, pressure, $\mathrm{pH}$, radiation, pulse-electric field, ultrasonic waves, etc. Physical modifications result in the variation in particle size, surface properties, solubility index and functional properties such as water absorption, swelling capacity, pasting and gelation ability of starch. These modifications directly influence the functional quality and selectivity and suitability of the modified starch for various nutritional, pharmaceutical and industrial formulations. Several studies have been reported on the physical modification of starch using different techniques. The commonly used methods of physical modification include superheating of starch, thermal inhibition treatment, UV and gamma irradiation, microwave treatment, high pressure, osmotic pressure and instantaneous controlled pressure treatment, mechanical activation by stirring ball mill, treatment by pulsed electric field, micronization in vacuum ball mill, annealing and freeze-thaw treatment [28, 29, $31,33,51,53,55,56,59-68]$. The most frequently used and the most effective methods of physical modification are presented in Figure 2 and their effects on the structure and properties of various starches are summarized in Table 1. 


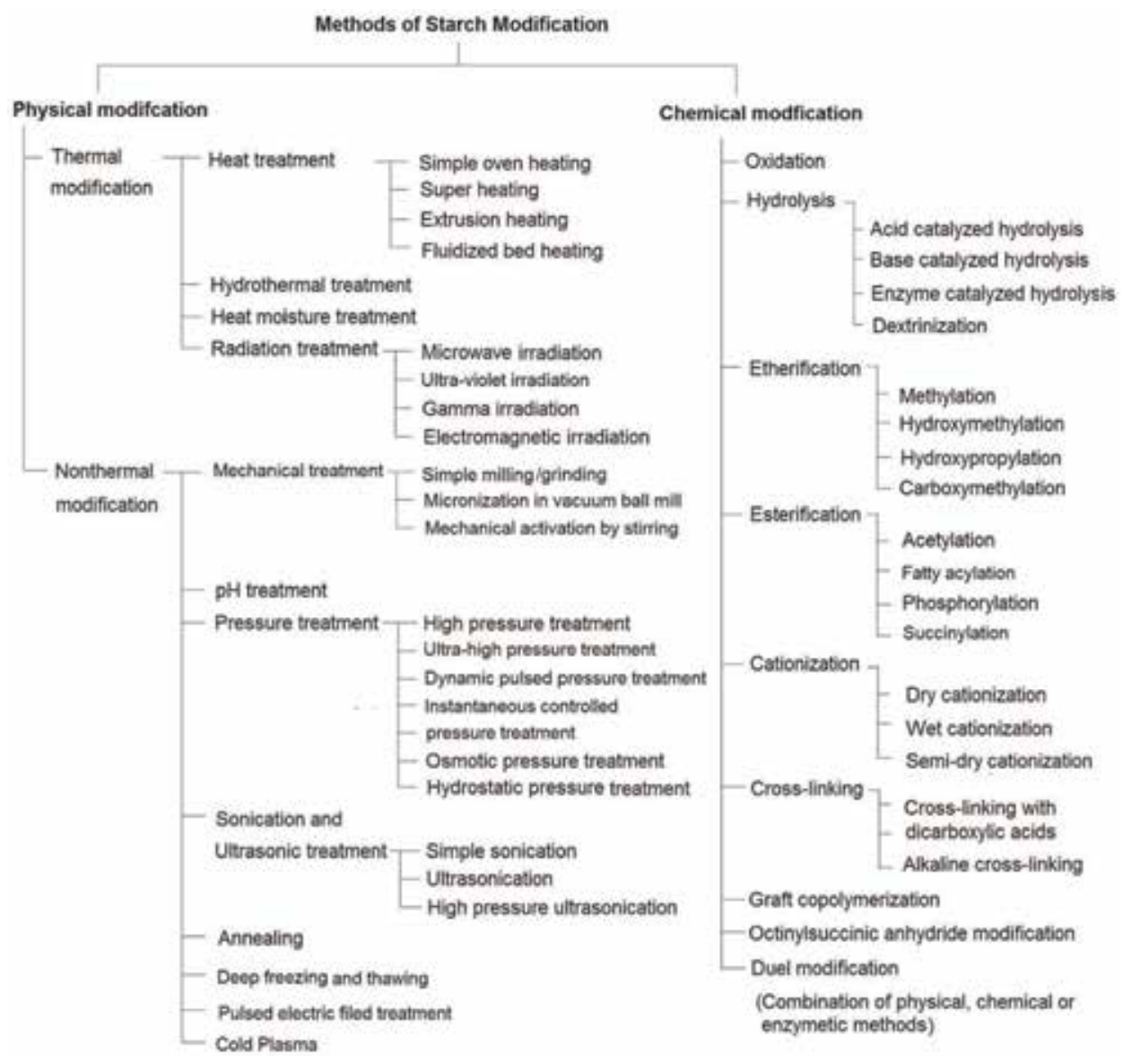

Figure 2.

Methods of physical and chemical modifications of starch.

\subsection{Chemical modification of starch}

The chemical modification involves the alteration of physiochemical properties of starch by introducing new chemical or functional groups in starch without any physical alteration in the shape and size of the molecule. Each of the glucose units in amylose and amylopectin has three reactive hydroxyl groups which are the major sites for chemical modification in starch. The chemical modification alters the physical behavior of starch including retrogradation, salting, and gelatinization that work by stabilizing the intermolecular and intramolecular bonding of starch granules. The commonly used methods of chemical modification of starch include oxidation by different oxidizing agents, etherification by addition of some hydroxyethyl, hydroxypropyl or carboxymethyl moieties on hydroxyl groups of starch, esterification by condensation of some fatty acids, other carboxylic acids and phosphates with active hydroxyl groups of starch, cationization by introducing some cationic molecules, cross-linking by addition of various cross-linkers and graft-polymerization of starch with synthetic polymers [40-43, 46, 68-72]. Cationic modifications involve the reaction of starch molecules that contain tertiary and secondary ammonium, imino, amino, sulfuric and phosphate groups which react with hydroxyl groups of starch. It improves the dielectric constant of starch granules. It has great importance in the textile industry as an additive, in paper and cosmetic industry due to low cost, rapid degradation and bioavailability [73]. 


\begin{tabular}{|c|c|c|c|c|}
\hline $\begin{array}{l}\text { Modification } \\
\text { method }\end{array}$ & Treatment & $\begin{array}{l}\text { Change in starch } \\
\text { structure }\end{array}$ & $\begin{array}{l}\text { Change in starch } \\
\text { properties }\end{array}$ & References \\
\hline \multicolumn{5}{|c|}{ Thermal modification } \\
\hline \multicolumn{5}{|c|}{ Heating treatments } \\
\hline Gentle heating & $\begin{array}{l}\text { Heating starch at low } \\
\text { temperature }\left(45-65^{\circ} \mathrm{C}\right)\end{array}$ & $\begin{array}{l}\text { It causes slight changes in } \\
\text { starch structure and } \\
\text { amylopectin to amylose } \\
\text { ratio. }\end{array}$ & $\begin{array}{l}\text { It shows no significant } \\
\text { effect on the } \\
\text { physicomechanical } \\
\text { properties of starch. }\end{array}$ & [35] \\
\hline Superheating & $\begin{array}{l}\text { Heating starch at } \\
\text { relatively high } \\
\text { temperature }\left(180-220^{\circ}\right. \\
\text { C) }\end{array}$ & $\begin{array}{l}\text { It results in the formation } \\
\text { of spreadable gel particles } \\
\text { with a creamy texture on } \\
\text { cooling. }\end{array}$ & $\begin{array}{l}\text { It improves the } \\
\text { gelatinization and pasting } \\
\text { properties of starch. }\end{array}$ & {$[76]$} \\
\hline $\begin{array}{l}\text { Extrusion } \\
\text { heating }\end{array}$ & $\begin{array}{l}\text { Application of } \\
\text { mechanical force in } \\
\text { low-temperature } \\
\text { environment }\end{array}$ & $\begin{array}{l}\text { It causes the degradation } \\
\text { of amylose and } \\
\text { amylopectin of the starch } \\
\text { polymer by random } \\
\text { chain-splitting. It also } \\
\text { causes a high degree of } \\
\text { granule disruption with } \\
\text { complete loss of } \\
\text { crystallinity }\end{array}$ & $\begin{array}{l}\text { It lowers the swelling } \\
\text { power and viscosity and } \\
\text { improves the water } \\
\text { solubility and } \\
\text { digestibility of starch. }\end{array}$ & {$[51,77]$} \\
\hline $\begin{array}{l}\text { Hydrothermal } \\
\text { treatment }\end{array}$ & $\begin{array}{l}\text { Heating of starch in an } \\
\text { aqueous medium. }\end{array}$ & $\begin{array}{l}\text { It causes physical } \\
\text { reorganization of starch } \\
\text { granules }\end{array}$ & $\begin{array}{l}\text { It improves the granule } \\
\text { size, mobility, and } \\
\text { stability which make it } \\
\text { able to be digested easily } \\
\text { by amylase. It also } \\
\text { improves the } \\
\text { gelatinization properties } \\
\text { of starch. }\end{array}$ & {$[30,67,78]$} \\
\hline $\begin{array}{l}\text { Heat-moisture } \\
\text { treatment }\end{array}$ & $\begin{array}{l}\text { Heat application in the } \\
\text { presence of limited } \\
\text { moisture levels: } 22-27 \% \\
\text { and high temperature } \\
\text { above the glass- } \\
\text { transition temperature: } \\
100-120^{\circ} \mathrm{C} \text { for a } \\
\text { specified length of } \\
\text { time: } 1-24 \mathrm{~h}\end{array}$ & $\begin{array}{l}\text { It results in a change in } \\
\text { size, shape and granular } \\
\text { and crystalline structure } \\
\text { of starch. It causes a } \\
\text { partial or complete } \\
\text { conversion of the B-type } \\
\text { crystalline starch to A- } \\
\text { type. It also causes } \\
\text { disruption of helical } \\
\text { structures within the } \\
\text { amorphous regions of } \\
\text { starch granules. It } \\
\text { induces the molecular } \\
\text { degradation of starch and } \\
\text { increases the degree of } \\
\text { polarization. }\end{array}$ & $\begin{array}{l}\text { It decreases the amylose } \\
\text { leaching, peak viscosity, } \\
\text { and swelling capacity and } \\
\text { enhances the solubility, } \\
\text { thermal stability, } \\
\text { gelatinization } \\
\text { temperatures, pasting } \\
\text { temperature, pasting } \\
\text { time, interaction } \\
\text { properties and } \\
\text { susceptibility of starch to } \\
\text { chemical and enzymatic } \\
\text { attack ( } \alpha \text {-amylase and } \\
\text { acid hydrolysis). }\end{array}$ & $\begin{array}{l}{[28,50} \\
59,79-82]\end{array}$ \\
\hline \multicolumn{5}{|c|}{ Radiation treatment } \\
\hline $\begin{array}{l}\text { Microwave } \\
\text { irradiation }\end{array}$ & $\begin{array}{l}\text { Application of } \\
\text { microwave radiation at } \\
\text { different ranges of } \\
\text { moisture and } \\
\text { temperature to } \\
\text { influence the dielectric } \\
\text { constant of starch. }\end{array}$ & $\begin{array}{l}\text { It improves the granular } \\
\text { crystallinity and surface } \\
\text { morphology. }\end{array}$ & $\begin{array}{l}\text { Microwave treatment } \\
\text { Improves the water and } \\
\text { oil holding capacity, } \\
\text { emulsifying activity, } \\
\text { swelling capacity, } \\
\text { solubility, and gelling } \\
\text { ability. It also increases } \\
\text { the pasting temperature } \\
\text { and paste viscosity. It } \\
\text { decreases the peak } \\
\text { viscosity and } \\
\text { gelatinization, and the } \\
\text { degree of relative } \\
\text { crystallinity. }\end{array}$ & $\begin{array}{l}{[27,31} \\
53,83]\end{array}$ \\
\hline
\end{tabular}




\begin{tabular}{|c|c|c|c|c|}
\hline $\begin{array}{l}\text { Modification } \\
\text { method }\end{array}$ & Treatment & $\begin{array}{l}\text { Change in starch } \\
\text { structure }\end{array}$ & $\begin{array}{l}\text { Change in starch } \\
\text { properties }\end{array}$ & References \\
\hline $\begin{array}{l}\text { Ultraviolet } \\
\text { (UV) } \\
\text { irradiation }\end{array}$ & $\begin{array}{l}\text { Starch granules } \\
\text { exposed to UV light. }\end{array}$ & $\begin{array}{l}\text { It causes free radical- } \\
\text { induced cross-linking and } \\
\text { depolymerization, } \\
\text { oxidative } \\
\text { photodegradation, and } \\
\text { dextrinization in starch. }\end{array}$ & $\begin{array}{l}\text { UV treatment Influences } \\
\text { the physical, chemical } \\
\text { and functional properties } \\
\text { of starch. }\end{array}$ & {$[61,84,85]$} \\
\hline $\begin{array}{l}\text { Gamma } \\
\text { irradiation }\end{array}$ & $\begin{array}{l}\text { Exposure of starch } \\
\text { granules to various } \\
\text { doses of high energy } \\
\text { gamma radiation. }\end{array}$ & $\begin{array}{l}\text { Gamma irradiation } \\
\text { causes the breakage of } \\
\text { the amylopectin chains at } \\
\text { the amorphous regions } \\
\text { and decreases the } \\
\text { amylopectin to amylose } \\
\text { ratio. It also causes the } \\
\text { radiolysis and radio- } \\
\text { depolymerization of } \\
\text { starch }\end{array}$ & $\begin{array}{l}\text { The exposure to gamma } \\
\text { radiation decreases the } \\
\text { pasting viscosity, and } \\
\text { enthalpy change of starch } \\
\text { and molecular weight and } \\
\text { gyration radius of } \\
\text { amylopectin. It increases } \\
\text { the susceptibility of } \\
\text { starch towards amylase. } \\
\text { It also improved the } \\
\text { rheological properties } \\
\text { such as gelatinization } \\
\text { viscosity, swelling power, } \\
\text { and solubility. }\end{array}$ & {$[54,86-88]$} \\
\hline \multicolumn{5}{|c|}{ Non-thermal modification } \\
\hline $\mathrm{pH}$ treatment & $\begin{array}{l}\text { Addition of some acid } \\
\text { or base to change the } \\
\text { pH of the medium. }\end{array}$ & $\begin{array}{l}\text { A high } \mathrm{pH} \text { results in } \\
\text { partial degradation of } \\
\text { starch granules with a } \\
\text { decrease in molar size } \\
\text { and radius of gyration. A } \\
\text { low pH results in } \\
\text { hydrolysis of starch } \\
\text { particularly in the } \\
\text { amorphous region of } \\
\text { granules and decreases } \\
\text { the molecular weight of } \\
\text { the starch. }\end{array}$ & $\begin{array}{l}\text { Increase in } \mathrm{pH} \text { improves } \\
\text { the solubility, swelling } \\
\text { power, and compression } \\
\text { properties. Low } \mathrm{pH} \\
\text { treatment improves the } \\
\text { gelation properties of } \\
\text { starch. }\end{array}$ & $\begin{array}{l}{[35,48,} \\
49,89]\end{array}$ \\
\hline $\begin{array}{l}\text { Moisture } \\
\text { treatment }\end{array}$ & & $\begin{array}{l}\text { Moisture acts as } \\
\text { plasticizer and anti- } \\
\text { plasticizer for starch } \\
\text { films for different } \\
\text { properties }\end{array}$ & $\begin{array}{l}\text { It causes a plasticizing } \\
\text { effect on calorimetric } \\
\text { glass transition } \\
\text { temperature, linear } \\
\text { expansion, tensile } \\
\text { modulus, and water } \\
\text { vapor permeability while } \\
\text { an anti-plasticizing effect } \\
\text { on mechanical properties } \\
\text { i.e. tensile strength and } \\
\text { toughness. }\end{array}$ & {$[90]$} \\
\hline \multicolumn{5}{|c|}{ Mechanical treatment } \\
\hline $\begin{array}{l}\text { Simple } \\
\text { milling/ } \\
\text { grinding }\end{array}$ & $\begin{array}{l}\text { It involves the grinding } \\
\text { of starch by physical } \\
\text { forces. }\end{array}$ & $\begin{array}{l}\text { It decreased the } \\
\text { crystalline/amorphous } \\
\text { ratio, crystallinity, } \\
\text { content of double helix of } \\
\text { starch. It also results in a } \\
\text { rapid increase and then a } \\
\text { gradual decrease in } \\
\text { surface parameters. }\end{array}$ & $\begin{array}{l}\text { It reduces the viscosity } \\
\text { and increases the } \\
\text { susceptibility of physical } \\
\text { and chemical factors to } \\
\text { starch. It increases water- } \\
\text { binding capacity, } \\
\text { adsorptive capacity, and } \\
\text { reactivity of starch. }\end{array}$ & {$[91,92]$} \\
\hline $\begin{array}{l}\text { Micronization } \\
\text { in vacuum ball } \\
\text { mill }\end{array}$ & & $\begin{array}{l}\text { It damages the B-type } \\
\text { starch granules, results in } \\
\text { loss of the granular order } \\
\text { and double-helix content } \\
\text { and reductions in } \\
\text { crystallinity. It also }\end{array}$ & $\begin{array}{l}\text { Changes the rheological } \\
\text { properties of starch. It } \\
\text { increases the water } \\
\text { adsorption, iodine } \\
\text { binding capacity, granule } \\
\text { swelling, solubility and }\end{array}$ & {$[59,93,94]$} \\
\hline
\end{tabular}




\begin{tabular}{|c|c|c|c|c|}
\hline $\begin{array}{l}\text { Modification } \\
\text { method }\end{array}$ & Treatment & $\begin{array}{l}\text { Change in starch } \\
\text { structure }\end{array}$ & $\begin{array}{l}\text { Change in starch } \\
\text { properties }\end{array}$ & References \\
\hline & & $\begin{array}{l}\text { causes depolymerization } \\
\text { of starch polymer } \\
\text { molecules. }\end{array}$ & $\begin{array}{l}\text { susceptibility of starch to } \\
\text { amylase. It decreases the } \\
\text { viscosity, and elasticity of } \\
\text { paste. }\end{array}$ & \\
\hline $\begin{array}{l}\text { Mechanical } \\
\text { activation by } \\
\text { stirring }\end{array}$ & $\begin{array}{l}\text { Application of } \\
\text { mechanical force on } \\
\text { starch by stirring ball } \\
\text { mill. }\end{array}$ & $\begin{array}{l}\text { The treatment results in } \\
\text { the degradation of the } \\
\text { crystal structure to } \\
\text { amorphous particles and } \\
\text { formation of an } \\
\text { agglomerate of the } \\
\text { resulting amorphous } \\
\text { particles. }\end{array}$ & $\begin{array}{l}\text { It reduces the } \\
\text { gelatinization } \\
\text { temperature and } \\
\text { enthalpy, shear-thinning, } \\
\text { and apparent viscosity of } \\
\text { starch resulting in } \\
\text { enhancement of cold- } \\
\text { water solubility of the } \\
\text { starch. }\end{array}$ & [29] \\
\hline
\end{tabular}

\begin{tabular}{|c|c|c|c|c|}
\hline \multicolumn{5}{|c|}{ Pressure treatment } \\
\hline $\begin{array}{l}\text { High-pressure } \\
\text { treatment }\end{array}$ & $\begin{array}{l}\text { Treatment of starch } \\
\text { under pressure } \\
<400 \mathrm{MPa} \text {. }\end{array}$ & $\begin{array}{l}\text { It exerts a pressure and } \\
\text { time-dependent effect on } \\
\text { the microstructure of } \\
\text { starch. It causes melting } \\
\text { of amylopectin crystals } \\
\text { and loss of birefringence. }\end{array}$ & $\begin{array}{l}\text { The pressure treatment } \\
\text { causes changes in } \\
\text { rheological properties of } \\
\text { starch. It increases the } \\
\text { hardness and chewiness } \\
\text { and improves the freeze- } \\
\text { thaw stability of the } \\
\text { starch gels. }\end{array}$ & {$[33,95]$} \\
\hline $\begin{array}{l}\text { Ultra-high } \\
\text { pressure } \\
\text { treatment }\end{array}$ & $\begin{array}{l}\text { Treatment pf starch } \\
\text { under } \\
\text { pressure > } 400 \mathrm{MPa} \text {. }\end{array}$ & $\begin{array}{l}\text { It distorts in the } \\
\text { crystalline region and } \\
\text { transits A-type crystalline } \\
\text { starch to B-type. }\end{array}$ & $\begin{array}{l}\text { It increases the swelling } \\
\text { of starch granules and } \\
\text { restricts the amylose } \\
\text { leaching. It lowers the } \\
\text { gelatinization } \\
\text { temperature. }\end{array}$ & {$[33,59,65]$} \\
\hline $\begin{array}{l}\text { Instantaneous } \\
\text { controlled } \\
\text { pressure } \\
\text { treatment }\end{array}$ & & $\begin{array}{l}\text { The treatment increases } \\
\text { the median volume } \\
\text { diameter in cold water. }\end{array}$ & $\begin{array}{l}\text { It decreases the } \\
\text { gelatinization enthalpy } \\
\text { and birefringence under } \\
\text { polarized light. }\end{array}$ & {$[30]$} \\
\hline $\begin{array}{l}\text { Osmotic } \\
\text { pressure } \\
\text { treatment }\end{array}$ & $\begin{array}{l}\text { Heating of starch in a } \\
\text { hypertonic (saturated) } \\
\text { solution of sodium } \\
\text { sulfate at } 100-120^{\circ} \mathrm{C} \\
\text { across the } \\
\text { semipermeable } \\
\text { membrane }\end{array}$ & $\begin{array}{l}\text { It causes distortion in the } \\
\text { shapes of starch granules } \\
\text { and changes the B-type } \\
\text { crystalline starch to A- } \\
\text { type. }\end{array}$ & $\begin{array}{l}\text { This modification } \\
\text { increases the } \\
\text { gelatinization } \\
\text { temperature. }\end{array}$ & {$[32,80,96]$} \\
\hline $\begin{array}{l}\text { Hydrostatic } \\
\text { pressure } \\
\text { treatment }\end{array}$ & $\begin{array}{l}\text { Application of high } \\
\text { pressure ranging from } \\
400 \text { to } 900 \mathrm{MPa} \text {. }\end{array}$ & $\begin{array}{l}\text { It causes the } \\
\text { disintegration and } \\
\text { retrogradation of starch } \\
\text { granules. }\end{array}$ & $\begin{array}{l}\text { It retards the swelling of } \\
\text { granules or reduces } \\
\text { viscosity with preserving } \\
\text { the taste and nutrient of } \\
\text { starch }\end{array}$ & [56] \\
\hline \multicolumn{5}{|c|}{ Ultrasound treatment } \\
\hline $\begin{array}{l}\text { Ultra- } \\
\text { sonication }\end{array}$ & $\begin{array}{l}\text { Treatment of starch } \\
\text { with ultrasonic waves. }\end{array}$ & $\begin{array}{l}\text { It distorts the starch } \\
\text { granules. }\end{array}$ & $\begin{array}{l}\text { It increases the solubility, } \\
\text { viscosity and swelling } \\
\text { capacity of granules and } \\
\text { reduces the pasting } \\
\text { ability and digestibility of } \\
\text { starch. It also increases } \\
\text { the gelatinization } \\
\text { temperature and } \\
\text { enthalpy and decreases } \\
\text { the solubility. }\end{array}$ & {$[36,53,63]$} \\
\hline $\begin{array}{l}\text { High-pressure } \\
\text { ultra- } \\
\text { sonication }\end{array}$ & $\begin{array}{l}\text { The treatment of } \\
\text { ultrasound waves to } \\
\text { native starch granules. }\end{array}$ & $\begin{array}{l}\text { It distorts in the } \\
\text { crystalline region of the } \\
\text { starch granules. }\end{array}$ & $\begin{array}{l}\text { It decreases the enthalpy } \\
\text { of gelatinization, } \\
\text { consistency coefficient, }\end{array}$ & {$[63,97]$} \\
\hline
\end{tabular}




\begin{tabular}{|c|c|c|c|c|}
\hline $\begin{array}{l}\text { Modification } \\
\text { method }\end{array}$ & Treatment & $\begin{array}{l}\text { Change in starch } \\
\text { structure }\end{array}$ & $\begin{array}{l}\text { Change in starch } \\
\text { properties }\end{array}$ & References \\
\hline & $\begin{array}{l}\text { at } 24 \mathrm{KHz} \text { to } 360 \mathrm{KHz} \\
\text { frequency }\end{array}$ & & $\begin{array}{l}\text { crystallinity and } \\
\text { molecular weight of } \\
\text { starch granules. }\end{array}$ & \\
\hline Annealing & $\begin{array}{l}\text { Modification of starch } \\
\text { in the presence of } \\
\text { intermediate water } \\
\text { contents }(40-50 \% \mathrm{w} / \\
\text { w) or excess water } \\
\text { more than } 65 \% \mathrm{w} / \mathrm{w} \text { at } \\
\text { temperatures lower } \\
\text { than the onset } \\
\text { temperature of } \\
\text { gelatinization }\end{array}$ & $\begin{array}{l}\text { It increases interaction } \\
\text { between the amylose- } \\
\text { amylopectin and } \\
\text { amylose-amylose chains } \\
\text { and the crystalline } \\
\text { perfection. } \\
\text { It enhances the mobility } \\
\text { of double-helical chain } \\
\text { segments within } \\
\text { granules, allows } \\
\text { subsequent } \\
\text { recrystallization, } \\
\text { restructuring, or both of } \\
\text { starch chains, enhances } \\
\text { molecular order and } \\
\text { provides more } \\
\text { homogeneity among } \\
\text { crystallites. }\end{array}$ & $\begin{array}{l}\text { Decreases the amylose } \\
\text { leaching and swelling of } \\
\text { granules and increases } \\
\text { thermal stability } \\
\text { gelatinization } \\
\text { temperatures, and } \\
\text { susceptibility towards } \alpha- \\
\text { amylase. }\end{array}$ & {$[59,80]$} \\
\hline $\begin{array}{l}\text { Thermal } \\
\text { inhibition }\end{array}$ & $\begin{array}{l}\text { Dehydration of starch } \\
\text { at a high temperature } \\
\text { until it becomes } \\
\text { anhydrous }(<1 \% \\
\text { moisture }\end{array}$ & $\begin{array}{l}\text { It results in a decrease in } \\
\text { granular size. }\end{array}$ & $\begin{array}{l}\text { It increases the cohesive- } \\
\text { texture and stabilizes the } \\
\text { viscosity of starch. }\end{array}$ & {$[52,98]$} \\
\hline Cold plasma & $\begin{array}{l}\text { Treatment of starch } \\
\text { with low-temperature } \\
\text { plasma or glow- } \\
\text { discharge plasma. }\end{array}$ & $\begin{array}{l}\text { It causes free radical- } \\
\text { induced cross-linking } \\
\text { of starch and increases } \\
\text { the amylose leaching. } \\
\text { It reduces the relative } \\
\text { crystallinity due to } \\
\text { active plasma } \\
\text { species-induced } \\
\text { depolymerization. }\end{array}$ & $\begin{array}{l}\text { It influences the physical } \\
\text { and functional properties } \\
\text { of starch. It increases } \\
\text { the pasting and } \\
\text { viscosity but decreases } \\
\text { the retrogradation } \\
\text { tendency. }\end{array}$ & [99-101] \\
\hline $\begin{array}{l}\text { Pulsed electric } \\
\text { field (PEF) } \\
\text { treatment }\end{array}$ & $\begin{array}{l}\text { Processing of starch- } \\
\text { water suspension in } \\
\text { electric field strength of } \\
50 \mathrm{kV} / \mathrm{cm} \text {. }\end{array}$ & & $\begin{array}{l}\text { It reduces enthalpy, } \\
\text { gelatinization } \\
\text { temperature, enthalpy, } \\
\text { viscosity and crystallinity } \\
\text { of granules. The granule } \\
\text { diameters increase with } \\
\text { increase in the field } \\
\text { strength. }\end{array}$ & $\begin{array}{l}{[62,64} \\
102,103]\end{array}$ \\
\hline Freezing & $\begin{array}{l}\text { Freezing the starch at } \\
\text { very low temperature } \\
\text { (sub-zero levels) }\end{array}$ & $\begin{array}{l}\text { Reversible structural } \\
\text { disorder on starch } \\
\text { granules, }\end{array}$ & $\begin{array}{l}\text { It causes the change in } \\
\text { the texture and } \\
\text { gelatinization properties } \\
\text { and increase in } \\
\text { retrogradation. }\end{array}$ & {$[80]$} \\
\hline $\begin{array}{l}\text { Freeze-Thaw } \\
\text { treatment }\end{array}$ & $\begin{array}{l}\text { Heating of starch at } \\
\text { high temperature ( } 59- \\
79^{\circ} \mathrm{C} \text { ) flowed by } \\
\text { freezing and defrosting. }\end{array}$ & $\begin{array}{l}\text { An increase in the } \\
\text { number of Free-Thaw } \\
\text { cycles changes the } \\
\text { complex modulus and } \\
\text { phase angle of the starch. }\end{array}$ & $\begin{array}{l}\text { Affects the rheological } \\
\text { properties of starch. } \\
\text { Increases the swelling } \\
\text { power, viscosity, and } \\
\text { thermal stability of } \\
\text { starch. It also } \\
\text { influences the surface } \\
\text { properties of the starch } \\
\text { granules. }\end{array}$ & $\begin{array}{l}{[60]} \\
{[38,51]}\end{array}$ \\
\hline $\begin{array}{l}\text { Duel } \\
\text { modification }\end{array}$ & \multicolumn{4}{|c|}{$\begin{array}{l}\text { Treatment of starch with a combination of different } \\
\text { physical factors. }\end{array}$} \\
\hline
\end{tabular}




\begin{tabular}{|c|c|c|c|c|}
\hline $\begin{array}{l}\text { Modification } \\
\text { method }\end{array}$ & Treatment & $\begin{array}{l}\text { Change in starch } \\
\text { structure }\end{array}$ & $\begin{array}{l}\text { Change in starch } \\
\text { properties }\end{array}$ & References \\
\hline $\begin{array}{l}\text { Heat-moisture } \\
\text { treatment- } \\
\text { annealing }\end{array}$ & $\begin{array}{l}\text { Heat-moisture } \\
\text { treatment followed by } \\
\text { annealing. }\end{array}$ & $\begin{array}{l}\text { No significant damage of } \\
\text { individual treatment on } \\
\text { the structure of starch } \\
\text { granules has been } \\
\text { observed. } \\
\text { Heat-moisture-annealing } \\
\text { treatment resulted in } \\
\text { disruption of crystalline } \\
\text { structure. }\end{array}$ & Increase in enthalpy. & {$[58,72]$} \\
\hline $\begin{array}{l}\text { Annealing- } \\
\text { sonication and } \\
\text { Sonication- } \\
\text { annealing }\end{array}$ & $\begin{array}{l}\text { Annealing followed by } \\
\text { sonication and vice } \\
\text { versa. }\end{array}$ & $\begin{array}{l}\text { Both treatments promote } \\
\text { a synergic behavior on } \\
\text { crystallite collapse and } \\
\text { result in a decrease in } \\
\text { relative crystallinity. The } \\
\text { later also results in } \\
\text { irregular surface } \\
\text { morphologies and } \\
\text { granule disintegration. }\end{array}$ & $\begin{array}{l}\text { Both increase the pasting } \\
\text { viscosity }\end{array}$ & \\
\hline
\end{tabular}

Table 1.

Methods of physical modification of starch and changes in starch structure and properties.

\begin{tabular}{|c|c|c|c|c|}
\hline $\begin{array}{l}\text { Modification } \\
\text { method }\end{array}$ & Treatment & Change in structure & $\begin{array}{l}\text { Change in } \\
\text { properties }\end{array}$ & References \\
\hline Oxidation & $\begin{array}{l}\text { Addition of carboxyl } \\
\text { and carbonyl group } \\
\text { to native starch by } \\
\text { the use of an } \\
\text { oxidizing agent. }\end{array}$ & $\begin{array}{l}\text { It causes } \\
\text { depolymerization of } \\
\text { starch resulting in } \\
\text { retardation in } \\
\text { recrystallization due } \\
\text { to the incorporation } \\
\text { of carbonyl and } \\
\text { carboxyl groups. }\end{array}$ & $\begin{array}{l}\text { It increases the } \\
\text { stability, clarity and } \\
\text { biding properties } \\
\text { but reduces the } \\
\text { dispersion viscosity } \\
\text { of starch. }\end{array}$ & $\begin{array}{l}{[23,44,} \\
104]\end{array}$ \\
\hline $\begin{array}{l}\text { Stabilization by } \\
\text { addition of a } \\
\text { polymer }\end{array}$ & $\begin{array}{l}\text { Copolymerization } \\
\text { with synthetic } \\
\text { polymers }\end{array}$ & $\begin{array}{l}\text { It provides the } \\
\text { structural stability to } \\
\text { starch and reduces } \\
\text { the retrogradation. }\end{array}$ & $\begin{array}{l}\text { It improves the } \\
\text { freeze-thaw } \\
\text { stability and shelf } \\
\text { life of starch-based } \\
\text { food products. }\end{array}$ & {$[23]$} \\
\hline \multicolumn{5}{|l|}{ Etherification } \\
\hline Hydroxyethylation & $\begin{array}{l}\text { Introduction of } \\
\text { hydroxyethyl group } \\
\text { to the starch. }\end{array}$ & $\begin{array}{l}\text { Changes in the } \\
\text { granular structure. }\end{array}$ & $\begin{array}{l}\text { Improves the drug } \\
\text { binding ability for } \\
\text { some anticancer and } \\
\text { other drugs. }\end{array}$ & {$[71]$} \\
\hline Hydroxypropylation & $\begin{array}{l}\text { Addition of } \\
\text { hydroxypropyl } \\
\text { group on the starch. }\end{array}$ & $\begin{array}{l}\text { It disrupts the inter- } \\
\text { and intra-molecular } \\
\text { hydrogen bonds and } \\
\text { weakens the } \\
\text { granular structure of } \\
\text { starch. It increases } \\
\text { the motional } \\
\text { freedom of starch } \\
\text { chains in amorphous } \\
\text { regions. }\end{array}$ & $\begin{array}{l}\text { It increases the peak } \\
\text { viscosity, water } \\
\text { binding capacity, } \\
\text { swelling power, } \\
\text { solubility and } \\
\text { enzymatic } \\
\text { digestibility of } \\
\text { starch. It also } \\
\text { improves the paste } \\
\text { clarity and freeze- } \\
\text { thaw stability. } \\
\text { However, it } \\
\text { decreases the } \\
\text { gelatinization } \\
\text { parameters, }\end{array}$ & $\begin{array}{l}{[26,68,} \\
105]\end{array}$ \\
\hline
\end{tabular}




\begin{tabular}{|c|c|c|c|c|}
\hline $\begin{array}{l}\text { Modification } \\
\text { method }\end{array}$ & Treatment & Change in structure & $\begin{array}{l}\text { Change in } \\
\text { properties }\end{array}$ & References \\
\hline & & & $\begin{array}{l}\text { enthalpy of } \\
\text { gelatinization, and } \\
\text { transition } \\
\text { temperatures. It also } \\
\text { decreases the } \\
\text { hardness and } \\
\text { adhesiveness of the } \\
\text { gels. }\end{array}$ & \\
\hline Carboxymethylation & $\begin{array}{l}\text { Carboxymethyl } \\
\text { substitution of } \\
\text { hydroxyl groups in } \\
\text { starch }\end{array}$ & $\begin{array}{l}\text { It adds the } \\
\text { hydrophobic groups } \\
\text { on the starch } \\
\text { molecule. }\end{array}$ & $\begin{array}{l}\text { It increases the } \\
\text { stability of starch in } \\
\text { aqueous media, } \\
\text { reduces the } \\
\text { recrystallizing } \\
\text { ability and prevents } \\
\text { the damage from } \\
\text { heat and } \\
\text { microorganisms. }\end{array}$ & {$[51]$} \\
\hline \multicolumn{5}{|l|}{ Esterification } \\
\hline Acetylation & $\begin{array}{l}\text { Reaction of an acetyl } \\
\text { group with the } \\
\text { hydroxyl group of } \\
\text { polymeric starch }\end{array}$ & $\begin{array}{l}\text { It retards the } \\
\text { crystallization or } \\
\text { retrogradation in } \\
\text { starch granules. }\end{array}$ & $\begin{array}{l}\text { It inhibits the } \\
\text { formation of } \\
\text { intramolecular } \\
\text { hydrogen bonds and } \\
\text { enhances the } \\
\text { viscosity and } \\
\text { swelling capacity of } \\
\text { granules. It reduces } \\
\text { the pasting } \\
\text { temperature and } \\
\text { solubility. }\end{array}$ & {$[39,99]$} \\
\hline Fatty acylation & $\begin{array}{l}\text { Reaction of fatty } \\
\text { acids with starch }\end{array}$ & $\begin{array}{l}\text { It results in the } \\
\text { formation of } \\
\text { amylose-fatty acyl } \\
\text { complexes. }\end{array}$ & $\begin{array}{l}\text { It changes the } \\
\text { optical activity and } \\
\text { thermal behavior of } \\
\text { starch }\end{array}$ & {$[106]$} \\
\hline Phosphorylation & $\begin{array}{l}\text { Addition of } \\
\text { phosphate group on } \\
\text { hydroxyl groups of } \\
\text { starch }\end{array}$ & $\begin{array}{l}\text { It results in the } \\
\text { formation of either } \\
\text { monophosphate or } \\
\text { diphosphate starch. } \\
\text { It increases the steric } \\
\text { hindrance and } \\
\text { prevents the } \\
\text { linearity of } \\
\text { molecular chains. }\end{array}$ & $\begin{array}{l}\text { It improves the } \\
\text { viscosity, textural } \\
\text { properties, paste } \\
\text { clarity and Freeze- } \\
\text { Thaw stability of } \\
\text { starch. It also } \\
\text { increases resistance } \\
\text { to low pH, high } \\
\text { temperature, and } \\
\text { high shear. It } \\
\text { decreases the } \\
\text { temperature of } \\
\text { gelatinization. }\end{array}$ & $\begin{array}{l}{[68]} \\
{[45]}\end{array}$ \\
\hline Succinylation & $\begin{array}{l}\text { Treatment of starch } \\
\text { with Octinyl succinic } \\
\text { anhydride }\end{array}$ & $\begin{array}{l}\text { It results in the } \\
\text { derivatization of } \\
\text { starch with alkenyl } \\
\text { succinic anhydrides. }\end{array}$ & $\begin{array}{l}\text { The modification } \\
\text { increases the } \\
\text { swelling volume, } \\
\text { peak viscosity, hot } \\
\text { paste viscosity, and } \\
\text { cool paste viscosity } \\
\text { but decreases the } \\
\text { gelatinization } \\
\text { temperature and gel } \\
\text { hardness. It also } \\
\text { increases the }\end{array}$ & $\begin{array}{l}{[107]} \\
{[108]} \\
{[51]}\end{array}$ \\
\hline
\end{tabular}




\begin{tabular}{|c|c|c|c|c|}
\hline $\begin{array}{l}\text { Modification } \\
\text { method }\end{array}$ & Treatment & Change in structure & $\begin{array}{l}\text { Change in } \\
\text { properties }\end{array}$ & References \\
\hline & & & $\begin{array}{l}\text { production of slow- } \\
\text { digesting and } \\
\text { resistant starch. }\end{array}$ & \\
\hline Cationization & $\begin{array}{l}\text { Treatment of starch } \\
\text { with various cationic } \\
\text { molecules. }\end{array}$ & $\begin{array}{l}\text { Introduction of } \\
\text { amino, ammonium, } \\
\text { imino, phosphonium } \\
\text { or sulfonium groups } \\
\text { to give a positive } \\
\text { ionic charge to } \\
\text { starch. }\end{array}$ & $\begin{array}{l}\text { Increases the } \\
\text { solubility, stability, } \\
\text { dispersibility, and } \\
\text { clarity of the starch. }\end{array}$ & {$[43]$} \\
\hline Dry cationization & $\begin{array}{l}\text { Dry heating of citric } \\
\text { acid to anhydride. } \\
\text { The cationic } \\
\text { molecules are } \\
\text { sprayed in the } \\
\text { absence of liquid } \\
\text { phase on dried starch } \\
\text { during extrusion. }\end{array}$ & $\begin{array}{l}\text { It results in the } \\
\text { formation of cross- } \\
\text { linked starch citrate. }\end{array}$ & $\begin{array}{l}\text { It alters the granular } \\
\text { structure of starch } \\
\text { and improves its } \\
\text { adsorption } \\
\text { properties. }\end{array}$ & {$[70,80]$} \\
\hline Wet cationization & $\begin{array}{l}\text { Homogenous and } \\
\text { heterogenous } \\
\text { reactions of starch } \\
\text { with cationic } \\
\text { molecules in the } \\
\text { presence of a liquid } \\
\text { medium. }\end{array}$ & $\begin{array}{l}\text { It also results in the } \\
\text { formation of cross- } \\
\text { linked starch. }\end{array}$ & $\begin{array}{l}\text { It increases the } \\
\text { viscosity and } \\
\text { decreases the paste } \\
\text { temperature. }\end{array}$ & {$[70]$} \\
\hline $\begin{array}{l}\text { Semi-dry } \\
\text { cationization }\end{array}$ & $\begin{array}{l}\text { Mixing of starch } \\
\text { with cationic } \\
\text { molecules followed } \\
\text { by a thermal } \\
\text { reaction. }\end{array}$ & $\begin{array}{l}\text { Results in cationic } \\
\text { cross-linking of } \\
\text { starch. }\end{array}$ & $\begin{array}{l}\text { It produces a high } \\
\text { degree of } \\
\text { substitution in } \\
\text { starch granules. }\end{array}$ & {$[70]$} \\
\hline $\begin{array}{l}\text { Cross-linking } \\
\text { (Formation of inter } \\
\text { and intramolecular } \\
\text { bridges) }\end{array}$ & $\begin{array}{l}\text { Etherification and } \\
\text { esterification of } \\
\text { granules with cross- } \\
\text { linking polymers by } \\
\text { reacting with a } \\
\text { mixture (99:1) of } \\
\text { sodium } \\
\text { trimetaphosphate } \\
\text { and sodium } \\
\text { tripolyphosphate or } \\
\text { other cross-linkers in } \\
\text { an aqueous alkaline } \\
\text { slurry containing } \\
\text { sodium sulfate. }\end{array}$ & $\begin{array}{l}\text { It reduces the } \\
\text { mobility of } \\
\text { amorphous chains in } \\
\text { the starch granule. It } \\
\text { introduces the inter- } \\
\text { and intra-molecular } \\
\text { bonds with } \\
\text { multifunctional } \\
\text { small molecules with } \\
\text { hydroxyl groups on } \\
\text { starch to strengthen } \\
\text { the granules against } \\
\text { various factors. It } \\
\text { increases the } \\
\text { ordering of internal } \\
\text { granule structure } \\
\text { and stability. }\end{array}$ & $\begin{array}{l}\text { It decreases the } \\
\text { solubility of starch } \\
\text { in water which } \\
\text { reduces its } \\
\text { association with } \\
\text { lipids, moisture, and } \\
\text { proteins. It also } \\
\text { causes decreases in } \\
\text { viscosity, swelling } \\
\text { capacity, } \\
\text { digestibility, } \\
\text { retrogradation rate, } \\
\text { the peak } \\
\text { temperature of } \\
\text { relaxation } \\
\text { endotherm and } \\
\text { enthalpy of starch. } \\
\text { It increases the } \\
\text { gelatinization } \\
\text { temperature, glass } \\
\text { transition } \\
\text { temperature, } \\
\text { melting enthalpy, } \\
\text { free volume of } \\
\text { starch chains, } \\
\text { relaxation enthalpy } \\
\text { and stability of }\end{array}$ & $\begin{array}{l}{[23,42,} \\
45,46, \\
109,110]\end{array}$ \\
\hline
\end{tabular}




\begin{tabular}{|c|c|c|c|c|}
\hline $\begin{array}{l}\text { Modification } \\
\text { method }\end{array}$ & Treatment & Change in structure & $\begin{array}{l}\text { Change in } \\
\text { properties }\end{array}$ & References \\
\hline & & & $\begin{array}{l}\text { starch to high } \\
\text { temperature. }\end{array}$ & \\
\hline Acid cross-linking & $\begin{array}{l}\text { The reaction of } \\
\text { starch with acids }\end{array}$ & & $\begin{array}{l}\text { It increases the } \\
\text { gelatinization } \\
\text { temperature and the } \\
\text { breadth of the } \\
\text { gelatinization } \\
\text { endotherm. }\end{array}$ & {$[48]$} \\
\hline $\begin{array}{l}\text { Graft } \\
\text { copolymerization }\end{array}$ & $\begin{array}{l}\text { Copolymerization of } \\
\text { starch with synthetic } \\
\text { polymers such as } \\
\text { poly (ethylene } \\
\text { terephthalate), } \\
\text { polyethylene, } \\
\text { polypropylene, } \\
\text { polyvinyl chloride, } \\
\text { and polystyrene. }\end{array}$ & $\begin{array}{l}\text { It changes the } \\
\text { structure of starch } \\
\text { from a homopolymer } \\
\text { to heteropolymer. }\end{array}$ & $\begin{array}{l}\text { It results in changes } \\
\text { in physical } \\
\text { properties and } \\
\text { reactivity of starch. }\end{array}$ & {$[41]$} \\
\hline \multirow[t]{2}{*}{$\begin{array}{l}\text { Duel modification } \\
\text { (Modification using } \\
\text { the combination of } \\
\text { different physical } \\
\text { and chemical } \\
\text { methods) }\end{array}$} & $\begin{array}{l}\text { Modification with a } \\
\text { combination of } \\
\text { microwave and } \\
\text { ultrasound } \\
\text { irradiation and } \\
\text { esterification of } \\
\text { carboxymethyl cold- } \\
\text { water-soluble starch } \\
\text { with octenyl succinic } \\
\text { anhydride. }\end{array}$ & & $\begin{array}{l}\text { It reduces the } \\
\text { esterification time } \\
\text { and produces the } \\
\text { starch with better } \\
\text { emulsifying and } \\
\text { surfactant } \\
\text { properties, good } \\
\text { freeze-thaw } \\
\text { stability. }\end{array}$ & {$[42,69]$} \\
\hline & $\begin{array}{l}\text { Cross-linking in } \\
\text { combination with } \\
\text { hydroxypropylation } \\
\text { or acetylation. }\end{array}$ & & $\begin{array}{l}\text { It increases the } \\
\text { production of slow- } \\
\text { digesting and } \\
\text { resistant starch. }\end{array}$ & {$[108]$} \\
\hline
\end{tabular}

Table 2.

Methods of chemical modification and changes in the structure and properties of modified starches.

Cross-linking is the mechanism of covalent interaction between starch molecules. The reagents used to form copolymer in starch are sodium trimetaphosphate, sodium tripyrophosphate, epichlorohydrin and phosphoryl chloride. It has been reported to modify the starch to form frozen products in the food industry and also used to make plastics due to resistant properties $[42,45,46]$. The mechanism of addition of anhydrous acetyl group or vinyl acetate in the presence of sodium hydroxide and potassium hydroxide to native starch granules is called esterification. Acetylated starch has great importance at the industrial level as a thickener, stabilizer, adherent and encapsulator [39, 74, 75]. The commonly used effective methods of chemical modification of starch are presented in Figure 2 and their effects on the structure and properties of various starches are summarized in Table 2.

\section{Effect of modification on the reactivity of starch}

Both the physical and chemical modifications have been found to result in a change in the granular and molecular structure of starch which leads to the change in its reactivity and functionality. The mechanical, thermal radiolytic, and acidcatalyzed hydrolytic degradation of starch granules result in an increase in its 
reactivity due to the exposure of reactive functional groups after the breakdown of amylose and amylopectin chains. Oxidation, acetylation, phosphorylation, carboxymethylation, cationization, and copolymerization also introduce some new functional groups on starch resulting in a change in reactivity of starch towards the water, oil, acids, enzymes, and other chemical species. Cross-linking by the addition of cross-linker molecules also results in the formation of inter and intramolecular bridges among the components of starch which alters its reactivity and specificity for use in industrial and biomedical fields.

\title{
4. Conclusion
}

The physical and chemical modifications have been found to improve the functional quality of starch for its use in certain formulations while such modifications may also limit its use for other purposes. The choice of modification type and treatment method depends on what types of changes in functionality and reactivity of starch are required for a specific application. The modification of starch by various physical methods have been found to affect its structural parameters and physical and functional properties including crystallinity, surface properties, solubility, viscosity, swelling ability, pasting and gelatinization properties, and thermal and freeze-thaw stability. The modifications of starch by the chemical method have been also found to affect the molecular structure and reactivity of starch by addition of new functional groups, degradation of the polymeric structure, oxidation by free radical or cross linking of starch molecules. The change in the polarity due to exposure of reactive functional groups and the increase in the degree of substitution and intermolecular cross-linking results in a change in the reactivity of starch towards water, oil, acids, enzymes, and other chemical species. These modification techniques may lead to some revolutionary changes in reactivity, functionality starch and application of starch in the nutritional, pharmaceutical, biomedical and industrial field. However, the selection of a suitable modification method is much more important for the researchers to make the desired and targeted improvement in the functional quality of starch.

\section{Conflict of interest}

I confirm that there are no conflicts of interest.

\section{Author details}

\author{
Haq Nawaz*, Rashem Waheed, Mubashir Nawaz and Dure Shahwar \\ Department of Biochemistry, Bahauddin Zakariya University, Multan, Pakistan \\ *Address all correspondence to: haqnawaz@bzu.edu.pk
}

\section{IntechOpen}

(C) 2020 The Author(s). Licensee IntechOpen. This chapter is distributed under the terms of the Creative Commons Attribution License (http://creativecommons.org/licenses/ by/3.0), which permits unrestricted use, distribution, and reproduction in any medium, provided the original work is properly cited. (c) BY 


\section{References}

[1] Smith AM. The biosynthesis of starch granules. Biomacromolecules. 2001;2: 335-341

[2] Tester RF, Karkalas J, Qi X. Starchcomposition, fine structure and architecture. Journal of Cereal Science. 2004;39:151-165

[3] Santana ÁL, Meireles MAA. New starches are the trend for industry applications: a review. Food and Public Health. 2014;4:229-241

[4] Srichuwong S, Sunarti TC, Mishima T, Isono N, Hisamatsu M. Starches from different botanical sources I: Contribution of amylopectin fine structure to thermal properties and enzyme digestibility. Carbohydrate Polymers. 2005;60:529-538

[5] Srichuwong S, Sunarti TC, Mishima T, Isono N, Hisamatsu M. Starches from different botanical sources II: Contribution of starch structure to swelling and pasting properties. Carbohydrate Polymers. 2005;62:25-34

[6] Annison G, Topping DL. Nutritional role of resistant starch: Chemical structure vs physiological function. Annual Review of Nutrition. 1994;14: 297-320

[7] Englyst HN, Kingman SM, Cummings JH. Classification and measurement of nutritionally important starch fractions. European Journal of Clinical Nutrition. 1992;46:S33-S50

[8] Tharanathan RN, Mahadevamma S. Grain legumes-a boon to human nutrition. Trends in Food Science and Technology. 2003;14:507-518

[9] Elvira C, Mano JF, San Roman J, Reis RL. Starch-based biodegradable hydrogels with potential biomedical applications as drug delivery systems. Biomaterials. 2002;23:1955-1966
[10] Santander-Ortega MJ, Stauner T, Loretz B, Ortega-Vinuesa JL, BastosGonzález D, Wenz G, et al. Nanoparticles made from novel starch derivatives for transdermal drug delivery. Journal of Controlled Release. 2010;141:85-92

[11] Vilivalam VD, Illum L, Iqbal K. Starch capsules: An alternative system for oral drug delivery. Pharmaceutical Science \& Technology Today. 2000;3: 64-69

[12] Bertolini AC. Trends in Starch Applications. Boca Raton, FL: CRC Press; 2009

[13] Janssen L, Moscicki L. Thermoplastic Starch. Weinheim, Germany: John Wiley \& Sons; 2009

[14] Song JH, Murphy RJ, Narayan R, Davies GBH. Biodegradable and compostable alternatives to conventional plastics. Philosophical Transactions of the Royal Society B. 2009;364:2127-2139

[15] Jiménez A, Fabra MJ, Talens P, Chiralt A. Edible and biodegradable starch films: a review. Food and Bioprocess Technology. 2012;5: 2058-2076

[16] Eliasson A-C. Starch in Food: Structure, Function and Applications. CRC press; 2004

[17] Vamadevan V, Bertoft E. Structurefunction relationships of starch components. Starch. 2015;67:55-68

[18] Case SE, Capitani T, Whaley JK, Shi YC, Trzasko P, Jeffcoat R, et al. Physical properties and gelation behavior of a low-amylopectin maize starch and other high-amylose maize starches. Journal of Cereal Science. 1998; 27:301-314 
[19] Fredriksson H, Silverio J, Andersson R, Eliasson A-C, Åman P. The influence of amylose and amylopectin characteristics on gelatinization and retrogradation properties of different starches. Carbohydrate Polymers. 1998;35: 119-134

[20] Pérez S, Bertoft E. The molecular structures of starch components and their contribution to the architecture of starch granules: A comprehensive review. Starch. 2010;62:389-420

[21] Svihus B, Uhlen AK, Harstad OM. Effect of starch granule structure, associated components and processing on nutritive value of cereal starch: A review. Animal Feed Science and Technology. 2005;122:303-320

[22] Lee B-H, Bello-Pérez LA, Lin AH-M, Kim CY, Hamaker BR. Importance of location of digestion and colonic fermentation of starch related to its quality. Cereal Chemistry. 2013;90: 335-343

[23] Boukhalfa F, Kadri N, Bouchemel S, Ait Cheikh S, Chebout I, Madani K, et al. Chemically modified starch and utilization in food stuffs. Mediterranean Journal of Nutrition and Metabolism. 2018;11:37-50

[24] Jane J, Shen L, Chen J, Lim S, Kasemsuwan T, Nip W. Physical and chemical studies of taro starches and flours1 2. Cereal Chemistry. 1992;69: 528-535

[25] Lii C-Y, Chang S-M, Young Y-L. Investigation of the physical and chemical properties of banana starches. Journal of Food Science. 1982;47: 1493-1497

[26] Liu H, Ramsden L, Corke H. Physical properties and enzymatic digestibility of hydroxypropylated ae, wx, and normal maize starch. Carbohydrate Polymers. 1999;40: 175-182
[27] Colman TAD, Demiate IM, Schnitzler E. The effect of microwave radiation on some thermal, rheological and structural properties of cassava starch. Journal of Thermal Analysis and Calorimetry. 2014;115:2245-2252

[28] da Rosa ZE, Dias ARG. Impact of heat-moisture treatment and annealing in starches: A review. Carbohydrate Polymers. 2011;83:317-328

[29] Huang Z-Q, Lu J-P, Li X-H, Tong ZF. Effect of mechanical activation on physico-chemical properties and structure of cassava starch. Carbohydrate Polymers. 2007;68: 128-135

[30] Loisel C, Maache-Rezzoug Z, Esneault C, Doublier J-L. Effect of hydrothermal treatment on the physical and rheological properties of maize starches. Journal of Food Engineering. 2006;73:45-54

[31] Nawaz H, Shad MA, Saleem S, Khan MUA, Nishan U, Rasheed T, et al. Characteristics of starch isolated from microwave heat treated lotus (Nelumbo nucifera) seed flour. International Journal of Biological Macromolecules. 2018;113:219-226

[32] Pukkahuta C, Shobsngob S, Varavinit S. Effect of osmotic pressure on starch: New method of physical modification of starch. Starch. 2007;59: 78-90

[33] Shaoxiao LWGZZ, Baodong Z. The influence of ultra high pressure treatment on the physicochemical properties of areca taro starch. Journal of the Chinese Cereals and Oils Association. 2013;5:80-84

[34] Singh N, Singh J, Kaur L, Sodhi NS, Gill BS. Morphological, thermal and rheological properties of starches from different botanical sources. Food Chemistry. 2003;81:219-231 
[35] Wicaksono Y, Nuri N, Wisudyaningsih B. Effect of temperature and $\mathrm{pH}$ of modification process on the physical-mechanical properties of modified cassava starch. Molekul. 2016;11:248

[36] Yu S, Zhang Y, Ge Y, Zhang Y, Sun T, Jiao Y, et al. Effects of ultrasound processing on the thermal and retrogradation properties of nonwaxy rice starch. Journal of Food Process Engineering. 2013;36:793-802

[37] Jekle M, Mühlberger K, Becker T. Starch-gluten interactions during gelatinization and its functionality in dough like model systems. Food Hydrocolloids. 2016;54:196-201

[38] Szymońska J, Wodnicka K. Effect of multiple freezing and thawing on the surface and functional properties of granular potato starch. Food Hydrocolloids. 2005;19:753-760

[39] Betancur AD, Chel GL, Cañizares HE. Acetylation and characterization of Canavalia ensiformis starch. Journal of Agricultural and Food Chemistry. 1997;45:378-382

[40] Greenwood CT, Muir DD, Whitcher HW. Hydroxyethyl starch as a cryoprotective agent for human red blood cells the relation between the molecular properties and the cryoprotective effect. Starch. 1977;29: 343-347

[41] Hernández AR. Chemical modification of starch with synthetic. Applications of Modified Starches. 2018; 2:3-22

[42] Jyothi AN, Moorthy SN, Rajasekharan KN. Effect of cross-linking with epichlorohydrin on the properties of cassava (Manihot esculenta Crantz) starch. Starch. 2006;58:292-299

[43] Korma SA, Kamal-Alahmad NS, Ammar A-F, Zaaboul F, Zhang T.
Chemically modified starch and utilization in food stuffs. International Journal of Food Sciences and Nutrition. 2016;5:264-272

[44] Kuakpetoon D, Wang Y-J. Characterization of different starches oxidized by hypochlorite. Starch. 2001; 53:211-218

[45] Nabeshima EH, Grossmann MVE. Functional properties of pregelatinized and cross-linked cassava starch obtained by extrusion with sodium trimetaphosphate. Carbohydrate Polymers. 2001;45:347-353

[46] Páramo-Calderón DE, CarrilloAhumada J, Juárez-Arellano EA, BelloPérez LA, Aparicio-Saguilán A, AlvarezRamirez J. Effect of cross-linking on the physicochemical, functional and digestibility properties of starch from Macho (Musa paradisiaca L.) and Roatan (Musa sapientum L.) banana varieties. Starch. 2016;68:584-592

[47] Karim AA, Sufha EH, Zaidul ISM.

Dual modification of starch via partial enzymatic hydrolysis in the granular state and subsequent hydroxypropylation. Journal of Agricultural and Food Chemistry. 2008; 56:10901-10907

[48] Singh V, Ali SZ. Acid degradation of starch. The effect of acid and starch type. Carbohydrate Polymers. 2000;41: 191-195

[49] Wang L, Wang Y-J. Structures and physicochemical properties of acidthinned corn, potato and rice starches. Starch. 2001;53:570-576

[50] Kulp K, Lorenz K. Heat-moisture treatment of starches. I.

Physicochemical Properties. 1981;58: 46-48

[51] Lawal MV. Modified starches as direct compression excipients-effect of physical and chemical modifications on 
tablet properties: A review. Starch. 2019;71:1800040

[52] Lim S-T, Han J-A, Lim HS, BeMiller JN. Modification of starch by dry heating with ionic gums. Cereal Chemistry. 2002;79:601-606

[53] Nadir AS, Helmy IMF, Nahed MA, Wafaa MMA, Ramadan MT.

Modification of potato starch by some different physical methods and utilization in cookies production. International Journal of Current Microbiology and Applied Sciences. 2015;4:556-569

[54] Nene SP, Vakil UK, Sreenivasan A. Effect of gamma radiation on physicochemical characteristics of red gram (Cajanus cajan) starch. Journal of Food Science. 1975;40:943-947

[55] Silihe K, Zingue S, Winter E, Awounfack C, Bishayee A, Desai N, et al. Starch Modification and Applications. International Journal of Molecular Sciences. 2017;18:1073

[56] Stute R, Klingler RW, Boguslawski S, Eshtiaghi MN, Knorr D. Effects of high pressures treatment on starches. Starch. 1996;48:399-408

[57] Villareal RM, Resurreccion AP, Suzuki LB, Juliano BO. Changes in physicochemical properties of rice during storage. Starch. 1976;28:88-94

[58] Zia-ud-Din, Xiong H, Fei P. Physical and chemical modification of starches: A review. Critical Reviews in Food Science and Nutrition. 2017;57:2691-2705

[59] BeMiller JN, Huber KC. Physical modification of food starch

functionalities. Annual Review of Food Science and Technology. 2015;6:19-69

[60] Eliasson A-C, Kim HR. Changes in rheological properties of hydroxypropyl potato starch pastes during freeze-thaw treatments I. A rheological approach for evaluation of freeze-thaw stability. Journal of Texture Studies. 1992;23: 279-295

[61] Fiedorowicz M, Tomasik P, You S, Lim S-T. Molecular distribution and pasting properties of UV-irradiated corn starches. Starch. 1999;51:126-131

[62] Han Z, Zeng X, Zhang B, Yu S. Effects of pulsed electric fields (PEF) treatment on the properties of corn starch. Journal of Food Engineering. 2009;93:318-323

[63] Jambrak AR, Herceg Z, Šubarić D, Babić J, Brnčić M, Brnčić SR, et al. Ultrasound effect on physical properties of corn starch. Carbohydrate Polymers. 2010;79:91-100

[64] Jeyamkondan S, Jayas DS, Holley RA. Pulsed electric field processing of foods: A review. Journal of Food Protection. 1999;62:1088-1096

[65] Katopo H, Song Y, Jane J. Effect and mechanism of ultrahigh hydrostatic pressure on the structure and properties of starches. Carbohydrate Polymers. 2002;47:233-244

[66] Raffi J, D’Urbal M, Pollin C, SaintLebe L, Dauberte B. Gamma radiolysis of starches derived from different foodstuffs. Starch. 1981;33(Pt. 4): 301-306

[67] Tester RF, Debon SJ. Annealing of starch-a review. International Journal of Biological Macromolecules. 2000;27: 1-12

[68] Waliszewski KN, Aparicio MA, Bello LA, Monroy JA. Changes of banana starch by chemical and physical modification. Carbohydrate Polymers. 2003;52:237-242

[69] Čížová A, Sroková I, Sasinková V, Malovíková A, Ebringerová A. Carboxymethyl starch octenylsuccinate: Microwave-and ultrasound-assisted 
synthesis and properties. Starch. 2008; 60:389-397

[70] Liu J, Yang R, Yang F. Effect of the starch source on the performance of cationic starches having similar degree of substitution for papermaking using deinked pulp. BioResources. 2015;10: 922-931

[71] Paleos CM, Sideratou Z, Tsiourvas D. Drug delivery systems based on hydroxyethyl starch. Bioconjugate Chemistry. 2017;28: 1611-1624

[72] Zanella Pinto V, Goncalves Deon V, Moomand K, Levien Vanier N, PilattiRiccio D, da Rosa ZE, et al. Characteristics of modified carioca bean starch upon single and dual annealing, heat-moisture-treatment, and sonication. Starch. 2019;71:1800173

[73] Zhang L-M. A review of starches and their derivatives for oilfield applications in China. Starch. 2001;53: 401-407

[74] Wang Y-J, Wang L. Characterization of acetylated waxy maize starches prepared under catalysis by different alkali and alkaline-earth hydroxides. Starch. 2002;54:25-30

[75] Xu Y, Ding W, Liu J, Li Y, Kennedy JF, Gu Q, et al. Preparation and characterization of organic-soluble acetylated starch nanocrystals. Carbohydrate Polymers. 2010;80: 1078-1084

[76] Majzoobi M, Radi M, Farahnaky A, Jamalian J, Tongdang T, Mesbahi G. Physicochemical properties of pregelatinized wheat starch produced by a twin drum drier. Journal of Agricultural Science and Technology. 2011;13: 193-202

[77] Acosta S, Chiralt A, Santamarina P, Rosello J, González-Martínez C, Cháfer M. Antifungal films based on starch-gelatin blend, containing essential oils. Food Hydrocolloids. 2016; 61:233-240

[78] Priya B, Gupta VK, Pathania D, Singha AS. Synthesis, characterization and antibacterial activity of biodegradable starch/PVA composite films reinforced with cellulosic fibre. Carbohydrate Polymers. 2014;109: 171-179

[79] Jyothi NVN, Prasanna PM, Sakarkar SN, Prabha KS, Ramaiah PS, Srawan GY. Microencapsulation techniques, factors influencing encapsulation efficiency. Journal of Microencapsulation. 2010;27:187-197

[80] Omoregie E, Okugbo O. Various techniques for the modification of starch and the applications of its derivatives. Journal of Pharmacology Bioresource. 2015;11:66

[81] Vamadevan V, Bertoft E, Soldatov DV, Seetharaman K. Impact on molecular organization of amylopectin in starch granules upon annealing. Carbohydrate Polymers. 2013;98: 1045-1055

[82] Vermeylen R, Goderis B, Delcour JA. An X-ray study of hydrothermally treated potato starch. Carbohydrate Polymers. 2006;64: 364-375

[83] Amini AM, Razavi SMA, Mortazavi SA. Morphological, physicochemical, and viscoelastic properties of sonicated corn starch. Carbohydrate Polymers. 2015;122: 282-292

[84] Bertolini AC, Mestres C, Colonna P, Raffi J. Free radical formation in UVand gamma-irradiated cassava starch. Carbohydrate Polymers. 2001;44: 269-271

[85] Merlin A, Fouassier J-P. Etude de radicaux libres forméas par irradiation 
ultraviolette de l'amidon: Application aux réctions de photodégradation et de photogreffage. Die Makromolekulare Chemie. 1981;182:3053-3068

[86] Bao J, Ao Z, Jane J. Characterization of physical properties of flour and starch obtained from gamma-irradiated white rice. Starch. 2005;57:480-487

[87] Michel JP, Raffi J, Saint-Lebe L.

Experimental study of the radiodepolymerization of starch. Starch. 1980;32:295-298

[88] Raffi J, Agnel JP, Saint-Lebe L, Dauberte B. Gamma radiolysis of starches derived from different foodstuffs. Starch. 1981;33(Pt. 3): 269-271

[89] Lee JH, Han J-A, Lim S-T. Effect of $\mathrm{pH}$ on aqueous structure of maize starches analyzed by HPSEC-MALLS-RI system. Food Hydrocolloids. 2009;23: 1935-1939

[90] Chang YP, Cheah PB, Seow CC. Plasticizing-Antiplasticizing effects of water on physical properties of tapioca starch films in the glassy state. Journal of Food Science. 2000;65:445-451

[91] Grant LA. Effects of starch isolation, drying, and grinding techniques on its gelatinization and retrogradation properties. Cereal Chemistry. 1998;75: 590-594

[92] Liu TY, Ma Y, Yu SF, Shi J, Xue S. The effect of ball milling treatment on structure and porosity of maize starch granule. Innovative Food Science and Emerging Technologies. 2011;12: 586-593

[93] Tamaki S, Hisamatsu M, Teranishi K, Yamada T. Structural change of wheat starch granule by ballmill treatment. Journal of Applied Glycoscience. 1997;44:505-513

[94] Tamaki S, Hisamatsu M, Teranishi K, Adachi T, Yamada T.
Structural change of maize starch granules by ball-mill treatment. Starch. 1998;50:342-348

[95] Stolt M, Oinonen S, Autio K. Effect of high pressure on the physical properties of barley starch. Innovative Food Science and Emerging

Technologies. 2000;1:167-175

[96] Pukkahuta C, Suwannawat B, Shobsngob S, Varavinit S. Comparative study of pasting and thermal transition characteristics of osmotic pressure and heat-moisture treated corn starch. Carbohydrate Polymers. 2008;72: 527-536

[97] Czechowska-Biskup R, Rokita B, Lotfy S, Ulanski P, Rosiak JM.

Degradation of chitosan and starch by $360-\mathrm{kHz}$ ultrasound. Carbohydrate

Polymers. 2005;60:175-184

[98] Chiu C-W, Schiermeyer E, Thomas DJ, Shah MB. Thermally inhibited starches and flours and process for their production. 1998

[99] Thirumdas R, Trimukhe A, Deshmukh RR, Annapure US.

Functional and rheological properties of cold plasma treated rice starch.

Carbohydrate Polymers. 2017;157: 1723-1731

[100] Sarangapani C, Devi Y, Thirundas R, Annapure US, Deshmukh RR. Effect of low-pressure plasma on physico-chemical properties of parboiled rice. LWT- Food Science and Technology. 2015;63:452-460

[101] Zou J-J, Liu C-J, Eliasson B. Modification of starch by glow discharge plasma. Carbohydrate Polymers. 2004;55:23-26

[102] Han Z, Zeng XA, Fu N, Yu SJ, Chen XD, Kennedy JF. Effects of pulsed electric field treatments on some properties of tapioca starch. 
Carbohydrate Polymers. 2012;89:

1012-1017

[103] Han Z, Zeng XA, Yu SJ, Zhang BS, Chen XD. Effects of pulsed electric fields (PEF) treatment on physicochemical properties of potato starch. Innovative Food Science and Emerging Technologies. 2009;10: 481-485

[104] Rutenberg MW, Solarek D. Starch derivatives: Production and uses. Starch: Chemistry and Technology. 2nd ed. 1984:311-388

[105] Lee HL, Yoo B. Effect of hydroxypropylation on physical and rheological properties of sweet potato starch. LWT- Food Science and Technology. 2011;44:765-770

[106] Bulpin PV, Welsh EJ, Morris ER. Physical characterization of amylosefatty acid complexes in starch granules and in solution. Starch. 1982;34:335-339

[107] Bao J, Xing J, Phillips DL, Corke H. Physical properties of octenyl succinic anhydride modified rice, wheat, and potato starches. Journal of Agricultural and Food Chemistry. 2003;51:2283-2287

[108] Han J-A, BeMiller JN. Preparation and physical characteristics of slowly digesting modified food starches. Carbohydrate Polymers. 2007;67: 366-374

[109] Klein MI, DeBaz L, Agidi S, Lee H, Xie G, Lin AH-M, et al. Dynamics of Streptococcus mutans transcriptome in response to starch and sucrose during biofilm development. PLoS One. 2010;5: e13478

[110] Chung H-J, Woo K-S, Lim S-T. Glass transition and enthalpy relaxation of cross-linked corn starches. Carbohydrate Polymers. 2004;55:9-15 



\title{
Starch Source and Its Impact on Pharmaceutical Applications
}

\author{
Olobayo O. Kunle
}

\begin{abstract}
Starch can be obtained from a variety of plant sources. The specific source of starch, the environmental conditions during starch maturation, and the age of the plant affect the physicochemical composition of the starch. This is because of the effect they have on critical factors especially the amylose amylopectin content of the starch as well as their relative quantities. These factors also affect the starch granule size and size distribution and the levels of minor components such as phosphates, lipids, and the nature of these interactions with amylose and amylopectin. In its wide use as a pharmaceutical excipient especially as binder and disintegrant, unmodified starch is affected in its functionality by the physicochemical properties of the starch. These factors especially by their influence on the swelling power and gelatinization as well as granule size and shape determine the properties of dosage forms in which the starches are used. This results in dosage forms that, although meeting compendial standards, differ in specific properties. The source of starches therefore affects the properties of pharmaceutical dosage forms. This should be taken into consideration in the choice of excipients in drug formulation and before the substitution of one starch for another in a formulation.
\end{abstract}

Keywords: starch, source, amylose, amylopectin, swelling, viscosity, pharmaceutical excipients

\section{Introduction}

In its native form, pure starch is a white, amorphous relatively tasteless powder which is odorless and is insoluble in water and other common organic solvents. It is one of the most widely distributed chemical substances in nature being the energy storage form of plant materials.

Microscopically, starch consists of colorless, highly refractive particles whose size and shape depend on various factors most important of which is the source of the starch. A starch granule involves alternating regions of amorphous and crystalline lamellae seen as rings which are essentially the crystalline portion.

Starch is chemically a carbohydrate composed of two similar carbohydrate molecules-amylose and amylopectin. Amylose is a straight chain $\alpha-1,4$-glycosidic bonds, while amylopectin is a branched polymer also made of $\alpha-1,4$-glycosodic with branched chain linked by $\alpha-1,6$-glycosidic bonds. This conformational difference confers different properties on each of these polymers. For example the short branching of amylopectin at the $\alpha-1,6$-glycosidic bonds is responsible for the crystalline region of the granules [1-3]. In the natural state, starch is approximately $20-30 \%$ amylose and $70-80 \%$ amylopectin. 
Amylose which is rigid due to packing resulting from its straight chain is insoluble in water but soluble in hot water without gel formation. Amylopectin is, however, nonrigid in structure and soluble in water and forms a gel in hot water.

Starch which is largely synthesized in the amyloplast of the storage organs of plants and/or the chloroplast of plant leaves also contains traces of lipids and phosphate groups.

\section{Pharmaceutical applications of starch}

Starch is one of the most widely used pharmaceutical excipients because it is one of the few natural products that, with minimal processing, meet most of the requirements for excipients. It is nontoxic, odorless, inexpensive, widely available, and biocompatible.

In its native form, starch is used in the formulation of a number of dosage forms where its particular functions depend on the specific dosage form. This section discusses the most commonly utilized functions of starches as an excipient.

\subsection{Binder}

Starch is widely used as a binder in the wet granulation process of massing and screening which is an important step in the production of tablets, capsules, and other solid dosage forms. The granulation process is used to improve the flow of APIs which tend to be very cohesive. Flow is critical to the maintenance of dosage form weight consistency in high-speed manufacturing equipment, to avoid the dose variation that can result from irregular flow and powder segregation. In this process, starch is used as a liquid binder to create agglomerates with good flow properties. The paste produced on heating a suspension of starch is used to cause the "sticking together" of the particles in the formulation to create larger sized agglomerates that will reduce cohesiveness and encourage flow. This is achieved by the creation of bonding between particles in the powder bed which become solid bridges on drying. The more viscous the paste, the stronger the bridges formed, and the larger the size of the particles formed up to a limit [4]. It would therefore imply that any factors that affect the viscosity of the starch paste would affect the functionality of the starch as a binder. Studies have shown that the source and by implication the chemical composition and nature of starches influence their viscosity [5].

\subsection{Disintegrant}

A disintegrant is an excipient included in a pharmaceutical formulation to achieve the breakup of solid dosage forms such as tablets or granules into smaller discrete particles. Disintegration is a critical step in the process of drug release and absorption as it exposes a larger surface area for the drug to more easily and quickly go into solution. This accelerates the dissolution process, drug release, and absorption to achieve the desired therapeutic activity of the drug. Starch is a cheap and convenient disintegrant which is thought to exert this action as a result of the swelling properties of its particles in the presence of water leading to the disruption of the solid bridges and other binding forces in the dosage form. The extent of swelling is a function of the source or type of the starch which is reflective of the relative proportion and conformation of the amylose and amylopectin in the particular starch [6,7]. Weak associative forces in a starch could be an indication of its potential as a disintegrant [1]. Disintegrant action could also be due to the formation of channels through which fluids are able to penetrate the solid dosage form allowing the dissolution of the drug. 


\subsection{Diluent}

Some drugs are used at very low doses thus making it very difficult to process them and eventually compress them into tablets and other required dosage forms. In such cases, inert materials that do not exert the pharmacological effect of the drug can be included in the formulation to bulk it up to allow for the normal formulation processes. Because it is bland, odorless, and digestible, starch is used for this purpose.

\subsection{Absorbents}

Starch is hygroscopic and can absorb moisture up to $10-17 \%$ when equilibrated at normal atmospheric conditions [8]. It therefore finds use as an absorbent in drug formulations to keep powders dry and ensure the stability of drugs that are liable to deteriorate by hydrolysis and other similar chemical reactions.

\subsection{Glidant/lubricant}

Starches have been studied for use as lubricants and glidants [9] because of their slippery nature and ability to adhere to surfaces.

\subsection{Modified starches}

In its native form, the uses of starch are limited by its inability to withstand some processing conditions such as high temperatures, varying $\mathrm{pH}$, freeze-thaw cycles, its tendency for retrogradation and decomposition, and brittleness.

When modified, starch becomes even more versatile in its pharmaceutical applications. For example, acetylation results in improved paste clarity and flow, as well as increased swelling capacity $[10,11]$, while with carboxylmethylation there is increased water solubility, lowered gelatinization temperature, and paste stability $[12,13]$. An important factor in the modification processes and the specific properties of the modified products is the physicochemical characteristics of the particular starch used. Modifications could be physical using heat and moisture, gelatinization, extrusion, spray drying, granulation, or agglomeration. Starch can also be modified chemically by the introduction of functional groups using derivatization techniques such as esterification, cationization, cross-linking, or hydrolysis and oxidation which are usually achieved by the replacement of all or some of the hydroxyl groups.

\section{Starch source and its pharmaceutically relevant properties}

Starch is one of the most widely distributed substances in nature and can therefore be obtained from several different plant sources. Starch for use as an excipient is one that meets the official compendial standards of quality in the relevant official books (pharmacopeias) and is generally referred to as official starch. Examples of such are potato, corn, rice, and tapioca starches. Pharmaceutical grade starch can be obtained from several plant sources but generally meet the standards shown in Table 1.

In addition to the compendial starches, several other plant sources have been investigated by various workers and reported as suitable sources of pharmaceutical grade starch in studies using the pharmacopeial starches as standards $[9,14,15]$. 


\begin{tabular}{ll}
\hline Description & $\begin{array}{l}\text { Starch grains, size, shape and distribution, presence/absence of hilum, and striations } \\
\text { depend on the plant material from which the starch is obtained }\end{array}$ \\
\hline Characteristics & $\begin{array}{l}\text { Fine to very fine powder, white to slightly yellowish, tasteless, insoluble in cold water } \\
\text { and alcohol }\end{array}$ \\
\hline Identification & $\begin{array}{l}\text { A translucent whitish jelly is produced on cooling } 1 \mathrm{~g} \text { of the starch mixed with } 2 \mathrm{ml} \text { of } \\
\text { cold water, stirred into } 15 \mathrm{ml} \text { of boiling water, and boiled gently for } 2 \mathrm{~min} \text {. A reddish } \\
\text { violet to deep blue color is obtained on adding iodine to water slurry of the starch }\end{array}$ \\
\hline Foreign matter & Not more than traces of cell membranes and protoplasm should be present \\
\hline Acidity & $\begin{array}{l}\text { Not }>2.0 \text { ml of } 0.1 \mathrm{M} \text { NaOH should be required to change the color of } 50 \mathrm{ml} \text { of a } \\
\text { solution obtained from shaking suspension of } 10 \mathrm{~g} \text { starch in } 100 \mathrm{ml} \text { ethanol }(70 \% \\
\mathrm{v} / \mathrm{v}), \text { previously neutralized to } 0.5 \mathrm{ml} \text { of phenolphthalein solution, for } 1 \mathrm{~h} \text { and filtered }\end{array}$ \\
\hline Loss on drying & $\leq 15 \%$ determined by drying1g in an oven at $100-105^{\circ} \mathrm{C}$ \\
\hline Sulfated ash & $\leq 0.6 \%$ determined on $1 \mathrm{~g}$ of starch \\
\hline Microbial limits & Total viable aerobic count $<103$ bacteria/g (determined by plate count) \\
\hline & Absence of $E$. coli \\
\hline
\end{tabular}

Table 1.

Pharmacopoeial requirements of pharmaceutical grade starch [14].

These reports show that although starches from a variety of sources can be used as excipients, the specific effects (especially quantitative) on the formulation properties are dependent on the source. For example, the disintegrant effect of yam starch was higher than that of cocoyam starch. This is attributed to the difference in the fundamental properties of the starches such as particle size and the amylose/ amylopectin ratio which affect functional properties such as swelling, water sorption, and viscosity [16].

Pharmaceutical grade starches can come from either underground plant storage organs such as tubers, rhizomes, or roots or from grains and cereals. The choice of starch source is largely dependent on the availability, ease of extraction, and the yield. The underground storage organs tend to be more easily processed as they are less associated extraneous materials.

While the general physical and chemical properties of starches are the same, their specific functional properties are dependent on the particular plant source which determines their physicochemical properties. The biological origin of starch serves as a determining factor in the granule shape, size, and morphology [17]. This section will examine the effect that the specific plant sources have on some physicochemical properties of starch that are relevant to their use in pharmaceutical formulations.

\subsection{Swelling and gelatinization properties}

\subsubsection{Gelatinization}

The most common use of starch as a pharmaceutical excipient is as binder and disintegrant in the formulation of tablets and other solid dosage forms. Its behavior in the presence of water is therefore its most important property from the perspective of the pharmaceutical industry. While the disintegrant action of starch is substantially determined by the response of the starch particle to water uptake leading to a ballooning before the leakage of its contents and complete rupture, its use as a binder will depend on the cohesiveness resulting from the series of events that result in increased viscosity of the starch paste. The extent of changes induced 
in the starch particle by heating depends on the temperature and duration [18] and has been reported to be greatly influenced by the starch species [1].

Gelatinization is the disruption of the granular structure of starch by heating with an excess of water. This is because as the suspension is heated gradually, the starch particles begin to swell tangentially [19], and particle content begins to leak with the leakage of amylose, until the eventual rupture of the granule which results in further increase in viscosity and solubility. Initially some amylose is retained in the interior cavity, but rupture and collapse and dissolution of the swollen granule occur during prolonged heating. This process results in a gradual increase in viscosity of the suspension until the complete rupture of the starch granules until the peak viscosity is attained [20].

It essentially involves the weakening of the micellar network within the particle subjected to heat in a suspension by disrupting the hydrogen bonds which permits further hydration and irreversible starch particle swelling. This conversion has been related to various irreversible changes such as granule swelling, loss of birefringence, leaching of amylose, and increased viscosity and solubility and tangential swelling of the particle [19]. From a thermodynamic standpoint, gelatinization refers to the enthalpic transitions involving the starch granule treated as a semicrystalline entity (spherulite). Collapse of the crystalline structure leads to a gain in entropy. This tends to dislodge the hydrogen bonding network occurring in the spherulite.

The apparent viscosity of a starch paste is essentially the result of properties of the individual swollen entities, their fragments, presence of starch soluble, and the interaction or cohesiveness between swollen particles.

Gelatinization begins from portions of the granule where bonding is weakest, and so since the degree of association in individual particles differs and is influenced by factors such as plant source and some environmental conditions of growth, gelatinization temperature and pattern would differ from one starch source to another [14].

\subsubsection{Retrogradation}

Retrogradation is a slow recrystallization of starch components (amylose and amylopectin) upon cooling or dehydration [21]. It is as a result of the long molecular chains and the numerous hydroxyl groups present causing a great tendency for bonding between chains, thus producing bundles of amylase molecules which are rigid resulting in rigid gels and insoluble precipitates. The rate of retrogradation in a starch paste depends on the amount of amylose, the size of the amylose molecule, and the method of preparation of the paste $[22,23]$.

\subsubsection{Factors that affect gelatinization/swelling properties}

The strength of the starch granular structure would depend on the specific nature of the component molecules, their association, and spatial arrangement as well as their interaction with water molecules. Since the crystalline region of starch is largely composed of amylose, the exact amount will have a bearing on the gelatinization process. There is significant correlation between apparent amylose content and viscosity parameters such as peak viscosity $(\mathrm{PV})$, minimum viscosity $(\mathrm{MV})$, final viscosity (FV), breakdown (BD), total setback viscosity (TSV), and setback viscosity (SV) [24]. Phosphate monoester derivatives increase the paste viscosity; potato starch which contains a large amount of phosphate monoesters is more resistant to heat and shearing than cereal starches, but hot paste stability is lost when potassium bound to phosphate monoester is displaced by other cations [25]. 
Amylopectin is primarily responsible for granule swelling and viscosity [26], and starch pasting properties are affected by amylose and lipid contents [27, 28]. Increased gelatinization temperatures have been associated with higher levels of amylopectin double helices resulting in enhanced rigidity of the amorphous region [29].

The lipids contained in starches in the form of phospholipids and free fatty acids [30] tend to form complexes with amylose and the long branches of amylopectin resulting in starch granules with limited solubility [28]. They result in opaque and low-viscosity pastes [31] significantly reducing the swelling capacity of starch particles [32]. The phosphorylation level, which appears to be confined to the amylopectin fraction and is enriched in the amorphous regions, is lower in cereal than in tuber starches [33]. It is associated with increased granular hydration and lowered crystallinity, yielding pastes with higher transparency, viscosity, and freeze-thaw stability [34].

The swelling power of starch is associated more with granule structure and chemical composition especially amylose and lipid component than with granule size. Higher amounts of lipid-complexed amylose would inhibit swelling and gelatinization [26].

\subsubsection{Moisture sorption}

Moisture sorption by starch which leads to particle swelling has been attributed to the interaction between the hydroxyl groups of the hexose moiety and water molecules. Although water molecules form hydrogen bonds with both amylose and amylopectin, the amylopectin structure has been shown to physically trap water molecules. Based on this, it has been hypothesized that starch particles high in amylopectin would have a higher moisture sorption potential. Crystalline polymers have been proposed to have extensive secondary intermolecular bonding. This secondary bonding causes the hydroxyl groups on adjacent glucose units to interact with each other and hence reduces the available sites for absorption of water molecules. As a result, the higher degree of crystallinity could reduce the moisture sorption [1].

\subsubsection{Effect of growth conditions}

The conditions of growth of starch-containing plants especially during starch maturation affect the content and gelatinization behavior of the starch [35]. Gelatinization peak temperature has been reported to be lower for barley cultivar grown at low temperatures [36].

Higher growing temperature and abundant moisture during the development of starch granules could cause annealing of starch and result in higher onset and narrower gelatinization temperatures of the starch [37]. The swelling properties of starch particles are significantly affected by the growing temperatures of the plant during its development.

\subsection{Amylose/amylopectin content}

Amylose/amylopectin ratio, molecular weight, and molecular fine structure influence the physicochemical properties of starch and are therefore major determinants of its functional properties such as flow and swelling properties [38]. This is especially because of its swelling and pasting characteristics which have been earlier mentioned and are critical to the pharmaceutical uses of starch. Physicochemical properties of starch in solution are likely direct functions of the molecular constitution of the polymer including the molecular size, unit chain length distribution, branching pattern, degree of phosphate substitution, and granule size and 
distribution [39]. Thermal properties are largely influenced by the branch chain length of amylopectin [40, 41].

A number of factors including environmental and genetic [42] factors influence the amylose amylopectin content and their relative content in a particular starch.

It can occur within the range 65-85:15-20. This difference in composition has been reported to result in some of the peculiar physical and functional properties seen in some starches, such as a difference in crystallinity, starch granule size, gelling, pasting, and flow properties. The membranous structures and physical characteristics of plastids can affect the arrangement and association of the amylose and the amylopectin molecules within the granules [43] with amylose content increasing with granule maturity [44].

The effect of growth conditions on the gelatinization behavior of starches is essentially through their effects on their amylose content. For example, studies have shown that matured at 15 degrees had higher peak viscosity temperatures. FV, TSV, and shorter time maintained at greater than $80 \%$ of peak viscosity than starch from plants grown at ambient temperature in the field due to the difference in amylose content [35].

The elevation of growth temperature increases the gelatinization temperature of wheat starch due primarily to the enhanced presence of amylopectin double helices and probably enhanced rigidity of the amorphous region [29]. The effect of environmental temperature on amylose content is dependent on the specific plant with the possibility of both increase and decrease.

The amylose content of rice and maize were reduced at elevated growth temperatures $[38,45]$, while with wheat the amylose content increased slightly as a function of temperature [29] indicating that the specific plant is also important. Further illustrating the effect of temperature on the amylose content, it was found to differ significantly in plants grown at $15^{\circ}$ from those grown at $20^{\circ}$ and that the longer rice plants were exposed to cool temperatures, the greater the accumulation of amylose [46]. Additionally, starch granule size is a factor in amylose content of a starch, with the level increasing with granule size $[40,41]$.

\subsection{Starch granule size}

Granule size influences the physicochemical characteristics of starch, and since starches from different botanical origins differ in morphology [47], it is one of the important physicochemical parameters that could affect the functional properties of different starches. Characteristics affected include starch composition, gelatinization and pasting properties, enzyme susceptibility, crystallinity, swelling, and solubility. The membranous structures and physical characteristics of plastids can impart a particular shape or morphology to the starch granules [43]. Granules of tuber and root starches, for example, are generally oval [17] while granules from fruits and nuts vary in shape. Granules of small granule starches are characterized by their very irregular, polygonal shape [43].

At similar amylose contents, small granule starches tend to have a lower pasting temperature and more amylose leakage out of the intact granule than do their larger granules at 55 degrees and above [48]; they (small granules) are associated with a higher rate of water absorption, earlier hydration, and more swelling than larger granules [49]. This is due to the less crystallized arrangement of the polysaccharide chains in the smaller starch particles thus providing a higher proportion of amorphous zones which are more accessible to water. Other factors such as amylose/amylopectin ratio and molecular weight and molecular fine structure also contribute [47] with amylose content increasing with granule size [44]. The branch chain length of amylopectin is also correlated with granule size and granule size 
distribution. Decreasing granule size has been associated with reduced degree of polymerization of amylopectin, and smaller less branched amylose polymers are seen in large size starch granules $[49,50]$.

However the dissociation enthalpy of the amylose-lipid complexes of small granules is higher than that of large granules $[51,52]$. The pattern is similar for acid or enzyme hydrolysis with small granules hydrolyzing faster than do large granules $[53,54]$. The pattern of enzyme digestion also differs between small and large granules [55].

Starch particle size distribution is affected by the environment with the elevation of growth temperature tending to decrease the number and size of starch granules [41].

\section{Effect of source on the pharmaceutical applications of starch}

Starches that have been investigated for their potential as pharmaceutical excipients differ in their granule morphology, amylose/amylopectin ratios, water sorption, swelling power, and gelatinization characteristics. A number of workers have found that the physicochemical properties of starches affect the pharmaceutico-technical properties of the dosage forms produced using the various starches $[9,14,15]$. This is the case irrespective of the particular use to which the starch was put in the formulation.

While, in most cases, formulations containing novel starches meet the compendial quality standards, they differed from those containing the official starches. These differences can be attributed to the differences in the physicochemical properties of the starches.

As earlier stated the pharmaceutical uses of starch, especially in drug formulation, are largely based on its water sorption, swelling, and gelatinization properties. While these properties are generally applicable and qualitatively similar whatever the source of the starch, the previous section has shown that the specific or quantitative values of these properties differ from one starch source to another and even among starches from the same source if growth conditions differ. A few cases are mentioned below to illustrate the effect of these differing properties on dosage form characteristics.

A comparative study indicated that cocoyam starch has a higher viscosity than yam and cassava starches, when used as binder resulted in more fragile tablets relative to the other starches as indicated by the high tablet friability values obtained for such tablets [16].

Tablets produced by dry granulation with yam (a large granule) starch as disintegrant were more friable than those formulated with cocoyam (a small granule) starch which also had the highest hardness. There was also an inverse relationship between the starch swelling power and the rate and extent of disintegration and dissolution of the tablets. This is an indication that one of the mechanisms of tablet disintegration by starches is by swell rupture [56].

Starch size and shape affect the compaction characteristics of granulations for tableting. Yam starch which is ovoid in shape with a high mean diameter has high densification as a result of die filling and less densification from subsequent rearrangement of particles at low pressures, while potato and cassava starches with smaller diameters and more rounded shape were the reverse. While yam starch had the highest yield pressure, it had the lowest tensile strength and brittle fracture index [57].

The gelatinization characteristics of Tacca starch as determined by onset, peak, and conclusion temperatures of gelatinization, crystallinity, and enthalpy of gelatinization were lower than for maize starch. This implies that it has more crystalline 
regions that are thermally and structurally less stable than maize starch [1]. These differences in properties resulted in the starches having different compaction properties. While they both underwent plastic deformation, the deformation for maize was more extensive than for Tacca which was more resistant to deformation. Maize starch also produced harder compacts. There was a correlation between these formulation characteristics and the starch properties [58].

Other workers have reported similar co relationship between fundamental properties and formulation properties $[59,60]$.

The functionality of the modified starches used in modified drug formulations has also been reported to be dependent on the source of the native starch. Studies using starches obtained from diverse sources have shown that the source of a starch will affect its function as a sustained release excipient [61-63].

\section{Conclusion}

Starch is a widely available natural material. It is versatile and has found use in many industries due to its different physical and functional properties. A number of modifications or derivatives can be produced because of the presence of a high number of hydroxyl groups on the surface. In the pharmaceutical industry, it finds extensive use as an excipient especially as a disintegrant and binder in the formulation of solid dosage forms. This use is dependent on its behavior in the presence of moisture, essentially the way it interacts and behaves in the presence of water.

Its use as a disintegrant is largely dependent on its insolubility which creates channels in the compact that allow for water to penetrate the compact to dissolve the active drug component. It also depends on the swelling of starch particles which results in the disruption of the solid bridges formed in the compact. The swelling behavior of any particular starch is dependent on a number of factors which are closely related to the exact chemical composition (amylose, amylopectin, lipids, and phosphates) of the starch. The relative quantities of the two carbohydrate moieties - the straight chained amylose and the branched chained amylopectin-is critical to the pattern and extent of interaction between starch and water since it determines the extent of interaction as well as the speed of interaction between water and the $\mathrm{OH}$ group on the chain. The conformation and the extent of branching of the molecules also determine the speed with which water can access and eventually disrupt the bonds within the molecule.

The use of starch as binder is dependent on its behavior when a suspension of starch powder is subjected to increased temperatures which cause the gradual weakening of the intermolecular bonding in the starch granule. The continued supply of energy in the form of heat eventually results in the breakdown of the granules, the outflow of the amylose, and eventually the breakdown of amylopectin. All these processes result in increased viscosity. It is the viscous gel produced that provides the gluing property exploited for the binding of powder particles to obtain granules in drug formulation. On drying, the wet bridges formed dry into solid stable bridges that create the granules for improved flow. This process is also dependent on the amylose amylopectin ratio as well as the moisture content of the starch and the conditions during the production of the starch in the plants.

The relative quantities of amylose and amylopectin, the extent of branching, the conformation of the moieties, the presence of phospholipids, the interaction between the carbohydrates and lipid, the particle size, and the extent of phosphorylation, all of which are affected by environmental and genetic factors, influence starch fundamental (physicochemical) properties that relate to its functional properties as a pharmaceutical excipient. 
In general it can be concluded that although starches from different sources can be used as pharmaceutical excipients, as long as they meet compendial standards, consideration should always be given to the fact that their performance in formulation is dependent on their source. Since they affect functional properties especially the key properties of swelling and pasting, it is necessary to collect as much information on the growth conditions and physicochemical properties of starches to be used as pharmaceutical excipients to ensure batch-to-batch consistency in drug production. These considerations are particularly important when considering changing from one type of starch to another as excipients and in formulary development.

\section{Author details}

Olobayo O. Kunle

National Institute for Pharmaceutical Research and Development (NIPRD), Abuja, Nigeria

*Address all correspondence to: kunleoo@hotmail.com

\section{IntechOpen}

(C) 2019 The Author(s). Licensee IntechOpen. This chapter is distributed under the terms of the Creative Commons Attribution License (http://creativecommons.org/licenses/ by/3.0), which permits unrestricted use, distribution, and reproduction in any medium, provided the original work is properly cited. (cc) BY 


\section{References}

[1] Manek RV, Kunle OO, Emeje MO, Builders P, Rama Rao GV, Lopez GP, et al. Physical, thermal and sorption profile of starch obtained from tacca leonpetaloides. Starch/Starke. 2005;57:55-61

[2] Emeje M, Rodrigues A. Starch: From food to medicine. In: Valdez B, editor. Scientific, Health and Social Aspects of the Food Industry. Vol. 2012. Croatia, IntechOpen; 2012. pp. 355-380

[3] Cheetham NW, Tao L. Variation in crystalline type with amylases content in maize starch granules: An X-ray powder diffraction study. Carbohydrate Polymer. 1998;36(4):277-284

[4] Kunle OO, Bangudu AB. The effects of some starches on the properties of sulphadimidine tablets. Pharmacy World Journal. 1990;7(1):26-31

[5] Gunsel WC, Kanig JL. Tablets. In: Lachman I, Lieberman HA, Kanig JL, editors. Theory and Practice of Industrial Pharmacy. Philadelphia: Lea and Febiger; 1976. pp. 321-357

[6] Chan HT, Bhat R, Karim I. Physicochemical and functional properties of ozone-oxidized starch. Journal of Agricultural and Food Chemistry. 2009;57:5965-5970

[7] Kusumanyati H, Handayani NA, Santosa H. Swelling power and solubility of cassava and sweet potatoes flour. Procedia Environmental Sciences. 2015;23:164-167

[8] Leach HW. Gelatinization of starch. In: Whistler RL, Paschall EF, editors. Starch: Chemistry and Technology. Vol. 1. New York: Academic Press; 1965. p. 20

[9] Builders PF, Arhewoh MI.

Pharmaceutical applications of native starch in conventional drug delivery. Starch-Starke. 2016;68(9/10):864-873
[10] Lawal O. Composition, physicochemical properties and retrogradation characteristics of native, oxidized, acetylated and acid thinned new cocoyam (Xanthosoma sagittifolium) starch. Food Chemistry. 2004;87(2):205-218

[11] Betancur AD, Chel GL, Canizares HE. Acetylation and characterization of Canavalia ensiformis starch. Journal of Agricultural and Food Chemistry. 1997;45(2):378-382

[12] Hofreiter BT. Miscellaneous modifications. In: Wurzburg O, editor. Modified Starch: Properties and Uses. Boco Raton, FL: CRC Press; 1987. pp. $177-196$

[13] Rutenburg MW, Solarek D. Starch derivatives: Production and uses. In: Starch: Chemistry and Technology. 2nd ed. New York: Elsevier; 1984. pp. 311-388

[14] Kunle OO. Review: Pharmaceutical grade starch and some of its potential sources in Nigeria. Journal of Phytomedicine and Therapeutics. 2002;7(1\&2):1-17

[15] Odeku AO. Potentials of tropical starches as pharmaceutical excipients; a review. Starch-Starke. 2013;65:89-106

[16] Kunle OO, Bangudu AB. The effects of some starches on the properties of sulphadimidine tablets. Pharmacy World Journal. 1990;7(1):26-31

[17] Hoover R. Composition, molecular structure, and physicochemical properties of tuber and root starches: A review. Carbohydrate Polymers. 2001;45(3):253-267

[18] Greenwood CT. The thermal degradation of starch. Advances in Carbohydrate Chemistry. 1967;22:483 
[19] Chabot JF, Hood LF, Allen JE. Effect of chemical modifications on the ultrastructure of corn, waxy, maize and tapioca starches. Cereal Chemistry. 1976;53(1):85-91

[20] Hofstee J. Properties of different starches and its interpretation. Die Starke. 1953;5:836 cited through Chem. Abs, 48;964 of 53

[21] Sharmal K, Shinomi E, Bianco-Peled H. Small angle X-ray scattering of resistant starch type III. Biomacromolecules. 2003:209-218

[22] Whistler RL, Johnson C. Cereal chem. 25, 418 cited through Whistler RL Fraction of starch. In: Whistler RL, Paschall EF, editors. Starch: Chemistry and Technology. Vol. 1. New York: Academic Press; 1965. p. 345

[23] Lansky S, Kool M, Schoch TJ. J. Am. Chem. Soc. 71, 4066 cited through Starch: Chemistry and Technology. In: Whistler RL, Paschall EF, editors. Fundamental Aspects. Vol. 1. New York: Academic Press; 1965. p. 332

[24] Zeng M, Morris CF, Batey IL, Wrigley CW. Sources of variation for starch gelatinization, pasting, and gelation properties in wheat. Cereal Chemistry. 1997;74:63-71

[25] Hofstee J, de Willigen AHA. Starch. In: Bair GWS, Nikuni J, Isemura T, editors. Foodstuffs, Their Plasticity, Fluidity and Consistency. Tokyo: Asakura Shoten; 1956. pp. 1-33

[26] Tester RF, Morrison WR. Swelling and gelatinization of cereal starches. I. Effects of amylopectin, amylase, and lipids. Cereal Chemistry. 1990;67:551-557

[27] Jane J, Chen YY, Lee LF, McPherson AE, Wong KS, Radosavljevic M, et al. Effects of amylopectin branch chain length and amylose content on the gelatinization and pasting properties of starch. Cereal Chemistry. 1999;76:629-637

[28] Morrison WR, Tester RF, Snape CE, Law R, Gidley MJ. Swelling and gelatinization of cereal starches. IV. Some effects of lipid-complexed amylase and free amylase in waxy and normal barley starches. Cereal Chemistry. 1993;70:385-391

[29] Tester RF, Morrison WR, Ellis RH, Piggott JR, Batts GR, Wheeler TR, et al. Effects of elevated growth temperature and carbon dioxide levels on some physicochemical properties wheat starch. Journal of Cereal Science. 1995;22:63-71

[30] Tester RF, Karkalas J, Qi X. StarchComposition, fine structure and architecture. Journal of Cereal Science. 2004;39(2):151-165

[31] Craig SAS, Maningat CC, Seib PA, Hoseney RC. Starch paste clarity. Cereal Chemistry. 1989;66(3):173-182

[32] Alcazar-Alay SC, Meireles MAA. Physicochemical properties, modifications and applications of starches from different botanical sources. Journal of Food Science and Technology. 2015;35(2):215-236

[33] Stephen AM, Philip GO. In: Stephen AM, Philip GO, editors. Food polysaccharides and their applications. 2nd ed. Boca Raton: CRC Press; 2016

[34] Reis RL, Cunha AM.

Characterization of two biodegradable polymers of potential application within the biomaterials field. Journal of Materials Science. Materials in Medicine. 1995;6(12):786-792

[35] Yanagisawa T, Kiribuchi-Otobe C, Fujita M. Increase in apparent amylase content and change in starch pasting properties at cool growth temperatures 
in mutant wheat. Cereal Chemistry. 2004;81(1):26-30

[36] Myllarinen P, Schulman AH, Salovaara H, Poutanen K. The effect of growth temperature on gelatinization properties of barley starch. Acta Agriculturae Scandinavica, Section BSoil \& Plant Science. 1998;48:85-90

[37] Tester RF, Debon SJJ, Sommerville MD. Annealing of maize starch. Carbohydrate Polymers. 2000;42:287-299

[38] Asaoka M, Okuno K, Sugimoto Y, Kawakami J, Fuwa H. Effect of environmental temperature during development of rice plants on some properties of endosperm starch. Starch. 1984;36:189-193

[39] Blennow A, Bay-Smidt AM, Bauer R. Amylopectin aggregation as a function of starch phosphate content studied by size exclusion chromatography and on-line refractive index and light scattering. International Journal of Biological Macromolecules. 2001;28:409-420

[40] Lu T, Jane J, Keeling PL, Singletary GW. Maize starch fine structures affected by ear development temperature. Carbohydrate Research. 1996;282:157-170

[41] Tester RF. Influence on growth conditions on barley starch properties. International Journal of Biological Macromolecules. 1997;21:37-45

[42] Umemoto T, Nakamura Y, Ishikura N. Activity of starch synthase and the amylose content in rice endosperm. Phytochemistry. 1995;40:1613-1616

[43] Jane JL, Kasemsuwan T, Leas S, Robyt JF. Anthology of of starch granule morphology by scanning electron microscopy. Starch-Starke. 1994;46:121-129
[44] Morrison WR, Gardan H. The amylose and lipid contents of starch granules in developing wheat endosperm. Journal of Cereal Science. 1987;2:263-276

[45] Ferguson VL, Zuber MS. Influence of environment content on maize endosperm. Crop Science. 1962;2:209-211

[46] Hirano HY, Sano Y. Enhancement of $W_{x}$ gene expression and the accumulation of amylose in response to cool temperatures during seed development in rice. Plant \& Cell Physiology. 1998;39:807-812

[47] Lindeboom N, Chang PR, Tyler RT. Analytical, biochemical and physicochemical aspects of starch granule size, with emphasis on small granule starches: A review. StarchStarke. 2004;56:89-99

[48] Zheng GH, Sosulski FW. Physicochemical properties of small granule starches. In: AACC Annual Meeting; San Diego. 1997

[49] Tang H, Ando H, Watanaba K, Takeda Y, Mitsunaga T. Physicochemical properties and structure of large, medium and small granule starches in fraction of normal barley endosperm. Carbohydrate Research. 2001;330:241-248

[50] Takeda Y, Takeda C, Mizukami H, Hanashiro I. Structures of large, medium and small starch granules of barley grain. Carbohydrate Polymers. 1999;38:109-114

[51] Chiotelli E, Le Meste M. Effect of small and large wheat starch granules on thermo-mechanical behaviour of starch. Cereal Chemistry. 2002;79:286-293

[52] Myllarinen P, Autio K, Schulman AH, Potanen K. Heat induced structural 
changes of small and large barley starch granules. Journal of the Institute of Brewing. 1998;104:343-349

[53] Kulp K. Characteristics of small granule starch of flour and wheat. Cereal Chemistry. 1973;50:666-679

[54] Vasnthan T, Bhatty RS.

Physicochemical properties of smalland large-granule starches of waxy, regular, and high-amylose barley. Cereal Chemistry. 1996;73:199-207

[55] Elaisson AC. Carbohydrates in Food. New York: Marcel Dekker Inc.; 1996

[56] Kunle OO, Hezekiah SN. The effect of some starch properties on the disintegration and dissolution properties of salicylic acid tablets produced by dry granulation. Pharmacy World Journal. 1991;8(4):117-119

[57] Itiola OA. Compressional characteristics of 3 starches and the mechanical properties of tablets. Pharmacy World Journal. 1991;8(3):91-94

[58] Kunle OO, Ibrahim YKE, Emeje MO, Shaba S, Kunle Y. Extraction, physicochemical and compaction characteristics of tacca starch-A potential pharmaceutical excipient. Starch-Starke.

2003;55:319-325

[59] Ibezim EC, Ofoefule SI, Omeje EO, Onyinshi VI, Odoh UE. The role of ginger as binder in acetaminophen tablets. Journal of Scientific Research and Assay. 2008;3(2):46-50

[60] Ofoefule SI, Osuji AC, Okorie O. Effects of physical and chemical modifications on the disintegrant and dissolution properties of tacca involucrate starch. Bio-

Research. 2004;2(1):97-102

[61] Adebiyi AB, Omojola MO, Orishadipe AT, Afolayan MO,
Olalekan D. Tacca starch citrate-A potential pharmaceutical excipient. Archives of Applied Science Research. 2011;3(6):114-121

[62] Alebiowu G, Itiola OA. The effects of starches on mechanical properties of paracetamol tablet formulation I. Pregelatinization of starch binders. Acta Pharmaceutica (Zagreb, Croatia). 2003;53:231-237

[63] Emeje M, Kalita R, Isimi C, Buragohain A, Kunle O, Ofoefule S. Synthesis, physicochemical characterization, and functional properties of an esterified starch from an underutilized source in Nigeria. African Journal of Food, Agriculture, Nutrition and Development. 2012; 12(7):7001-7018 
Section 2

\section{Application of Starch}





\title{
Studies on the Property and Application of Starch Sugar Ester Dodecenylsuccinic
}

\author{
Liu Zhongdong, Liu Boxiang, Wei Guohua, Zhu Xin \\ and Wang Huabin
}

\begin{abstract}
In this study, we have prepared starch and Brown algae sugar ester dodecenylsuccinic, and by using infrared rays, scanning electron microscopy (SEM), and differential scanning calorimetry (DSC), we studied the structures and properties of the starch and Brown algae sugar ester dodecenylsuccinic. In addition, we studied the possibility of using this modified starch and Brown algae as emulsifier that can be used in ice cream.
\end{abstract}

Keywords: starch sugar ester dodecenylsuccinic (Brown algae sugar modified), property and application

\section{Introduction}

Starch sugar ester is one kind of starch derivatives and it is obtained by modifying starch via former liquefying, then esterifying or by former esterifying, then liquefying. It is an important kind of safe additive, which possessed good emulsification and dense increasing abilities, and is degradable. Starch sugar ester has been an important modified starch in food industry [1-3]. Starch sugar ester, in particular, has been used to stabilize flavor concentrates in beverages, oil in salad oil, and to encapsulate flavors, fragrances, and vitamins. Also it can be used in meat foods, cooking foods, cheese, etc. Starch sugar ester has also important application in papermaking industry, medicine industry, petroleum and chemical industry, etc. With the incorporation of alkenylsuccinates groups into normally starch molecules, starch sugar ester obtains hydrophobic and hydrophilic properties. After liquefaction, we can get starch products of different dense and mobile properties. Starch sugar ester, particularly starch sugar ester dodecenylsuccinate, has some good properties, which other products do not have, and its dense and emulsification abilities are specific [4].

\section{Experimental}

\subsection{Materials}

The materials used were as follows: wheat starch (Anyang Hei Tai Limited Liability Company of wheat starch), alkenylsuccinate 
(LvShun Chemical Factory have purified by distillation), Termamyl®120L, Types (Novo, Inc.).

\subsection{Reagents and instrument}

Acetone, hydrochloric acid, $\mathrm{NaOH}$, DMSO, LD4-2 centrifuge (Beijing Centrifuge Factory), JJ-1 Mixer (Shenzhen GUOHUA Instruments Factory), PHS-3C pH meter (Shanghai Leici Instrument Factory), Spray dried Meter (NIRO, Danman), Model 1000B Scanning electron microscopy (AMYRAY, America), Differential Scanning (Calorimetrg-2C, PE, America), PERKIN-ENMER 983G Infrared Rays Merer (PE, America).

\subsection{Preparation of wheat starch sugar ester dodecenylsuccinic}

\subsubsection{The first method}

\subsubsection{Preparation of wheat starch dodecenylsuccinic}

Starch was agitated in deionized water with vigorous stirring. The $\mathrm{pH}$ was maintained between 8.0 and 9.0 using a $4 \% \mathrm{NaOH}$ solution. Dodecenylsuccinic anhydride was added slowly, the reaction was allowed to proceed for several hours, then adjusted to 7.0 using $\mathrm{HCl}$, the slurry was filtered, washing with deionized water three times, then washing with acetone one time, centrifuging the isolated insoluble product was air-dried.

\subsubsection{Liquefaction of wheat starch dodecenylsuccinic}

Wheat starch dodecenylsuccinate was slurried with deionized water. The $\mathrm{pH}$ was regulated to 5.7; Termamyl®120L, Type $S$ was added with stirring and made to react for some time, and then, the slurry was dried by spray.

\subsubsection{The second method}

Wheat starch was agitated in deionized water to consistency of 35\%. The $\mathrm{pH}$ was regulated to 5.7; Termamyl ${ }^{\circledR} 120 \mathrm{~L}$, Type $\mathrm{S}$ was added with stirring, and reacting it for $50 \mathrm{~min}$ at $85^{\circ} \mathrm{C}$ killed enzymes. Then, the $\mathrm{pH}$ was maintained between 8.0 and 9.0; dodecenylsuccinic anhydride was added slowly, reaction for several hours, then adjusted to 7.0 using $\mathrm{HCl}$, the slurry was filtered, washing with deionized water three times, washing with acetone one times, centrifuging the isolated product was dried by spray.

\subsection{The properties analysis of products}

\subsubsection{Scanning electron microscopy}

Scanning electron microscopy measurements were carried out by the procedure of Shiying [5].

\subsubsection{Infrared rays}

The products was mixed with $\mathrm{KBr}$, pressed to slice, and then determined with Perkin-Elmer 983G Infrared Rays Meter [6]. 


\subsubsection{Different scanning calorimetry (DSC)}

Samples (about $5 \mathrm{mg}$ ) were weighed directly into previously weighed aluminum DSC pans (Table 1). Water was added to obtain the starch-water ratio of 1:1, and the pans were sealed. An empty pan was used as reference. The scanning rate was $2 \mathrm{deg} / \mathrm{min}$. The scanning range was between 320 and $470 \mathrm{k}$; Means and standard deviations were calculated.

\subsubsection{The analysis of the abilities of water-holding and the stability of thawing-melting}

Dry starch ( $1 \mathrm{~g})$ was agitated in deionized water $(49 \mathrm{~g})$, heated to boil, cooled to room temperature, centrifuged for $10 \mathrm{~min}(3000 \mathrm{r} / \mathrm{min})$, then the volume of upper part was determined $\left(\mathrm{V}_{1}\right)$, the lower part for $24 \mathrm{~h}\left(-18^{\circ} \mathrm{C}\right)$ was frozen, then thawed, centrifuged for $10 \mathrm{~min}$ (3000 r/min), determining the volume of upper part $\left(\mathrm{V}_{2}\right)$ [7].

$$
\begin{gathered}
\text { the ability of water }- \text { hoding }=\frac{50-V_{1}-V_{2}}{\text { weight of starch }} \\
\text { the resistment of thawing }- \text { melting }=\frac{1}{V_{2}}
\end{gathered}
$$

Thawing-melting cycle and water-holding capacity are shown in Table 2.

\subsubsection{Degree of substitution (DS) determination}

A known weight of the sample was dissolved in $10 \mathrm{ml}$ of DMSO by heating $\left(70^{\circ} \mathrm{C}\right.$, $10 \mathrm{~min}$ ) [8]. After cooling, 5-6 drops of phenolphthalein in dictator were added. This solution was titrated against $0.05 \mathrm{M}$ standard $\mathrm{NaOH}$ solutions until a permanent pale pink color was seen. The DS was calculated by using the following equation:

$$
D S=\frac{0.162 A}{1-0.2664 A}
$$

where $\mathrm{A}$ is the millimolarity of the $\mathrm{NaOH}$ solution in which $1 \mathrm{~g}$ sample is reacted. $\mathrm{A}$ is calculated as follows:

$$
\mathrm{A}=\frac{V \times M}{m}
$$

\begin{tabular}{llllll}
\hline $\mathbf{N o}$ & $\mathbf{T}(\mathbf{K})$ & $\mathbf{T}_{\mathbf{p}}(\mathbf{K})$ & $\mathbf{T}_{\mathbf{c}}(\mathbf{K})$ & $\mathbf{T}_{\mathbf{c}}-\mathbf{T}(\mathbf{K})$ & $\Delta \mathbf{H}(\mathbf{J} / \mathbf{g})$ \\
\hline 1 & 394.8 & 419.5 & 434.3 & 39.5 & 1152.67 \\
\hline 2 & 365.4 & 387.0 & 403.8 & 38.4 & 345.05 \\
\hline 3 & 380.2 & 385.8 & 394.3 & 14.1 & 673.33 \\
\hline 4 & 372.5 & 386.8 & 400.5 & 28.0 & 549.19 \\
\hline 5 & 378.5 & 389.8 & 405.9 & 27.4 & 130.63 \\
\hline 6 & 394.5 & 396.9 & 412.2 & 16.7 & 706.41 \\
\hline 7 & 379.7 & 397.7 & 411.9 & 32.2 & 506.07 \\
\hline
\end{tabular}

Table 1.

DSC parameters for native and modified starches. 


\begin{tabular}{|c|c|c|c|c|c|}
\hline No. & Sample & $\begin{array}{l}\mathrm{V}_{1} \\
(\mathrm{ml})\end{array}$ & $\begin{array}{c}\mathrm{V}_{2} \\
(\mathrm{ml})\end{array}$ & $\begin{array}{c}\text { The rate of } \\
\text { water-holding }\end{array}$ & $\begin{array}{l}\text { The } \\
\text { antifreeze ability }\end{array}$ \\
\hline 1 & Unmodified wheat starch & 27.0 & 9.8 & 13.2 & 0.102 \\
\hline 2 & $\begin{array}{l}\text { Wheat starch dodecenylsuccinate of the first } \\
\text { method (DS }=0.0073)\end{array}$ & 27.4 & 5.4 & 17.2 & 0.185 \\
\hline 3 & $\begin{array}{l}\text { Wheat starch dodecenylsuccinate of the first } \\
\text { method }(D S=0.0102)\end{array}$ & 29.0 & 5.6 & 15.4 & 0.179 \\
\hline 4 & $\begin{array}{l}\text { Wheat starch dodecenylsuccinate of the first } \\
\text { method (DS }=0.0150)\end{array}$ & 28.9 & 5.8 & 15.3 & 0.172 \\
\hline 5 & $\begin{array}{l}\text { Wheat starch esterdodecenylsuccinate of the } \\
\text { first method ( } D E=4.1)\end{array}$ & 47.7 & 0 & 2.3 & $\begin{array}{c}\text { No water } \\
\text { separated out }\end{array}$ \\
\hline 6 & $\begin{array}{l}\text { Wheat starch ester dodecenylsuccinate of the } \\
\text { first method ( } \mathrm{DE}=5.1)\end{array}$ & 47.5 & 0 & 2.5 & $\begin{array}{c}\text { No water } \\
\text { separated out }\end{array}$ \\
\hline 7 & $\begin{array}{l}\text { Wheat starch ester dodecenylsuccinate of the } \\
\text { first method }(\mathrm{DE}=6.9)\end{array}$ & 48.0 & 0 & 2.0 & $\begin{array}{c}\text { No water } \\
\text { separated out }\end{array}$ \\
\hline 8 & $\begin{array}{l}\text { Wheat starch ester dodecenylsuccinate of the } \\
\text { second method (DS }=0.0099 \text { ) }\end{array}$ & 47.0 & 0 & 3.0 & $\begin{array}{c}\text { No water } \\
\text { separated out }\end{array}$ \\
\hline 9 & $\begin{array}{l}\text { Wheat starch ester dodecenylsuccinate of the } \\
\text { second method (DS }=0.0112)\end{array}$ & 47.1 & 0 & 2.9 & $\begin{array}{c}\text { No water } \\
\text { separated out }\end{array}$ \\
\hline 10 & $\begin{array}{l}\text { Wheat starch ester dodecenylsuccinate of the } \\
\text { second method }(\mathrm{DS}=0.0146)\end{array}$ & 48.0 & 0 & 2.0 & $\begin{array}{c}\text { No water } \\
\text { separated out }\end{array}$ \\
\hline
\end{tabular}

Table 2.

Thawing-melting cycle and water-holding capacity.

where $\mathrm{V}$ is the volume of $\mathrm{NaOH}$ solution used during titration, $\mathrm{M}$ is the molarity of the $\mathrm{NaOH}$ solution, and $\mathrm{m}$ is the weight of sample analyzed.

\subsection{The preparation of ice cream in which the modified starch is used as emulsifier}

\subsubsection{The rate of ice-cream expanding}

\subsubsection{Determination of the resistance of ice-cream melting}

The ice cream was cut to a block (about $100 \mathrm{~g}$ ) at room temperature $\left(27^{\circ} \mathrm{C}\right.$ ), and then it was put in the sieve and the time of the first drop dripped was recorded [9].

\section{Result and discussion}

\subsection{Scanning electron microscopy}

Figure 1 shows the wheat starch ester dodecenylsuccinate of the first method (1\#: Unmodified wheat starch, 2\# DS $=0.0073,3 \# \mathrm{DS}=0.0102,4 \# \mathrm{DS}=0.0150,5 \#$ $\mathrm{DE}=4.5,6 \# \mathrm{DE}=6.9)$; wheat starch ester dodecenylsuccinate of the second method $(7 \# \mathrm{DE}=8.2,8 \# \mathrm{DE}=9.7,9 \# \mathrm{DE}=11.6)$; and wheat starch ester dodecenylsuccinate of the second method $(10 \# \mathrm{DS}=0.0099,11 \# \mathrm{DS}=0.0112,12 \# \mathrm{DS}=0.0146)$.

The unmodified starch granules have an oval or round pattern. For the DS of products, (2\#) is low. We only saw individual granules surface were corroded. With the rising of DS, the number of starch granules corroded rises and forms some holes 
Studies on the Property and Application of Starch Sugar Ester Dodecenylsuccinic DOI: http://dx.doi.org/10.5772/intechopen.89744
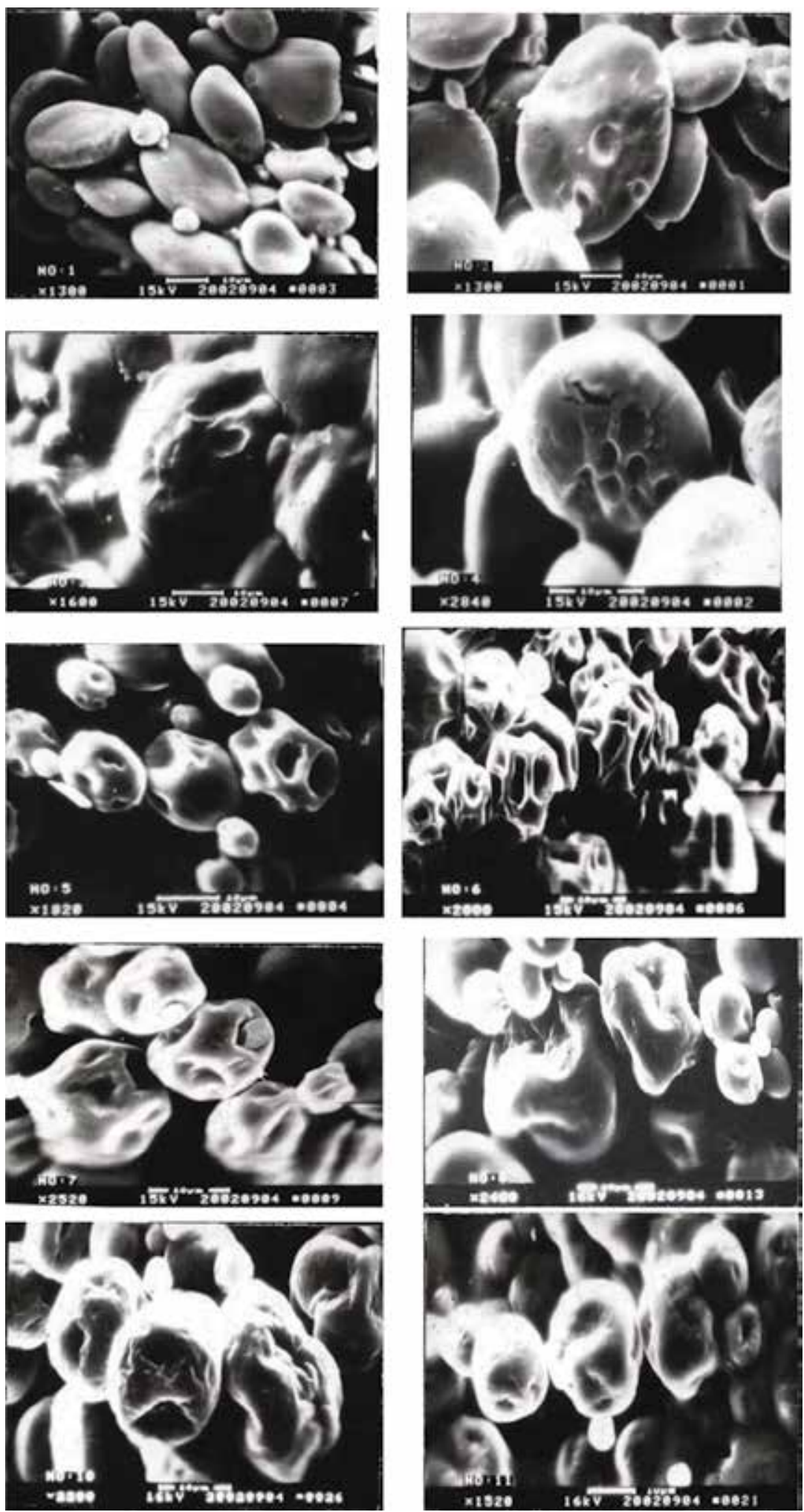

Figure 1.

SEM images of different starch. 
( $3 \#$ and $4 \#$ ). This shows that the reaction is at the granule surface first. From the images of $5 \#, 6 \#, 7 \#, 8 \#$, and $9 \#$, we can see the obvious holes, which indicate that it is feasible and that we liquefied starch granules with $\alpha$-amylase. Either liquefaction former or latter, the starch granules all maintaining granule pattern liquefaction first can increase the reaction area on starch granules surface.

\subsection{The infrared ray analysis of different products}

Figure 2 shows the analysis of the different products, where 1\#: unmodified wheat starch; 2\#: wheat starch sugar ester dodecenylsuccinate of the first method (DS $=0.0150)$; 3\#: wheat starch sugar ester dodecenylsuccinate of the first method $(\mathrm{DE}=6.3)$; and $4 \#$ : wheat starch sugar ester dodecenylsuccinate of the second method (DS $=0.0146)$.

In Figure 2, the absorptions of $1737 \mathrm{~cm}^{-1}$ of $2 \#, 1738 \mathrm{~cm}^{-1}$ of $3 \#, 1739 \mathrm{~cm}^{-1}$ of 4\# are the absorptions $\gamma_{c}=0$-the character of ester, the absorptions of diene bond $(\mathrm{C}=\mathrm{C}-\mathrm{C}=\mathrm{C})$. From the analysis of the ester bond and diene bond and the comparison the spectrums unmodified wheat starch, it was proved that the products have been estered.

\subsection{The differential scanning calorimetric analysis of different products}

1\#: unmodified wheat starch, wheat starch esterdodecenylsuccinate of the first method $(2 \# \mathrm{DS}=0.0073,3 \# \mathrm{DS}=0.0150,4 \# \mathrm{DS}=0.0121,5 \# \mathrm{DE}=6.3)$. Wheat
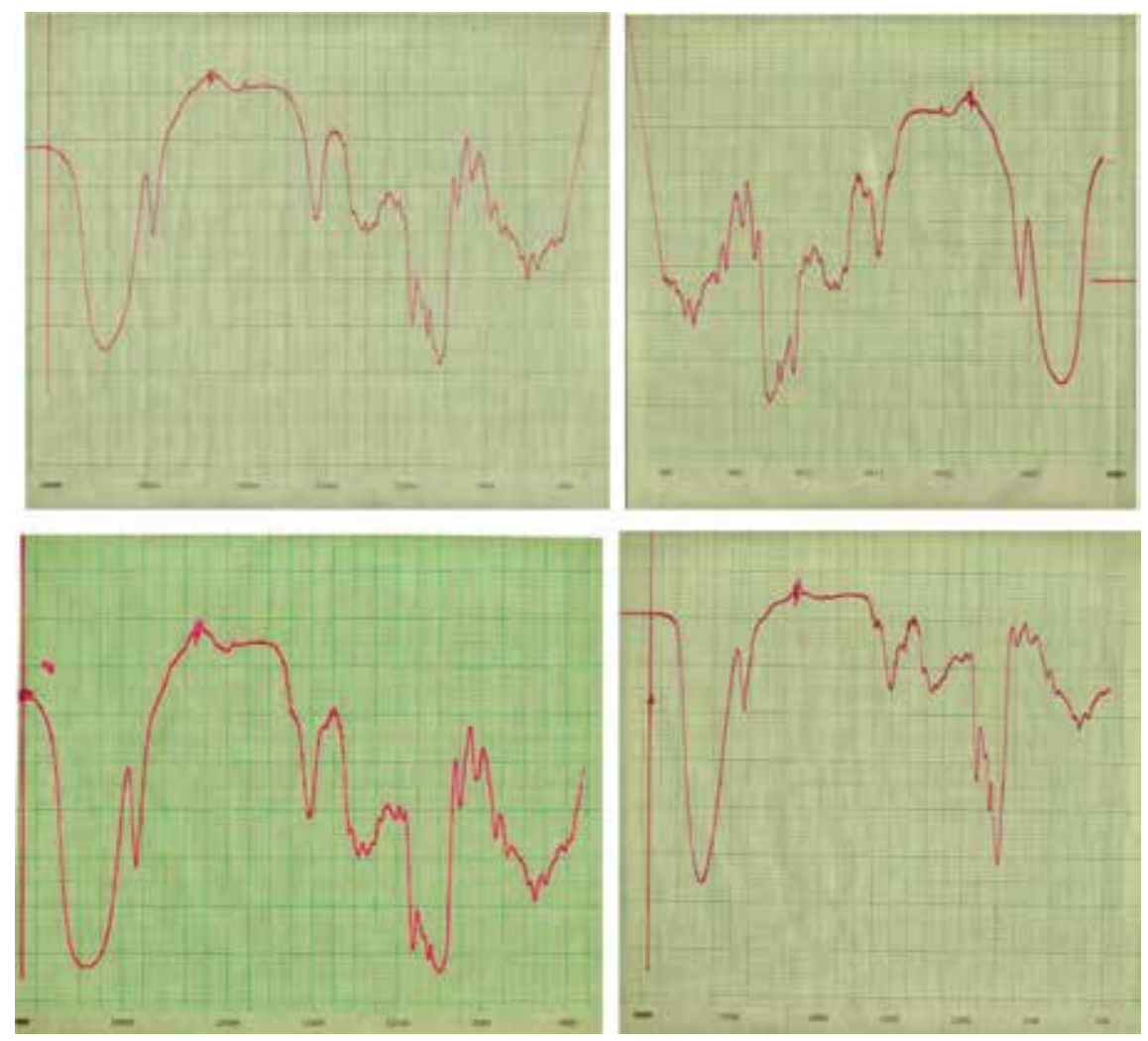

Figure 2.

Infrared rays thermograms of the different products. 
starch ester dodecenylsuccinate of the second method $(6 \# \mathrm{DE}=0.0107,7 \#$ DS $=0.0146$ ).

Compared with unmodified wheat starch, the different phases temperature of starch sugar ester descend, and they have low gelatinization enthalpy. This shows that after the alkenylsuccinate group was lead into the starch molecule, it could block hydrogen bond to form between starch chains, decreasing the bonding power away the molecule and making the structure of starch granule to become limp. Crystallized region becomes smaller, which shortens the procedure of gelatinization, and it needs less heat quantity. The reason of absorbing enthalpy of $5 \#$ may be the high DE value. The action of $\alpha$-amylase was found not only in the amorphous region of starch granule but also in the region of crystallization. Also it may be eroded the molecule chain of the starch granule and easy to be melted, so the absorbing enthalpy becomes small.

\subsection{Determination of the abilities of water-holding and the stability of thawing-melting}

Using the first method, the starch ester dodecenylsuccinic has better waterholding ability and antifreeze capacity than the unmodified starch. From the date of $2 \#, 3 \#$, and $4 \#$, we found that the low degree of substitution of starch ester dodecenylsuccinic is better than the high one in the stability of thawing-melting. The unfrozen paste of unmodified starch separated out lots of water, the paste was white and muddy, elasticity and became fragment after stirring. We did the same action to the starch ester dodecenylsuccinic and found that the paste can hold transparent gel, in which the elasticity and the frame structure were good. The change was neglectable between after freezing and before freezing. Using the first method, the starch sugar ester dodecenylsuccinic had better water-holding ability than the unmodified wheat starch and wheat starch ester dodecenylsuccinic. The stability of thawing-melting was similar between the two methods of starch sugar ester dodecenylsuccinic.

\subsection{Approachment of the application of starch sugar ester which is used as emulsifier in ice cream}

\subsubsection{Directions for producing ice cream and emulsifier}

Directions for producing ice cream are shown in Table 3 and directions for producing emulsifier are shown in Table 4.

\begin{tabular}{lccc}
\hline Material & Weight $(\mathbf{g})$ & Material & Weight $(\mathbf{g})$ \\
\hline Dried-skimmed milk & 180 & CMC & 3.6 \\
\hline Maripa oil & 180 & Sodium alginate & 0.9 \\
\hline Sucrose & 420 & Xanthan gum & 1.8 \\
\hline Glucose syrup & 150 & Sodium hexameta-phosphate & 3 \\
\hline Maltodextrin & 120 & Emulsifier & 9 \\
\hline Egg & 45 & Water & 1883.1 \\
\hline Guar gum & 3.6 & & \\
\hline Total weight: $3000 \mathrm{~g}$. & & & \\
\hline
\end{tabular}

Table 3.

Composition of ice-cream. 


\begin{tabular}{ccc}
\hline No. & Emulsifier & Weight $(\mathbf{g})$ \\
\hline 1 & $\times$ & 0 \\
\hline 2 & Wheat starch ester dodecenylsuccinate (DS = 0.0200) & 9 \\
\hline 3 & Wheat starch ester dodecenylsuccinate of the first method (DE = 6.1) & 9 \\
\hline 4 & Wheat starch ester dodecenylsuccinate of the second method $(\mathrm{DS}=0.0146)$ & 9 \\
\hline 5 & Glycerol monostearate & 9 \\
\hline 6 & Sucrose ester & 9 \\
\hline 7 & $2 \#+5 \#$ & $4.5+4.5$ \\
\hline 8 & $2 \#+6 \#$ & $4.5+4.5$ \\
\hline
\end{tabular}

Table 4.

Types and mass of emulsifier.

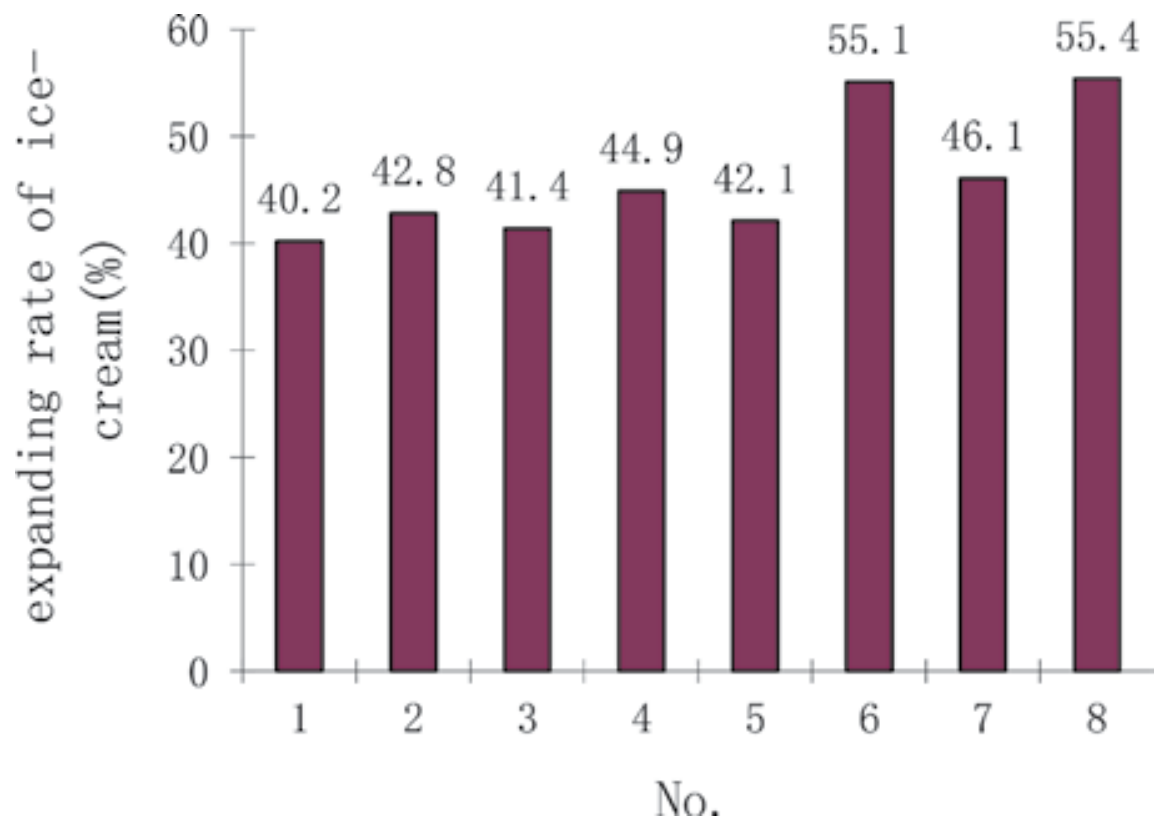

Figure 3.

The rate of ice cream expanding.

\subsubsection{Determination of the expanding rate of ice cream}

The results of expanding rate of ice cream are shown in Figure 3.

Compared with the ice cream without emulsifier, the expanding rate increased after using starch sugar ester as emulsifier. After using the mixture of starch sugar ester, glycerol monostearate and sucrose ester, the expanding rate of ice cream increased a lot. This showed that the starch sugar ester mixture, glycerol monostearate and sucrose ester, has a cooperative effect.

\subsubsection{Determination of melting rate of ice cream}

The results of melting rate of ice cream are shown in Figure 4.

From Figure 4, we find that using starch sugar ester as emulsifier, the melting rate of ice cream can increase $12 \%$, compared with glycerol monostearate and 


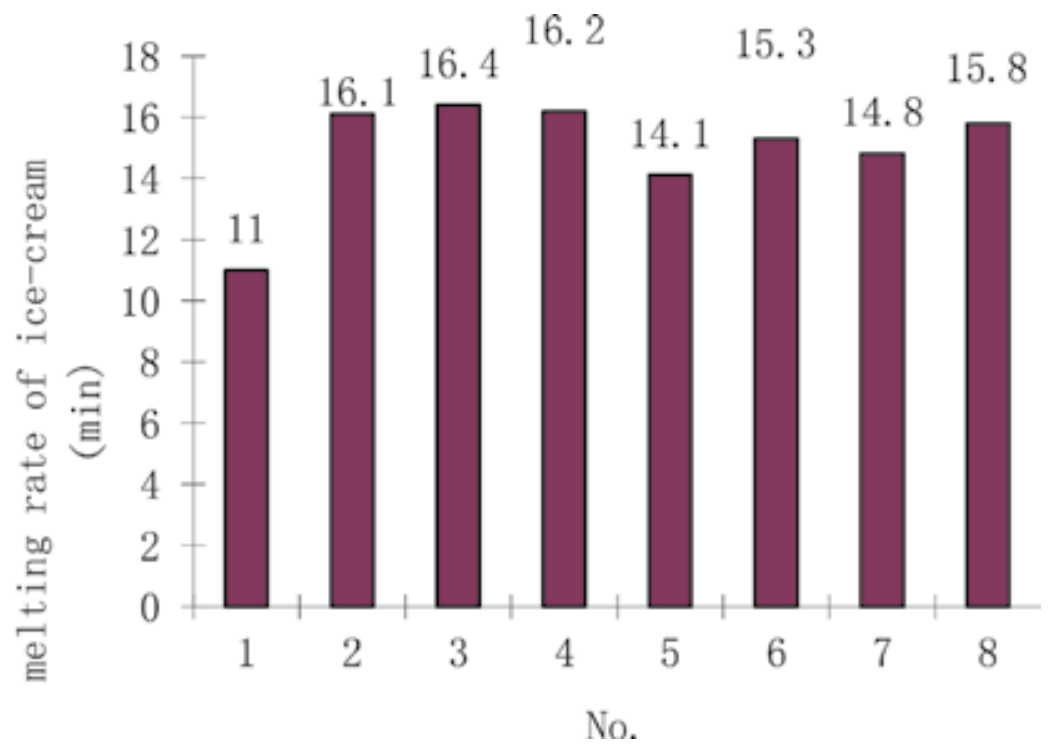

Figure 4.

Melting rate of ice cream.

sucrose ester. Also using the mixture of starch sugar ester, glycerol monostearate and sucrose ester, the melting rate of ice cream can increase $8 \%$.

\section{Conclusions}

1. After analysis of infrared rays, we found that the wheat starch had been estered.

2. From SEM, we found the reaction did on the starch granule surface. Also they created some obvious holes by the $\alpha$-amylase before esterification.

3. From the analysis of DSC, the different phases temperature of starch sugar ester descended, and they had a low gelatinization enthalpy.

4. The starch sugar ester can be used as emulsifier of ice cream; it has good cooperative effect with glycerol monostearate and sucrose ester.

\section{Acknowledgements}

This work was supported by National Natural Science Foundation of China Grant No. 30270762. We thank National Natural Science Foundation Committee for financial support. 


\section{Author details}

Liu Zhongdong, Liu Boxiang*, Wei Guohua, Zhu Xin and Wang Huabin Henan University of Technology, Zhengzhou, P.R. China

*Address all correspondence to: jollier.liu@gmail.com

\section{IntechOpen}

(C) 2020 The Author(s). Licensee IntechOpen. This chapter is distributed under the terms of the Creative Commons Attribution License (http://creativecommons.org/licenses/ by/3.0), which permits unrestricted use, distribution, and reproduction in any medium, provided the original work is properly cited. (cc) BY 


\section{References}

[1] Ntawukulilyayo JD, Desmedt S-C, Demeester J, et al. Stabilization of suspensions using sucrose esters and low substituted noctenylsuccinate starch xanthan gum associations. International Journal of Pharmaceutics. 1996;128 (1-2):73-79

[2] Trubiano PC. The role of specialty food starches in flavor encapsulation. ACS Symposium Series. 1995;610: 244-253

[3] Tsubomoto H, Matsubara I. Starch containing octenyl succinate as additive to cheese. Japanese Kokai Tokkyo Koho. JP111-69,072[99169,072]

[4] Jiancheng L, Changgui Y. Starch sugar ester-A new food emulsifier. China Food Additives. 2001;3:26-29

[5] Shiying Z, Chuntao Z. Study on edible phosphate monoester starch. Journal of Wuxi University of Light Industry. 1989;8(4):7-14

[6] Aburto J, Alric I, et al. Properties of long-chain esters of starch using fatty acid chlorides in the absence of an organic solvent. Starch-Starke. 1999;51: 132-135

[7] Lisheng F. Study on properties of sweet potato starch. Grain and Fodder Industry. 2001;2:49-51

[8] Jeon Y-S, Viswanathan A, Gross RA. Studies of starch esterification:

Reactions with alkenyl succinates in aqueous slurry systems. Starch-Starke. 1999;51:90-93

[9] State Standard of China/T 10009-1998. Test Methods for Frozen Food 



\title{
Chemical Properties of Starch and Its Application in the Food Industry
}

\author{
Henry Omoregie Egharevba
}

\begin{abstract}
Starch is an important food product and a versatile biomaterial used world-wide for different purposes in many industrial sectors including foods, health, textile, chemical and engineering sector. Starch versatility in industrial applications is largely defined by its physicochemical properties and functionality. Starch in its native form has limited functionality and application. But advancements in biotechnology and chemical technological have led to wide-range modification of starch for different purposes. The objective of this chapter is to examine the different chemical reactions of starch and expose the food applications of the modification products. Several literatures on starch and reaction chemistry including online journals and books were analyzed, harmonized and rationalized. The reactions and mechanisms presented are explained based on the principles of reaction chemistry. Chemical modification of starch is based on the chemical reactivity of the constituent glucose monomers which are polyhydroxyl and can undergo several reactions. Starch can undergo reactions such as hydrolysis, esterification, etherification and oxidation. These reactions give modified starches which can be used in baked foods, confectionaries, soups and salad dressings. This chapter discusses the different chemical reactions of starch, the associated changes in functionality, as well as the applications of chemically modified starches in the food industry.
\end{abstract}

Keywords: reactions of starch, hydrolysis, esterification, etherification, baked products, confectioneries, gravies, soups and sauces, mayonnaises and salad dressing

\section{Introduction}

Starch also known as amylum, is an important food product and biomaterial used world-wide for different purposes. Though traditionally used in the food industry, technological advancement has led to its steady relevance in many other sectors such as health and medicine, textile, paper, fine chemicals, petroleum engineering, agriculture, and construction engineering [1]. It is used in the food industry either as food products or additives for thickening, preservation and quality enhancer in baked foods, confectioneries, pastas, soups and sauces, and mayonnaises. Starch is a polysaccharide of glucose made of two types of $\alpha$-D-glucan chains, amylose and amylopectin. Starch molecules produced by each plant species have specific structures and compositions (such as length of glucose chains or the 
amylose/amylopectin ratio), and the protein and fat content of the storage organs may vary significantly. Therefore, starch differs depending on the source. This inherent functional diversity due to the different biological sources enlarges its range of industrial uses $[2,3]$.

The structural and compositional differences in starches from different sources determine its properties and mode of interactions with other constituents of foods that gives the final product the desired taste and texture. In the food industry, starch can be used as a food additive to control the uniformity, stability and texture of soups and sauces, to resist the gel breakdown during processing and to raise the shelf life of products [2]. Starch is relatively easily extractable and does not require complicated purification processes. It is considered to be available in large quantities in major plant sources such as cereal grains and tubers. These sources are generally considered inexpensive and affordable and serve as raw materials for commercial production [4].

Starch from Zea mays (corn, Figure 1) account for $80 \%$ of the world market production of starch. Maize starch is an important ingredient in the production of many food products, and has been widely used as a thickener, stabiliser, colloidal gelling agent, water retention agent and as an adhesive due to its very adaptive physicochemical characteristics [5]. Starches from tubers of roots such as potato tubers (Figure 1), which are considered non-conventional sources have found usefulness in providing options for extending the spectrum of desired functional properties, which are needed for added-value food product development.

The stability of native starch under different $\mathrm{pH}$ values and temperatures varies unfavorably. For instance, native starch granule is insoluble in water at room temperature and extremely resistant to hydrolysis by amylase. Hence native starch has limited functionality. In order to enhance properties and functionality such as solubility, texture, viscosity and thermal stability, which are necessary for the desired product or role in the industry, native starches are modified. The widening vista of application possibilities of starches with different properties has made research in non-conventional starches and other native starches more imperative $[2,6,7]$. Recent studies on the relationship between the structural characteristics and functional properties of starches from different sources have continued to provide important information for optimizing industrial applications.

Modification has been achieved mostly by physical and chemical means. Enzymic and genetic modifications are biotechnological processes which are increasingly being explored [8]. While physical modification methods seemed simple and cheap, such as superheating, dry heating, osmotic pressure treatment, multiple deep freezing and thawing, instantaneous controlled pressure-drop process, stirring ball milling, vacuum ball milling, pulsed electric fields treatment, corona electrical discharges, etc., chemical modification involves the introduction of new functional moieties into the starch molecule via its hydroxyl groups, resulting in marked

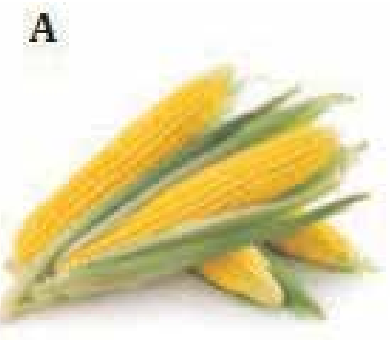

B

Figure 1.

Corn (A) and potato tuber (B) [2]. 
change in its physicochemical characteristic. The functional characteristics of chemically modified starch depends on a number of factors including the botanic origin of the native starch, reagent used, concentration of reagent, $\mathrm{pH}$, reaction time, the presence of catalyst, type of substituent, degree of substitution, and the distribution of the substituents in the modified starch molecule. Modification is generally achieved through chemical derivatization, such as etherification, esterification, acetylation, cationization, oxidation, hydrolysis, and cross-linking [7]. This chapter discusses the chemical properties of starch and how they determine its application in the food industry.

\section{Amylose and amylopectin}

The chemical behaviour of starch is dependent on the nature of its constituent compounds. Starch is a homopolysaccharides made up of glucose units. However, the homopolysaccharide are of two types namely: amylose, which is a linear chain consisting of about 500-2000 glucose units, and amylopectin, which is highly branched and consist of over 1,000,000 glucose units. The two types of homopolysaccharides constitute approximately $98-99 \%$ of the dry weight of starch [2]. The ratio of the two polysaccharides usually varies depending on the botanical origin of the starch. Botanic source reports that starch chain generally consist of $20 \%$ amylose and up to $80 \%$ amylopectin by mass. It is believed that starch with up to $80 \%$ amylose can exist [7]. Some classification categorize starch containing $<15 \%$ amylose as 'waxy', $20-35 \%$ as 'normal' and greater $\geq 40 \%$ as 'high' amylose starches [9].

Amylose and amylopectin have different physiochemical properties which impact on the overall properties of the starch. Hence it is often important to determine the concentration of each individual component of the starch, as well as the overall starch concentration [10]. The physicochemical (e.g., gelatinization and retrogradation) and functional (e.g., solubility, swelling, water absorption, syneresis and rheological behaviour of gels) properties determine the potential uses of starches in the food industry. These properties depend on the molecular and structural composition of amylose and amylopectin, percent composition and arrangement of these two homopolysaccharides in starch granules which often determine the granule size and shape depending on other genetic factors as a result of the particular species of plant [2].

In food products, the functional roles of starch could be as a thickener, binding agent, emulsifier, clouding agent or gelling agent. In the food industry, native starch is usually reprocessed and modified through chemical processes to improve its functionality for the desired purpose. Chemical modification involves the introduction of new functional groups into the starch molecule which produces in a modified starch with markedly altered physicochemical properties. Such modified starch shows profound change in functionality such as solubility, gelatinization, pasting and retrogradation [11].

The chemical reactivity of starch is dependent on the reactivity of the constituent glucose units [11]. The chemical and functional properties achieved following such modification depends largely on the reaction conditions such as modifying reagent(s), concentration of the reactants, reaction time, type of catalyst used, $\mathrm{pH}$, and temperature. The type of substituents, degree of substitution and distribution of substituents in the starch molecule affects the functional properties.

\subsection{Amylose}

Amylose is a linear polymer of $\alpha$-D-glucose units linked by $\alpha-1,4$ glycosidic bonds (Figure 2). The linear nature of amylose chain and its percentage content in starch, 


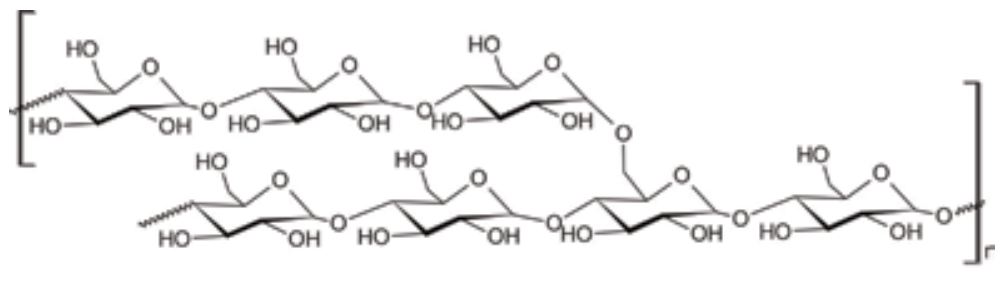

Amylopectin chain

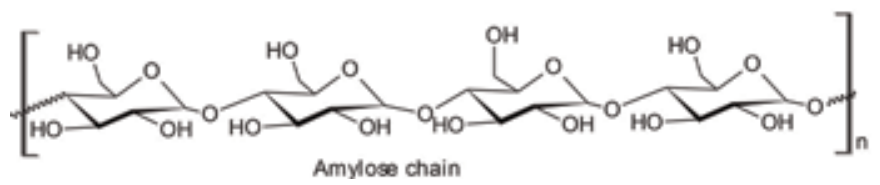

Figure 2.

Chemical structure of amylopectin chain and amylose chain.

and the relative molecular arrangement with amylopectin affect the overall functionality of the starch. Hence starch varies greatly in form and functionality between and within botanical species and even from the same plant cultivar grown under different conditions. This variability provides starches of different properties, which can create challenges of raw materials inconsistency during processing [12].

\subsection{Amylopectin}

Amylopectin is a branched polymer of $\alpha$-D-glucose units linked by $\alpha-1,4$ and $\alpha-1,6$ glycosidic bonds (Figure 2 ). The $\alpha-1,6$ glycosidic linkages occurs at the branching point while the linear portions within a branch are linked by $\alpha-1,4$ glycosidic bonds. In comparison to amylose, amylopectin is a much larger molecule with a higher molecular weight and a heavily branched structure built from about 95\% $(\alpha-1,4)$ and 5\% $(\alpha-1,6)$ linkages. Amylopectin unit chains are relatively short with a broad distribution profile, compared to amylose molecules. They are typically, 18-25 units long on average $[13,14]$.

\section{Physicochemical properties of starch}

Physical properties are those properties exhibited without any change in chemical characteristics of starch and do not involve the breaking and creation of chemical bonds such as solubility, gelatinization, retrogradation, glass transition, etc. On the other hand, chemical properties changes due to chemical reactions and usually involve the breakage and creation of new bonds. Examples of such chemical processes in starch include hydrolysis, oxidation, esterification and etherification. Research strongly indicates that the molecular weight and branching attributes of starch which play important roles in the shape and size of granules can potentially be used for predicting some of its functionality such as texture, pasting, retrogradation, etc. $[12,15]$. Amylose has more proportional relationships with pasting and gel textural properties, while amylopectin which are predominant in regular and waxy corn starches, has higher proportional relationship with firmness.

\subsection{Solubility and gelatinization}

When unprocessed or native starch granules which are relatively inert are heated in the presence of adequate water, usually during industrial processes, swelling of the 
granules occur and the amylose dissolves and diffuses out of the swollen granules which upon cooling forms a homogenous gel phase of amylose-amylopectin. The swollen amylopectin-enriched granules aggregate into gel particles, generating a viscous solution. This two-phase structure, called starch paste, is desirable for many food applications where processed starches are used as thickeners or binders $[2,16]$.

\subsection{Retrogradation and shear}

Retrogradation of starch is a phenomenon that occurs when the disordered arrangement of the polymer molecules of gelatinized starch begins to re-align into an ordered structure in the food product [15]. Preventing retrogradation affects the freeze-thaw stability and textural characteristics and helps to elongate the shelf life of the food product. Starch modification through chemical means, such as, hydrolysis and esterification are generally used to produce starches that can withstand retrogradation. Preventing retrogradation of starch is important for starch used in frozen foods because it is accelerated at cold temperatures, producing an opaque, crystallized, coarse texture as a result of the separation of the liquid from the gel or syneresis $[17,18]$. Crosslinked oxidized starches have been reported be more stable against retrogradation [15].

Amylose linear chain dissolves in water at $120-150^{\circ} \mathrm{C}$ and is characterized by high thermostability, resistance to amylase, high crystallinity and high susceptibility to retrogradation. Amylopectin, which is the branched chain is however, slow to retrogradation, with crystalline forms appearing only on the outside of the globule and characterized by a significantly lower re-pasting temperature of $40-70^{\circ} \mathrm{C}$ and an increased susceptibility to amylases activity than amylose. Retrogradation of starch is affected botanical origin of the starch, amylose content, length of the amylopectin chains, density of the paste, paste storage conditions, physical or chemical modifications and the presence of other compounds. Recrystallization of starch applies only to amylose chains, and it occurs most readily at temperatures around $0^{\circ} \mathrm{C}$, and also at temperatures above $100^{\circ} \mathrm{C}$ [8]. Physical modification process such as repeated freezing and thawing of the starch paste aggravate retrogradation. The resulting starch thus produced is resistant starch that exhibit resistance to digestibility by amylase enzymes and can be used as an alternative nutrient source for diabetic patients and as a rate controlling polymer coat in controlled drug delivery systems [8].

Starch granules swollen with water are predisposed to fragmentation if exposed to physical severe pressure change. This becomes of major concern where the integrity of the granules is required to maintain viscosity. Shear is the disintegration phenomenon of swollen starch granules or gel. Starch shear arises from the shear stress which builds up during the process of retrogradation and/or gel drying of the gelatinized starch [19]. The stress acting in opposite directions creates a fault-line that causes the material to open up or tear apart. Shearing generally depends on the fluid (gel) viscosity and flow velocity [20]. Starch granules in their raw unswollen forms are not susceptible to damage by shear even in the slurry before cooking. But once cooked or gelatinized, starch granules becomes susceptible to shear, resulting in loss of viscosity and textural stability [19].

\section{Chemical properties of starch}

The chemical properties of starch are dependent on the reactivity of starch which is a function of the polyhydroxyl functional groups in the constituent glucose monomers. The hydroxyl groups at position C-2, C-3 and C- 6 which are free from the glycosidic 
bond linkages and pyranose ring formation, are usually free for substitution reactions involving either the attached hydrogen or the entire hydroxyl group. While the $-\mathrm{OH}$ at C-6 is a primary alcoholic hydroxyl group, those at C-2 and C-3 are secondary alcoholic hydroxyl group. Hence starch can undergo hydrolytic cleavage of its chains at the glycosidic bonds; oxidative reaction with the $-\mathrm{OH}$ or $\mathrm{C}-\mathrm{C}$ bond creating carbonyl groups; and other reactions with various functional and multifunctional reagents to produce esterified and etherified starches. Most of the reactions require activation of the hydroxyl of glucose units in acidic or basic media [7].

\subsection{Reactions of starch}

The reactivity of starch is dependent on the hydroxyl functions of the constituent $\alpha$-D-glucan polymers (Figure 2). Thus starch is able to undergo the following reactions.

\subsubsection{Hydrolysis}

Hydrolysis is an addition reaction and simply involves the addition of a water molecule across a bond resulting in the cleavage of that bond and formation of the cleavage products, usually with hydroxyl group or alcohol functionality. Hydrolysis of starch can be achieved by chemical or enzymatic process. Chemical process of hydrolysis usually employs heating starch in the presence of water or dilute hydrochloric acid (Figure 3). Hydrolysis is also used to remove fatty substances associated with native starches. Hydrolysis under acidic condition is called roasting, resulting in acid modified starch. Treatment of starch with sodium or potassium hydroxide results in alkaline modified starch. Hot aqueous alkaline solutions can be used, and this improves the reducing value of that starch [21-23].

The products of starch hydrolysis include dextrin or maltodextrin, maltose and glucose. Dextrins are mixtures of polymers of D-glucose units linked by $\alpha-(1 \rightarrow 4)$ or $\alpha-(1 \rightarrow 6)$ glycosidic bonds. The percentage of products obtained depends on the conditions used for the reaction such as duration and strength/amount of reagents used. Enzymic hydrolysis uses the enzyme malto-amylase to achieve hydrolysis and this is the process that usually occurs in starch digestion in the gastrointestinal tract [9]. Dextrins are white, yellow, or brown water-soluble powder which yield optically active solutions of low viscosity. Most of them can be detected with iodine solution, giving a red coloration. White and yellow dextrins from starch roasted with little or no acid are called British gum. The properties of dextrinized starch is dependent upon the reaction conditions (moisture, temperature, $\mathrm{pH}$, reaction time) and the products characteristics vary in its content of reducing sugar, cold water solubility, viscosity, color and stability.

Hydrolytic processes have been used in the food industry to produce starch derivatives with better functional properties and processing applications [2]. Acid and alkali steeping are the two most widely used methods for starch isolation in the

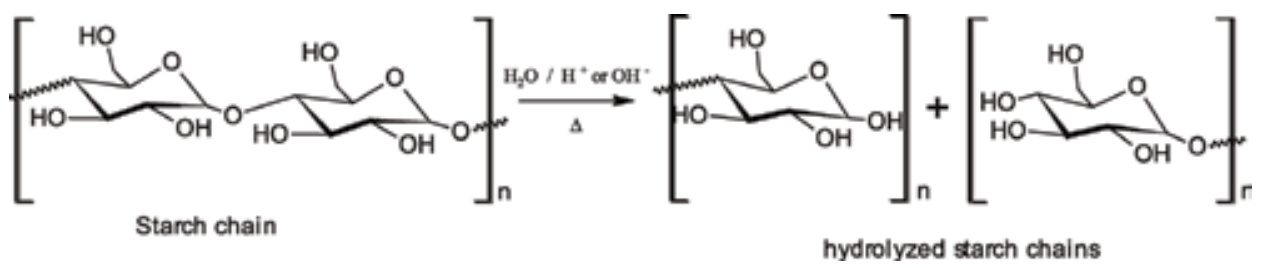

Figure 3.

Hydrolysis of $\alpha(1 \rightarrow 4)$ glycosidic bond. 


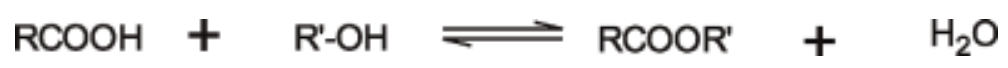

Figure 4.

Esterification reaction of carboxylic acids and alcohols.

food industry, with numerous modifications. Thermo-alkali isolation method known as nixtamalization has been used in Central America since pre-Hispanic times. Acid and alkali isolation processes affect the amylose/amylopectin, protein and lipid content as well as the granule size and shape of the final product [23].

\subsubsection{Esterification reaction}

The condensation of an alcohol and carboxylic acid usually under acidic condition, to produce an ester and water, is called esterification [24]. Basically, the reaction is between the carboxylic acid group and the alcohol group with the elimination of a water molecule (Figure 4). When the acid anhydride is used, an alkaline condition is preferred in the reaction.

The reaction is usually reversible and the forward reaction is favoured under low $\mathrm{pH}$ and excess of alcohol while the reverse is favoured under high $\mathrm{pH}$. Remover of one of the product during the reaction will also favour the forward reaction.

For starch, the reaction is between the carboxylic acid group $(-\mathrm{COOH})$ of fatty acids or $-\mathrm{COCl}$ of fatty acid chlorides and the alcohol group $(-\mathrm{OH})$ of the glucose units. Esterification is generally used to introduce more lipophilic groups into the starch molecule making it more lipophilic and for producing crosslink starch when polyfunctional compounds or multifunctional or reagents capable of esterification or etherification are used [15]. Esterification weakens the inter-molecular bonding that holds the granules together and hence alter the granule shape and sizes as well as other functional properties of the starch. The degree of substitution (DS) is dependent on the concentration of reagent used, the type of reagent used, the catalyst and the duration of reaction [25].

\subsubsection{Acetylation of starch}

Starch can be acetylated by reacting it with acetic anhydride to produce acetylated starch (Figure 5). The hydroxyl group of the glucose units are esterified with the acetyl groups from the acetic anhydride to give starch with glucose units with acetate function. The DS of the hydroxyl group with acetate group is dependent on the reaction conditions. Acetylated corn starch of DS 0.05, 0.07 and 0.08 have been obtained using 4, 6 and $8 \%$ (starch d.w.) acetic anhydride respectively and aqueous sodium hydroxide as catalyst [25].

The introduction of the more bulky acetyl group compares with hydroxyl group causes steric hindrance to the alignment of the linear chains. This allows for easy water percolation between chains thus increasing the granule swelling power and solubility resulting in lower gelatinization temperature [25]. The steric hindrance of

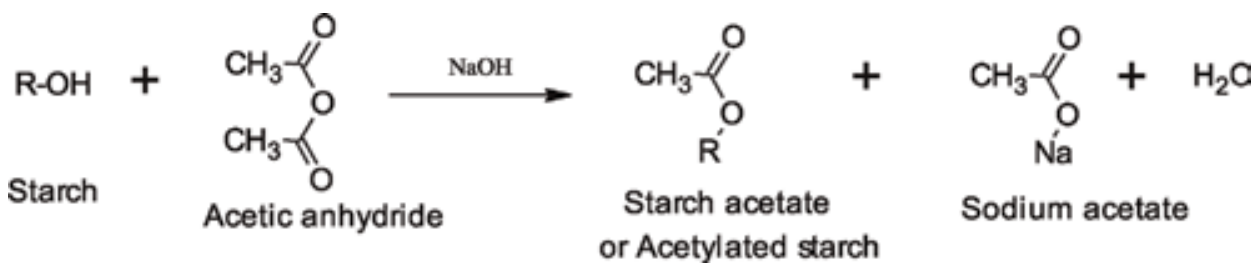

Figure 5 .

Acetylation of starch with acetic anhydride. 
less polar acetyl group also reduces the amount of inter-molecular hydrogen bond formation, and weakens the granule structure, preventing molecular re-association and realignment required for retrogradation. However, depending on the DS and the interplay between the a weakened granular structure as result of interruption of the inter- and intra-molecular bonds, and reduced bonding with water molecules as a result of the hydrophobicity of the acetyl groups, the viscosity of the final product can be enhanced.

Acetylation improves paste clarity and freeze-thaw stability of starch. Starch acetates of low DS are commonly used in the food industry for quality consistency, and as texture and stability enhancers. The Food and Drug Administration (FDA) maximum DS of acetylated starches for food application is 0.1 [19]. Starch acetate of high DS exhibit high degree of hydrophobicity and thermoplasticity and are soluble in organic solvents like chloroform and acetone, and are mostly used in nonfood applications [25]. At 0.0275 DS, corn starch exhibit lower paste gelling, which is practically lost at 0.05 DS. Most commercial starch acetates have <0.05 DS [19].

Acetylated distarch adipate, is a monosubstituted starch obtained by treating starch with acetic anhydride and adipic anhydride (Figure 6). It has been used since the 1950s due to desire for improved stability of product in cold and freezing weather conditions. It is a good temperature change resistant agent used in foods as a bulking agent, stabilizer and thickener. It improves smoothness and sheen of soups and sauces [19]. The improved freeze-thaw stability of acetylated crosslinked waxy maize starch has led to its use in frozen sauces in vegetables, appetizers and pastries. Hydroxypropylation of cross-linked starch also dramatically improves the stability quality of puddings and frozen sauces [19].

\subsubsection{Succinylation of starch}

When starch granule is esterified with succinic anhydride, it produces succinyl starch, and the process is commonly referred to as succinylation of starch.

Succinylation of starch was earlier achieved in the presence of aqueous pyridine and under reflux at $115^{\circ} \mathrm{C}$ (Figure 7). However, environmental concerns have led to the development of more green synthetic routes. Thus succinic ester of starch have been prepared by mixing starch with succinic anhydride solution in acetone and refluxing at $110^{\circ} \mathrm{C}$ for $4 \mathrm{~h}$ [25]. Sui et al. [26] was also able to induce a reaction by drop-wise addition of succinic anhydride to a water suspension of starch while maintaining $\mathrm{pH}$ at 8.5 by drop-wise addition of sodium hydroxide.

Succinyl group weakens the inter-molecular bonding of starch polymeric chains in the granules, facilitating swelling, solubilisation and gelatinization at lower temperatures. Paste clarity is enhanced and retrogradation is reduced. However, there

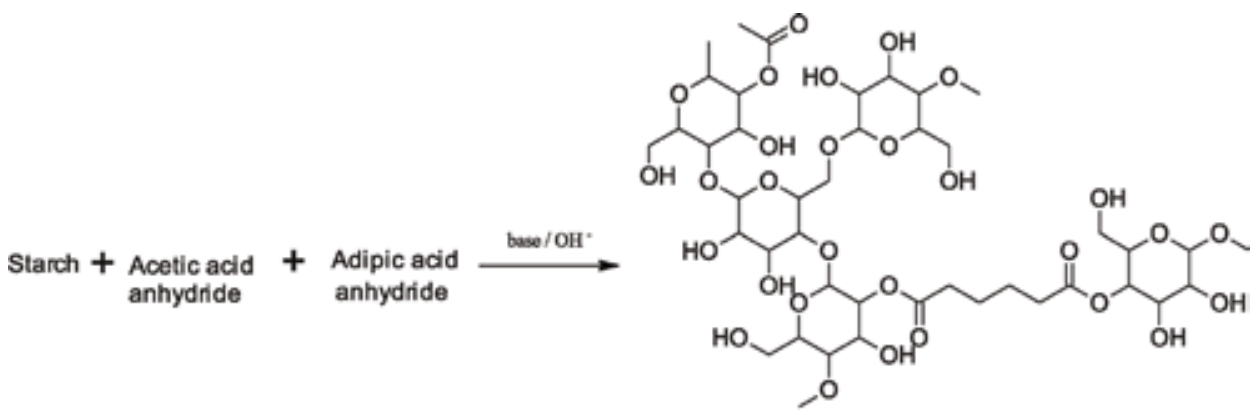

Acetylated distarch adipate

Figure 6.

Esterification of starch with acetic anhydride and adipic anhydride. 


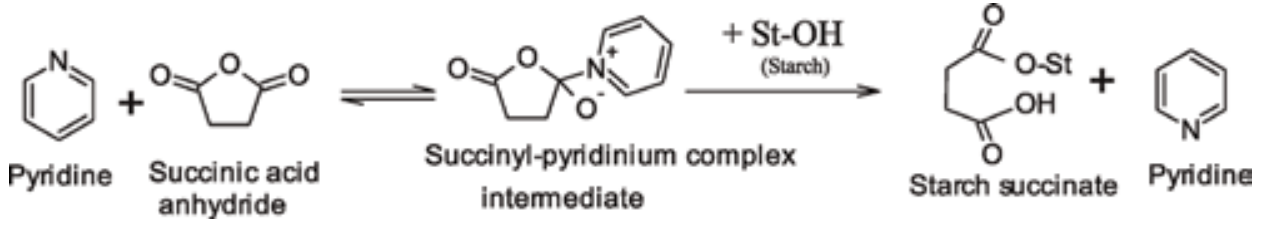

Figure 7.

Succinylation reaction of starch.

may be reduced stability against shear at high temperature and during cooling. Starch succinate is ionic and acts as polyelectrolytes. At low degree of substitution (DS), the succinate makes the starch more hydrophilic and viscos in solution $[8,25]$. For its viscosity enhancing effect, succinylated starches could find application in production of non-gelling custard creams, and for its increased hydrophilicity, it could be used for enhancing the juicy/smooth taste of meat and fried products. Starch succinates can also be used in soups, snacks, and frozen/refrigerated food products as thickening or stabilizing agents.

Esterification of starch with octenylsuccinic anhydride (OSA) or octenylsuccinic acid in the presence of an alkali yields starch octenylsuccinate (Figure 8), while esterification with dodecyl succinic acid yield starch dodecyl succinate. The octenyl or dodecyl group introduce a reasonable level of lipophilicity to the product making it have dual functionality which can be used in emulsification and flavours encapsulation. OSA treated starches are used to stabilize oil-in-water food emulsions associated with beverage concentrates containing flavor and clouding oils [19]. It helps to protect emulsified and spray dried flavour oils against oxidation during storage. FDA allows a DS of 0.02 .

Commercial production of acetylated starch dodecyl succinate, di-substituted starch of low dodecyl succinate residue employs acetic anhydride reagent at alkaline $\mathrm{pH}$ [15]. An alkali-starch complex forms first, which then interacts with the carboxylic anhydride to form a starch ester with the elimination of carboxylate ion and one molecule of water [15]. Starch succinate offers freeze-thaw stability, highthickening, low-gelatinization temperature, clarity of paste, good film-forming properties and resistance to retrogradation.

\subsubsection{Phosphorylation reaction}

Inorganic esters also exist, for instance, esters of phosphorous acid $\left(\mathrm{H}_{3} \mathrm{PO}_{3}\right)$ and phosphoric acid $\left(\mathrm{H}_{3} \mathrm{PO}_{4}\right)$. When starch granules are reacted with phosphorylating agents such as phosphoric acid, mono- or di-starch phosphate is formed (Figure 9). The resulting starch has increased stability at high and low temperatures, more
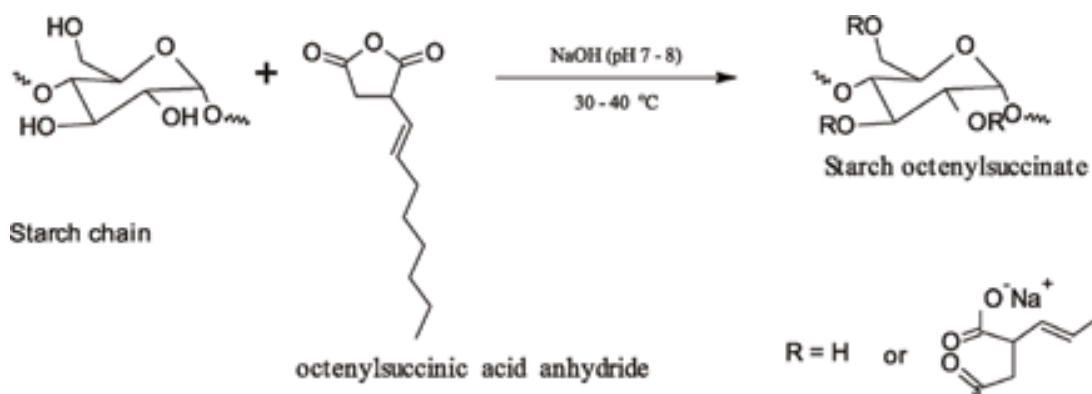

Figure 8.

Esterification of starch with octenylsuccinic acid anhydride. 


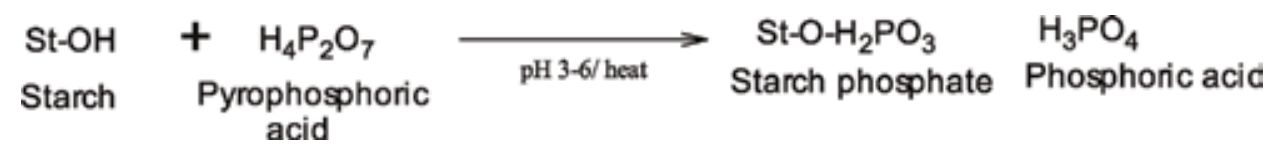

Figure 9.

Phosphorylation reaction of starch.

resistant against acidic condition, and is applicable as a thickening agent. Orthophosphate and pyrophosphate has been used to achieve phosphorylation of starch under slightly acidic and high temperature conditions [27].

Phosphoryl trichloride (Figure 10), sodium tripolyphosphate (Figure 11) and sodium trimetaphosphate (Figure 12) have also been used under higher $\mathrm{pH}$ to obtain monostarch phosphate and di-starch phosphate $[15,28]$. Phosphorylation reactions produce either monostarch phosphate or distarch phosphate which is a cross-linked derivative. However this depends on the reagents and reaction conditions. Usually, monoesters, rather than diesters, are produced with a higher degree of substitution [8]. Steric hindrance as a result of the introduced phosphate groups

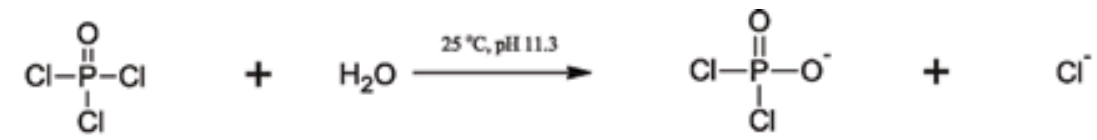

Phosphoryl trichloride

Dichlorophosphate anion

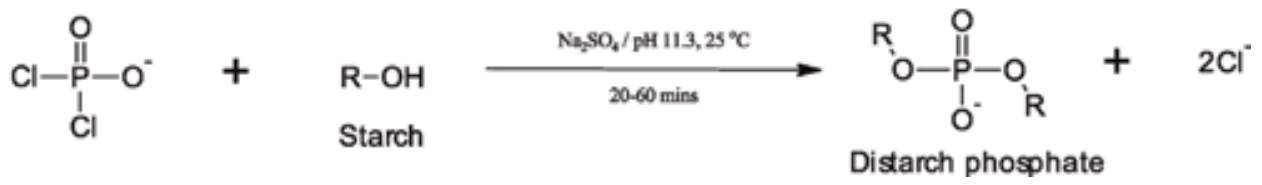

Figure 10.

Phosphorylation of starch with phosphoryl trichloride.
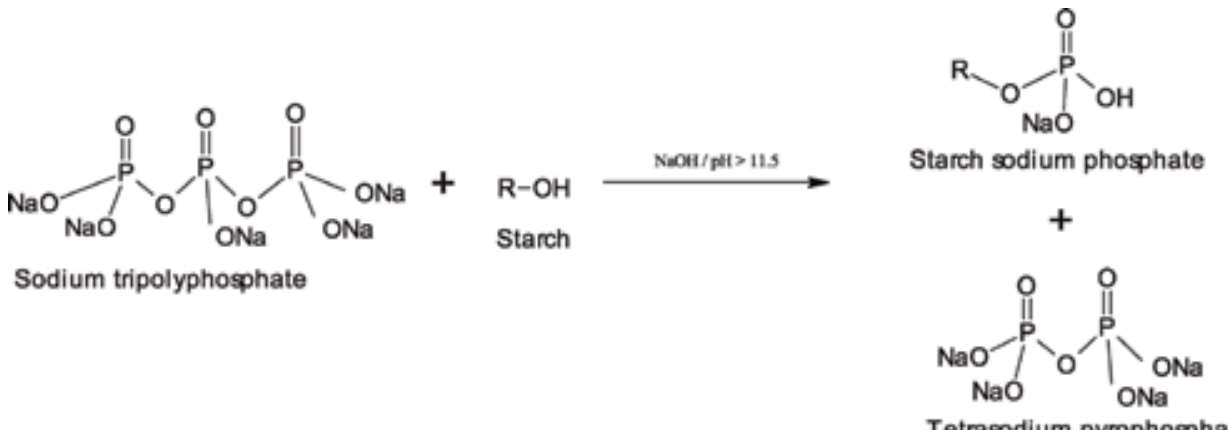

Figure 11.

Phosphorylation of starch with sodium tripolyphosphate.

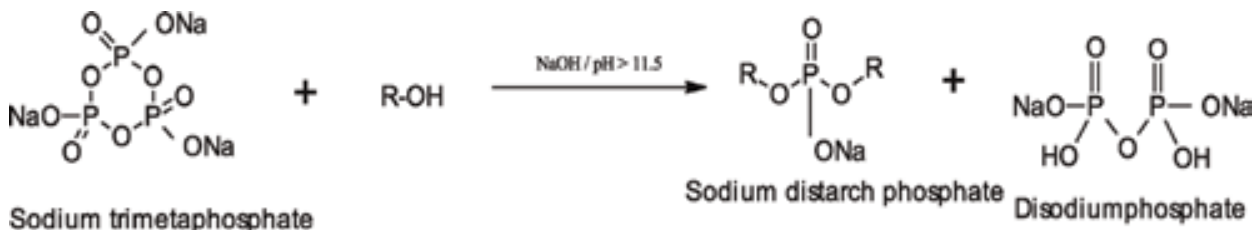

Figure 12.

Phosphorylation of starch with sodium trimetaphosphate. 
inhibits the linearity of amylose or the outer branch of the amylopectin chain where it reacted. This weakens the inter-molecular association and creates chains disaggregation, which leads to better paste clarity [8].

Distarch phosphate has the phosphate group esterified with two hydroxyl groups of two neighbouring starch polymer chains [29]. The phosphate bridge or cross-linking strengthens the mechanical structure of the starch granules. Phosphate cross-linked starches exhibit stability against high temperature, low $\mathrm{pH}$ and shear, and improved firmness of the swollen starch granule as well as improved viscosity and textural characteristic. Distarch phosphate is used as thickener and stabilizer and provides stability against gelling and retrogradation and high resistance to syneresis during storage [8].

In solution, several specie of the phosphate ion can exist and anyone may be responsible for the phosphorylation reaction depending on the reaction conditions. Phosphorylation has been demonstrated to mostly occur at the C-3 and C- 6 of the glucose units, and the degree of phosphorylation depends on distribution of the chain length of the starch polymers [30]. Blennow et al. [31] also demonstrated that phosphate groups may play important role in the size distribution of the amylopectin side chains of phosphorylated starches. Some researchers have reported that about $60-70 \%$ of total phosphorus of starch monophosphate is located at C-6 while the rest is located at C-3 of anhydroglucose units. Most phosphate groups (88\%) are on chain $\beta$ of amylopectin [9].

Landerito and Wang [32] reported that phosphorylated starch prepared by the slurry treatment exhibited a lower gelatinization temperature, a higher peak viscosity, a lesser degree of retrogradation, and improved freeze-thaw stability compared with those prepared by the dry-mixing treatment. They believed that phosphorylation probably occurred in both amylose and amylopectin chains, and the amount and location of incorporated phosphate groups varied with starch types, which may be due to their different amylose and amylopectin contents. Waxy starch was more prone to phosphorylation, followed by common and high-amylose starches. Enzymic phosphorylation of starch has been reported [33]. Extrusion condition of $200^{\circ} \mathrm{C}$, sodium tripolyphosphate concentration of $\geq 1.4 \mathrm{~g} / 100 \mathrm{ml}$ and $\mathrm{pH} 8.5$ have been used to obtain starch phosphate with high degree of substitution [34].

\subsubsection{Etherification}

Generally, alcohols $(-\mathrm{OH})$ groups condenses with one another at high temperatures under acidic conditions to form ethers (Figure 13). The reaction mechanism is through a proton transfer from the catalyst to one of the molecule to form a cation, which loses the proton by extracting the $-\mathrm{OH}$ of the second molecule to form an ether and water.

Etherification of starch is usually done by use of epoxide reagents as depicted in Figures 14 and 15. The epoxides are first reduced to diols through a nucleophilic ring opening of the epoxide (cleaving the $\mathrm{C}-\mathrm{O}$ bond under aqueous, acidic or alcoholic condition) before the eventual condensation of one of the $-\mathrm{OH}$ group with that of starch [24]. Some etherification reactions occur under alkaline condition. Like esterification, etherification helps to mostly introduce lipophilic alkyl

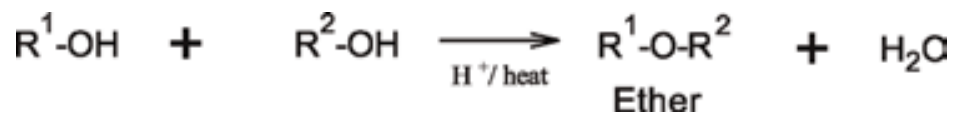

Figure 13.

Etherification reaction. 


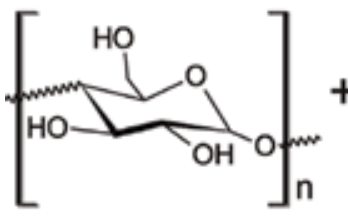

Glucose unit of Starch<smiles>CC1CO1</smiles>

Propylene oxide
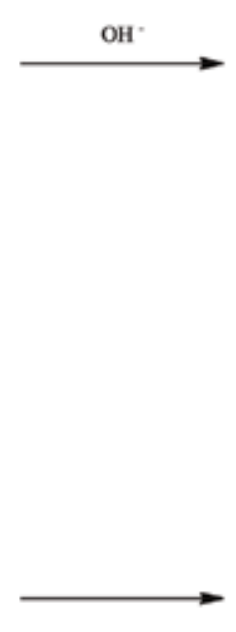

Ethylene oxide

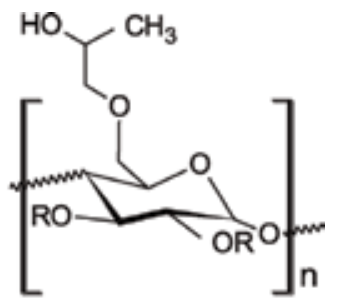

$\mathrm{R}=\mathrm{CH}_{3} \mathrm{CH}_{2} \mathrm{CHOH}$

Hydroxypropyl starch

Figure 14.

Etherification of starch with propylene oxide.

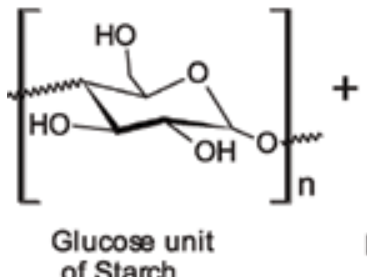

of Starch

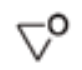

Figure 15.

Etherification of starch with ethylene oxide.

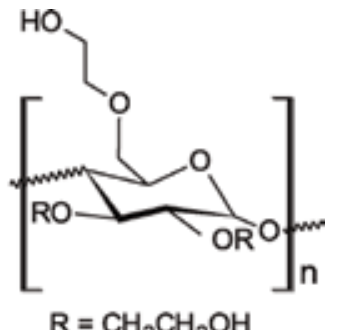

$\mathrm{R}=\mathrm{CH}_{2} \mathrm{CH}_{2} \mathrm{OH}$

Hydroxyethyl starch

groups into the starch chains thereby reducing the hydrophilicity and the degree of inter- and intra-molecular hydrogen bonding [8].

\subsubsection{Hydroxypropylation of starch}

This reaction process produces hydroxypropylated starch (HPS), which is a starch ether produce by reaction of starch with propylene epoxide in the presence of an alkaline catalyst (Figure 14). HPS is used for enhancing stability and viscosity of food products. The hydroxypropyl groups introduced into the starch chains affect the inter- and intra-molecular hydrogen bonds, thereby allowing for more ease of displacement of starch chains in the amorphous regions [8]. HPS is more stable to prolonged high temperatures than starch acetate especially at $\mathrm{pH}$ 6, and has improves freeze-thaw stability. It is mostly used in refrigerated or frozen foods and in the dairy industry. The FDA allowable DS for HPS is 0.2 [19].

\subsubsection{Hydroxyethylation of starch}

Hydroxyethylation of starch is performed by reacting starch with epoxyethane or ethylene oxide to produce the starch ether, hydroxyethylated starch (HES) (Figure 15). The health concerns of hydroxyethylated starch are limiting its use in the food industry. However they are mostly used in medicine and pharmaceuticals as plasma volume expander and extracorporeal perfusion fluids [35].

\subsubsection{Carboxymethylation of starch}

This is an etherification reaction process where starch is reacted with sodium chloroacetate or chloroacetic acid under certain conditions to produce 
carboxymethylated starch (CMS) (Figure 16). The reaction involves refluxing chloroacetic acetic acid with dry starch (anhydroglucose units) in the presence of sodium hydroxide in a solvent mixture of ethanol/isopropanol (ratio 3:5).

Anhydroglucose unit can be obtained from acid hydrolysed starch [36].

\subsection{Cationization of starch}

Another etherification reaction is cationization of starch in which starch react with electrophiles or electron-withdrawing reagents such as ammonium, amino, imino, sulfonium, or phosphonium groups to produce cationic starches (Figures 17-19), which are important industrial derivatives [15]. Cationic starches are usually prepared under alkaline conditions, and they exhibit higher dispersibility and solubility with better transparency and stability.

Cationic starches containing tertiary amino or quaternary ammonium groups are the most important commercial derivatives, however they are mostly used in the textile and paper industry.

For the production of sulfonium starch, halogenoalkyl sulfonium salts (e.g., 2-chloroethyl-methyl-ethyl sulfonium iodide or any $\beta$-halogenoalkyl sulfonium salt), vinyl sulfonium salts and the epoxy alkyl sulfonium can be used (Figure 19). Usually $\mathrm{R}^{1}$ is unsaturated group like alkylene, hydroxyalkylene, aralkylene, cycloalkylene, and phenylene group, while each of $\mathrm{R}^{2}$ and $\mathrm{R}^{3}$ can be alkyl, aryl,

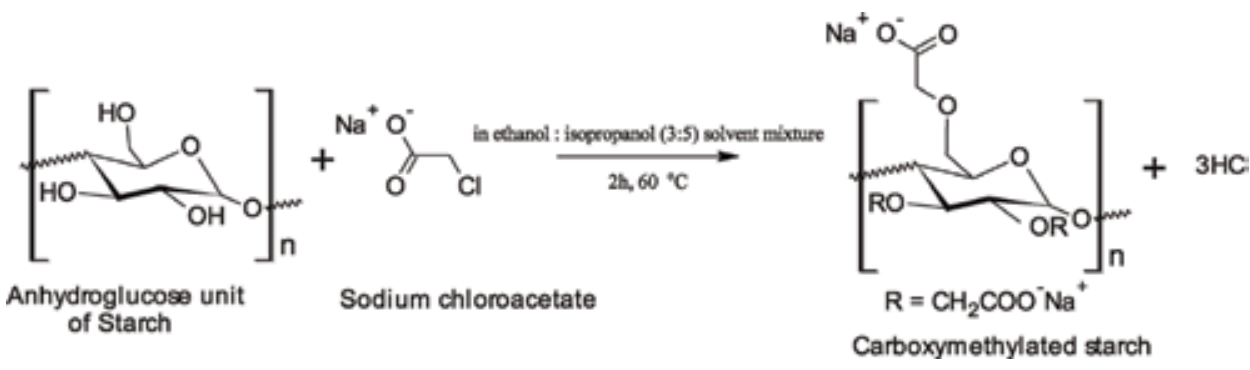

Figure 16.

Etherification of starch with sodium chloroacetate.

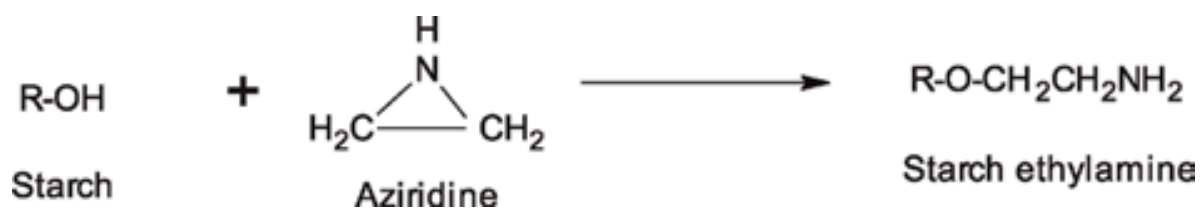

Figure 17.

Reaction of starch with aziridine to produce amino-ethylated starches [15].

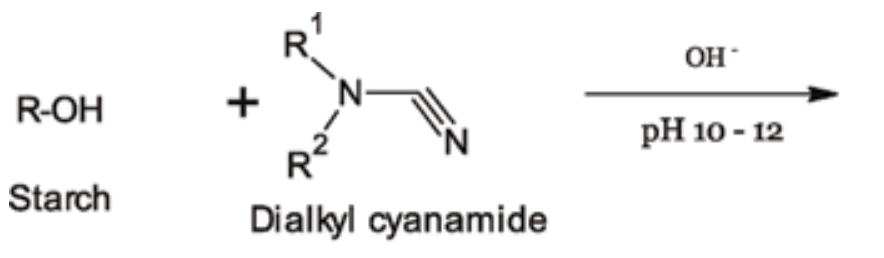

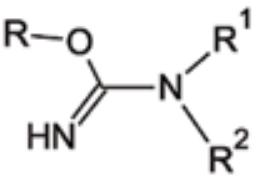

Iminoalkyl starch

Figure 18.

Reaction of starch and dialkyl cyanamides to produce aminoalkyl starches [15]. 


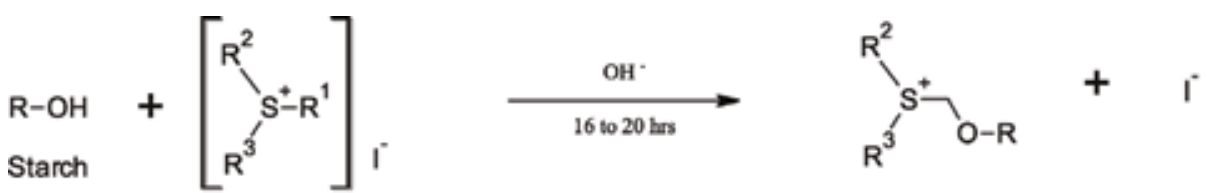

Sulfonium where $R$ is an alkylene group

Dialkyl sulfonium hydroxyalkyl starch ether

Figure 19.

Etherification of starch with sulfonium salt to produce a sulfonium cationic starch.

aralkyl, cycloalkyl and alkylene sulfonium groups and may also contain ether oxygen linkages and amino groups [37]. Factors such as reagent used and temperature, affect the reaction period which usually takes about 16-20 h.

Sulfonium starch display positive charge and can be used as thickeners in the form of aqueous dispersions or pastes. These dispersions are made by heating the suitable amount of sulfonium starch and water to a temperature of approximately $93^{\circ} \mathrm{C}$. Upon cooling, the resulting dispersion becomes considerably clearer and more resistant to viscosity change compared to the untreated starch. Starch succinate and starch citrates which are obtained through esterification reactions have also been observed to exhibit high cationic properties [8].

\subsubsection{Oxidation}

Oxidation of starch with strong oxidizing agents mimics reaction of primary alcohols and diols. Primary alcohol $-\mathrm{OH}$ functions are oxidized (Figure 20) to its corresponding carbonyls (aldehydes and carboxylic acid), while vicinal diols (Figure 21) are cleaved by strong oxidants like periodic acid into its corresponding carbonyl compounds (aldehyde and/or ketones) [24]. Oxidation of secondary alcohol $-\mathrm{OH}$ produces ketones (Figure 22). Oxidation may result in breakage of some intra- and inter-molecular bonds and partial depolymerization of the starch chains [38].

Starches treated with oxidants fall into two broad classes: oxidized and bleached.

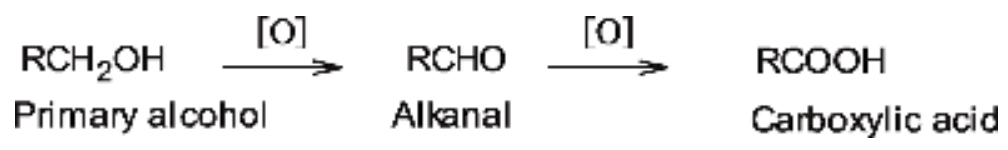

Figure 20.

Oxidation reaction of primary hydroxyl groups of alcohols.

\section{$\mathrm{R}^{2} \mathrm{CH}(\mathrm{OH}) \mathrm{CH}(\mathrm{OH}) \mathrm{R}^{1} \longrightarrow \mathrm{R}^{2} \mathrm{C}=\mathrm{O}+\mathrm{O}=\mathrm{CR}^{1}$}

Figure 21.

Oxidation reaction of vicinal hydroxyl groups of alcohols.
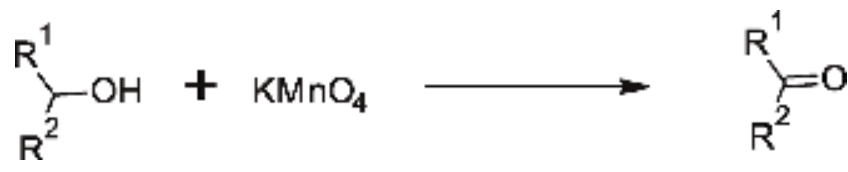

Figure 22.

Oxidation reaction of secondary hydroxyl groups of alcohols. 


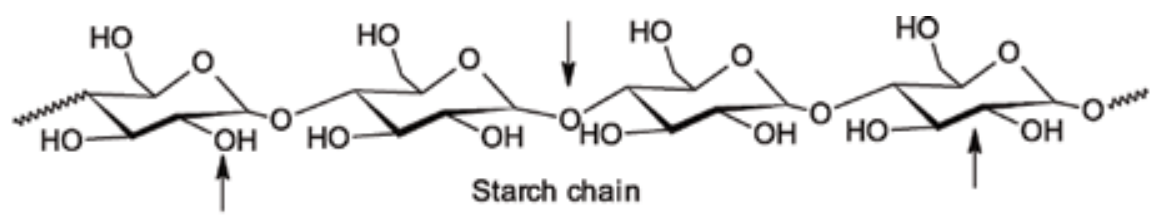

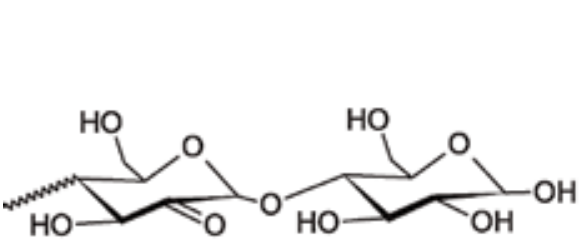

Oxidized Starch

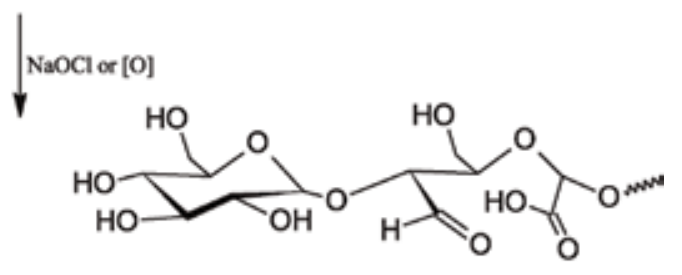

Oxidized Starch

Figure 23.

Oxidation reaction of starch to produce oxidized starch.

Oxidized starches are starches treated with oxidizing agents like sodium hypochlorite $(\mathrm{NaOCl})$. The oxidizing agent can attack the glycosidic bonds hydrolysing them to alcohol $(-\mathrm{OH})$ functions or/and $\mathrm{C}-\mathrm{C}$ bonds of the glucose unit, oxidizing them to carbonyl functions of aldehydes, ketones and carboxylates (Figure 23). Higher $\mathrm{pH}$ favors formation of carboxylate groups over aldehydes and ketones. Some depolymerization usually occurs in the process. Introduction of carboxylate groups provides both steric hindrance and electrostatic repulsion. Oxidation is usually carried out on whole granules and it causes the granule to dissolve, rather than swell and thicken [19]. The reaction can introduce up to $1.1 \%$ of carboxyl groups in the granule [39]. Oxidation with chlorine or sodium hypochlorite reduces the tendency of amylose to associate or retrograde. The reaction rate of starch with hypochlorite is remarkably affected by $\mathrm{pH}$, which tend to be higher at about $\mathrm{pH} 7$ but becomes very slow at $\mathrm{pH} 10$ [40]. Oxidized starches are used where intermediate viscosity and soft gels are desired, and where the instability of acid-converted starches is unacceptable [41]. Hence, pastes of oxidized starches have a lower tendency to gel compared to those of thin-boiling (or acid hydrolized) starches of comparable viscosity.

Other oxidants such as chlorine, hydrogen peroxide and potassium permanganate, dichromates and chlorochromates, etc. are less commonly used. Oxidized starches are reported to give batters improved adhesion to meat products and are widely used in dough and baked foods [41].

Bleached starch is obtained from oxidation of starch with lower concentrations of oxidizing agents like hydrogen peroxide, sodium hypochlorite, potassium permanganate or other oxidants used to remove color from naturally occurring pigments. Bleaching is done to improve the whiteness and/or eliminate microbial contamination. Reagent levels of about $0.5 \%$ are usually used, and loss of some starch viscosity due to hydrolysis usually occurs.

\subsubsection{Cross-linking of starch}

Cross-linking of the starch polymer chains with reagents that could form bonds with more than one hydroxyl group of molecule results in cross-linked starch. Such reactions randomly add inter- and intra-molecular bonds at different locations in the starch granule which helps to strengthen and stabilize the polymers in the granule. Such processes may employ hydrolysis, oxidation, esterification, etherification, phosphorylation or combinations of these methods in a sequential or 
one-mix procedure to achieve the desired product that meets the required physicochemical characteristic of gelatinization, viscosity, retrogradation, and textural properties for food applications. In some instances, multifunctional reagents capable of forming either ether or ester inter-molecular linkages between hydroxyl groups on starch molecules are used. Reactions usually take place at the primary - $\mathrm{OH}$ group of C-6 and secondary $-\mathrm{OH}$ of C-2 and C-3 of the glucose units. Epichlorohydrin monosodium phosphate, phosphoryl trichloride, sodium trimetaphosphate, sodium tripolyphosphate, a mixture of adipic and acetic anhydride, and vinyl chloride are the main agents used to cross-link food grade starches [15]. Di-starch phosphate (Figure 12) which is a phosphorylated starch is an example of a crosslinked starch. Acetylated distarch adipate (Figure 6), hydroxypropyl distarch phosphate, hydroxypropyl distarch glycerol are other examples of crosslinked starch [8]. The FDA specify that not more than $0.1,1$ and $0.12 \%$ DS (w/w of starch) of phosphoryl chloride, sodium trimetaphosphate and adipic-acetic mixed anhydride, respectively, should be used for food grade starch [19].

Cross-linked starch exhibit increased resistance to processing conditions such as high or low temperatures and $\mathrm{pH}$. Cross-linking reduces granule rupture, loss of viscosity and the formation of a stringy paste during cooking, providing a starch suitable for canned foods and products. Cross-linked starch shows smaller swelling volume, lower solubility and lower transmittance than native starch [15]. While oxidation may increase retrogradation, crosslinking reduces it. Hence a combination of the two chemical modification methods can be used to get the starch with desired balanced characteristics.

\subsubsection{Approaches to modification of starch}

As mentioned in the introductory section, native starches are modified to improve their physicochemical properties due to different reasons. Different approaches have been reported including physical, chemical, enzymatic and genetic approach. But the most widely used is the chemical approach. For instance, since starch must be gelatinized for it to be digestible in human diet and nutrition, and the process of gelatinizing native starches usually takes appreciable amount of time for granule to swell and form paste of gel as obtained in cooking rice and corn flour porridge, it can be modified to reduce gelatinization time by physical methods such as extrusion, spray-drier and drum dryer, which promote fast starch gelatinization to produce pregelatinized starch [42-44]. Pre-gelatinized starch exhibit reduced gelatinization temperature and time. The modified starches are usually dries to obtain flours and/or pre-gelatinized starches of long-term stability and quick preparation [9]. Pregelatinized starches are partially or totally soluble in cold water and readily form pastes [45]. It absorbs more water and disperses readily in water than the untreated starch, forming gel at room temperature and less prone to deposit [46]. Using gelatinized starch in food products affects the food qualities and properties, such as, bread volume and crumb [47]; pastas elasticity and softness, lusciousness and digestibility, tolerance in the properties of beating and cake mixtures, ice creams, doughnuts, growth of sugar crystals in food products [48]; texture, volume, shelf-live and stability during thawing of cakes and breads [49]. Liquefaction, partial hydrolysis and dextrinization may occur during pregelatinization depending on the processing conditions [42-44].

The process of physical modification does not involved any chemical reaction of starch with a modifying reagent and is referred to as physical modification of starch and the products are known as physically modified starches. However, most modifications of starches are performed through chemical processes. The chemical 
reactions of starch (hydrolysis, esterification, etherification, oxidation and cationization) are generally exploited in the industry to produce converted or modified starches fit for different purposes in the industry.

According to the Food and Nutrition Program (FNP) of the FAO [50], a modified starch is a food starch which has one or more of its original physicochemical characteristics altered by treatment in accordance with good manufacturing practice by one of the reaction procedures such as hydrolysis, esterification, etherification, oxidation and cross-linking. For starches subjected to heating in the presence of acid or with alkali, the alteration (mainly hydrolysis) is considered a minor fragmentation. Bleaching is also essentially a process resulting in the colour change only. However, oxidation involves the deliberate creation of carboxyl groups. Treatment of starch with substituting reagents such as orthophosphoric acid etc., results in partial substitution in the 2-, 3- or 6-position of the anhydroglucose unit (AGU) unless the 6-position is occupied for branching in amylopectin chain. For cross-linked starch, where polyfunctional substituting agent, such as phosphorus oxychloride, connects two chains, the structure can be represented by Starch-O- $\mathrm{R}-\mathrm{O}-$ Starch, where $\mathrm{R}$ is the cross-linking group and Starch refers to the linear and/or branched structure [50].

Evolving biotechnological innovations are progressing with enzymatic and genetic modification of starch as a greener alternative to chemical modification due to environmental concerns. Enzymatic modifications basically employ hydrolytic enzymes found in certain bacteria. For instance amylomaltases or $\alpha-1,4-\alpha-1,4-$ glucosyl transferases from Thermus thermophiles and cyclomaltodextrinase (CDase 1-5) from alkalophilic Bacillus sp. [48]. While $\alpha-1,4-\alpha-1,4$-glucosyl transferases breaks existing $\alpha-1,4$ bonds and make new ones to produce modified starch used in foods and non-foods applications, CDase 1-5 can be used to produce starches which are low in amylose content without changing the amylopectin distribution. The granule of starch-cyclomaltodextrin complex produced special tastes and flavours, as well as light, heat and oxygen-sensitivity stability. Transglucosidase, maltogenic $\alpha$-amylase and $\beta$-amylase have been used to produce resistant starches of various degrees of digestibility $[8,51,52]$. On the other hand, genetic modification employs biotechnology to targets the starch biosynthetic process. Genetic regulation of enzymes such as starch synthetase and branching enzymes, involved in starch synthesis through starch synthase genes are used to produces cereal crops that yield amylose- free starch, high-amylose starch and altered amylopectin structure in starch [8].

\section{Starch functionality and its applications in food}

The reactions of starch explained above are exploited to create different types of modified or converted starched to obtain starches with appropriate physicochemical characteristics such as gelatinization, retrogradation, heat stability, solubility, transmittance, colour, texture, etc., for different industrial applications. The food industry is very mindful of safety of chemical residues hence not all types of modified starched are used in foods. Generally, modified starches are used for adhesion and as binder in battered and breaded foods, formed meat and snack seasonings; as dustings for chewing gum and products produced in the bakery; as crisping cover for fried snacks; fat replacer and juiciness enhancement in ice cream and salad dressings; flavour encapsulating agents in beverage clouds; emulsion stabilizers in beverages, creamers and canned foods; foam stabilizer in marshmallows; gelling agents in gum drops and jelly gum; and as expanders in baked snacks 
and cereal meals [19]. Table 1 gives a summary of the chemical modification processes and their food application.

\subsection{Baked products (bread, pies, samosas, wafers, biscuits and sausages)}

Baked products like biscuits, pies, bread, cakes wafers and sausages are high density products requiring heat resistant starches. Hence crosslinked starches are used since they are more resistant to oven baking temperatures of $120 \geq 230^{\circ} \mathrm{C}$. Gelatinized starches are also used in ready-to-eat cereal meals such as corn-flakes, etc. The temperature, humidity and degree of stirring determine the texture and quality of the product.

\subsection{Confectionery (candy, sweets and sweetmeat)}

Oxidized starches have high clarity or transmittance, low viscosity and low temperature stability. It is frequently used in confectioneries for coating candies and sweets since they easily melt.

\subsection{Gravies, soups and sauces (soups, sauces, tomato paste or ketchup)}

Etherified and crosslinked starches are mostly used. Crosslinked starched have higher stability for granules-swelling, high temperature resistant, high shear stability and acidic conditions stability. They are used as viscosifiers and texturizers in soups, sauces, gravies, bakery and dairy products. Etherified starches have improved clarity of starch paste, greater viscosity, reduced syneresis and freezethaw stability. Crosslinked starches are used in wide range of food applications such as gravies, dips, sauces, fruit pie fillings and puddings.

\subsection{Mayonnaises, salad dressing, ice cream, spreads and beverages}

Hydrolyzed and esterified starches are mostly used in salad dressing and beverages. Hydrolyzed starch (acid-modified starches) has lower paste viscosity under cold and hot conditions. Hence they are used in mayonnaises and salad dressing [19]. Esterified starches have lower gelatinization temperature and retrogradation, lower tendency to form gels and higher paste clarity, and are used in refrigerated and frozen foods, as emulsion stabilizers and for encapsulation of beverage clouds. OSA starch is used as emulsifiers in mayonnaises and salad dressings.

\subsection{Pasta (spaghettis, macaroni, others)}

Pregelatinized and crosslinked starches are mostly used in pastas. Gelatinized starch affects pastas elasticity and softness, delectableness and digestibility. Crosslinking gives the needed structural firmness to the pasta.

\subsection{Puddings (custard, pap, others)}

Pregelatinized starches are used in puddings, instant lactic mixtures and breakfast foods to achieve thickening or water retention without employing heat. They are also used in ready-to-use bread mixtures. They are used where little or no heat is required and the increased absorption and retention of water improves the quality of the product; as an agglutinant in the meat industry; and as a filling for fruit pies $[9,49]$. 


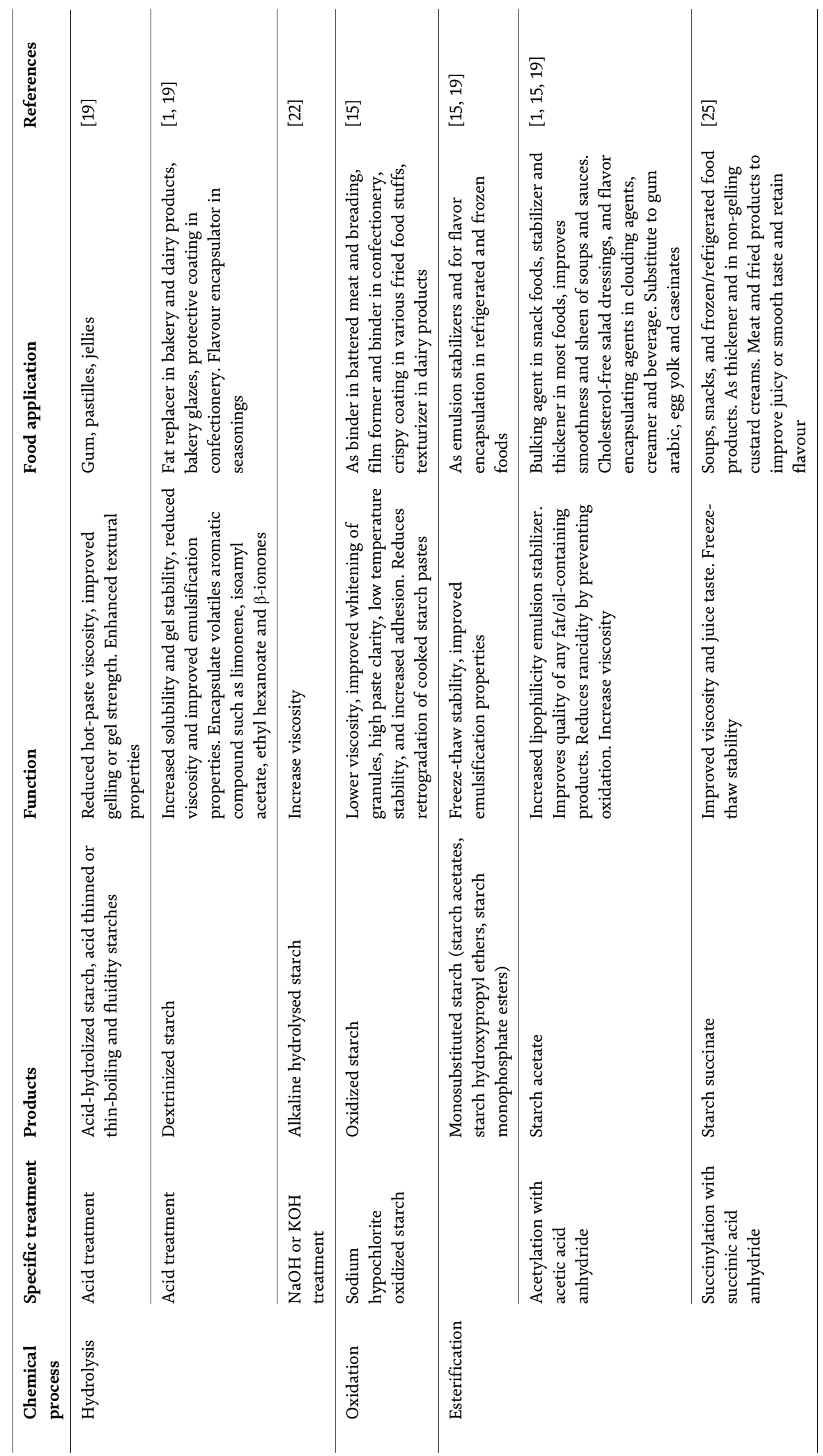




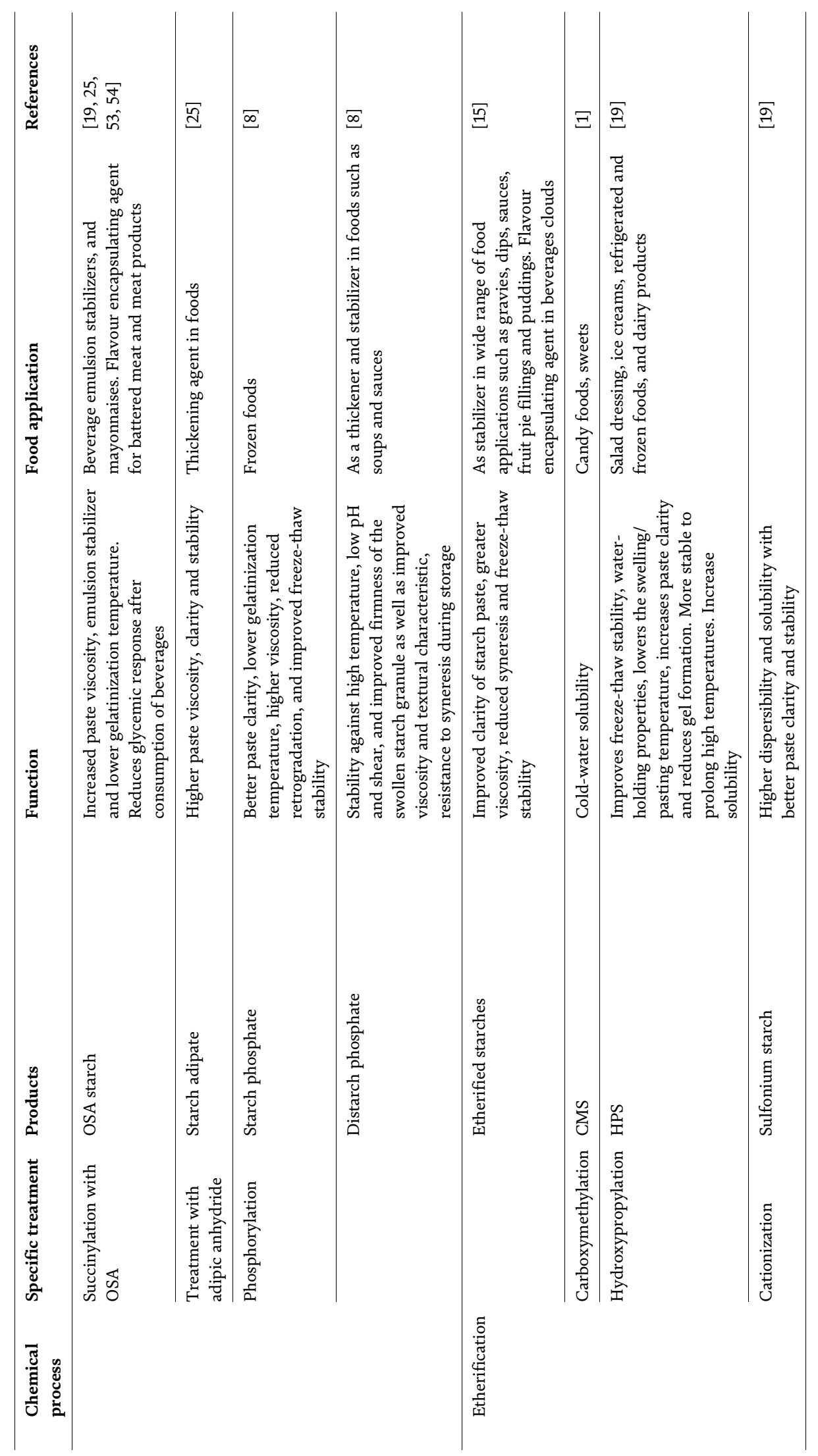


Chemical Properties of Starch and Its Application in the Food Industry

DOI: http://dx.doi.org/10.5772/intechopen.87777

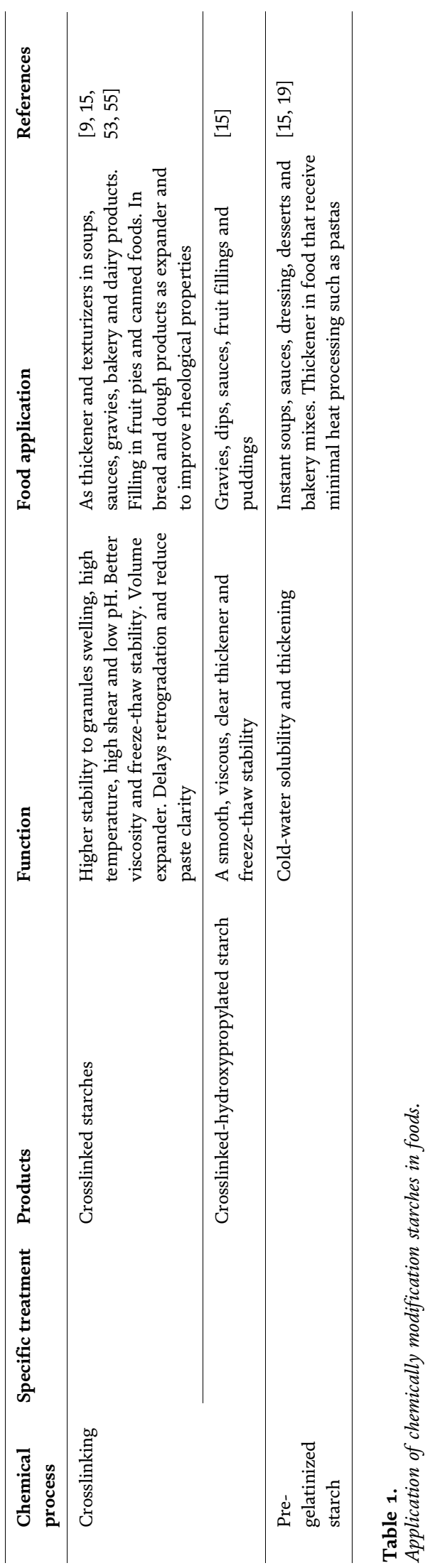




\section{Conclusion}

The importance of starch as a biopolymer continues to be on the upward trend due to its versatility. It has transformed from its traditional use as energy-source food to more sophisticated food and non-food applications. Its growing relevance in modern technological application is as a result of its susceptibility to modification, which transforms the native properties into more desirable and malleable characteristics fit for different purposes. These modifications are only possible due to the chemical reactivity of the constituent glucose monomers of the starch chains. Though the starch granule is inherently almost unreactive, it is however easily activated for reaction by certain conditions such as high or low $\mathrm{pH}$, higher temperature, presence of a catalyst, etc. Under the right condition, starch molecules can undergo hydrolysis, oxidation, esterification and etherification reactions to produced products of improved organoleptic, textural, mechanical and thermoplastic properties of desirable foods and non-foods application. Modified starches like starch acetate, starch phosphate, HPS, CMS, sulfonium starches and their crosslinked derivatives are used for various applications in the food industry. However, concerns for chemical residues in these products and environmental considerations for hazardous chemicals used in some of the process, have led to more studies for greener modification processes. Though biotechnology has evolved enzymic and genetic modification processes for production of some modified starches, they are still highly limited and sometimes uneconomical, hence chemical modification remains the most versatile and mostly used.

\section{Conflict of interest}

The author declares no conflict of interest.

\section{Author details}

Henry Omoregie Egharevba

Department of Medicinal Plant Research and Traditional Medicine, National

Institute for Pharmaceutical Research and Development (NIPRD), Abuja, Nigeria

*Address all correspondence to: omoregieegharevba@yahoo.com

\section{IntechOpen}

(C) 2019 The Author(s). Licensee IntechOpen. This chapter is distributed under the terms of the Creative Commons Attribution License (http://creativecommons.org/licenses/ by/3.0), which permits unrestricted use, distribution, and reproduction in any medium, provided the original work is properly cited. (c) BY 


\section{References}

[1] Shuren J. Production and use of modified starch and starch derivatives in China. In: Howeler RH, Tan SL, editors. Cassava's Potential in Asia in the 21st Century: Present Situation and Future Research and Development Needs. In: Proceedings of 6th Regional Workshop; 21-25 February 2000; Ho Chi Minh City, Vietnam; 2000. pp. 553-563

[2] Santana AL, Meireles MAA. New starches are the trend for industry applications: A review. Food and Public Health. 2014;4(5):229-241. DOI: 10.5923/j.fph.20140405.04

[3] Agrosynergie. Evaluation of Common Agricultural Policy Measures Applied to the Starch Sector Final Report-AGROSYNERGIE-November 2010 [Internet]. 2010. Available from: https://ec.europa.eu/agriculture/sites/ag riculture/files/evaluation/market-a nd-income-reports/2010/starch/fullte xt_en.pdf [Accessed: 13 March 2019]

[4] Daudt RM, Külkamp-Guerreiro IC, Cladera-Olivera F, Thys RCS, Marczak LDF. Determination of properties of pinhão starch: Analysis of its applicability as pharmaceutical excipient. Industrial Crops and Products. 2014;52:420-429

[5] Zhu F, Wang YJ. Characterization of modified high-amylose maize starch- $\alpha$ naphthol complexes and their influence on rheological properties of wheat starch. Food Chemistry. 2013;138(1): 256-262

[6] Albano KM, Franco CML, Telis VRN. Rheological behavior of Peruvian carrot starch gels as affected by temperature and concentration. Food Hydrocolloids. 2014;40:30-43

[7] Eltaboni F, Alabidi A. Physical and chemical modifications of starches. In: Proceeding of 2nd Libya Conference on
Chemistry and its Applications (LCCA-2); 9-11 May 2017; Benghazi, Libya: University of Benghazi, LCCA-2; 2017. pp. $120-123$

[8] Neelam K, Vijay S, Lalit S. Various techniques for the modification of starch and the applications of its derivatives. International Research Journal of Pharmacy. 2012;3(5):25-31

[9] MTPS C. Physical and/or chemical modifications of starch by thermoplastic extrusion. In: El-Sonbati A, editor. Thermoplastic Elastomers. InTech; 2012. pp. 39-56. Available from: http:// www.intechopen.com/books/ thermoplastic-elastomers/physicaland-or-chemical-modificationsofstarch-by-thermoplastic-extrusion [Accessed 25 March 2019]

[10] McClements DJ. Analysis of Food Products Food Science. In: 581.

Carbohydrate. Chenoweth Lab [Internet]. 2019. Available from: http:// people.umass.edu/ mcclemen/ 581Carbohydrates.html [Accessed 14 March 2019]

[11] Emeje MO, Asha R. Starch: From food to medicine. In: Benjamin V, Michael S, Roumen Z, editors. Scientifc, Health and Social Aspects of the Food Industry. Rijeka, Croatia: InTechOpen; 2014. pp. 355-373

[12] Copeland L, Blazek J, Salman H, Tang MC. Form and functionality of starch. Food Hydrocolloids. 2009;23(6): 1527-1534

[13] Tester RF, Karkalas J, Qi X. StarchComposition, fine structure and architecture. Journal of Cereal Science. 2004;39:151-165

[14] Wurzburg OB. Modified Starches: Properties and Uses. Boca Raton: CRC Press; 1989, 1989. $277 \mathrm{p}$ 
[15] Korma SA, Alahmad K, Niazi S, Ammar AF, Zaaboul F, Zhang T. Chemically modified starch and utilization in food stuffs. International Journal of Nutrition and Food Sciences. 2016;5(4):264-272. DOI: $10.11648 / \mathrm{j}$. ijnfs.20160504.15

[16] Santelia D, Zeeman SC. Progress in Arabidopsis starch research and potential biotechnological applications. Current Opinion in Biotechnology. 2011;22(2):271-280

[17] Light JM. Modified food starches: Why, where, and how. Cereal Foods World. 1990;35(11):1081-1092

[18] Almanza-Benitez S, Osorio-Díaz P, Méndez-Montealvo G, Islas-

Hernández JJ, Bello-Perez LA. Addition of acid-treated unripe plantain flour modified the starch digestibility, indigestible carbohydrate content and antioxidant capacity of semolina spaghetti. LWT_Food Science and Technology. 2015;62(2):1127-1133

[19] Mason WR. Starch use in foods. In: Starch: Chemistry and Technology. 3rd ed. (BeMiller JN editor). San Diego, California, USA: Elsevier Inc. Academic Press; 2009. p. 745-795

[20] Day MA. The No-Slip Condition of Fluid Dynamics. Netherlands: Springer; 2004. pp. 285-296

[21] Taylor TC, Salzman GM. Actions of aqueous alkali on starches, amylose and modified starches. Journal of the

American Chemical Society. 1933;55(1): 264-275

[22] Maher GG. Alkali gelatinization of starches. Starch-Starke. 1983;35(7): 226-234

[23] Palacios-Fonseca AJ, Castro-Rosas J, Gómez-Aldapa CA, Tovar-Benítez T, Millán-Malo BM, del Real A, et al. Effect of the alkaline and acid treatments on the physicochemical properties of corn starch. CyTA Journal of Food. 2013; 11(1):67-74. DOI: 10.1080/19476337. 2012.761651

[24] Carey FA. Organic Chemistry. 5th ed. New York, NY: McGraw-Hill; 2003. pp. $638-684$

[25] Ackar D, Babic J, Jozinovic A, Milicevic B, Jokic S, Milicevic R, et al. Starch modification by organic acids and their derivatives: A review. Molecules. 2015;20:19554-19570

[26] Sui Z, Huber KC, BeMiller JN. Effects of the order of addition of reagents and catalyst on modification of maize starches. Carbohydrate Polymers. 2013;96:118-130

[27] Huang R, Li CP, Chen D, Zhao G, Cheng W, Zhang Y, et al. Preparation of phosphorylated starch by dry-heating in the presence of pyrophosphate and its calcium-phosphate solubilizing ability. Journal of Food Science and Technology. 2013;50(3):561-566

[28] Sechi NSM, Marques PT. Preparation and physicochemical, structural and morphological characterization of phosphorylated starch. Materials Research. 2017;20 (Suppl. 2):174-180. DOI: http://dx.doi. org/10.1590/1980-5373-MR-2016-1008

[29] Nabeshima EH, Grossmann MVE. Functional properties of pregelatinized and crosslinked cassava starch obtained by extrusion with trimetaphosphate. Carbohydrate Polymers. 2001;45: 347-353

[30] Blennow A, Bay-Smidt AM, Wischmann B, Olsen CE, Møller BL. The degree of starch phosphorylation is related to the chain length distribution of the neutral and phosphorylated chains of amylopectin. Carbohydrate Research. 1998;307(1):45-54

[31] Blennow A, Engelsenb SB, Munckb L, Møller BL. Starch molecular 
structure and phosphorylation

investigated by a combined

chromatographic and chemometric

approach. Carbohydrate Polymers.

2000;41:163-174

[32] Landerito NA, Wang YJ.

Preparation and properties of starch phosphates using waxy, common, and high-amylose corn starches. I. Ovenheating method. Cereal Chemistry. 2005;82(3):264-270

[33] Blennow A, Nielsen TH, Baunsgaard L, Mikkelsen R, Engelsen SB. Starch phosphorylation: A new front line in starch research. Trends in Plant Science. 2002;7(10):445-450

[34] Salay E, Ciacco CF. Production and properties of starch phosphates produced by the extrusion process.

Starch. 1990;42(1):15-17

[35] Treib J, Baron JF, Grauer MT, Strauss RG. An international view of hydroxyethyl starches. Intensive Care Medicine. 1999;25:258-268

[36] Spychaj T, Zdanowicz M, Kujawa J, Schmidt B. Carboxymethyl starch with high degree of substitution: Synthesis, properties and application. Polimery. 2013;58(7-8):503-511

[37] Rutenberg MW, Plainfield N, Volpe JL. Sulfonium ether derivatives of starch. Patent number 2,989,520;

Patented 20 June 1961; New Brunswick, N.J., Assignors to National Starch and Chemical Corporation; United States Patent Office; 1961. p. 3

[38] Lewicka K, Siemion PB, Kurcok P. Chemical modifications of starch: Microwave effect. International Journal of Polymer Science (Hindawi). 2015:10. Article ID 867697

[39] Wurzburg OB. In: Stephen AM, editor. Food Polysaccharides and their Applications. New York, NY: Marcel Dekker; 1995. p. 67
[40] Singh J, Kaur L, OJ MC. Factors influencing the physico-chemical, morphological, thermal and rheological properties of some chemically modified starches for food applications-A review. Food Hydrocolloids. 2007;21(1):1-22

[41] Langan RE. In: Wurzberg OB, editor. Modified Starches: Properties and Uses. Boca Raton, FL: CRC Press; 1986. p. 199

[42] Linko P, Colonna P, Mercier C. HTST-extrusion of cereal based materials. In: Advances in Cereal Science and Technology. America Association of Cereal Chemists - AACC international, St. Paul Minnesota, USA. 1981;4:145-235

[43] Gomez MH, Aguilera JM. Changes in starch fraction during extrusioncooking of corn. Journal of Food Science. 1983;48:378-381

[44] Gomez MH, Aguilera JM. A physicochemical model for extrusion of corn starch. Journal of Food Science. 1984;49(1):40-43

[45] Colonna P, Doublier JL, Melcion JP, Monredon F, Mercier C. Extrusion cooking and drum drying of wheat starch, part I, physical and macromolecular modifications. Cereal Chemistry. 1984;61(6):538-543

[46] Powell EL. Production and uses of pre-gelatinized starches. In:

Whistler RL, Paschall EF, editors. Starch Chemistry and Technology. Vol. II. New York: Academic Press; 1965

[47] Williams PC, Lesselleur GC. Determination of damaged starch in flour, a comparative study of present day procedures. Cereal Science Today. 1970;15:4

[48] Kaper T, van der Maarel MJEC, Euverink GJ, Dijkhuizen L. Exploring and exploiting starch-modifying amylomaltases from thermophiles. 
Biochemical Society Transactions. 2003;

32:279-282

[49] Michael E, Brown JA. Improve texture, consistency, shelf life and freeze-thaw stability at reduced cost. Food Processing. 1968;28(6):436-443

[50] FAO-FNP (Food and Agricultural Organisation-Food and Nutrition Program). Modified Starch (FNP 40, 1990). Available from: http://www.fao. org/3/w6355e/w6355e0o.htm [Accessed 17 April 2019]

[51] Auh JH, Chae HY, Kim YR, Shim KH, Yoo SH, Park KH. Modification of rice starch by selective degradation of amylose using alkalophilic Bacillus cyclodextrinase. Journal of Agricultural and Food Chemistry. 2006;54:2314-2319

[52] Ao Z, Simsek S, Zhang G, Venkatachalam M, Reuhs BL, Hamaker BR. Starch with a slow digestion property produced by altering its chain length, branch density and crystalline structure. Journal of Agricultural and Food Chemistry. 2007; 55:4540-4547

[53] Abbas KA, Khalil SK, Hussin ASM. Modified starches and their usages in selected food products: A review study. Journal of Agricultural Science. 2010;2

(2):90-100

[54] Le Thanh-Blicharz J, Małyszek Z, Szwengiel A, Zięba T, Lewandowicz G. Sodium salt of starch octenylsuccinate as an emulsifier in "light" type mayonnaises. Acta Scientiarum Polonorum. Technologia Alimentaria. 2012;11(3):265-271

[55] Hung PV, Morita N. Dough properties and bread quality of flours supplemented with cross-linked corn starches. Food Research International. 2004;37(5):461-467 


\title{
Application of Starch and Starch Derivatives in Pharmaceutical Formulation
}

\author{
Christian Chibuogwu, Ben Amadi, Zikora Anyaegbunam, \\ Benjamin Emesiani and Sabinus Ofoefule
}

\begin{abstract}
Starch is a homo-glucose unit connected with glycosidic linkage. It is well known for its biodegradability, renewability, low cost, flexibility, and availability. However, to reach its potential in the pharmaceutical application, modification is necessary to solve the problem of solubility, retrogradation, and loss of viscosity. In this chapter, we discuss the different physical, chemical, enzymatic, and biotechnological modifications and their subsequent pharmaceutical application both as an excipient and directly as drug delivery vehicles. Overall, there were different characteristics conferred in a modification which were exploited in pharmaceutics, drug delivery, and antimicrobial preparation. We, however, believe that collation of the data on modification would go a long way toward standardizing the application of the modified products.
\end{abstract}

Keywords: starch, modification, pharmaceutical, drug, delivery

\section{Introduction}

Starch is the most abundant reservoir of carbohydrate in plants and a naturally occurring polysaccharide whose wide distribution makes it the second most abundant biomass material found in nature, only second to cellulose [1]. It is a product of the photosynthetic process in plants, storing the chemical energy of the sun in different parts of plants including the leaves of green plants, seeds, fruits, stems, roots, and tubers of most plants and making it available to nonphotosynthetic organisms with humans being the most significant beneficiaries. Starch is a polymeric molecule consisting of the six-carbon-ring glucose molecules with molecular weight varying from $10^{4}$ to $10^{7}$ Daltons and produced as discrete granules with distinct morphology in different plants [2-4]. Starch is formed in the chloroplasts of green leaves and amyloplasts of seeds, fruits, and tubers. Sources of starch include cereal grains such as corn, wheat, sorghum, rice, and tubers and roots such as cassava, potato, tapioca, yam, etc., which are all sources of dietary carbohydrates [5]. Beyond its natural usefulness as food, this polysaccharide has obtained wide acceptance in various industries such as in textile for stiffening fabrics, in the food industry as additives and thickeners among other uses, in the pharmaceutical industry as an excipient and more recently used as a drug carrier, and also in cosmetics and paper industries [1]. 
Starch is utilized either in its native form or in the modified form. Native starch refers to starch in its natural, unmodified state, as extracted from its plant source, while modified starch is one in which certain properties have been modified or altered to meet the desired specifications. In its native state, starch is unsuitable for many industrial processes mainly due to its poor solubility and also its inability to withstand industrial conditions such as high temperatures. Therefore, modifications are done not only to alter the physicochemical properties of starch and improve its technological value but also to exhibit desired qualities in finished products [5].

\section{Starch composition}

Structurally, starch is a polysaccharide composed of glucose (monosaccharide) units connected by $\alpha$-D-(1-4) and $\alpha$-D-(1-6) linkages. The starch molecule consists of two major types of polymers, namely amylose and amylopectin. Amylopectin consists of linear chains of glucose units linked by $\alpha-1,4$ glycosidic bonds and is highly branched at the $\alpha-1,6$ positions by small glucose chains at intervals of $10 \mathrm{~nm}$ along the molecule's axis, constituting about $70-85 \%$ of common starch. Amylose, on the other hand, is a linear chain of $\alpha-1,4$ glucans with limited branching points at the $\alpha-1,6$ positions and constitutes between 15 and $30 \%$ of common starch [2]. There are, however, exceptions to the rule in terms of glucan compositions (amylose/amylopectin ratio) of starches. This is because modifications have been introduced to starch molecules recently to alter the glucan composition to meet specific requirements with some starches genetically modified to have almost a $100 \%$ amylose content while some are designed to be amylose-free [3]. Irrespective of the source, the starch molecule is usually present as granules. However, the size and shape of starch granules depend on their botanical origin. For example, the granule size for rice starch is about 3-8 $\mu \mathrm{m}$, while potato starch ranges from 15 to about $100 \mu \mathrm{m}$ [4].

Starch granules have very complex structures, resulting from variations in their components. They also exhibit variations between amorphous and crystalline regions. The amorphous region of the granules consists of amylose associated with large branches of amylopectin molecules. On the other hand, the crystalline region consists of amylopectin molecules with short branches; therefore, the higher the amylopectin proportion in starch granules, the greater the crystallinity [5]. Starch granules have also been found to exist in varying shapes, including oval, round, elliptical, flattened ovoid, polygonal, lenticular, and disc shapes [4].

In addition to amylose and amylopectin, starch also contains other noncarbohydrate components such as lipids (up to $1 \%$ ), residues of protein $(0.4 \%)$, and a relatively small amount $(<0.4 \%)$ of minerals (calcium, magnesium, phosphorus, potassium, and sodium) of which phosphorus occupies an important position $[6,7]$ (Figures 1 and 2).

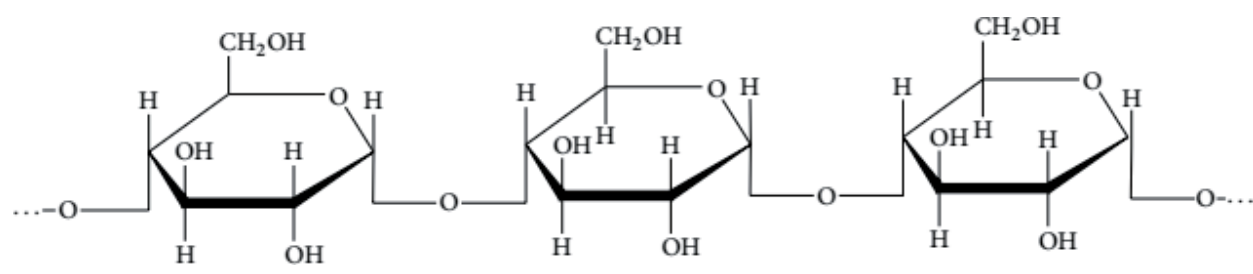

Figure 1.

Structure of amylose [8]. 


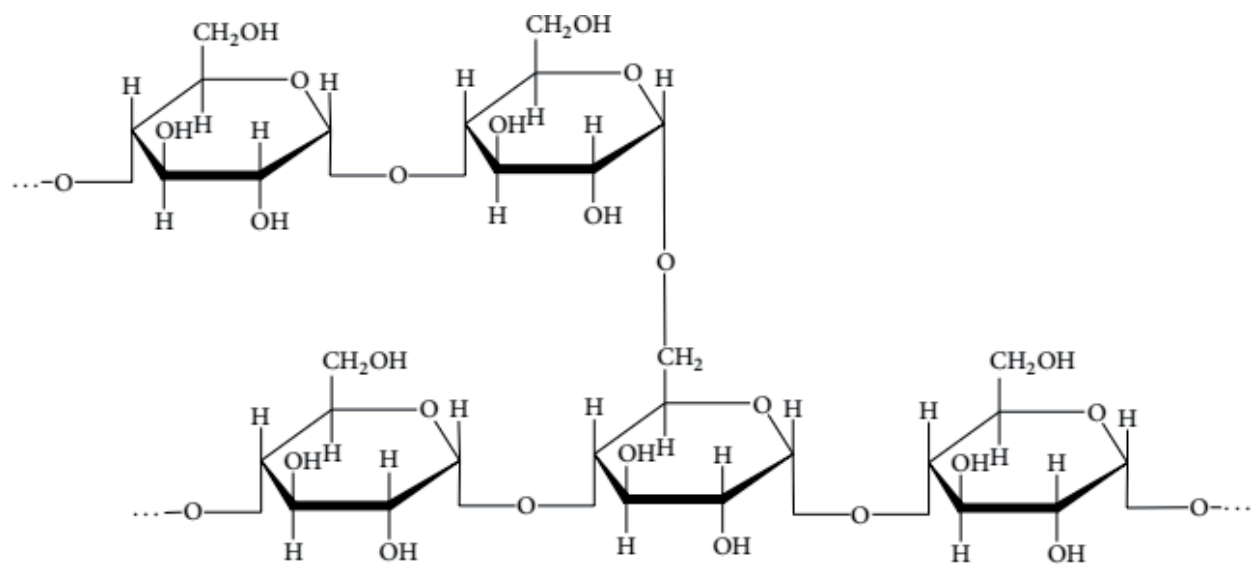

Figure 2.

Structure of amylopectin [8].

Lipids in starch are present in the form of phospholipids and free fatty acids and are usually associated with the amylose fraction. Lipids, particularly phospholipids, have great tendencies to form helical complexes with starch (mainly with amylose). The lipid complexes in starch granules are present as a hydrophobic nucleus situated within helices formed by amylose chains [9], and, although representing a small fraction of the starch granules, lipid complexes can significantly reduce not just the solubility of the granules but also the swelling capacity of the starch paste [7].

Phosphorus is a noncarbohydrate component of starch whose presence has been found to exert significant influence on functional characteristics such as clarity and viscosity of starch pastes. It is present either as monoester phosphates (proportionally associated with the amylopectin fraction by covalent bonds) or as phospholipids (proportionally associated with the amylose content of starch), with the latter significantly lowering these characteristics [10]. Properties such as solubility and transmittance of starch granules are also affected by the nature of the phosphorus present in the starch. It is reported that the presence of phosphorus in the form of monoester phosphates enhances these properties in starch granules [11].

\section{Properties of starch}

\subsection{Structure of starch granules}

X-ray analyses of starch granules reveal varying degrees of crystallinity of the granules. Three distinct X-ray patterns (A-, B-, and C-patterns) have been observed with the A-pattern's characteristic of cereal grain starches, such as maize, waxy maize, wheat, and rice, while the B-patterns are characteristics of tuber, fruit, and stem starches, such as canna, potato, sago, banana starches, and some mutant maize starches such as amylomaize-5 and amylomaize-7. C-type patterns are found in roots such as tapioca starch, beans, and peas and are an intermediate between A- and B-types [11]. Also B- and C-type native starches can be converted to the A-type by heat-moisture treatment $\left(30^{\circ} \mathrm{C}\right.$ for B-type and approximately $50^{\circ} \mathrm{C}$ for $\mathrm{C}$-type). However, the original structure of the A-type starches needs to be destroyed and allowed to recrystallize for conversion into other crystalline forms to occur [12]. 


\subsection{Swelling capacity and solubility}

One of the characteristics of starch is the ability of its granules to absorb water. Water absorption results in swelling of the starch granule contributing to amylopectin-amylose phase separation and loss of crystallinity, which in turn promotes the leaching of amylose to the intergranular space [13]. Heating of starch molecules in excess water causes the breaking of its semicrystalline structure, allowing water molecules to interact (via hydrogen bonding) with the hydroxyl groups exposed on the amylose and amylopectin molecules. This association causes swelling and increases granule size and solubility. The extent of this interaction is influenced by the amylose-amylopectin proportion as the swelling capacity of the starch granule is a function of its amylopectin content. The high tendency of the amylose component of starch granules to complex with phospholipids (forming amylose-lipid complexes) greatly inhibits the solubility and, consequently, the swelling capacity of starch granules [11].

\subsection{Gelatinization of starch}

Starch, when heated in excess water, undergoes a transition phase known as gelatinization. Gelatinization of starch is useful in particular industries, especially the textile and hydrolyzed starch industries. Generally, starch gelatinization can be defined as the conversion of starch from the crystalline, granular form to the dispersed and amorphous state [6]. Gelatinization occurs when water diffuses into the granule, which then swells substantially due to hydration of the amorphous phase causing loss of crystallinity and molecular order [14]. The gelatinization temperature of the starch granules varies depending on the source of starch. This is due to the influence of the organization (packing of the double helices) of the glucan chains in the crystalline lamellae of the granules. This includes the nature of the branching pattern (distance between the branching points and numbers of chains in the building blocks) and the length of external chains. Other factors include the concentration of amylose and the lipid content of the starch. Chemical methods of starch gelatinization and consequent solubilization are also available such as the use of alkali $(\mathrm{NaOH})$ and dimethyl sulfoxide (DMSO). However, the conditions and pathways of gelatinization are different from the process of boiling water. For instance, apart from occurring at a low temperature $\left(20^{\circ} \mathrm{C}\right)$, starch granules do not swell in DMSO as they do in hot water but dissolve slowly by fragmentation of the interior of the granule into smaller pieces [15].

\subsection{Retrogradation}

Retrogradation refers to the molecular interaction produced after gelatinization and cooling of the starch paste, that is, the recrystallization of glucan chains in gelatinized starch. It can be described as the tendency for solvated, amorphous starch to return to an insoluble, aggregated, or crystalline state when stored at a temperature above its glass transition temperature. This characteristic of starch is favored both by low temperature $\left(0-5^{\circ} \mathrm{C}\right)$ and high starch concentration [6]. This property is one of the causes of staleness of baked products during storage and is generally considered unfavorable in terms of food quality. The glucan composition (amylose/amylopectin ratio of starch), as well as the presence of other noncarbohydrate components, has a significant influence on the retrogradation potentials of starch. For instance, high amylose content increases retrogradation potentials of starch, whereas amylose-free starches have less tendency towards this behavior. This is because, during retrogradation, amylose molecules associate with other 
glucose units to form a double helix, while amylopectin molecules recrystallize through the association of its small chains [11]. The presence of other components such as proteins, lipids, other carbohydrates, salts, and polyphenols significantly affects retrogradation. For example, proteins can complex with starch to retard the retrogradation process during refrigerated storage [16].

\section{Starch modification and pharmaceutical application}

The abundance, biodegradability, and cost-friendly characteristics of starch make it an important raw material for many industrial processes. However, certain properties of starch make it undesirable for all applications. Most native starches are limited in their direct application due to poor solubility in water and a strong tendency for decomposition and retrogradation. They also display high instability with respect to changes in temperature, $\mathrm{pH}$, and shear forces [15]. Therefore, starches are often subjected to either physical, chemical, or enzymatic modifications. These modifications are done to develop specific properties such as solubility, hydrophobicity, thermal stability, amphiphilicity, paste clarity, mechanical strength, freezethaw stability retrogradation resistance texture, adhesion, and tolerance to high temperatures used in industrial $[6,17]$.

Several factors affect the digestibility of native starch and, hence, possible pharmaceutical application. These include amylopectin: amylose ratio, amylopectin chain length, degree of crystallinity, and intermolecular association in granules [17]. Modification typically affects all these properties, and the choice of modification can lead to customization and flexibility in starch use.

Summarily, these are modification methods currently in use:

\subsection{Physical modification}

Physical treatments are generally divided into thermal and nonthermal treatments. Thermal treatments involve the use of heat to rearrange the amylopectin: amylose ratio and length of chain. This typically leads to highly soluble excipients, and when exposed to such temperature conditions, gelatinization occurs, improving the swellability and solubility. Thus starch produced in this manner is easily plasticized and can be used in the production of antimicrobial films and also as superdisintegrants.

Thermal treatments include pregelatinization, heat-moisture treatment, annealing, dry heating, and osmotic pressure treatment.

Pregelatinization involves the starches to be cooked at a specified temperature and dried to allow little or no molecular reassociation.

Heat moisture treatment consists of heating starch granules at a temperature above the starch's glass transition temperature at the adiabatic condition with a relative humidity of $10-40 \%$ for $1-24 \mathrm{~h}$ [17]. The changes observed show no crystallinity in A-type; however, B-type starch granules change to C-type. Increase in crystallinity, however, is only a desired trait in sustained release formulation [17].

The nonthermal treatment includes ultrasonic treatment, milling, high-pressure treatment, pulsed electric field, freezing/thawing, and freeze-drying treatment.

\subsection{Chemical modification}

This involves the insertion of a new functional group on the starch backbone to give unique properties to the starch. There are numerous methods of chemical modification, but the most relevant are acid hydrolysis, cross-linking, acetylation, dual modification, oxidation, and grafting. 


\subsection{Enzymatic modification}

The enzymatic modification of starch targets the amylopectin: amylose chain length and content and also the molecular weight. Typically, when the mentioned variables are reduced, the modified starch can be used to formulate fast-releasing micro and nano-particles. Alternatively, used in immediate release tablet formulation. The modification, however, does not improve the swellability of the starch granules, and as such, it cannot be used as a disintegrant.

\section{Advances of modified starch in some drug delivery application}

The modification of starch has given it some controlled delivery in drug delivery system, and depending on the modification carried out in the starch, such as acid modified, pre-gelatinized, freeze-dried, cross-linked, and hydroxypropylation, the disintegration and binding properties are affected. This can subsequently affect the rate of release.

A study was done by Alexiou et al. [18] to study the biocompatibility of starch as a carrier to targeting cancer cells. Phosphate-modified starch was used to prepare iron oxide nanoparticle, which was then mixed with mitoxantrone. The iron oxide nanoparticles improved drug concentration and targeting using a magnetic field. This improved the in vivo effect.

Rice starch modified with carboxylation and oxidation [20] was used in the tablet preparation of metronidazole. It was found out that the starch conferred a controlled release mechanism owing to its enzymatic and $\mathrm{pH}$ resistance leading to a slow-release with prolonged effect.

Thermosensitivity of starch derivative was recently tested in the drug delivery system. Acid-hydrolyzed starch treated with butyl glycidyl ether to yield 2-hydroxy-3-butoxypropyl starch polymer micelles was loaded with prednisolone and the in vitro dissolution profile investigated in distilled water at 20 and $40^{\circ} \mathrm{C}$. It was discovered that $38 \%$ of the drug was released at $20^{\circ} \mathrm{C}$, while $90 \%$ was released at $40^{\circ} \mathrm{C}$. The effect of molar substitution (MS) and lower critical solution temperature (LCST) of the modified starch offered a mechanism to this release. The above factors were investigated and discovered to be inversely proportional, thus, when MS was doubled from 0.32 to 0.67 , the LCST decreased from 32.5 to $4^{\circ} \mathrm{C}$. This increase in molar substitution affects the micelles leading to swelling and controlled release at different temperature [20].

Antimicrobial agents have low molecular weight and can display poor retention, and easily leaking out without attaining stability in the formulation. This has provided the rationale for conjugating the antimicrobials with high-molecularweight starches which prevent leaching and improve the encapsulation efficiency. A work done by Guan et al. [20] showed the microbicidal effect of covalently bonded polyhexamethylene guanidine hydrochloride (PHGH) and potato starch on the activity of nonresistant Escherichia coli and Staphylococcus aureus. The microbial growth was inhibited to almost $100 \%$ when $1 \%$ of the PHGH was used in the modification [28].

There is no direct compilation of how the different modifications affect the inherent properties of native starch to the point of predictive usage, but the effect is always felt in the modification technique used and the observed pharmaceutical function. Below is a tabulated list of some of the current usages of modified starches in drug delivery systems (Tables 1 and 2 ). 
Application of Starch and Starch Derivatives in Pharmaceutical Formulation

DOI: http://dx.doi.org/10.5772/intechopen.88273

\begin{tabular}{|c|c|c|c|c|c|}
\hline Starch & $\begin{array}{l}\text { Antimicrobial } \\
\text { agent }\end{array}$ & Concentration & $\begin{array}{c}\text { Micro- } \\
\text { organism }\end{array}$ & Observation & References \\
\hline \multirow[t]{3}{*}{ Potato } & PHGH & $1 \%$ & E. coli & $100 \%$ & [19] \\
\hline & \multicolumn{5}{|c|}{ S. aureus } \\
\hline & & $12 \%$ & E. coli & $\begin{array}{l}\text { Excellent antimicrobial } \\
\text { activities }\end{array}$ & \\
\hline Cassava & $\begin{array}{l}\text { Chitosan- } \\
\text { oregano }\end{array}$ & $0.1,0.5,1.0 \%$ & $\begin{array}{l}\text { E. coli, } \\
\text { S. aereus }\end{array}$ & $\begin{array}{l}\text { Increased biocidal activity } \\
\text { against gram-positive } \\
\text { than gram-negative } \\
\text { bacteria }\end{array}$ & {$[20]$} \\
\hline \multirow[t]{3}{*}{$\begin{array}{l}\text { Sweet } \\
\text { potato }\end{array}$} & $\begin{array}{l}\text { Potassium } \\
\text { sorbate }\end{array}$ & $5,10,15 \%$ & E. coli & Inhibition at $5 \%$ only & [21] \\
\hline & & & S. aureus & No inhibition zones & \\
\hline & Chitosan & $5,10,15 \%$ & E. coli & $\begin{array}{l}\text { Excellent antimicrobial } \\
\text { activities }\end{array}$ & \\
\hline \multirow[t]{2}{*}{ Wheat } & Chitosan & & $\begin{array}{l}\text { Bacillus } \\
\text { subtilis, } \\
\text { E. coli }\end{array}$ & Low inhibition & \\
\hline & $\begin{array}{l}\text { Chitosan- } \\
\text { lauric acid }\end{array}$ & $8 \%$ & $\begin{array}{l}\text { B. subtilis, } \\
\text { E. coli }\end{array}$ & Efficient inhibitory effect & [22] \\
\hline Potato & $\begin{array}{c}\text { Guanidine } \\
\text { hydrochloride }\end{array}$ & $4,8,12,16 \mathrm{~mol}$ & $\begin{array}{l}\text { E. coli, } \\
\text { S. aereus }\end{array}$ & $\begin{array}{c}\text { Excellent antimicrobial } \\
\text { properties }\end{array}$ & \\
\hline Key $\mathrm{PHGH}-$ & examethylene & nidine hydrochlor & & & \\
\hline
\end{tabular}

Table 1.

Antimicrobial modified starch and its activities.

\begin{tabular}{|c|c|c|c|c|}
\hline Material & $\begin{array}{l}\text { Delivery } \\
\text { method }\end{array}$ & $\begin{array}{l}\text { Preparation } \\
\text { technique }\end{array}$ & In vitro result & References \\
\hline $\begin{array}{l}\text { Corn starch- } \\
\text { polycaprolactone } \\
\text { blend }\end{array}$ & $\begin{array}{l}\text { Porous } \\
\text { microparticles }\end{array}$ & $\begin{array}{l}\text { Emulsion } \\
\text { solvent } \\
\text { extraction/ } \\
\text { evaporation }\end{array}$ & $\begin{array}{l}\text { There was a steady release } \\
\text { of the drug over } 30 \text { days }\end{array}$ & [23] \\
\hline $\begin{array}{l}\text { Sweet potato } \\
\text { starch }\end{array}$ & Microparticle & $\begin{array}{l}\text { Spray drying } \\
\text { of gelatinized } \\
\text { starch }\end{array}$ & $\begin{array}{l}\text { There was a sustained } \\
\text { release for up to } 6 \mathrm{~h} \text {. the } \\
\text { concentration of starch } \\
\text { used also affected the } \\
\text { release model }\end{array}$ & {$[24,28]$} \\
\hline $\begin{array}{l}\text { Corn and potato } \\
\text { starch }\end{array}$ & Hydrogel & $\begin{array}{l}\text { Isostatic ultra- } \\
\text { high pressure }\end{array}$ & $\begin{array}{l}\text { Corn starch showed } \\
\text { sustained release while } \\
\text { potato starch hydrogel } \\
\text { showed fast drug release }\end{array}$ & {$[25]$} \\
\hline $\begin{array}{l}\text { Hydrolyzed } \\
\text { potato starch }\end{array}$ & Microsphere & $\begin{array}{l}\text { Single } \\
\text { emulsion } \\
\text { cross-linking }\end{array}$ & $\begin{array}{l}\text { The release was rapid } \\
\text { within the first } 2 \mathrm{~h}\end{array}$ & {$[26]$} \\
\hline $\begin{array}{l}\text { Cross-linked } \\
\text { starch }\end{array}$ & $\begin{array}{l}\text { Mucoadhesive } \\
\text { nanoparticle }\end{array}$ & & $\begin{array}{l}\text { The nanoparticles led } \\
\text { to rapid drug delivery } \\
\text { and were also directly } \\
\text { depend on the extent of } \\
\text { cross-linking }\end{array}$ & {$[27,29]$} \\
\hline
\end{tabular}

Table 2.

Modified starch and their application towards drug delivery systems. 


\section{Conclusion}

The role of starch keeps diversifying. The pharmaceutical potential of modification of starch in drug delivery systems has been shown in this report to vary and is not easily predictable until the final outcome. It is our recommendation that documenting the observable physical and molecular change in the starch modification alongside with the observable drug delivery effect would improve the predictional use of this versatile material.

\section{Author details}

Christian Chibuogwu*, Ben Amadi, Zikora Anyaegbunam, Benjamin Emesiani and Sabinus Ofoefule

Institute for Drug-Herbal Medicine-Excipient Research and Development, University of Nigeria, Nsukka, Nigeria

*Address all correspondence to: christian.chibuogwu@unn.edu.ng

\section{IntechOpen}

(C) 2019 The Author(s). Licensee IntechOpen. This chapter is distributed under the terms of the Creative Commons Attribution License (http://creativecommons.org/licenses/ by/3.0), which permits unrestricted use, distribution, and reproduction in any medium, provided the original work is properly cited. (cc) BY 


\section{References}

[1] Emeje MO, Rodrigues A. In: Valdez B, editor. Starch: From Food to Medicine, Scientific, Health and Social Aspects of the Food Industry. InTech; 2012. ISBN: 978-953-307-916-5. Available from: http://www.intechopen.com/ books/scientific-health-and-socialaspects-of-the-food-industry/ starch-fromfood-to-medicine

[2] Durrani CM, Donald AM. Physical characterization of amylopectin gels. Polymer Gels and Networks. 1995;3(1):1-27

[3] Bertoft E. Understanding starch structure: Recent progress. Agronomy. 2017;7:56. DOI: 10.3390/ agronomy7030056

[4] Waterschoot J, Gomand SV, Fierens E, Delcour JA. Production, structure, physicochemical and functional properties of maize, cassava, wheat, potato and rice starches. Starch/Staerke. 2015;67(1-2):14-29

[5] Cheetham NWH, Tao L. Variation in crystalline type with amylose content in maize starch granules: An X-ray powder diffraction study. Carbohydrate Polymers. 1998;36(4):277-284

[6] Jane J. Starch properties, modifications, and applications. Journal of Macromolecular Science, Part A: Pure and Applied Chemistry. 1995;32(4):751-757

[7] Alcázar-Alay SC, Meireles MAA. Physicochemical properties, modifications, and applications of starches from different botanical sources. Food Science and Technology. 2015;35(2):215-236

[8] Lewicka K, Siemion P, Kurcok P. Chemical modifications of starch: Microwave effect. International Journal of Polymer Science. 2015;2015:867697
[9] Tester RF, Karkalas J, Qi X. StarchComposition, fine structure and architecture. Journal of Cereal Science. 2004;39(2):151-165

[10] Craig SAS, Maningat CC, Seib PA, Hoseney RC. Starch paste clarity. Cereal Chemistry. 1989;66(3):173-182

[11] Singh N, Singh J, Kaur L, Sodhi NS, Gill BS. Morphological, thermal and rheological properties of starches from different botanical sources. Food Chemistry. 2003;81(2):219-231

[12] Robyt JF. Starch: Structure, properties, chemistry, and enzymology. In: Fraser-Reid B, Tatsuta K, Thiem J, editors. Glycoscience. Heidelberg, Berlin: Springer-Verlag; 2008.

pp. $1437-1472$

[13] Conde-Petit B, Nuessli J, Arrigoni E, Escher F, Amadò R. Perspectives of starch in food science. Chimia. 2001;55(3):201-205

[14] Jiménez A, Fabra MJ, Talens P, Chiralt A. Edible and biodegradable starch films: A review. Food and Bioprocess Technology. 2012;5(6):2058-2076

[15] Wu Y, Chen Z, Li X, Wang Z. Retrogradation properties of high amylose rice flour and rice starch by physical modification. LWTFood Science and Technology. 2010;43(3):492-497

[16] Berski W, Ptaszek A, Ptaszek P, Ziobro R, Kowalski G, Grzesik M, et al. Pasting and rheological properties of oat starch and its derivatives. Carbohydrate Polymers. 2011;83(2):665-671

[17] Hoover R. Composition, molecular structure, and physicochemical properties of tuber and root starches: A review. Carbohydrate Polymers. 2001;45(3):253-267 
[18] Alexiou C, Schmid RJ, Jurgons R, Kremer M, Wanner G, Bergemann C, et al. Targeting cancer cells: Magnetic nanoparticles as drug carriers. European Biophysiology Journal. 2006;35:446-450

[19] Ziaee Z, Qian L, Guan Y, Fatehi P, Xiao H. Antimicrobial/antimold polymer-grafted starches for recycled cellulose fibers. Journal of Biomaterials Science. Polymer Edition. 2010;21(10):1359-1370

[20] Guan Y, Qian L, Xiao H, Zheng A. Preparation of novel antimicrobialmodified starch and its adsorption on cellulose fibers: Part I. Optimization of synthetic conditions and antimicrobial activities. Cellulose. 2008;15:609-618

[21] Pelissari FM, Grossmann MVE, Yamashita F, Alfonso E, Pineda G. Antimicrobial, mechanical, and barrier properties of cassava starch-chitosan films incorporated with oregano essential oil. Journal of Agricultural and Food Chemistry. 2009;57:7499-7504

[22] Shen XL, Wu JM, Chen Y, Zhao G. Antimicrobial and physical properties of sweet potato starch films incorporated with potassium sorbate or chitosan. Food Hydrocolloids. 2010;24:285-290

[23] Balmayor ER, Tuzlakoglu K, Azevedo HS, Reis RL. Preparation and characterization of starchpoly- $\varepsilon$-caprolactone microparticles incorporating bioactive agents for drug delivery and tissue engineering applications. Acta Biomaterialia. 2009;5:1035-1045

[24] Liu C-S, Desai KGH, Meng X-H, Chen X-G. Sweet potato starch microparticles as controlled drug release carriers: Preparation and in vitro drug release. Drying Technology. 2007;25:689-693

[25] Szepes A, Makai Z, Blümer C, Mäder K, Kása P, Szabó-Révész P. Characterization and drug delivery behaviour of starch-based hydrogels prepared via isostatic ultrahigh pressure. Carbohydrate Polymers. 2008;72:571-578

[26] Malafaya PB, Stappers F, Reis RL. Starch-based microspheres produced by emulsion crosslinking with a potential media dependent responsive behavior to be used as drug delivery carriers. Journal of Materials Science. Materials in Medicine. 2006;17:371-377

[27] Jain AK, Khar RK, Ahmed FJ, Diwan PV. Effective insulin delivery using starch nanoparticles as a potential trans-nasal mucoadhesive carrier. European Journal of Pharmaceutics and Biopharmaceutics. 2008;69:426-435

[28] Zaki Ahmad M, Akhter S, Ahmad I, Rahman M, Anwar M, Jain GK, et al. Development of polysaccharide-based colon targeted drug delivery system: Design and evaluation of Assam bora rice starch-based matrix tablet. Current Drug Delivery. 2011;8:575-581

[29] French D. Organization of starch granules. In: Whistler RJ, BeMiller JN, Paschall EF, editors. Starch: Chemistry and Technology. 2nd ed. New York: Academic Press; 1984. pp. 200-210 
Section 3

\section{Resistant Starch}





\title{
Resistant Starch from Exotic Fruit and Its Functional Properties: A Review of Recent Research
}

\author{
Lee-Hoon Ho and Shi-Yun Wong
}

\begin{abstract}
Resistant starch is a functional food ingredient that can resist enzymatic digestion in the small intestine and fermentation in large intestine. Resistant starch has many benefits to human health by promoting a balanced blood sugar and beneficial gut bacteria. This review highlighted the sources of different exotic fruit starch, such as banana, jackfruit, cempedak, durian, and breadfruit. The functional properties of these exotic fruit resistant starches were covered in this review. The effect of resistant starch on glycaemic index of food was revealed. This review also discussed on the applications of resistant starch in the production of food products and their effects on food quality. The provided information through the overall review could especially benefit the food industry in producing functional food products with great consumer acceptability.
\end{abstract}

Keywords: resistant starch, banana, jackfruit, cempedak, durian, breadfruit, functional properties, glycaemic index, product quality

\section{Introduction}

Starch is the main glycaemic carbohydrate reserve in plants, including cereals, tubers, roots, and unripe fruits. Starch is considered the second largest natural biopolymer next to cellulose [1]. Dietary starches are important sources of energy for the majority of the world's population. Starch is a polymer with molecular formula (C6H10O5)n and contains two D-glucopyranose polymers, namely, amylose and amylopectin. Amylose is a glucopyranosyl linear polymer, whereas amylopectin is a glucopyranosyl chain polymer [2]. It contributes up to $70-80 \%$ of total carbohydrates in human diet. Starch plays a major part in human nutrition by supplying metabolic energy that enables the body to perform its different functions [3]. Nowadays, dietary guidelines are focused on lowering fat intake by increasing complex carbohydrate intake (i.e. starch and dietary fibre) [4].

Nutritionally, starch can be grouped based on its rate and extent of digestion: rapidly digestible starch (RDS), slowly digestible starch (SDS), and resistant starch (RS) [5]. Recently, the consumption of RS in daily diet has gained increasing worldwide attention due to its health-promoting benefits and functional properties. The starch molecules undergo several physical modifications, depending upon the type of starch and severity of the conditions applied during processing of starchy foods, leading to RS formation [6]. 
RS positively influences the functions of the digestive tract, microbial flora, blood cholesterol level, and glycaemic index (GI) and assists in the control of diabetes [3]. Apart from the potential health benefits of RS, another positive advantage is its lower impact on food sensory properties than traditional fibre sources. Starch contributes to the physicochemical properties of food products which are made from cereals, tubers, roots, legumes, and fruits. Among its desirable physicochemical properties are its swelling capacity, viscosity, gel formation, and water-binding capacity, which make starch useful in a variety of food [7].

Starch digestion rate is affected by the nature of food composition (e.g. phosphorylated starch, RS, dietary fibre, phytonutrients, protein, and fat content) [8]. In addition, the types of chemical structure and physicochemical properties of starch and fibre present in food are important to determine their effects in the gastrointestinal tract [9]. The types of carbohydrate as well as total amount of carbohydrates in food will affect the blood glucose level [10]. According to FosterPowell et al. [11], different digestibility rates of carbohydrate is related with some physiological functions, which have different health effects, for example, reduction in insulinemic and glycaemic responses to food, hypocholesterolemic action, and protective effects against colorectal cancer.

The functional properties of starch must be considered when developing food formulations due to its influence on the quality of end products. Starch functional properties depend on the molecular structure composition of amylose and amylopectin together with the arrangement of their starch granules. Starch paste consistency depends on the gelatinisation degree and swelling power of starch granule. The paste texture is determined by viscoelastic deformation and depends on the strength of molecular bonds and amount of broken granules. In addition the paste or gel clarity varies from clear to opaque, and this property is related to light dispersion that results from the association between amylose and other components present in starch [12]. Therefore, the functional properties of the raw materials are influenced by variety, climate, and soil conditions where the plant is grown [13].

\section{Resistant starch (RS)}

Resistant starch is defined as a portion of starch that cannot be digested by amylases in the small intestine [14]. However, RS can be degraded through glycolysis by microorganisms in the colon even though at the first stage it cannot be digested or absorbed by amylase in the human digestive tract $[15,16]$. RS was introduced in recent years as a functional food ingredient important to human nutrition. RS has become an attractive functional food ingredient in food processing among food manufacturers to develop new nutritional food products [16]. The RS degree of formation in food depends on the type of starch contained and adopted processing conditions, such as water content, $\mathrm{pH}$, heating temperature and time, number of heating and cooling cycles, freezing, and drying. It is also influenced by the duration and storage conditions [17-19]. Moreover, Eroglu and Buyuktuncer [19] reported that cooking methods like steaming, baking, and autoclave cooking increased the amount of RS in food, whereas pressure cooking was found to decrease the amount of RS in food. Cooking methods, such as boiling, microwave heating, extrusion, and frying, have the potential to increase the amount of RS, depending on the source of starch and processing conditions.

RS content is an important parameter to be considered mainly from the nutritional point of view as starch in this form is less easily digested and may impart health benefits [20]. In addition, RS was revealed to have various health benefits, 
including the prevention of colon cancer, inhibition of fat accumulation, reduction of gall stone formation, increase in absorption of minerals, hypoglycaemic and hypocholesterolemic effects, and acceleration of probiotic growth [21]. A diet high in RS can reduce blood cholesterol and triglyceride levels due to higher excretion rates of cholesterol and bile acids [22].

RS has a unique equivalent behaviour to fibre which can escape from enzymatic digestion in the small intestine but be fermented in the large intestine by colonic microflora to serve as source of nutrient for the colonic bacteria $[5,23]$. When the carbohydrate metabolises, it lowers the colonic $\mathrm{pH}$ and releases short fatty acids, such as propionate, butyrate, and acetate, to encourage the spread of beneficial bacteria in the intestine $[18,21,24]$. RS plays a vital role in health food manufacturing [5]. With its unique characteristic that is resistant to human digestive enzymes, $\mathrm{RS}$ is slowly broken down throughout the entire small intestine and then produces a slow release of glucose, and thus acts as an evidence for the low GI of indigested starch [25]. This can help to reduce postprandial response and promote glucose regulation in diabetes and control body weight for the obese, reducing glycaemic and insulinemic responses to food [26, 27].

There are five general subtypes of RS fraction in food: type 1 RS (RS I), type 2 RS (RS II), type 3 RS (RS III), type 4 RS (RS IV), and type 5 RS (RS V) [28]. The RS fractions are classified based on the nature of starch in food [5]. For RS I, it is corresponded to the physically inaccessible starches which are entrapped in the cellular matrix found in whole grains and seeds. RS II is native uncooked granules of some starches, such as starch in green bananas, raw potatoes, some legumes, and high amylose starches (i.e. high amylose corns), in which crystallinity makes them scarcely susceptible to hydrolysis. Meanwhile, RS III is retrograded amylose and amylopectin during food processing which causes a reduction in glycaemic response [29]. This starch is found in cooked and cooled food such as potatoes, bread, and corn flakes. Chemically modified starches generally belong to RS IV, and their molecular structures are chemically altered in many ways. RS IV is used by food manufacturers to improve the functional characteristics of starch [3]. RS V comprises amylose-lipid complexes, which have helical structures with fatty acid tails at the central cavities of the inclusion complex formed by alpha-amylase and polar lipids $[5,30]$. These types of starch require higher temperatures for gelatinisation and are more susceptible to retrogradation [18].

\section{Functional properties of resistant starch produced from exotic fruits}

\subsection{Banana}

Several studies have reported that banana starch contains a high level of amylase that is often related to a high retrogradation [24, 31, 32]. Vatanasuchart et al. [31] reported that flour produced from indigenous banana cultivars has a high content of apparent amylose. Several reports revealed that consumption of green bananas confers beneficial effects on human health. This is often associated with their high content levels of RS, dietary fibre (i.e. non-starch polysaccharides), functional components, and other nutritive values [24].

In addition, green banana, which is a rich source of complex carbohydrates, is mainly RS and fibres, which is an important functional food [33]. Green banana starch is highlighted as one of the good substitutes for the starch industry [32]. Moreover, bananas are also a good source of energy due to the presence of a large amount of starch and sugar. The slow digestion of unripe plantain starch is associated with its starch granule properties (i.e. amylase and amylopectin), and its 
physical characteristic is related to the plant cell wall that can contribute in lowering total starch gelatinisation [34].

Unripe bananas or green bananas were reported to contain high amount of RS II (i.e. ungelatinised starch granules that are protected from hydrolysis by the crystalline structure of the starch granule). The dense starch granules with crystalline structure property of green banana contribute to its high resistance to acid and digestive system enzyme (e.g. $\alpha$-amylase) [35]. RS that is present in green banana helps to improve peptic ulcer and prevent damage of the mucosal lining [36].

A recent study showed that starch produced from the green banana variety of Mysore (Musa AAB-Mysore) had good physicochemical features and functional properties [37]. It is observed that starch from green variety of Mysore exhibited good swelling power which shows potential for its use in products that require water retention, such as meat and jellies. In addition, the low percentage of water loss during storage and low setback obtained by a folder profile study showed that starch is less prone to syneresis, which is one of the important factors to be considered during development of food products which require to be kept under refrigeration [37]. Fontes et al. [37] described the shape of starch granules of banana from the green variety of Mysore as ellipsoidal in shape with irregular diameters that range between axes of $10 \mu \mathrm{m}$ and $100 \mu \mathrm{m}$ and smooth surface. Another study done by Khawas and Deka [38] indicated that isolated culinary banana starch experienced restricted swelling and solubility profile and was unstable during freezing and thawing cycles. However, the starch demonstrated a high pasting temperature which indicated that culinary banana starches have high gelatinisation temperature and resistance towards swelling. Culinary banana starch exhibited a mixture of A-type and B-type polymorphs when observed under X-ray diffractometer. In addition, culinary banana starch has various functional groups which suggest C-type starch with a mixture of spherical and elliptical granules [38].

The banana starch was double-chemical modified by using two different cross-linking agents (i.e. phosphorus oxychloride and a mixture of sodium trimetaphosphate/sodium tripolyphosphate) [39]. The modified banana starch has a bigger average particle size than unmodified starch due to the swelling of the granules during chemical modification, and aggregates were also formed. The chemicalmodified banana starches presented an A-type X-ray diffraction pattern with slightly decreased crystallinity as compared to the unmodified banana starch. In addition, the modified starch decreased the temperature and enthalpy of gelatinisation and the decomposition temperature which were due to partial disorganisation during chemical treatment [39].

Many studies were conducted to produce and characterise the RS from banana starch; for example, González-Soto et al. [23] reported that banana starch is a good source for RS production by autoclaving after starch debranching. According to González-Soto et al. [23], banana starch without treatment has higher available starch $(80.5 \%)$ and lower RS content (9.1\%) than the banana starch that was debranched for $5 \mathrm{~h}$ and longer (70.0-77.5\% for available starch and 14.5-18.5\% for RS). A recent study done by Khawas and Deka [38] indicated that the RS III produced from culinary banana starch through enzyme debranching and hydrothermal process showed remarkable changes in physicochemical, functional, morphological, and thermal characteristics when different processing conditions were employed. It was reported that the modification of starch to RS III occurred due to retrogradation of the amylose fraction. Accordingly, the temperature and storage conditions enhanced its formation. Through analyses of scanning electron microscopy, Fourier transform infrared spectra, and thermogravimetric analysis, the results revealed various significant morphological changes and was observed with increase in starch concentration and elicited prominent modifications in enzyme-debranched RS [38]. 
Furthermore, starch from the peel of Agung banana, variety of Semeru, was isolated and characterised by Hadisoewignyo et al. [2]. The study reported that the characteristics of the resulting processed starch from Agung banana peel met the required specifications with regard to its form, taste, odour, and the presence of hyllus and lamellae. Hyllus is an initial point of starch formation, while lamellae are smooth lines surrounding the hyllus. However, the white colour index $\left(\sim 56^{\circ}\right)$ of Agung banana peel starch did not meet the required specifications (i.e. $95^{\circ}$; white colour) due to an oxidation process that occurred during the starch preparation. In terms of the original shape of starch, starch isolated from the peel of Agung banana showed a small particle size [2] as compared to the elongated and cylindrical shape of green banana starch granules [40]. Moreover, the gel of Agung banana peel starch was reported to be twice more viscous than cassava starch gel, which made it very suitable as an ingredient in various food and nonfood industries including pharmaceutical industries, especially in making a tablet dosage form (i.e. tablet binder) [2].

Subrahmanyan et al. [41] reported that banana pseudostem contains $44.80 \%$ starch. The banana pseudostem was reported to contain high-quality starch [41, 42]. The study reported that starch granules of banana pseudostem are irregular in shape and are bigger in size than those of fruit starch. It also has similar intrinsic viscosity to that of potato starch. The amylose content of the banana pseudostem starch compare well with that of banana fruit and potato starch (21\%) [42]. In addition, Ho et al. [43] reported that banana pseudostem was high in RS (12.81\%). Since there is no updated scientific data related to the functional properties of the RS produced from banana pseudostem, there is an urgency to search for the functional properties of RS produced from banana pseudostem, so that it can be used to produce various value-added functional food products in the near future.

\subsection{Jackfruit}

Jackfruit (Artocarpus heterophyllus) seeds are considered as by-product of the canned and chips food industries. It has long been used as food among the indigenous people in many areas of the world. The seeds are usually consumed boiled, steamed, roasted, or are eaten as a snack [12]. Jackfruit seeds are recognised by many research studies as a raw material for a new source of starch [12]. The jackfruit seeds have been well documented to contain an average of above $60 \%$ dry basis of starch [44]. Native jackfruit seed can contain a reasonable amount of type II RS due to its relatively high amylose content 24-32\% [45]. Jackfruit seed starch is widely used in many manufactured food products as it provides a gelling property that is suitable for various baked products [46]. According to Noor et al. [47], jackfruit seed flour contains amylose of $26.4-30.21 \%$ and starch content of $81.05-82.52 \%$. In terms of proximate composition, the isolated starch from jackfruit seed was reported to contain $8.39-12.20 \%$ of moisture, $1.09-3.67 \%$ of protein, $1.18-1.40 \%$ of fat, and $0.03-0.59 \%$ of ash content. Moreover, the study reported that compared with alkali and enzyme methods, distilled water was the most effective solvent in the extraction of starch from jackfruit seed by presenting the highest yield, protein content, amylose, and total starch [47].

Jackfruit seed starch has been widely studied on its physicochemical, functional, and pharmaceutical properties $[12,48]$. The results revealed that it had potential as functional ingredient for application in food and pharmaceutical products $[44,49]$. Rengsutthi and Charoenrein [44] reported that starch from jackfruit seed had higher amylose content and its granules were much smaller than corn starch and potato starch granules. With regard to the pasting profile, jackfruit seed starch paste showed more resistance to thermal and mechanical shear during cooking. In addition, the jackfruit seed starch granules were round and bell-shaped, and some had irregular 
cuts on their surface [12] with A-type crystallinity pattern [12, 44]. Zhang et al. [48] reported that the starches isolated from different varieties of jackfruit seeds, namely, four exotic jackfruit cultivars (i.e. Artocarpus heterophyllus Lam. cv. Malaixiya No. 2, Malaixiya No. 3, Malaixiya No. 4, Malaixiya No.8) and one local cultivar Xiangyinsuo 1 hao, had differences in average weight-average molar mass ( $\mathrm{Mw})$ of amylose and amylopectin and a fine amylopectin structure. The findings showed that jackfruit seed starch with a larger Mw of amylose and proportions of DP 25-36, DP $\geq 37$, and chain length had lower peak viscosity, breakdown, final viscosity, setback, and adhesiveness but with a higher pasting and gelatinisation temperature, gelatinisation temperature range, gelatinisation enthalpy, and relative crystallinity. In addition, the local cultivar had lower amylopectin Mw, smaller particle size, and good amylopectin structure.

Kittipongpatana and Kittipongpatana [45] applied heat-moisture treatment to increase the yield of type II resistant jackfruit seed starch. It was reported that the native jackfruit seed contained approximately $30 \% \mathrm{w} / \mathrm{w}$ of type II RS and this amount was successfully increased to $52.2 \% \mathrm{w} / \mathrm{w}$ through heat-moisture treatment under the conditions of $25 \%$ moisture content, heating at $80^{\circ} \mathrm{C}$ for $16 \mathrm{~h}$. In addition, thermal profile of the jackfruit seed RS showed an increase in the gelatinisation temperature as the moisture content was increased in the samples. Amylose contents of jackfruit seed RS exhibited a correlation trend with RS content. Jackfruit seed treated with heat-moisture treatment with higher RS demonstrated less swelling, while the solubility remained unchanged [45]. In addition, Madruga et al. [12] observed that the swelling power and solubility of jackfruit seed starch increased with increase in temperature, showing opaque pastes.

Jiamjariyatam [49] studied the effect of blends between wheat flour and jackfruit seed starch on the physical and chemical properties of batter coating. The wheat flour and jackfruit seed starch exhibited the A-type crystal form. Increasing jackfruit seed starch in blends was found to significantly increase amylose content and relative crystallinity in the starch mixture. An amylose content of $40-41 \%$ jackfruit seed starch was found to be suitable as batter coating for deep-frying.

\subsection{Cempedak}

Cempedak (Artocarpus integer (Thunb.) Merr.) belongs to the Moraceae family, which is in the same family as jackfruit (A. heterophyllus Lam.) [50]. Cempedak seeds are the underutilised by-product from the fruit industry which have promising commercial value because they contain an appreciable amount of carbohydrate, protein, dietary fibre, minerals, and various vitamins, such as B1, B2, B3, and C [51]. Research was conducted to determine the composition of cempedak (ripe and unripe) between flesh and seed. Lim et al. [50] reported that unripe cempedak flesh and seeds had higher crude fibre than that of ripe cempedak, while both ripe and unripe cempedak flesh contained more crude fibre than the seed.

Starch extracted from cempedak seed was also studied by Tongdang [52] for its compositions and properties. The study reported that pure starch recovered from cempedak seed yielded $17.5 \%$. The cempedak seed starch comprised approximately $22.64 \%$ of amylose and $16.12 \%$ of RS. Amylose content in fruit seed starch is related to its viscosity as amylose molecules may reassociate to form a gel network during the cooling time after starch gelatinisation [52]. Microscopic morphology of cempedak starch granules are semioval or bell-shaped but differ in size, mainly in the range of 1-10 $\mu \mathrm{m}$. When cempedak starch granules are viewed under normal light, hilum in the centre of the granules is observed. On the other hand, Maltese cross indicates the semicrystalline structure of cempedak seed starch granules are shown under polarised light [52]. 
Important starch properties that affect the characteristic of starchy food were also investigated in a study by Tongdang [52]. Cempedak seed starches swelled up slowly at $55-75^{\circ} \mathrm{C}$, but its swelling power was rapidly increased at $75^{\circ} \mathrm{C}$ and kept increasing until $95^{\circ} \mathrm{C}$. The swelling power showed by cempedak seed starch well agrees with its pasting temperature of around $82^{\circ} \mathrm{C}$. Meanwhile, solubility of cempedak seed starch was also rapidly increased after $75^{\circ} \mathrm{C}$. According to Su et al. [53], several factors can influence the swelling power and solubility of starch, such as granular size, molecular structure of amylopectin, and amylose to amylopectin ratio and composition altered by contaminants. High gelatinisation temperature $\left(76.76-82.19^{\circ} \mathrm{C}\right)$ of cempedak seed starch can be an indicator of a strong bonding of molecules in the granules.

The utilisation of cempedak seeds with its nutritional properties by processing it into flour has become a new source of fibre in bakery products. Cempedak seed flour provides a good source of total dietary fibre (TDF) and RS [51]. The presence of dietary fibre in food products to consumers is becoming important since it shows beneficial effects on the reduction of cholesterol level and colon cancer risk [51]. RS escapes digestion and absorption in the small intestine which has a similar effect to some dietary fibres by conferring a protective effect against colonic diseases [54]. According to Yamada et al. [55], RS helped lower the GI value of food products by increasing the indigestible carbohydrate ingested in small and large intestines.

A study by Aziz and Zabidi [51] showed that the processing of cempedak seed into flour resulted in a composition change. It was observed that cempedak seeds flour (CSF) has higher insoluble dietary fibre (IDF) content of approximately $23.93 \%$ with a reduced RS content of approximately $14.77 \%$ than the original IDF content of $12.44 \%$ and RS content of $29.72 \%$ found in cempedak seeds. According to Vasanthan et al. [56], heating followed by subsequent cooling and dehydration during processing may convert the starch in cempedak seed into indigestible form. In addition, the reduced RS content in CSF was caused by the microstructural damage of the seed during processing which affected the water absorption capability [57]. It was also observed that the soluble dietary fibre (SDF) in cempedak seed and CSF comprised 16.0 and $9.6 \%$ of the total amount of dietary fibre, respectively. Dietary fibre promotes beneficial physiological effects, including the prevention of diseases due to its potential in reducing the risks of cancer and coronary heart diseases [58].

Substitution of non-wheat flour (i.e. CSF) in conventional wheat bread to improve its functional properties was of great interest in recent studies. Zabidi and Aziz [59] reported that CSF substitution at 20 and 30\% in bread formulation significantly increased the RS content in bread samples. The increased RS content reduced the hydrolysis index value which resulted in a lower GI. During bread making, starch gelatinisation upon heat treatment and followed by cooling process resulted in the formation of retrograded starch (RS3) [57]. Moreover, enzymeresistant amylose-amylose linkages that occurred upon retrogradation of starch aided in RS formation [60].

\subsection{Durian}

Durian (Durio zibethinus Murr.) seed is a waste that is comprised of 20-25\% of the whole fruit [61]. Durian seeds are mainly made up of starch and mucilage (gum). Properties of starch isolated from durian seeds to indicate its potential in food applications have become a great interest in recent studies. Based on previous studies, recovery of pure starch from durian seed showed a low yield of 1.8-4.2\% [62] and 10.1\% [52] as compared to other aromatic fruit seeds (i.e. 17.5\% in cempedak and $18.2 \%$ in jackfruit). The low pure starch recovery was due to the presence of gum in durian seeds, which absorbed a large amount of water [63] that trapped 
starch granules in a viscous suspension [64]. Durian seed starch showed an average granular size of $4-5 \mu \mathrm{m}$ which was closely associated to the swelling power and viscosity of starch [52].

According to Tongdang [52], amylose and RS contents of durian seed starch were about 23 and 5\%, respectively. Amylose content is crucial to functional properties of starch since high amylose is linked to high RS level in processed starchy food [65]. Starches that contain a low amount of amylose degrade faster than starches with a high amount of amylose [66]. Malini et al. [67] also reported that durian seed flour (DSF) contained $22.35 \%$ amylose and $66.33 \%$ amylopectin, suggesting that DSF contained similar amylose content with other common starch (i.e. tapioca). Amylose in the flour is important in the gel formation with a firm characteristic, while high amylopectin content is associated with the sticky property [68]. Flour with higher amylopectin content gelatinised faster [69] and reached a higher peak viscosity [67]. Due to similar amylose and amylopectin contents, it was found that DSF can be partially utilised to substitute tapioca flour as a filler ingredient in meatball without affecting its organoleptic quality [67].

A recent study of Baraheng and Karrila [64] was conducted to produce and characterise the durian seed flour and durian seed starch. The study reported that whole durian seed flour (WDSF) had lower starch content than demucilaged durian seed flour (DDSF), while durian seed starch (DS) contained the highest starch content. WDSF contains both starch and non-starch polysaccharides (gums). The removal of mucilage, which was considered a dietary fibre [70] led to an increase in starch content with a reduction in fibre content. Durian seed starch showed a pasting temperature of $76^{\circ} \mathrm{C}$ with its swelling power rapidly increased from 55 to $75^{\circ} \mathrm{C}$ [52]. Due to the presence of mucilage that enhanced water absorption [71], WDSF exhibited higher swelling power, water absorption capacity, peak viscosity, as well as emulsifying capacity and activity than that of DDSF and starch. However, WDSF showed the lowest gel hardness but highest syneresis in which water was released from gel at lower storage temperature [64]. These functional properties of WDSF suggest that it has potential to be used in hydrated product, emulsifier, and fat replacer, but it is not applicable in typical frozen food [64].

Innovative utilisations of the durian seeds as raw materials in food preparation is much encouraged. A recent study by Kumoro and Hidayat [72] on functional and thermal properties of fermented durian seed flour by using Lactobacillus plantarum revealed the potential of fermented durian seed to be used in the substitution of wheat flour as raw material. Fermentation produces acid and alters starch composition and morphology, increasing the gelatinisation temperature of durian seed flour (i.e. from 63.37 to $66.24^{\circ} \mathrm{C}$ ) which is closer to that of wheat flour (i.e. $70.30^{\circ} \mathrm{C}$ ) [72]. Mestres et al. [73] also described that fermentation may induce changes on the conformation of amylose and amylopectin in starch granules, which led to the alteration of gelatinisation temperature. On the other hand, fermented durian seed flour has higher fibre content and lower fat content, showing its superiority and high potential applications in food industry over wheat flour [72].

\subsection{Breadfruit}

Breadfruit (Artocarpus altilis) is rich in carbohydrates of approximately $76.7 \%$ [74] and has potential to be commercially processed into flour and starch. Breadfruit starch size is small with a granular size of $3.0-7.9 \mu \mathrm{m}$ and is irregular in shape (i.e. spherical, elliptical, and polyhedral) [75]. Breadfruit starch has amylose and amylopectin content of 22.52 and $77.48 \%$, respectively, and has moderately high breadfruit starch yield of $14.26 \%$. It has shown its commercial value in industrial food utilisation [76]. In addition, the high amylose content of breadfruit starch and 
its capacity to resist digestion suggest that products fortified with breadfruit can help to regulate blood sugar levels $[76,77]$.

Application of native breadfruit starch as food additive or functional ingredient is limited due to its poor paste clarity, readily retrograded characteristic [75]. Useful information gained from the study on breadfruit starch modification is necessary. In a study by Marta et al. [75], breadfruit starch was modified by using different thermal processes to characterise its physicochemical and pasting properties. Native breadfruit starches undergo changes in granule morphology, crystalline characteristic, pasting, and functionality due to heat-moisture treatment (HMT), microwave heating treatment (MHT), heat pressure treatment (HPT), and osmotic pressure treatment (OPT). Partial gelatinization, indicated by swelling, separation, and granular aggregation/fusion [78], caused HMT-treated and HPT-treated starches granules to lose their physical integrity. In addition, the X-ray diffraction pattern of the breadfruit starch changed from typical B type to A + B type due to HMT, MHT, and HPT, whereas OPT produced A-type breadfruit starch. Starch granules of A type and B type differed in their water content and packing of double helices [65] which were caused by the 36 water molecules vaporisation in the central channel of the B-unit cell and movement of a pair of double helices into the central channel [79]. Tan et al. [80] also described that transformation of crystalline structure of starch (i.e. from B type to A type) during HMT increased the SDS and RS contents in breadfruit starch. The higher compacity of A-type crystalline structure and the A-type amorphous lamellae which also had tight packing with higher density [81] could improve the enzyme resistance of starch during digestibility [80].

In respect to functional properties, thermal-modified breadfruit starch by using $\mathrm{HMT}$, HPT, and $\mathrm{OPT}$ showed higher pasting temperature (i.e. $\geq 76.65^{\circ} \mathrm{C}$ ) than native starch [75] due to the formation of a stronger crystalline structure (i.e. complex bonds between amylose in the crystalline region and amylopectin in amorphous region) which required water absorption of starch at higher temperature [82]. In addition, peak viscosity of thermal-modified breadfruit starch reduced significantly [75] which might be due to the increase in the extent of amylose-amylose and amylose-amylopectin chain interactions that occurred during the modification process [83].

Furthermore, breadfruit starch showed its potential use in fermented product indicated by previous studies. Haydersah et al. [84] observed that amylolytic lactic acid bacteria (ALAB) affected the digestibility of breadfruit starch by decreasing RDS content with an increase in RS content. Increased RS content in fermented breadfruit might be associated with the formation of limit dextrins that resulted from the action of $\alpha$-amylase on amylopectin [84] as well as the formation of type $3 \mathrm{RS}$ due to starch retrogradation during processing $[8,85]$. With increased RS content after fermentation, breadfruit showed its value in the development of fermented products with prebiotic properties since RS can trigger increased production of short-chain fatty acids to stimulate the microbiota of the human gastrointestinal tract [86]. Fermentation also reduced apparent viscosity of gelatinised breadfruit flour and changed its consistency from a thick sticky gelatinised form into semiliquid/liquid product [84].

\section{Effects of resistant starch fortification on glycaemic index of food}

Nowadays, the public have great interest with regard to the possibility of controlling the blood glucose level by altering the glycaemic impact of carbohydrate intake. Glycaemic index is one of the preferred tools used for ranking food with regard to the rate of blood glucose absorption level after food ingestion [5, 87]. GI ranks carbohydrate-containing food based on their blood glucose level effect. The 
postprandial glycaemic responses of carbohydrate-rich food and meals potion vary widely. Therefore, food is categorised according to their postprandial glycaemic responses with guidance of GI values [87]. Food can be grouped into three GI categories, namely, low GI $(\leq 55)$, medium GI (55-69), and high GI $(\geq 70)$.

Food that is categorised as a low GI usually contains a low concentration of soluble sugars but with a high concentration of unavailable carbohydrates [88]. According to Truswell [89], a low GI characteristic of food is usually linked to the RS content. Food with high RS content has more resistance to carbohydrate digestion and hence lower glucose absorption to prevent extreme blood glucose fluctuations, thus lowering the glycaemic level $[87,90]$. Moreover, food that contain slow-digesting carbohydrates have influence on prolonged satiating effects, as these types of food are more satisfying and satiety and thus increase the time elapsed between meals. Food with high amount of RS could be qualified as functional food and have high market opportunities. On the other hand, readily digestible carbohydrates could accelerate the elevated blood glucose level and insulin secretion, which directly lead to various health complications [91].

Plantain flour has market potential due to its favourable characteristic of being able to lower the GI of food then release glucose at a slower rate than high-GI food. This feature is to be useful in the innovation of healthy diets for diabetic and obese individuals. Agama-Acevedo et al. [92] found that low estimated glycaemic index (EGI) cookies can be produced by substituting unripe banana flour for wheat flour. Food produced by incorporating high level of RS is one of the ways to lower the GI of food [27, 92]. According to Saifullah et al. [93], noodles made of green banana flour has lower EGI value than control noodles (i.e. noodle made of $100 \%$ wheat flour). A research done by Okafor and Ugwu [94] showed that green banana and plantain have high and slow digestible starch with low GI value. This is due to the presence of high content of RS and dietary fibre of unripe plantain [94]. Another study performed by Choo and Aziz [95] showed that noodles prepared by partial incorporation of green banana flour for wheat flour had significantly reduced the EGI level of the noodles.

In addition, low GI rice noodles were developed by Srikaeo and Arranz-Martinez [96] by using fortified rice flour enriched with amylose and resistant starch.

Another research conducted by Srikaeo and Sangkhiaw [97] found that GI value of the rice noodles could be lowered to 51.84 (low GI food) by replacing tapioca starch with high amylose maize starch at $60 \%$ level in processing of rice noodles.

Native breadfruit starches contain $2.99 \%$ of SDS and $8.42 \%$ of RS [80]. Since breadfruit contains an appreciable amount of RS that could lower the glycaemic and insulinemic responses, there is a growing interest towards the utilisation of breadfruit in a wide range of products. Noor et al. [98] reported that breadfruit flour had higher crude fibre of $4.85 \%$ than commercial wheat flour, which contained $0.23 \%$ crude fibre. According to Zakaria et al. [99], the 5\% substitution of breadfruit RS in bread formulation gave a lower GI value of 76 than GI value of 97 showed by control bread. A study from Widanagamage et al. [100] also reported a significant lower GI value of 64 for breadfruit when white bread was used as a standard food for comparison. By using $100 \%$ of glucose as a standard food for comparison, boiled breadfruit showed a GI value of 47 [101]. Based on compiled studies, Turi et al. [102] suggested that cooked breadfruit has low to moderate GI which is a potential to be used in controlling diabetes.

\section{Effects of resistant starch fortification on food quality}

Fortification of RS to food can provide alternative ways to fill in the gap between the current RS intake and recommended intake amounts. In parallel, consumer 
demand for healthy food has grown significantly during the last few decades, whereby preference is given to food that contain RS due to its health benefits. This attention has created a good investment opportunity for food manufacturers to incorporate RS into a wide variety of food products, such as bakery products, dairy products, noodles, and pasta. However, manufacturers need to be wise about the RS types and amounts fortified to their products because adding RS to food creates alteration to the product formulation and can adversely affect the quality of many processed products, such as breads and other bakery products, pasta, and other extruded products.

RS can be used as a functional food ingredient for producing different food products to improve their nutritional value by increasing the fibre-like fraction. From the industrial point of view, RS has a low calorie profile and can be used as a bulking agent in reduced sugar or reduced fat food formulations. RS does not compete for the water needed by other ingredients as it significantly holds less water than traditional dietary fibre and allows easier processing because it does not contribute to stickiness. This may be advantageous in low moisture product productions, such as cookies and crackers. In most applications, it does not alter the taste, texture, or appearance of the food [3]. Moreover, according to Sajilata et al. [21], food products supplemented with RS has no negative effect on the texture or taste of the end product. These food products have received greater consumer acceptability and better palatability than food products supplemented with dietary fibres.

According to Nimsung et al. [103], a substantial percentage of RS present in bananas has capability to promote significant health benefits to food products. Several reported studies showed that an increase in RS content of food products (e.g. pasta, bread, and cookies) that was incorporated with unripe banana [35, 93, 104]. A research done by Juárez-García et al. [35] indicated that green banana flour contained high total starch (73.4\%), in which RS represented $17.5 \%$. Several studies demonstrated that the RS content of food products (i.e. noodles, spaghetti, pasta, and cookies) could be improved by the substitution of green banana and unripe plantain $[92,93,95,104]$.

According to Amaral et al. [18], it is technically possible to increase the RS amounts in food. The study investigated factors, such as formulation, loaf size, baking conditions, and storage conditions (i.e. time and temperature), that might affect the formation of RS in wheat bread. Findings indicated that RS content of wheat breads was enhanced by a higher level of moisture in the dough and a larger loaf size of the final product. An extended baking process also increased the RS formation. Storing bread at room temperature for 3 days demonstrated further enhancement of the RS content. Moreover, the RS content of wheat bread could be increased by manipulating the ratio of ingredients and processing time [18]. Studies performed by Sankhon et al. [6] showed that there was improvement in bread RS content as lower temperatures, and longer baking times were applied.

A recent research article [105] reported the substitution of RS for bread flour at $10 \%$ without detrimental effect on bread qualities. However it caused lighter crumb colour and lowered the specific volume when higher substitution levels (20 and 30\%) of RS were in bread formulation for bread making. In addition, at 30\% substitution level, the microstructure of crumbs showed less structural integrity and a coarser network structure [105]. The bread loaves containing RS presented harder bread crumb than the bread without RS substitution [105]. These obtained results were not in line with the reports from Korus et al. [106], whereby the study found that the crumb hardness was reduced with increase in the amount of RS in bread. Besides, the total dietary fibre of bread with RS was also found to increase to $89 \%$ as compared to bread without RS (control) [106]. 
Jiamjariyatam [49] studied on the effect of the blends between wheat flour and jackfruit seed starch on the physical and chemical properties of batter coating. It was found that the amount of oil absorption in the battered product significantly decreased with increase in jackfruit seed starch in the mixture. Higher jackfruit seed starch content in the batter provided greater homogeneity with a fine starch network and less porosity. In terms of sensory evaluation, adding jackfruit seeds starch in batter coating results in increased hardness and crispness, but decreased brittleness, puffiness, oiliness, and oil coating. The study concluded that the ratio of 50:50 (wheat flour:jackfruit seed starch) in batter coating system gave the highest score in overall preference [49].

Utilisation of jackfruit seed starch as a thickener and stabiliser in chilli sauce was successfully developed by Rengsutthi and Charoenrein [44]. Findings showed that the jackfruit seed starch was suitable as a thickener and stabiliser in chilli sauce because the chilli sauce with jackfruit seeds starch had the lowest serum separation and highest viscosity during storage at $37^{\circ} \mathrm{C}$ for 4 weeks [44]. Moreover, research by Rengsutthi and Charoenrein [44] showed that the jackfruit seed starch can be a useful stabiliser in a high acid sauce.

Pasta with lower glycaemic response was developed by adding different types of RS [107]. Findings indicated that the addition of resistant starches influenced the quality of both the raw and cooked pastas but had no effect on cooking quality (i.e. water absorption, cooking loss, swelling index, and dry matter) and sensory characteristics of pastas. On the other hand, a study on instant noodles showed that steaming followed by frying of noodle strands resulted in a slight increase in RS content at approximately 1.2 times. In addition, storage of instant noodles for 60 days at room temperature $\left(\sim 25^{\circ} \mathrm{C}\right)$ showed a significant increase in RS content by 1.4 times. Therefore, storage could help in RS formation [90].

\section{Conclusion and perspectives}

Resistant starch is one of the functional ingredients that is receiving attention due to its unique functional properties and potential physiological benefits. Different digestibility rates of food after ingestion are usually related to various physiological functions, and thus it causes different health effects, such as lowering the glycaemic and insulinemic responses to food, hypocholesterolemic action, and protective effect against colorectal cancer. Food products fortified with RS are becoming popular among consumers who are even ready to pay more for products enriched with RS to increase their dietary fibre intake.

The presence of RS in food is generally low, and it is determined by the starch botanical source, the condition of processing, and storage. The formation of RS during processing of carbohydrate-rich food is influenced by a few factors including moisture content, heating time and temperature, number of heating and cooling cycles, $\mathrm{pH}$, freezing, and drying. $\mathrm{RS}$ type 3 is stable to thermal and often used as a functional ingredient in a wide variety of food products. Due to the good functional properties of RS, with no negative effects on the texture and taste of the end product, it is often incorporated into food products. Food products supplemented with RS has more palatability and greater consumer acceptability in terms of taste and colour than those of food products added with functional ingredients that are associated with high fibre content.

Exploiting fruits as well as its by-products, such as seeds, trunk, and peel, provides opportunity in its use as a natural resource of functional food ingredient in preparing value-added products. Therefore, this can benefit both local farmers and food as well as pharmaceutical industries. But associated drawbacks are 
related to consumer acceptability and processing/extraction cost concerns. Based on the information recorded in this review, it is expected that more botanical sources can be exploited for their potential as functional food ingredients (i.e. RS), including more food products fortified with RS that can be developed for local and international markets. Therefore, researchers and nutritionists should work together on RS production from different botanical sources as well as the application of this processed RS in the development of carbohydrate-based functional foods with low GI.

\section{Acknowledgements}

The authors wish to thank Universiti Sultan Zainal Abidin for the financial support from the University Research Grant under the Lab Material (LABMAT) 2018 grant (UniSZA/LABMAT/2018/02; R0044-R002).

\section{Conflict of interest}

All authors declare there is no conflict of interest in this review.

\section{Notes}

This review is submitted in partial fulfilment of the requirements for the LABMAT 2018 grant (UniSZA/LABMAT/2018/02; R0044-R002) publication.

\section{Author details}

Lee-Hoon $\mathrm{Ho}^{*}$ and Shi-Yun Wong

Department of Food Industry, Faculty of Bioresources and Food Industry, Universiti Sultan Zainal Abidin, Besut, Terengganu, Malaysia

*Address all correspondence to: holeehoon@yahoo.com;

holeehoon@unisza.edu.my

IntechOpen

(C) 2019 The Author(s). Licensee IntechOpen. This chapter is distributed under the terms of the Creative Commons Attribution License (http://creativecommons.org/licenses/ by/3.0), which permits unrestricted use, distribution, and reproduction in any medium, provided the original work is properly cited. (cc) BY 


\section{References}

[1] Jyoshna E, Hymavathi TV. Review of studies on effect of resistant starch supplementation on glucose and insulin. Journal of Pharmacognosy and Phytochemistry. 2017;6(3):55-58

[2] Hadisoewignyo L, Foe K, Tjandrawinata RR. Isolation and characterization of Agung banana peel starch from East Java Indonesia. International Food Research Journal. 2017;24(3):1324-1330

[3] Liu Q. Understanding starches and their role in food. In: Cui S, editor. Food Carbohydrates: Chemistry, Physical Properties, and Applications. 1st ed. New York: CRC Press; 2005. pp. 309-349. DOI: $10.1201 / 9780203485286 . c h 7$

[4] Robertson MD, Bickerton AS, Dermis AL, Vidal H, Frayn KN. Insulinsensitizing effects of dietary resistant starch and effects on skeletal muscle and adipose tissue metabolism. The American Journal of Clinical Nutrition. 2005;82(3):55-567. DOI: 10.1093/ ajcn.82.3.559

[5] Englyst HN, Kingman SM, Cummings JH. Classification and measurement of nutritionally important starch fractions. European Journal of Clinical Nutrition. 1992;46:33-50

[6] Sankhon A, Amadou I, Yao W-R. Application of resistant starch in bread: Processing, proximate composition and sensory quality of functional bread products from wheat flour and African locust bean (Parkia biglobosa) flour. Agricultural Sciences. 2013;4(5B):122-129. DOI: 10.4236/ as.2013.45B023

[7] Fuentes-Zaragoza E, RiquelmeNavarrete MJ, Sánchez-Zapata E, Pérez-Álvarez JA. Resistant starch as functional ingredient: A review. Food Research International.
2010;43(4):931-942. DOI: 10.1016/j.

foodres.2010.02.004

[8] Rosin PM, Lajolo FM, Menezes EW. Measurement and characterization of dietary starches. Journal of Food Composition and Analysis. 2002;15(4):367-377. DOI: 10.1006/ jfca.2002.1084

[9] Jenkins DJ, Kendall CW, Axelsen M, Augustin LS, Vuksan V. Viscous and nonviscous fibres, nonabsorbable and low glycaemic index carbohydrates, blood lipids and coronary heart disease. Current Opinion in Lipidology. 2000;11:49-56. DOI: 10.1097/00041433-200002000-00008

[10] Sheard NF, Clark NG, Brand-Miller JC, Franz MJ, Pi-Sunyer FX, Mayer-Davis E, et al. Dietary carbohydrate (amount and type) in the prevention and management of diabetes: A statement by the American Diabetes Association. Diabetes Care. 2004;27:2266-2271. DOI: 10.2337/diacare.27.9.2266

[11] Foster-Powell K, Holt SH, Brand-Miller JC. International table of glycemic index and glycemic load values. The American Journal of Clinical Nutrition. 2002;76(1):55-56. DOI: $10.2337 / \mathrm{dc} 08-1239$

[12] Madruga MS, Albuquerque FSMD, Silva IRA, Amaral DSD, Magnani M, Neto VQ. Chemical, morphological and functional properties of Brazilian jackfruit (Artocarpus heterophyllus) seeds starch. Food Chemistry. 2014;143:440-445. DOI: 10.1016/j. foodchem.2013.08.003

[13] Aldana DLM, Gómez BT, Oca MMM, Ayerdi SGS, Meraz FG, Pérez LAB. Isolation and characterization of Mexican jackfruit (Artocarpus heterophyllus L) seeds starch 
in two mature stages. Starch/Stärke. 2011;63(6):364-372. DOI: 10.1002/ star.201100008

[14] Englyst HN, Cummings JH. Digestion of the polysaccharides of some cereal foods in the human smallintestine. American Journal of Clinical Nutrition. 1985;42:778-787. DOI: 10.1093/ajcn/42.5.778

[15] Zhang J, Wang ZW. Optimization of reaction conditions for resistant Canna edulis Ker starch phosphorylation and its structural characterization. Industrial Crops and Products. 2009;30(1):105-113. DOI: 10.1016/j. indcrop.2009.02.006

[16] Chung H, Liu Q, Hoover R. Effect of single and dual hydrothermal treatments on the crystalline structure, thermal properties, and nutritional fractions of pea, lentil, and navy bean starches. Food Research International. 2010;43:501-508. DOI: 10.1016/j. foodres.2009.07.030

[17] Ariffin F, Baharom MA, Kaur B, Murad M. The physicochemical properties and sensory evaluation of bread made with a composite flour from wheat and tempoyak (fermented durian). American Journal of Applied Sciences. 2015;12(11):775-784. DOI: 10.3844/ajassp.2015.775.784

[18] Amaral O, Guerreiro CS, Gomes A, Cravo M. Resistant starch production in wheat bread: Effect of ingredients, baking conditions and storage. European Food Research and Technology. 2016;242(10):1747-1753. DOI: 10.1007/s00217-016-2674-4

[19] Eroglu EI, Buyuktuncer Z. The effect of various cooking methods on resistant starch content of foods. Nutrition and Food Science. 2017;47(4):522-533. DOI: 10.1371/ journal.pone.0182604
[20] Hendrich S. Battling obesity with resistant starch. Food Technology. 2010;64(3):22-30

[21] Sajilata MG, Siigbal RS, Kulkarmi PR. Resistant starch-A review. Food Science and Food Safety. 2006;5:1-17. DOI: 10.1111/j.15414337.2006.tb00076.x

[22] Higgins JA, Higbee DR, Donahoo WT, Brown IL, Bell ML, Bessesen DH. Resistant starch consumption promotes lipid oxidation. Journal of Nutrition and Metabolism. 2004;1(1):1-8. DOI: 10.1186/1743-7075-1-8

[23] González-SotoRA,Agama-AcevedoE, Solorza-Feria J, Rendón-Villalobos R, Bello-Pérez LA. Resistant starch made from banana starch by autoclaving and debranching. Starch/Stärke. 2004;56:495-499. DOI: 10.1002/ star.200400283

[24] Aurore G, Parfait B, Fahrasmane L. Bananas, raw materials for making processed food products. Trends in Food Science and Technology. 2009;20(2):7891. DOI: 10.1016/j.tifs.2008.10.003

[25] Croghan M. Resistant starch-A better for you carbohydrate. In: Proceedings for Food Ingredients Asia Conference: Consumer Awareness on Healthy and Functional Ingredients; 16-17 September 2004; Thailand

[26] Jideani IA, Jideani VA.

Developments on the cereals grains Digitaria exilis (acha) and Digitaria iburua (iburu). Journal of Food Science and Technology. 2011;48:251-259. DOI: 10.1007/s13197-010-0208-9

[27] Odenigbo AM, Asumugha VU, Ubbor S, Nwauzor C, Otuonye AC, Offia-OluaBI, etal.Proximatecomposition and consumption pattern of plantain and cooking-banana. British Journal of Applied Science and Technology. 
2013;3(4):1035-1043. DOI: 10.9734/

BJAST/2014/4943

[28] Kwon C, Kim HR, Moon TW, Lee SH, Lee CJ. Structural and physicochemical characteristics of granular malic acid-treated sweet potato starch containing heatstable resistant starch. Journal of Chemistry. 2019;2019:ID2903252. DOI: 10.1155/2019/2903252

[29] Meenu M, Xu B. A critical review on anti-diabetic and anti-obesity effects of dietary resistant starch. Critical Reviews in Food Science and Nutrition. 2018;30:1-13. DOI: $10.1080 / 10408398.2018 .1481360$

[30] Xia J, Zhu D, Wang R, Cui Y, Yan Y. Crop resistant starch and genetic improvement: A review of recent advances. Theoretical and Applied Genetics. 2018;131(12):2495-2511. DOI: 10.1007/s00122-018-3221-4

[31] Vatanasuchart N, Niyomwit B, Wongkrajang K. Resistant starch contents and the in vitro starch digestibility of Thai starchy foods. Kasetsart Journal (Natural Science). 2009;43:178-186

[32] Mota RVD, Lajolo FM, Ciacco C, Cordenunsi BR. Composition and functional properties of banana flour from different varieties. Starch/Stärke. 2000;52:63-68. DOI: $10.1002 /($ SICI) $1521-$ 379X(200004)52:2/33.3.CO;2-M

[33] Ramli S, Alkarkhi AFM, Shin Yong Y, MinTze L, Easa AM. Effect of banana pulp and peel flour on physicochemical properties and in vitro starch digestibility of yellow alkaline noodles. International Journal of Food Sciences and Nutrition. 2009;60(4):326340. DOI: $10.1080 / 09637480903183503$

[34] Ayodele OE, Alebiosu CO. Burden of chronic kidney disease: An international perspective. Advances in Chronic Kidney Disease. 2010;17(3):215224. DOI: 10.1053/j.ackd.2010.02.001

[35] Juárez-García E, Agama-Acevedo E, SăyagoAyerdi SG, Rodrĭguez-Ambriz SL, Bello-Pěrez LA. Composition, digestibility and application in breadmaking of banana flour. Plant Foods for Human Nutrition. 2006;61:131-137. DOI: 10.1007/ s11130-006-0020-x

[36] Rabbani GH, Teka T, Zaman B, Majid N, Khatun M, Fuchs GJ. Clinical studies in persistent diarrhea: Dietary management with green banana or pectin in Bangladeshi children. Gastroenterology. 2001;121:554-560. DOI: 10.1053/gast.2001.27178

[37] Fontes SDM, Cavalcanti MT, Candeia RA, Almeida EL.

Characterization and study of functional properties of banana starch green variety of Mysore (Musa AABMysore). Food Science and Technology, Campinas. 2017;37(2):224-231. DOI: 10.1590/1678-457x.18916

[38] Khawas P, Deka SC. Effect of modified resistant starch of culinary banana on physicochemical, functional, morphological, diffraction, and thermal properties. International Journal of Food Properties. 2017;20(1):133-150. DOI: 10.1080/10942912.2016.1147459

[39] Carmona-Garcia R, Aguirre-Cruz A, Yee-Madeira H, Bello-Pérez LA. Dual modification of banana starch: Partial characterization. Starch/Stärke. 2009;61:656-664. DOI: 10.1002/star.200900152

[40] Sukhija S, Singh S, Riar CS. Isolation of starches from different tubers and study of their physicochemical, thermal, rheological and morphological characteristics. Starch/Stärke. 2015;67(1-9). DOI: 10.1002/ star.201500186 
[41] Subrahmanyan V, Lal G, Bhatia DS, Jain NL, Bains GS, Srinath KV, et al. Studies on banana pseudostem starch: Production, yield, physico-chemical properties and uses. Journal of the Science of Food and Agriculture. 1957;8(5):253-261. DOI: $10.1002 /$ jsfa.2740080502

[42] Shantha HS, Siddappa GS. Physicochemical nature of banana pseudostem starch. Journal of Food Science. 1970;35:72-74. DOI: 10.1111/ j.1365-2621.1970.tb12371.x

[43] Ho L-H, Noor Aziah AA, Bhat R. Mineral composition and pasting properties of banana pseudo-stem flour from Musa acuminata x balbisiana cv. Awak grown locally in Perak, Malaysia. International Food Research Journal. 2012;19(2):409-416

[44] Rengsutthi K, Charoenrein S. Physico-chemical properties of jackfruit seed starch (Artocarpus heterophyllus) and its application as a thickener and stabilizer in chilli sauce. LWT_Food Science and Technology. 2011;44(5):1309-1313. DOI: 10.1016/j. lwt.2010.12.019

[45] Kittipongpatana O, Kittipongpatana N. Resistant starch contents of native and heat-moisture treated jackfruit seed starch. The Scientific World Journal. 2015;2015. DOI: ID519854, 10.1155/2015/519854

[46] Gebre-Mariam T, Schmidt PC. Isolation and physicochemical properties of Enset starch. Starch/ Stärke. 1996;48:208-214. DOI: 10.1002/ star.19960480603

[47] Noor F, Rahman J, Mahomud S, Akter S, Talukder AI, Ahmed M. Physicochemical properties of flour and extraction of starch from jackfruit seed. International Journal of Nutrition and Food Sciences. 2014;3(4):347-354. DOI: 10.1016/j.lwt.2010.12.019
[48] Zhang Y, Zhang Y, Xu F, Wu G, Tan L. Molecular structure of starch isolated from jackfruit and its relationship with physicochemical properties. Scientific Reports. 2017;7:13423. DOI: 10.1038/ s41598-017-13435-8

[49] Jiamjariyatam R. Effect of jackfruit seed starch (Artocarpus heterophyllus) microstructure on properties and characteristics of fried battered product. Walailak Journal Agricultural Technology and Biological Sciences. 2018;15(12):879-892

[50] Lim LBL, Chieng HI, Wimmer FL. Nutrient composition of Artocarpus champeden and its hybrid (Nanchem) in Negara Brunei Darussalam. ASEAN Journal on Science and Technology for Development. 2011;28(2):122-138. DOI: 10.29037/ajstd.39

[51] Aziz NA, Zabidi MA. Partial substitution of wheat flour with chempedak (Artocarpus integer) seed flour in bread. In: Preedy VR, Watson RR, Patel VB, editors. Flour and Breads and their Fortification in Health and Disease Prevention. 1st ed. London: Academic Press; 2011. pp. 365-374. DOI: 10.1016/C2009-0-30556-5

[52] Tongdang T. Some properties of starch extracted from three thai aromatic fruit seeds. Starch/Stärke. 2008;60(3-4):199-207. DOI: 10.1002/ star.200800641

[53] Su HS, Lu W, Chang KC.

Microstructure and physicochemical characteristics of starches in six bean varieties and their bean paste products. Lebensmittel-Wissenchaft Technology. 1998;31:265-273. DOI: 10.1006/ fstl.1997.0350

[54] Bingham SA. Mechanisms and experimental and epidemiological evidence relating dietary fiber (nonstarch polysaccharides) and 
starch to protection against bowel cancer. Proceedings of the Nutrition Society. 1990;49:153-171. DOI: 10.1079/ PNS19900021

[55] Yamada Y, Hosoya S, Nishimura S, Tanaka T, Kajimoto Y, Nishimura A. Effect of bread containing resistant starch on postprandial blood glucose levels in humans. Bioscience, Biotechnology, and Biochemistry. 2005;69:559-566. DOI: 10.1271/ bbb.69.559

[56] Vasanthan T, Gaosong J, Yeung J, Li J. Dietary fiber profile of barley flour as affected by extrusion cooking. Food Chemistry. 2002;77:35-40. DOI: 10.1016/S0308-8146(01)00318-1

[57] Niba LL. Effect of storage period and temperature on resistant starch and b-glucan content in cornbread. Food Chemistry. 2003;83:493-498. DOI: 10.1016/S0308-8146(03)00130-4

[58] Larrauri JA. New approaches in the preparation of high dietary fiber powders from fruit by-products. Trends in Food Science and Technology. 1999;10:3-8. DOI: 10.1016/ S0924-2244(99)00016-3

[59] Zabidi MA, Aziz NAA. In vitro starch hydrolysis and estimated glycaemic index of bread substituted with different percentages of chempedak (Artocarpus integer) seed flour. Food Chemistry. 2009;117(1):64-68. DOI: 10.1016/j. foodchem.2009.03.077

[60] Onyango C, Noetzold H, Ziems A, Hofmann T, Bley T, Henle T. Digestibility and antinutrient properties of acidified and extruded maize-finger millet blend in the production of Uji. LebensmittelWissenchaft Technology. 2005;38:697707. DOI: 10.1016/j.lwt.2004.09.010

[61] Amin AM, Ahmad AS, Yin YY, Yahya N, Ibrahim N. Extraction, purification and characterization of durian (Durio zibethinus) seed gum.

Food Hydrocolloids. 2007;21(2):273-279.

DOI: 10.1016/j.foodhyd.2006.04.004

[62] Oates CG, Powell AD. Bioavailability of carbohydrate material stored in tropical fruit seeds. Food Chemistry. 1996;56:405-414. DOI: 10.1016/0308-8146(95)00209-X

[63] Amid BT, Mirhosseini H. Optimisation of aqueous extraction of gum from durian (Durio zibethinus) seed: A potential, low cost source of hydrocolloid. Food Chemistry. 2012;132(3):1258-1268. DOI: 10.1016/j. foodchem.2011.11.099

[64] Baraheng S, Karrila T. Chemical and functional properties of durian (Durio zibethinus Murr.) seed flour and starch. Food Bioscience. 2019;30:100412. DOI: 10.1016/j.fbio.2019.100412

[65] Lehmann U, Robin F. Slowly digestible starch-its structure and health implications: A review. Trends in Food Science and Technology. 2007;18(7):346-355. DOI: 10.1016/j. tifs.2007.02.009

[66] Cone JW, Wolters MGE. Some properties and degradability of isolated starch granules. Starch/Stärke. 1990;42(8):298-301. DOI: 10.1002/ star.19900420804

[67] Malini D, Arief I, Nuraini H. Utilization of durian seed flour as filler ingredient of meatball. Media Peternakan. 2016;39(3):161-167. DOI: 10.5398/medpet.2016.39.3.161

[68] Hakim UN, Rosyidi D, Widati AS. The effect of arrowroot flour (Maranta arrundinaceae) on physical and sensoric quality of rabbit nugget. Jurnal Ilmu dan Teknologi Hasil Ternak. 2013;8:9-22. DOI: 10.21776/ ub.jitek.2013.008.02.1

[69] Imanningsih N. Gelatinisation profile of several flour formulations 
for estimating cooking behaviour. The Journal of Nutrition and Food Research. 2012;35:13-22. DOI: $10.22435 /$ pgm. v35i1.3079.13-22

[70] Amin AM, Arshad R. Proximate composition and pasting properties of durian (Durio zibethinus) seed flour. International Journal of Postharvest Technology and Innovation. 2009;1(4):367-375. DOI: 10.1504/ IJPTI.2009.030685

[71] Aboubakar Y, Njintang N, Scher J, Mbofung CMF. Physicochemical, thermal properties and microstructure of six varieties of taro (Colocasia esculenta L. Schott) flours and starches. Journal of Food Engineering. 2008;86(2):294-305. DOI: 10.1016/j. jfoodeng.2007.10.006

[72] Kumoro AC, Hidayat JP. Functional and thermal properties of flour obtained from submerged fermentation of durian (Durio zibethinus Murr.) seed chips using Lactobacillus plantarum. Potravinarstvo Slovak Journal of Food Sciences. 2018;12(1):607-614. DOI: $10.5219 / 965$

[73] Mestres C, Zakhia N, Dufour D. Functional and physicochemical properties of sour cassava starch. In: Barsby TL, Donald AM, Frazier PJ, editors. Starch: Structure and Functionality. London: Royal Society of Chemistry; 1997. pp. 163-171. ISBN: 085404860X

[74] Adebowale KO, Olu-Owolabi BI, Olawumi EK, Lawal OS. Functional properties of native, physically and chemically modified breadfruit (Artocarpus altilis) starch. Industrial Crops and Products. 2005;21(3):343351. DOI: $10.1016 /$ j.indcrop.2004.05.002

[75] Marta H, Cahyana Y, Arifin HR, Khairani L. Comparing the effect of four different thermal modifications on physicochemical and pasting properties of breadfruit (Artocarpus altilis) starch.
International Food Research Journal. 2019;26(1):269-276

[76] Akanbi TO, Nazamid S, Adebowale AA. Functional and pasting properties of a tropical breadfruit (Artocarpus altilis) starch from Ile-Ife, Osun State, Nigeria. International Food Research Journal. 2009;16:151-157

[77] Nwokocha ML, Williams AP. Comparative study of physicochemical properties of breadfruit (Artocarpus altilis) and white yam starches. Carbohydrate Polymers. 2010;8:294302. DOI: 10.1016/j.carbpol.2011.01.050

[78] Deka D, Sit N. Dual modification of taro starch by microwave and other heat moisture treatments. International Journal of Biological Macromolecules. 2016;92(Supplement C):416-422. DOI: 10.1016/j.ijbiomac.2016.07.040

[79] Gunaratne A, Hoover R. Effect of heat-moisture treatment on the structure and physicochemical properties of tuber and root starches. Carbohydrate Polymers. 2002;49(4):425-437. DOI: $10.1016 /$ S0144-8617(01)00354-X

[80] Tan X, Li X, Chen L, Xie F, Li L, Huang J. Effect of heat-moisture treatment on multi-scale structures and physicochemical properties of breadfruit starch. Carbohydrate Polymers. 2017;161 (Supplement C):286294. DOI: 10.1016/j.carbpol.2017.01.029

[81] Zhang L, Xie W, Zhao X, Liu Y, Gao W. Study on the morphology, crystalline structure and thermal properties of yellow ginger starch acetates with different degrees of substitution. Thermochimica Acta. 2009;495(1-2):57-62. DOI: 10.1016/j. tca.2009.05.019

[82] Takahashi T, Miura M, Ohisa N, Kobayashi S. Modification of gelatinization properties of rice flour by heat-treatment. Journal of the Society 
of Rheology. 2005;33(2):81-85. DOI: 10.1678/rheology.33.81

[83] Gunaratne A, Corke H. Effect of hydroxypropylation and alkaline treatment in hydroxypropylation on some structural and physicochemical properties of heat-moisture treated wheat, potato and waxy maize starches. Carbohydrate Polymers. 2007;68(2):305-313. DOI: 10.1016/j. carbpol.2006.12.004

[84] Haydersah J, Chevallier I, Rochette I, Mouquet-Rivier C, Picq C, Marianne-Pépin T, et al. Fermentation by amylolytic lactic acid bacteria and consequences for starch digestibility of plantain, breadfruit, and sweet potato flours. Journal of Food Science. 2012;77(8):466-472. DOI: 10.1111/j.1750-3841.2012.02811.x

[85] Rastall RA. Functional oligosaccharides: Application and manufacture. Annual Review of Food Science Technology. 2010;1:305-339. DOI: 10.1146/annurev. food.080708.100746

[86] Brouns F, Kettlitz B, Arrigoni E. Resistant starch and "the butyrate revolution". Trends in Food Science and Technology. 2002;13:251-261. DOI: 10.1016/S0924-2244(02)00131-0

[87] Jenkins DJ, Kendall CW, Augustin LS, Franceschi S, Hamidi M, Marchie A, et al. Glycemic index: Overview of implications in health and disease. The American Journal of Clinical Nutrition. 2002;76:266S-273S. DOI: 10.1093/ ajcn/76/1.266S

[88] Menezes EW, Dan MCT, Cardenette GHL, Goñi I, Luis Arturo Bello-Pérez LA, Lajolo FM. In vitro colonic fermentation and glycemic response of different kinds of unripe banana flour. Plant Foods for Human Nutrition. 20106;5:379-385. DOI: 10.1007/s11130-010-0190-4
[89] Truswell AS. Glycaemic index of foods. European Journal of Clinical Nutrition. 1992;46:S91-S101

[90] Dhital S, Katawal SB, Shrestha AK. Formation of resistant starch during processing and storage of instant noodles. International Journal of Food Properties. 2010;13:454-463. DOI: 10.1080/10942910802627091

[91] Brouns F, Bjorck I, Frayn KN, Gibbs AL, Lang V, Slama G, et al. Glycaemic index methodology. Nutrition Research Reviews. 2005;18(1):145-171. DOI: 10.1079/ NRR2005100

[92] Agama-Acevedo E, Islas-Hernández JJ, Pacheco-Vargas G, Osorio-Díaz P, Bello-Pérez LA. Starch digestibility and glycemic index of cookies partially substituted with unripe banana flour. LWT-Food Science and Technology. 2012;46(1):177-182. DOI: 10.1016/j.lwt.2011.10.010

[93] Saifullah R, Abbas FMA, Yeoh SY, Azhar ME. Utilization of green banana flour as a functional ingredient in yellow noodle. International Food Research Journal. 2009;16:373-379

[94] Okafor CC, Ugwu EE. Comparative study of pasting properties of high fibre plantain based flour intended for diabetic food (fufu). Work Academy of Science, Engineering and Technology. 2013;79:193-197

[95] Choo LC, Abdul Aziz NA. Effects of banana flour and $\beta$-glucan on the nutritional and sensory evaluation of noodles. Food Chemistry. 2010;119:34-40. DOI: 10.1016/j. foodchem.2009.05.004

[96] Srikaeo S, Arranz-Martinez P. Formulating low glycaemic index rice flour to be used as a functional ingredients. Journal of Cereal Science. 2015;61:33-40. DOI: 10.1016/j. jcs.2014.10.002 
[97] Srikaeo K, Sangkhiaw J. Effects of amylose and resistant starch on glycaemic index of rice noodles. Food Science and Technology. 2014;59:1129-1135. DOI: 10.1016/j.lwt.2014.06.012

[98] Noor SNM, Zakaria Z, Hussin N. Comparative studies of the physicochemical and pasting properties of Malaysian breadfruit (Artocarpus altilis) flour and commercial wheat flour. In: Proceedings of the International Conference on Agriculture, Animal Sciences \& Food Technology (ICAFT '18); 30-31 October 2018; Malaysia. 2018. pp. $145-150$

[99] Zakaria Z, Rasdi FS, Hussin N, Shahidan N. Glycemic index and sensory evaluation of breadfruit resistant. In: Proceedings of the International Conference on Agriculture, Animal Sciences \& Food Technology (ICAFT '18); 30-31 October 2018; Malaysia. 2018. pp. 310-315

[100] Widanagamage RD, Ekanayake S, Welihinda J. Carbohydrate-rich foods: Glycaemic indices and the effect of constituent macronutrients. International Journal of Food Sciences and Nutrition. 2009;60:215-223. DOI: $10.1080 / 09637480902849195$

[101] Bahado-Singh PS, Wheatley AO, Ahmad MH, Morrisson EY, Asemota HN. Food processing methods influence the glycaemic indices of some commonly eaten West Indian carbohydrate-rich foods. British Journal of Nutrition. 2006;96:476-481. DOI: 10.1079/ BJN20061792

[102] Turi CE, Liu Y, Ragone D, Murch SJ. Breadfruit (Artocarpus altilis and hybrids): A traditional crop with the potential to prevent hunger and mitigate diabetes in Oceania. Trends in Food Science \& Technology. 2015;45(2):264-272. DOI: $10.1016 / j$. tifs.2015.07.014
[103] Nimsung P, Thongngam M, Naivikul O. Compositions, morphological and thermal properties of green banana flour and starch. Kasetsart Journal (Natural Science). 2007;41:324-330

[104] Ovando-Martinez MS, Sáyago-Ayerdi E, Agama-Acevedo Goñi I, Bello-Pérez LA. Unripe banana flour as an ingredient to increase the undigestible carbohydrates of pasta. Food Chemistry. 2009;113(1):121-126. DOI: 10.1016/j.foodchem.2008.07.035

[105] Shyu Y-S, Hwang J-Y, Huang T-C, Sung W-C. Effect of resistant starch on physicochemical properties of wheat dough and bread. Journal of Food and Nutrition Research. 2018;6(5):335-340. DOI: 10.12691/jfnr-6-5-9

[106] Korus J, Witczak M, Ziobro R, Juszczak L. The impact of resistant starch on characteristics of gluten-free dough and bread. Food Hydrocolloids. 2009;23:988-995. DOI: 10.1016/j. foodhyd.2008.07.010

[107] Gelensér T, Gál V, Hódsági M, Salgó A. Evaluation of quality and digestibility characteristics of resistant starch-enriched pasta. Food Bioprocess Technology. 2007;1(2):171-179. DOI: 10.1007/s11947-007-0040-z 



\title{
Chapter 8
}

\section{Resistant Starch}

\author{
William Russell Sullivan
}

\begin{abstract}
Not all starch that is ingested into the human body is digested into D-glucose the portion that defies this process is referred to as resistant starch (RS) where chemically and mechanically, five different forms have been identified. Regardless of the form, an extensive breadth of health benefits has been associated with the consumption of RS. These include the potential of RS becoming part of weight and diabetes management plans as well as improved colon health and prevention of colon cancer. Therefore, in the past decade, there has been a significant amount of research into how RS concentrations can be increased in various food systems, which have had varying degrees of success; however, are limited to either enzymatic, thermal, or acidic alterations to starch. In a similar fashion, chemical methods of RS measurement have also received a considerable amount of change and enhancement over time, though with most of them to some extent attempting to replicate human carbohydrate digestion.
\end{abstract}

Keywords: resistant starch, crystallinity, butanoic acid, health benefits, digestion, glycemic index

\section{Introduction}

Resistant starch could be the next "super food," its wide range of health benefits make it a very appealing ingredient in food formulations. It was first discovered in the early 1980s and since then large amounts of research have been devoted to RS and its applications in the food industry. The objectives of this chapter are to introduce and explain the different types of RS, identify the wide range of health benefits associated with the consumption of RS as well as the current mechanisms of increasing RS concentrations.

\section{Starch digestion}

The digestion of starches (carbohydrates) begins as soon as the food product enters the oral cavity where the act of chewing (mastication) breaks down the chunks of food into smaller particles [1]. These particles have a larger surface area to volume ratio allowing an effective and penetrating coating of saliva, secreted by the salivary glands in a response to chewing. Saliva ( $\mathrm{pH}$ 6.8), while mostly water, is approximately $1 \%$ a combination of electrolytes and enzymes [1]. One of these enzymes is a digestive protein known as $\alpha$-amylase, which initiates starch hydrolysis by randomly cleaving the $\alpha(1 \rightarrow 4)$ linkages found in starch [2].

Once the food is of a small enough size and sufficiently coated in saliva, it is then swallowed and passes through into the stomach via the pharynx and esophagus. 
The environment of the stomach has a very low $\mathrm{pH}$, around 1.0, due to the presence of hydrochloric acid $(\mathrm{HCl})$. This low $\mathrm{pH}$ environment deactivates the $\alpha$-amylase introduced in the mouth and as such no further carbohydrate digestion occurs in the stomach [3]. Other digestive enzymes including proteases and lipases are introduced initiating the degradation of proteins and lipids [4].

From the stomach, this mixture of acid, enzymes and partially digested food (known as chyme) enters the first section of the small intestine call the duodenum. Here, secretions from the pancreas and the gall bladder raise the $\mathrm{pH}$ up to around 7.8 allowing further $\alpha$-amylase to be introduced from the epithelial cell walls lining the small intestine. The breakdown (hydrolysis) of starch therefore continues in the small intestine creating shorter and shorter chains of carbohydrates with varying lengths until maltose or dextrins are reached. Figure 1 showcases the pathway that is carbohydrate digestion. Maltase, another pancreatic enzyme is introduced to

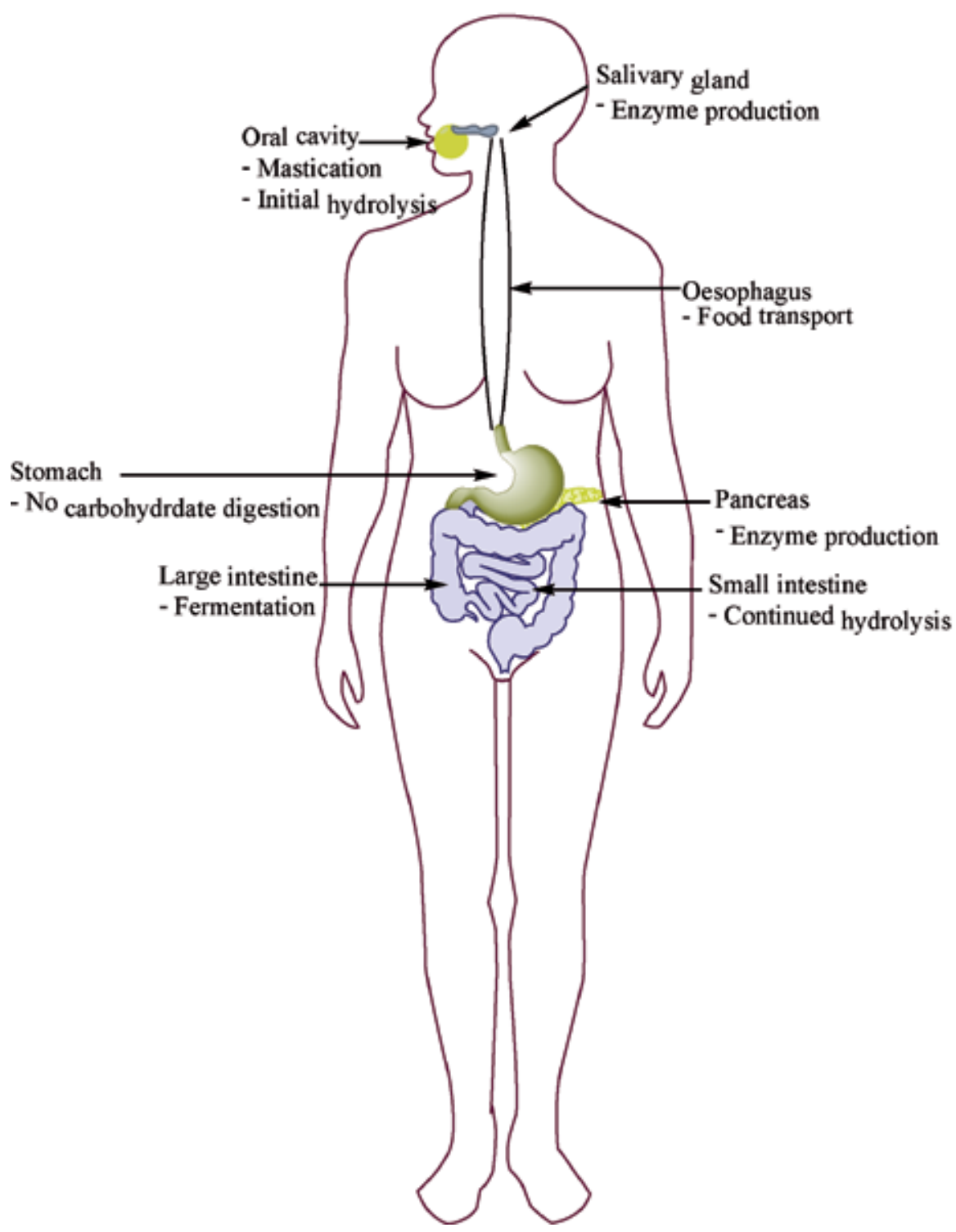

Figure 1.

A summary of different locations and organs, where carbohydrate digestion takes place. 
cleave the $\alpha(1 \rightarrow 4)$ linkage of maltose as $\alpha$-amylase cannot complete this process. $\alpha$-amylase cannot break $\alpha(1 \rightarrow 4)$ linkages if they are near or adjacent to already cleaved bonds, hence the requirement for the additional enzyme, maltase $[3,5]$. Once glucose is produced, monosaccharide is absorbed through the wall of the small intestine into the bloodstream via a number of complex pathways.

The extent and rate of carbohydrate digestion in the human body is highly dependent upon the chain length as it is ingested, hence, the number of glycosidic bonds present and their form. Small structured carbohydrates like maltose, glucose and fructose often present in sweet foods like confectionary and fruits are digested and absorbed relatively quickly as little or no enzymatic digestion is required [6]. Larger, more complex carbohydrates on the other hand such as oligosaccharides and starch can take a significantly longer time to digest - based on this information, starches can be classified into three main forms based on their rate of digestibility [7]:

- Rapidly digestible starch (RDS)

- Slowly digestible starch (SDS)

- Resistant starch (RS)

RDS is strongly correlated with high glycemic index foods as it is mainly amorphous starch that may have been either completely or partially gelatinized. These include baked goods likes white breads and cookies that are digested fairly quickly, in less than $20 \mathrm{~min}$ [6]. SDS is frequently found in weight loss and healthy eating programs as digestion takes significantly longer, between 20 and $110 \mathrm{~min}$. The result of this is a more consistent and controlled release of glucose into the bloodstream over a longer period of time, which also has an impact on sustained satiety (feeling of "fullness") [7].

\section{Resistant starch}

The term resistant starch (RS) was first coined by Englyst et al. in 1982 [8]. RS as a definition refers to the proportion of starch that is ingested though is not digested by human enzymes. This portion of starch therefore passes through the small intestine into the colon undigested, where it has been shown to act as a carbon substrate for beneficial bacteria, making RS a form of dietary fiber. At present, five different forms of RS have been classified (RS1 - RS5) grouped based on how they are resistant to digestion (Table $\mathbf{1}$ ).

RS1 is best described as physically inaccessible starch as a physical barrier is present which prevents enzymes from gaining access to the starch. This barrier is often a plant cell wall where RS1 is frequently found in grains and millet seeds [9]. R2S is commonly referred to as raw starch, or, native starch where the starch granule is completely intact and as such has undergone no form of pressure or thermal processing. Native forms of starch typically have higher degrees of crystallinity resulting in this resistant nature [9].

In comparison, RS3 has intentionally undergone a process of gelatinization and retrogradation (recrystallization) which is usually done hydrothermally. This heating process with subsequent cooling, allows additional starch to crystallize and hence RS to form. RS3 has a number of applications in food manufacturing as it has the ability to form during food processing, unlike both RS1 and RS2 [6]. RS3 is formed most efficiently when the amylose portion of the starch is higher than 


\begin{tabular}{llll}
\hline Form & Description & Food sources & Reference \\
\hline RS1 & $\begin{array}{l}\text { Physically inaccessible } \\
\text { starch }\end{array}$ & $\begin{array}{l}\text { Whole or partially milled seeds, legumes and } \\
\text { pasta }\end{array}$ & {$[11]$} \\
\hline RS2 & Raw, ungelatinized starch & Green bananas & {$[12]$} \\
\hline RS3 & Recrystallized amylose & $\begin{array}{l}\text { Foods that have been cooked then cooled, } \\
\text { including potato and pasta salads }\end{array}$ & {$[13]$} \\
\hline RS4 & $\begin{array}{l}\text { Chemically modified } \\
\text { starch }\end{array}$ & Not naturally occurring & {$[12]$} \\
\hline RS5 & Amylose-lipid complex & High amylose foods & {$[9]$} \\
\hline
\end{tabular}

Table 1.

Different forms of resistant starch with common food sources.

usual, allowing for efficient packing and stacking upon cooling. RS4 has reduced digestibility through chemical modification including etherization, esterification, or cross-linking. Finally, RS5 has only recently appeared in literature over the past 5 years and forms when the amylose portion of the starch complexes with a lipid, such as a free fatty acid to form a helical structure [10].

With ongoing research it would not be surprising if additional forms of RS are indeed discovered and this current classification of RS be altered or revisited in the future. Usually, in most staple, day to day foods, the RS content of foods is low $(<2 \%)$, which has been one of the main driving factors in the increase in research over the last decade investigating methods of how to increase this.

\section{Health benefits}

It is clear that the consumption of RS is positively associated with large and broad range of health benefits in disease prevention as well as treatment, often working complimentary. Briefly, in this section of the chapter, some of the more researched and significant health benefits of RS to date will be discussed, while it is noted that this is very much an active and broad research area [11].

A number of the health benefits associated with RS can be explained by microbial fermentation within the human colon, making RS a prebiotic. In order for a substance to be classified as a prebiotic, it must [12]:

1. resist digestion from both enzymes and acid produced by mammals

2. act as a carbon source for selected bacteria in the large intestine

3. contribute positively to the health of the host via fermentation

\subsection{Short-chain fatty acids}

Through fermentation in the large intestine, a range of short-chain fatty acids (SCFAs) are produced. The SCFAs are manufactured in varying quantities where it largely depends on the type of bacterium and the source of starch though almost always include a combination of acetic (usually the largest amount), propionoic, lactic, and butanoic acids [13]. As a synergistic combination, these acids assist in maintaining the low $\mathrm{pH}$ environment of the colon preventing the growth of pathogenic bacteria and enhancing the proliferation of beneficial, probiotic strains. 


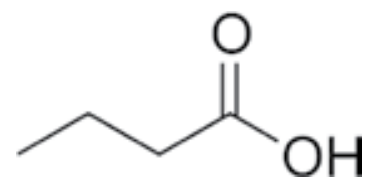

Figure 2.

The molecular structure of butanoic acid.

Butanoic acid (Figure 2) in particular has been shown to demonstrate a range of other health benefits including acting as a preferred carbon source for the cells of the colon (colonocytes). This improves the overall health of the colon by enhancing the strength of the epithelial layer, increasing blood flow, and reducing inflammation [14]. Several other studies have also found that increased quantities of butanoic acid may also be linked with a reduced risk of colon cancer. Butanoic acid has been shown to limit the growth of abnormal, fast growing tumor cells by stopping the G1 phase in cell replication [12]. Colon health is also enhanced by the ability of RS to hold water which increases defecation rates which in turn decreases the accumulation of mutagenic compounds.

\subsection{Glycemic effects}

Foods that have large amounts of RS are digested at a much slower rate when compared to similar foods containing larger concentrations of either SDS or RDS [15]. The effects of these slower digestive processes can be observed in human and animal test subjects with the measurement of blood glucose levels and subsequent insulin responses at different time periods post ingestion. It has been shown and would be expected that foods high in RS would be associated with low glycemic index foods [12]. Therefore, RS has the potential to become part of treatment plans and management programs for weight loss as well as diabetes type two [6].

MacNeil et al. [16] conducted a study where humans suffering from type two diabetes consumed baegels that were supplemented with varying amounts of RS2. Interestingly, when the RS replaced a portion of the total wheat flour, a reduction in postprandial glucose and insulin levels were observed. Although, when the RS2 was added in addition to the wheat flour these reductions were not seen - a phenomenon also observed by Luhovyy et al. [17] in cookies. Behall and Hallfrisch [18] facilitated the formation of RS3 by adding high amounts of amylose into bread formulations finding that when the amylose content made up $50 \%$ of the formation, significant reductions in postprandial glucose and insulin were observed - which was attributed to the straight chained nature of amylose, allowing for efficient stacking and hence crystallization upon cooling.

Evidence is also present to suggest that the consumption of RS can affect the regulation of satiety hormones including glucagon-like-peptide-1 (GPL-1) and peptide YY (PYY). Both hormones play a role in the stimulation of insulin secretion and facilitate a feeling of satiety through the central nervous system, working synergistically with leptin [15]. Zhou et al. [19] and Hoffmann [20] conducted similar studies measuring hormone levels after an increased intake of RS and saw increases in both GLP-1 and PYY while Hoffmann [20] additionally saw a decrease in levels of ghrelin.

It is evident that RS has the potential to have a multi-tiered approach when it comes to the management of weight as well as carbohydrate related conditions including diabetes, in addition to all of the secondary diseases that are commonly 
associated with obesity. RS therefore has significant potential from a health point of view to be incorporated into various food systems not only from a glycemic perspective but a lower bowel health perspective as well.

\section{Increasing resistant starch concentrations}

Given the range of health benefits that are associated with the consumption of RS, a great deal of research has been conducted around how concentrations can be increased in various food systems. In this chapter, we will focus on three main methods of achieving this, with, heat, enzymes and acid.

\subsection{Thermal treatments}

It was mentioned briefly at the start of this chapter that RS3 has a number of applications due to its ability to form during food processing. This is typically best achieved with starches that have higher percentages of amylose, the straight chained form of starch as when the starch is cooled, they have a higher ability and chance to stack together and hence crystallize via hydrogen bonding, compared to that of amylopectin [21]. Indeed, some of the most positive results have come from when researches that have exposed starch to a number of hydrothermal cycles, that is, heating and cooling at pre-determined temperatures and times, more than once [22]. For instance, Liu et al., [23], exposed buckwheat and sorghum starches to annealing and saw buckwheat RS increase from 3.3 to $4.8 \%$ and from 3.5 to 4.2 for sorghum. As expected, they also say an inverse relationship between RS and RDS - as RS increased, the RDS proportion decreased.

\subsection{Enzymatic treatments}

Debranching enzymes such as isoamylase and pullulanase are capable of cleaving the $\alpha(1 \rightarrow 6)$ bonds, commonly found in amylopectin and amylose to a smaller extent. By cleaving these branching points, the result are more straight chained forms of starch, similar to that of amylose - increasing RS concentrations in the same mechanism mentioned previously regarding thermal treatments [24]. Pullulanase in-particular, has received a considerable amount of recent research [24-26]. Shi et al. [26] studied investigated the effects of varying pullulanase concentrations on the digestion of waxy (high amylopectin content) maize starch. The native maize starch possessed an RS concentration of $1.2 \%$ while after an exposure to a pullulanase concentration at 20 enzyme U/g, produced a dramatic increase to $37.7 \%$ RS. They also saw an increase in the apparent amylose content, which would be expected as the sample, which in its native form is nearly $100 \%$ amylopectin, begins to have its $\alpha(1 \rightarrow 6)$ bonds cleaved. Interestingly, they also found a crystalline shift after the enzymatic and thermal treatment, where the maize moved from having an A-type crystal to having a combination of both B-type and V-type. The V-type, as measured with X-ray diffraction, refers to a complexation of amylose with a lipid, otherwise known as RS5 [10], though while still a form of resistant starch, this would indeed hinder the formation of the intended RS3.

\subsection{Acidic treatments}

The action of acidic on RS formation appears to have a very similar mechanism to that of the debranching enzymes - the ability of a low $\mathrm{pH}$ environment to hydrolyse glycosidic linkages increasing the crystalline forming capability. At this point, treating starches with acid appears to be the most ineffective method of increasing $\mathrm{RS}$ concentration, when compared to hydrothermal or enzymatic exposure rounds. 
Acid hydrolysis has been observed in various starches using scanning electron microscopy, where pores form on the outside of the starch granule after an extended exposure. These pores would then act as an access point for hydronium ions to enter the granule, reducing the proportion of amorphous starch present [27]. However, this does not appear to be the case with all starches, with Miao et al. [28] finding that the RS concentrations in maize starch first decreased before increasing with time of exposure, though increases were negligible.

\section{Measurement of resistant starch}

An effective means of measuring RS has proven to be a complex task, where a number of both in-vivo and in-vitro methods have been developed since the early 1980's, with many iterations and alterations since then. A great deal of development was done during the mid-1990s, one of which was by Englyst, Kingman and Cummings [29] in 1992, that effectively separated RDS, SDS, and RS. A method that is still commonly used to gain a broader understanding of digesting [24, 30], often relating to glycemic index studies. The design of this measurement model was to replicate human digestion using a range of additives such as proteases, $\mathrm{HCl}$ and guar gum to replicate the stomach. Starch digestion is achieved with an enzyme mixture of invertase, heat stable $\alpha$-amylase, pullulanase, pancreatin and amyloglucosidase (AMG) where aliquots are taken at different time periods of digestion. Aliquots from $20 \mathrm{~min}$ represent RDS, while $120 \mathrm{~min}$ of digestion refer to SDS and anything left after $240 \mathrm{~min}$ is defined as RS. Glucose concentrations are determined using glucose oxidase and the starch contents are calculated using the following equations:

$$
\begin{aligned}
& \operatorname{RDS}(\%)=\frac{(\mathrm{G} 20-\mathrm{FG}) \times 0.9}{\mathrm{TS}} \\
& \operatorname{SDS}(\%)=\frac{(\mathrm{G} 120-\mathrm{G} 20) \times 0.9}{\mathrm{TS}} \\
& \operatorname{RS}(\%)=\frac{\mathrm{TS}-(\mathrm{RDS}+\mathrm{SDS})}{\mathrm{TS}}
\end{aligned}
$$

One of the more commonly used methods nowadays was developed by McLeary and Monaghan [31] in 2002 and was the result of a comparative study between the different methods used at the time to measure RS in food systems. McLeary and Monaghan [31] experimented with a range of factors, including:

\section{- Concentration of AMG}

- Concentration of pancreatic amylase

- The effect of including proteases

- Incubation conditions such as time, temperature, $\mathrm{pH}$ and agitation

In this method (AOAC Method 2002.02/AACC 32-40.01) $100 \mathrm{mg}$ samples of the food are weighed out and exposed to an enzyme cocktail of both AMG and $\alpha$-amylase for $16 \mathrm{~h}$ at exactly $37^{\circ} \mathrm{C}$. In this step, the non-resistant starch is hydrolysed to glucose, before the reaction is then halted with the addition of ethanol in a repeated washing process. If the researcher requires to measure total starch content so, they can now 
take aliquots from the ethanol for subsequent quantification and addition to resistant starch contents. After the ethanol washing, a pellet contain the RS is obtained at the bottom of the centrifuge tube. The RS is dissolved with agitation over an iced bath with the addition of $\mathrm{KOH}$ before introducing AMG for the final time, to hydrolyse the remaining starch into D-glucose. Subsequently, the RS and total starch contents can be determined with the glucose oxidase peroxidase (GOPOD) reagent.

Clearly, the different methods of RS measurement in foods are complex and have the potential for a great deal of variability if users are not trained adequately. In addition, they can also be rather time intensive and expensive. The methods described here are by no means all of the methods researched - for a greater discussion on the topic, the reader is referred to Berry in 1986 [32], Bjork in 1986 [33] and Champ in 1992 [34].

\section{Conclusions}

In conclusion, it is clear that resistant starch has a large amount of potential to be incorporated into food systems in order to convey a wide range of health benefits from reducing the risk of colon cancer to managing weight loss and diabetes type two. A range of methods have been in trial in attempts to increase RS concentrations in from various sources of starch, including thermal, enzymatic and acidic treatments. Great success has been observed when a holistic approach has been adopted, manipulating each factor to optimize RS formation, rather than depending on one method individually. A great deal of future research lies in this area of optimizing RS concentrations at an economical level, as enzymatic treatments can add significant financial costs when done on a large scale.

\section{Author details}

William Russell Sullivan

School of Science, Bioscience and Food Technology Discipline, RMIT University, Melbourne, Victoria, Australia

*Address all correspondence to: william.sullivan@rmit.edu.au

IntechOpen

(C) 2020 The Author(s). Licensee IntechOpen. This chapter is distributed under the terms of the Creative Commons Attribution License (http://creativecommons.org/licenses/ by/3.0), which permits unrestricted use, distribution, and reproduction in any medium, provided the original work is properly cited. (cc) BY 


\section{References}

[1] Wrolstad RE. Food Carbohydrate Chemistry. United Kingdom: WileyBlackwell; 2012

[2] Dods FR. Understanding Diabetes: A Biochemical Perspective. New Jersey, USA: John Wiley \& Sons Inc; 2013

[3] Jackson AD, McLaughlin J. Digestion and absorption. Surgery (Oxford). 2009;27(6):231-236

[4] Perera A, Meda V, Tyler RT. Resistant starch: A review of analytical protocols for determining resistant starch and of factors affecting the resistant starch content of foods. Food Research International. 2010;43(8):1959-1974

[5] Wong DS, Robertson G. $\alpha$-Amylases, in Handbook of Food Enzymology. New York: CRC Press; 2002

[6] Sharma A, Yadav BS, Ritika. Resistant starch: Physiological roles and food applications. Food Reviews International. 2008;24(2):193-234

[7] Shevkani K et al. Wheat starch production, structure, functionality and applications-A review. International Journal of Food Science \& Technology. 2017;52(1):38-58

[8] Englyst H, Wiggins HS, Cummings JH. Determination of the non-starch polysaccharides in plant foods by gas-liquid chromatography of constituent sugars as alditol acetates. Analyst. 1982;107(1272):307-318

[9] Fuentes-Zaragoza E et al. Resistant starch as functional ingredient: A review. Food Research International. 2010;43(4):931-942

[10] Dupuis JH, Liu Q, Yada RY. Methodologies for increasing the resistant starch content of food starches: A review. Comprehensive Reviews in Food Science and Food Safety. 2014;13(6):1219-1234
[11] Sullivan WR et al. The effects of temperature on the crystalline properties and resistant starch during storage of white bread. Food Chemistry. 2017;228:57-61

[12] Zaman SA, Sarbini SR. The potential of resistant starch as a prebiotic. Critical Reviews in Biotechnology. 2016;36(3):578-584

[13] Zhang Y et al. The in vitro effects of retrograded starch (resistant starch type 3) from lotus seed starch on the proliferation of Bifidobacterium adolescentis. Food \& Function. 2013;4(11):1609-1616

[14] Moraes C, Borges NA, Mafra D. Resistant starch for modulation of gut microbiota: Promising adjuvant therapy for chronic kidney disease patients? European Journal of Nutrition. 2016;55(5):1813-1821

[15] Wong THT, Louie JCY. The relationship between resistant starch and glycemic control: A review on current evidence and possible mechanisms. Starch - Stärke.

2017;69(7-8):1600205

[16] MacNeil S et al. Resistant starch intake at breakfast affects postprandial responses in type 2 diabetics and enhances the glucose-dependent insulinotropic polypeptide - Insulin relationship following a second meal. Applied Physiology, Nutrition \& Metabolism. 2013;38(12):1187-1195

[17] Luhovyy BL et al. The effects of whole grain high-amylose maize flour as a source of resistant starch on blood glucose, satiety, and food intake in young men. Journal of Food Science. 2014;79(12):H2550-H2556

[18] Behall KN, Hallfrisch J. Plasma glucose and insulin reduction after consumption of breads varying in 
amylose content. European Journal of Clinical Nutrition. 2002;56:913-920

[19] Zhou J et al. Peptide YY and Proglucagon mRNA expression patterns and regulation in the gut. Obesity. 2006;14(4):683-689

[20] Hoffmann Sardá FA et al. Impact of resistant starch from unripe banana flour on hunger, satiety, and glucose homeostasis in healthy volunteers. Journal of Functional Foods. 2016;24(Supplement C):63-74

[21] BeMiller NJ, Whistler LW. Starch, Chemistry and Technology. 3rd ed. MA, USA: Academic Press; 2009

[22] Simsek S et al. Effect of acetylation, oxidation and annealing on physicochemical properties of bean starch. Food Chemistry. 2012;134(4):1796-1803

[23] Liu $\mathrm{H}$ et al. Changes in physicochemical properties and in vitro digestibility of tartary buckwheat and sorghum starches induced by annealing. Starch/Stärke. 2016;68(7-8):709-718

[24] Liu W et al. In structure and in-vitro digestibility of waxy corn starch debranched by pullulanase. Food Hydrocolloids. 2017;67:104-110

[25] Ozturk S, Koksel H, Ng PKW. Farinograph properties and bread quality of flours supplemented with resistant starch. International Journal of Food Sciences and Nutrition. 2009;60(6):449-457

[26] Shi M et al. Preparation and properties of RS III from waxy maize starch with pullulanase. Food Hydrocolloids. 2013;33(1):19-25

[27] Hoover R, Manuel H. The effect of heat-moisture treatment on the structure and physicochemical properties of normal maize, waxy maize, dull waxy maize and amylomaize
$\mathrm{V}$ starches. Journal of Cereal Science. 1996;23(2):153-162

[28] Miao M et al. Impact of mild acid hydrolysis on structure and digestion properties of waxy maize starch. Food Chemistry. 2011;126(2):506-513

[29] Englyst HN, Kingman SM, Cummings JH. Classification and measurement of nutritionally important starch fractions. European Journal of Clinical Nutrition. 1992;46(2):33-50

[30] Kim HR et al. Kinetic studies of in vitro digestion of amylosucrasemodified waxy corn starches based on branch chain length distributions. Food Hydrocolloids. 2017;65:46-56

[31] McLeary BV, Monaghan DA. Measurement of resistant starch. Journal of AOAC International. 2002;85(3):665-675

[32] Berry CS. Resistant starch: Formation and measurement of starch that survives exhaustive digestion with amylolytic enzymes during the determination of dietary fibre. Journal of Cereal Science. 1986;4(4):301-314

[33] Björck I et al. On the digestibility of starch in wheat bread - Studies in vitro and in vivo. Journal of Cereal Science. 1986;4(1):1-11

[34] Champ M. Determination of resistant starch in foods and food products: Interlaboratory study. European Journal of Clinical Nutrition. 1992;26(2):51-62 
Section 4

\section{Micrometry and Food Starch}





\title{
Chapter 9
}

\section{Value of Starch in Indian Traditional Food System}

\author{
Shyamalima Gogoi
}

\begin{abstract}
In India, food habit is profoundly influenced by traditions, cultural choices, and religions. For years traditional Indian foods have been prepared, and preparation varies across the country. The wisdom about processing of food, its preservation techniques, and their therapeutic effects has been established for many generations. Starch is the most commonly consumed type of carbohydrate which is found deposited in many crops, such as wheat, corn, rice, and potato, and it serves as the most important source of energy for humans. Starch is classified as complex carbohydrates, and traditionally, complex carbohydrates have been viewed as healthier options. India harbors many plants, out of which traditional starchy tubers and roots which have the potential to be used as sources of flours and starch are also recognized as functional foods because of the presence of functional components such as body-healing chemicals, antioxidants, dietary fibers, and probiotics.
\end{abstract}

Keywords: traditional, therapeutic effects, antioxidants, probiotics

\section{Introduction}

\subsection{Starch overview}

Starch is the major source of carbohydrate and energy reserve in plants, which accumulates in granules and in stems, tubers, corn, seeds, and roots [1]. Starchbearing cereal rice, corn, wheat, and maize are the main sources of dietary energy for the world's population. Plants constitute as the most useful raw material for starch production, and apart from cereals, tubers (such as potatoes) and roots (manioc or cassava) have also high content of starch. It has a wide use and application in food industry as a thickener, gelling agent, a stabilizer for making snacks, meat products, fruit juices, etc. [2]. It is the most common carbohydrate in human diets and represents one of the main sources of energy to sustain life [3].

\subsection{Constituents of starch}

Starch is a degradable, natural, renewable polymer of higher plants, which is white, tasteless, and odorless when grinded into powder that is insoluble in cold water or alcohol. Amylopectin and amylose are the two main constituents of starch which are high molecular weight polymers of linear chains of glucose units linked by $\alpha-1,4$ glycosidic bonds and are highly branched at the $\alpha-1,6$ positions by small glucose chains [4]. Amylose is generally linear, while amylopectin is highly branched with dense structure containing hundreds to thousands of glucose residues. 


\section{Traditional food}

India is well known for its vast knowledge on traditional practices, and they are used by various ethnic groups since prehistoric times. In India people mostly depend upon the agricultural resources and starch being the most abundantly available agricultural product. The Indian indigenous food or traditional food is localized, mainly confined to various indigenous tribal populations as they possess an immense knowledge of their surroundings. Traditional food system plays a significant role in maintaining the well-being and health of indigenous people [5].

\subsection{Traditional south and north Indian food with starch content}

\subsubsection{Rice}

Rice (Oryza sativa L.) is an important food crop providing nutrients and has been consumed by humans for the last 500 years. Rice is the most common and easily available food resource in India. There are different varieties of rice, and its preparation varies from region to region such as boiled, steamed, fried, flour, paste, etc.

White rice is a cereal grain with the husk, bran, and germ removed, and in North India, it is one of the staple foods. It is a good source of carbohydrates, especially for gluten-sensitive individuals and diabetics.

Black rice is a rare and a very old variety of rice that has been growing in India for centuries. It is mainly grown in the northeast region and the southern parts of India. Black rice is a good source of iron, vitamin E, and antioxidants, and the bran hull (outermost layer) of black rice contains one of the highest levels of anthocyanins [6].

\subsubsection{Roti}

Roti is Indian bread made from wheat flour, usually prepared on ghee (Indian butter). Usually people of North India prefer roti than rice which is taken with curries or vegetables. It contains gluten.

\subsubsection{Dal}

Indian legumes (pulses) and Indian dals, viz., chickpea (chana Dal), urad dal (black gram), and masoor dal (red lentils), contain high content of complex carbohydrate with a low glycemic index rating for blood glucose control. It is an indispensable part of a complete Indian dish (Indian thali). Each state of India has its own preference of dal, but the most commonly used are masoor, urad, moong, and chana dal.

\subsubsection{Corn}

In India, maize stands as the third most important crop after rice and wheat (https://farmer.gov.in/M_cropstaticsmaize.aspx). The major chemical component of the maize kernel is starch, which provides up to $73 \%$ of the kernel weight. The starch in maize is made up of two glucose polymers: amylose, an essentially linear molecule, and amylopectin, a branched form. Corn is mainly composed of carbohydrate and fairly high in fiber. Traditionally with the process of corn dry milling, the moist corn granules are turned into products like flakes, meal, and flour. Corn is nutritious, providing fiber, which aids in digestion, plus folate, thiamin, phosphorus, vitamin $C$, and magnesium. 


\subsection{Traditional northeast Indian food with starch content}

Northeast India is one of the mega diversities of India, where different types of tribes and communities reside together with a unique cultural heritage. Different kinds of unique ethnic foods and recipes are part of cultural identity that has developed through ages [7]. The traditional food of northeastern part of India is connected to the cultural, spiritual beliefs considering life and health of different tribes. Major agro-resources of the northeast are rice, maize, finger millet, soybeans, local varieties of potato, ginger, turmeric, seasonal fruits, edible bamboo shoots, etc.

\subsubsection{Cereals}

Rice is the staple food of Northeast India. Both the varieties japonica and the indica are found [8]. Joha is scented rice which is very popular in Assam. Either the rice is taken as steam boiled (ukhua) or it can be sun-dried (aaroi). There is also the prevalence of sticky rice (bora) which is mostly prepared during Bihu festivals of Assam. This sticky rice when consumed in high amount works as a sedative, so farmers mostly take it at night after work for a sound sleep. A special rice preparation "pitha" is made during Bihu festival; likewise in Meghalaya "pu tharo," "pu maloi," and "pu doh" are some of the indigenous snacks prepared from rice.

\subsubsection{Tubers and roots}

Tubers and roots (Figure 1) contain a significant number of mono-phosphate esters in amylopectin covalently bound to starch [9]. Whereas cereal-starch may be produced throughout the year, starchy tuber and root require production immediately after harvesting. They are the second global source of carbohydrates and play a vital role in human diet [10]. Potato, yam, sweet potato, cassava, and sesuk, are tubers and storage root with rich content of edible starch originated from diverse plant sources.

Potato, after rice and maize, is the most important food crop in terms of consumption. It provides high amount of starch, generally $65-80 \%$ [11]. Potato is consumed in the form of curry, fries, mesh potato (aloo pitika), roasted potato (pura aloo), etc. It is so widely used in Northeast India that it almost reached the status of a staple food.

In Assam, a tradition is followed to offer boil yam and sweet potato during one of the Bihu festivals as there is a cultural belief that it will give a better life in the next birth as human. It is also consumed with homemade curd or milk as a sweet dish.

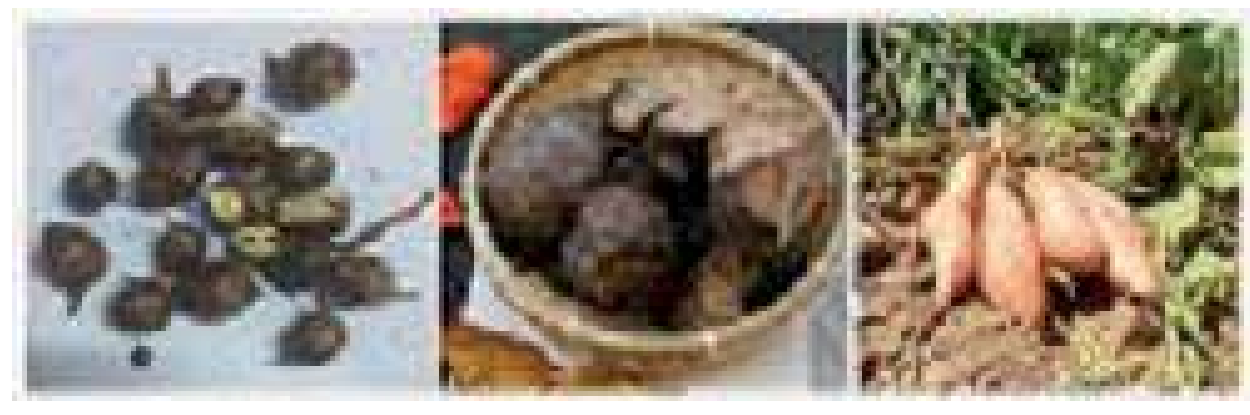

Figure 1.

Locally available tuber sweet potato, sesuk, and yam. 


\subsection{Common indigenous fermented food containing starch}

Fermentation is one of the oldest indigenous forms of food preservation, in which tradition and culture are considered during the preparation. Mostly the preparation is made from local crops, and it varies region to region [12]. Starch is the main carbohydrate from which fermented products are being prepared and has been used for a long time as an effective and low-cost means to preserve the quality and safety of the foods. The fermented foods are better than normal cooked food varieties in terms of nutrition, amenability for digestion, etc.

\subsubsection{Cereal-based fermented food}

Food is prepared by adding water to cooked rice and incubating the mixture overnight. It is the best remedy for gastritis. In some part of India, the rice is mixed with curd and salt after draining off the water.

Bhatooru, marchu, and chilra are fermented staple diet of tribal people of Himachal Pradesh prepared using wheat/barley/buckwheat flour [13]. They are taken in baked form or deep fried in oil.

Idli and dosa are most commonly used traditional fermented foods of southern part of India. Idli is a steamed cake prepared form rice powder and natural black gram dal with the hull removed. Likewise, dosa is made from wheat, maize instead of rice as in idli. Other fermented foods are dhokla and dosa where coarsely ground meals of wheat and maize are used for preparation. They should be consumed the same day as the acid content retards the growth of food.

Jalebi is a sweetened fermented product made from wheat flour, maida, mixed with dahi and water. The fermented batter is deep fat fried in oil and afterward immersed in sugar syrup for few minutes. This traditional food is prepared during marriage ceremonies and festivals of South India.

\subsubsection{Fermented bamboo shoot}

Region wise the preparation and consumption of bamboo shoot vary. Tribal people of eastern Himalayan regions use the fermented bamboo shoot product called mesu [14] as pickle and base of curry. In northeastern region, most of the indigenous dishes are prepared with fermented bamboo shoot, which gives odor and sour taste to the food. Soibum is an indigenous food of the state of Manipur produced exclusively from succulent bamboo shoots found to be an indispensable part of their diet [15].

In addition to the above, various types of traditional fermented foods like bhallae (black gram product), bhatura (white wheat flour product), kulcha (white wheat flour product), naan (wheat flour product), and warri (black gram product) are consumed by the people of India. Hawaijar is a sticky indigenous food prepared from fermented soybean commonly eaten in Manipur [16]. It is known for its strong flavor and can help in malnutrition. Hawaijar is eaten directly or used as a condiment or made into curry. Similarly, tungrymbai is also prepared from fermented beans which is one of the most common and mostly used Khasi delicacies which serves as a cheap source of high-protein food in local diet [17].

\subsection{Fermented alcoholic beverages}

Fermented alcohol like ghanti, jann, and daru popular in Himachal Pradesh and Uttaranchal are prepared from cereals [18]. In northeast region, local beer or wine is prepared from fermented local rice, such as laopani or haanz (Figure 2) by Ahom 


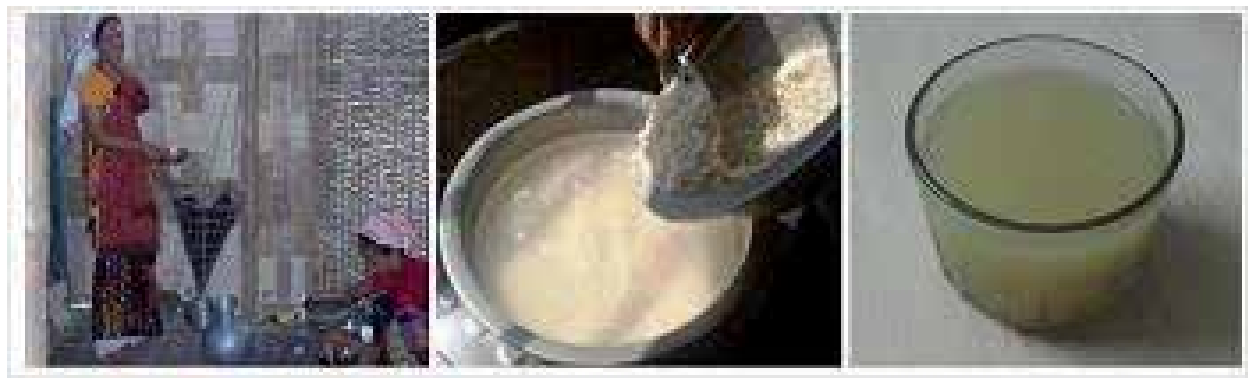

Figure 2.

Local rice beer and its preparation (fermented beverage).

in Assam, Opo in Arunachal, chang a beer made of millet in Sikkim, Kyat is the local rice beer popular in Meghalaya. In fact, this beer is also served to gods and goddesses during certain festivals and celebrations.

\section{Conclusion}

The diversity of indigenous food of India articulates the richness of tradition, culture, belief, and the food availability, but the food system has also undergone changes due to the impact of urbanization, and such kind of undocumented knowledge system is in the verge of extinction. The emphasis should be given for the conservation and documentation of traditional knowledge for the judicious utilization of food related to indigenous people of India.

\section{Author details}

Shyamalima Gogoi

ICMR-RMRC, NE Region, Dibrugarh, Assam, India

*Address all correspondence to: lima.gog4434@gmail.com

\section{IntechOpen}

(C) 2020 The Author(s). Licensee IntechOpen. This chapter is distributed under the terms of the Creative Commons Attribution License (http://creativecommons.org/licenses/ by/3.0), which permits unrestricted use, distribution, and reproduction in any medium, provided the original work is properly cited. (cc) BY 


\section{References}

[1] Smith AM. The biosynthesis of starch granules. Biomacromolecules. 2001;2:335-341

[2] Manek RV, Kunle OO, Emeje MO, Builders P, Rao GVR, Lopez GP, et al. Physical, thermal and sorption profile of starch obtained from Tacca leontopetaloides. Starch-Stärke. 2005;57:55-61

[3] Cornuéjols D. Starch: A structural mystery. Science in School. 2010;14(Spring):22-27

[4] Durrani CM, Donald A. Physical characterization of amylopectin gels. Polymer Gels and Networks. 1995;3:1-27

[5] Bhat S. Importance of traditional food system. Recent Trends in Food Science and Technology 1st ed. Karanataka: The Registrar, Tumkur University; 2012

[6] Yao SL, Xu Y, Zhang YY, Lu YH. Black rice and anthocyanins induce inhibition of cholesterol absorption in vitro. Food \& Function.

2013;4:1b602-1b11608

[7] Begum SS, Gogoi R. Herbal recipe prepared during Bohag or Rongali Bihu in Assam. Indian Journal of Traditional Knowledge. 2017;6:417-422

[8] Wikman J, Larsen FH, Motawia MS, Blennow A, Bertoft E. Phosphate esters in amylopectin clusters of potato tuber starch. International Journal of Biological Macromolecules. 2011;48:639-649

[9] Chandrasekar A, Josheph TJ. Roots and tuber crops as functional foods: A review on phytochemical constituents and their potential health benefits. International Journal of Food Science. 2016;2016:1-15. DOI: $10.1155 / 2016 / 3631647$
[10] Ratnayake WS, Jackson DS. Starch:

Sources and processing. In:

Encyclopedia of Food Science, Food

Technology and Nutrition. 2nd ed.

Hoboken, New Jersey: John Wiley \&

Sons, Inc; 2003. pp. 5567-5572

[11] Tamang JP, Tamang N, Thapa S, Dewan S, Buddhiman T, Yonzan H, et al. Nutritional value of ethnic fermented foods and alcoholic beverages of north East India. Indian Journal of Traditional Knowledge. 2012;11:7-25

[12] Savitri, Bhalla TC. Traditional food and beverages of Himachal Pradesh. Indian Journal of Traditional Knowledge. 2007;6:17-24

[13] Tamang B, Tamang JP. Lactic acid bacteria isolated from indigenous fermented bamboo products of Arunachal Pradesh in India and their functionality. Food Biotechnology. 2009;23:133-147

[14] Das AJ, Deka SC. Mini review on fermented foods and beverages of the north-East India. International Food Research Journal. 2012;19:377-392

[15] Keishing S, Thahira Banu A.

Hawaijar-A fermented soya of Manipur, India: Review. IOSR-Journal of Environmental Science, Toxicology and Food Technology. 2013;4:29-33. DOI: 10.9790/2402-0422933

[16] Sohliya I, Joshi SR, Bhagobaty RK, Kumar R. Tungrymbai- A traditional fermented soybean food of the ethnic tribes of Meghalaya. Indian Journal of Traditional Knowledge. 2009;8:559-561

[17] Roy B, Kala CP, Farooquee NA, Majila BJ. Indigenous fermented food and beverages: A potential for economic development of the high-altitude societies in Uttaranchal. Journal of Human Ecology. 2004;15:45-49 
Value of Starch in Indian Traditional Food System

DOI: http://dx.doi.org/10.5772/intechopen.89086

[18] Sekar S, Mariappan S. Usage of traditional fermented products by Indian rural folks and IPR. Indian Journal of Traditional Knowledge. 2007;6:111-120 



\title{
Micrometrics and Morphological Properties of Starch
}

\author{
Omolola Temitope Fatokun
}

\begin{abstract}
Starch occurs in form of granules and constitutes a primary manner in which of carbohydrates are stored chiefly in seeds and underground organs and sparingly in other morphological parts such as leaf and bark parts of plants. Grains of transitional starch can be found in the stroma of chloroplast and cytoplasm in leaf parts when exposed to the sun and transferred to organs for storage at dark times. The shape and size, ratio of amylose and amylopectin content of starch grains are peculiar to different biological sources. A literature survey was carried out using various search engines. Journals were searched for using keywords such as microscopy, amylopectin, starch granules etc. The relative qualitative and quantitative properties of starches from various morphological parts of 35 species from 15 families were studied. The qualitative features of shape and size as observed from microscopy were not specific or peculiar to each genus and family as similar shapes and sizes cut across different species. Amylopectin and amylose contents varied considerably among all the species and can be used as one of the means of identification for medicinal plants and the delineation of plant species along with other genetic and physicochemical properties.
\end{abstract}

Keywords: starch, botanical source, morphology, microscopy, amylose, amylopectin

\section{Introduction}

\subsection{Starch and formation of starch granules}

Starch, a polymer of glucose which is a metabolite from photosynthesis constitutes a major stored form of carbohydrate found in seeds, roots, rhizomes and tubers. Amylopectin ( $\alpha$-amylose) and amylose ( $\beta$-amylose) constitute over $80 \%$ of many starches. Amylopectin ( $\alpha$-amylose) has a branched structure while $\beta$-amylose consists of linear chains. $\beta$-amylose has a helical arrangement comprising of six glucosyl units and a diameter of $1.3 \mathrm{~mm}$. The differences in the structure and proportion or amounts of amylopectin and amylose give starch grains different properties and add immensely to the distinctive properties of starch from various sources [1-9].

The ubiquitous nature of starch granules to makes the presence or absence it a less important parameter in the identifying and classifying or re-classifying species however, each starch granule has some properties that are peculiar enough to a species and can thus be used to identify such specie. Research toward identify marker patterns in morphology and physicochemical properties are ongoing to identify morphotypes that could possibly be of use taxonomically. 


\section{Botanical sources of starch}

Starch is essentially sourced from plants with many species having from 2 to $12 \%$ starch content. The tuberic part houses most of the starch being a storage organ as in the tuber of Ipomoea batatas (Convolvulaceae) with 5-9\% starch. Other morphological parts such as the wood and stem bark of Rauvolfia serpentina (Apocynaceae); unscraped rhizome of Zingiber officinale Roscoe (Zingibereceae) containing 5-8\% of starch; bark of Cinnamomum zeylanicum Blume; flower bud of the Syzygium aromaticum (L.) Merr. \& L.M. Perry (Myrtaceae); Musa paradisiaca L. (Musaceae) fruits; Sorghum bicolor seeds among others. Starch grains have been found in most plant families. The most widely exploited botanical source of starch in which various cultivars have been developed to give varieties with different starch characteristics range from seeds of Zea mays (Corn starch, amylomaize, waxy maize, etc.), seeds of Oryza sativa (rice starch), tubers from Ipomoea species and root of Manihot esculentum (cassava starch). Other common families are Euphorbiaceae; Zingiberaceae; Cycadaceae, Taccaceae, Bombacaceae, Lamiaceae, Menispemaceae, Combreaceae, Leguminosae and Curcubitaceae (Table 1).

\subsection{Microscopy of starches}

Starch grains are either simple or compound and the number of components present in each compound granule is usually described as 2-, 3-, 4- or 5- etc. Compound granules such as in rice and cardamom are in many cases formed by simple granules clumping together. Granules are formed in from the amyloplast and marked by the hilum. The hilum might be eccentric, mostly longer than being broad, central, open or closed. When starch grains are dry, fissures as seen to begin from the hilum (Figure 1). Under a microscope, the position and various forms of the hilum can be described as a round dot, simple, curved, punctate, stellate or multiple cleft. Sizes of grains of starch have been observed to range from small $(2-10 \mu \mathrm{m})$, medium $(10-60 \mu \mathrm{m})$ and large (extending to $200 \mu \mathrm{m}$ usually from rhizomes and tubers) however small to medium sized grains are most common $[1,2]$. Starch grains come in a wide range of shapes e.g. Regular disc, oval, elongated, rounded, kidney/bean shaped, spherical (e.g. as starch grains from roots of Cassia sieberiana; tapioca starch), polyhedral (e.g. starch grains from maize, wheat, rice, etc.) and irregular forms. Starches high in amylose content are many times more elongated and irregular [3]. Surfaces of starch grain also vary in ornamentation, smoothness, roughness, etc. Many layers built around the hilum, lead to the formation of the starch grain. Different types of fissures such as radial, asymmetric, transverse and reverse fissures are more conspicuous in larger granules (Figure 1) e.g. starch from Ipomoea species, faintly visible in medium sized granules e.g. wheat starch or not visible at all as observed with much smaller starch grains. The striations usually due to the daytime deposition of the starch give rise to differences in some properties such as the starch density, crystallinity and refractive index of the granules. In describing and characterizing starches from different sources, the absence or presence of hilum, form and position of hilum, singular/multiple features in texture, absence or presence of striations which are well defined, fissures, vacuoles, faceting, depressions are all important characteristics [4].

\subsection{Properties of starch and the delineation of species}

The qualitative and quantitative morphological, chemical and genetic properties are peculiar to the source of the starch some of these characteristics include size, 


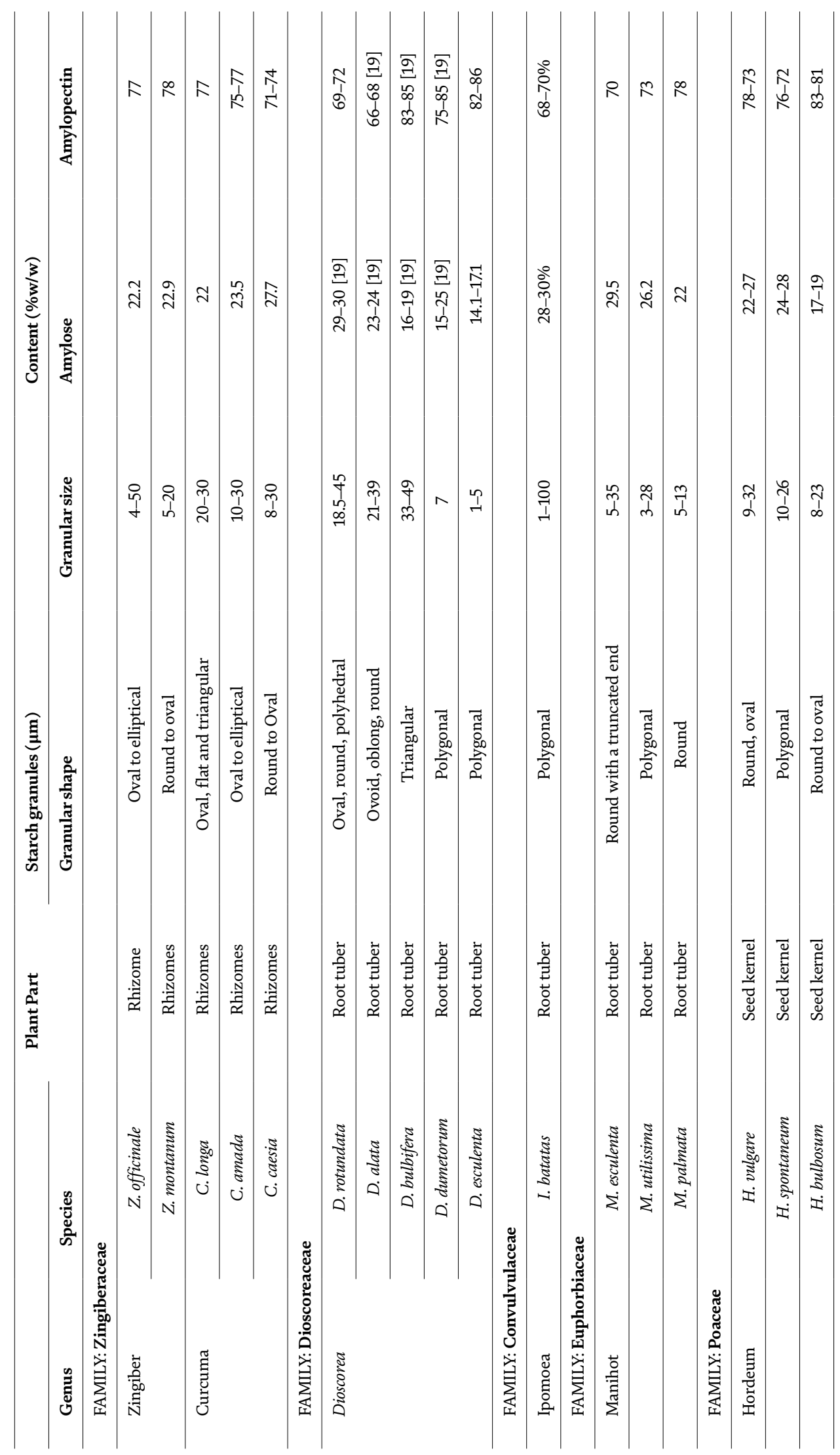




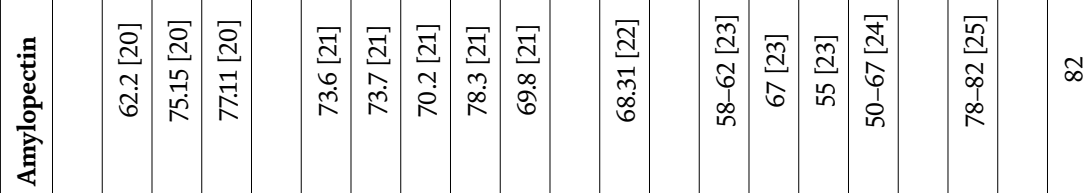

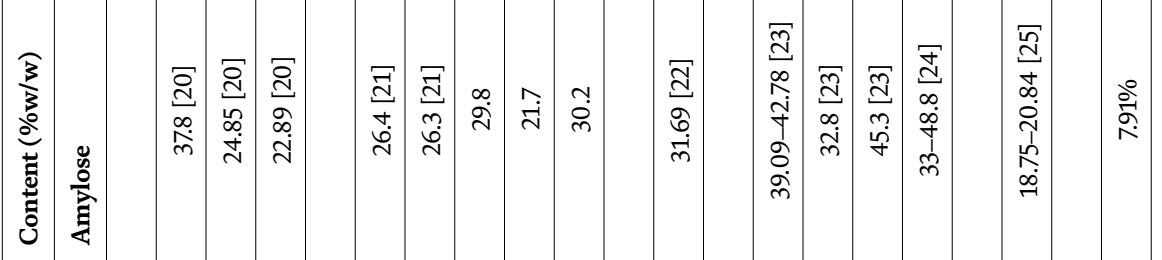

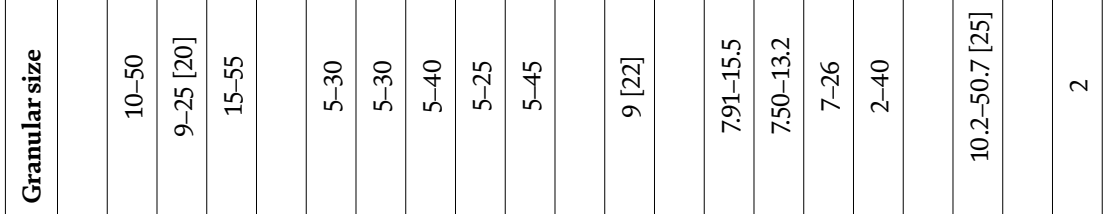

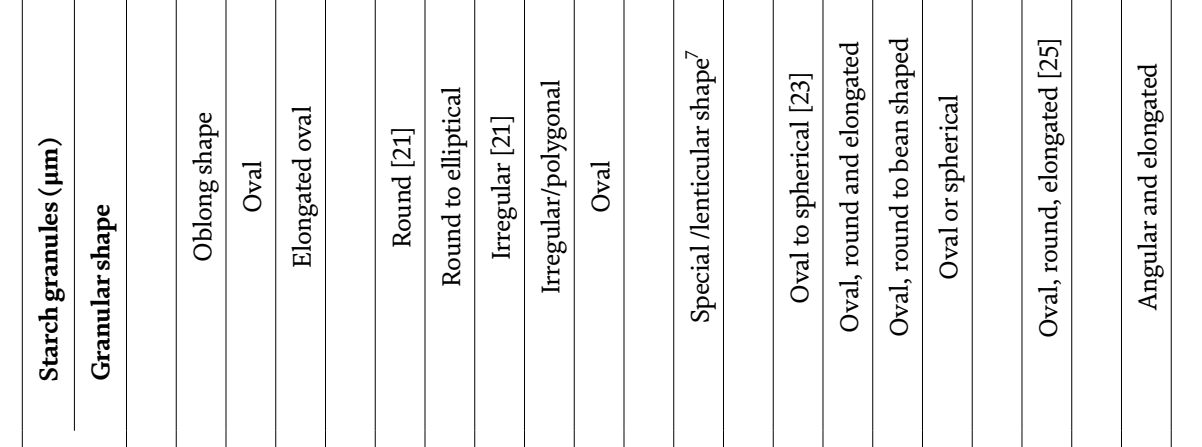

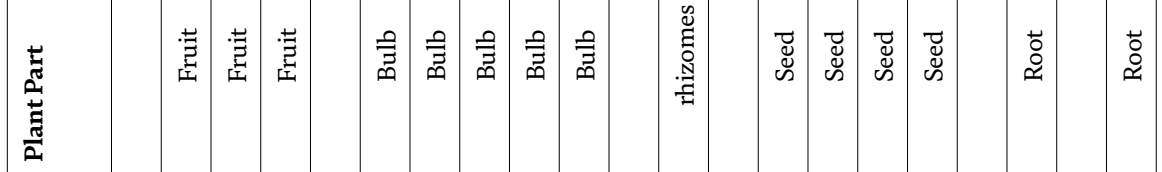

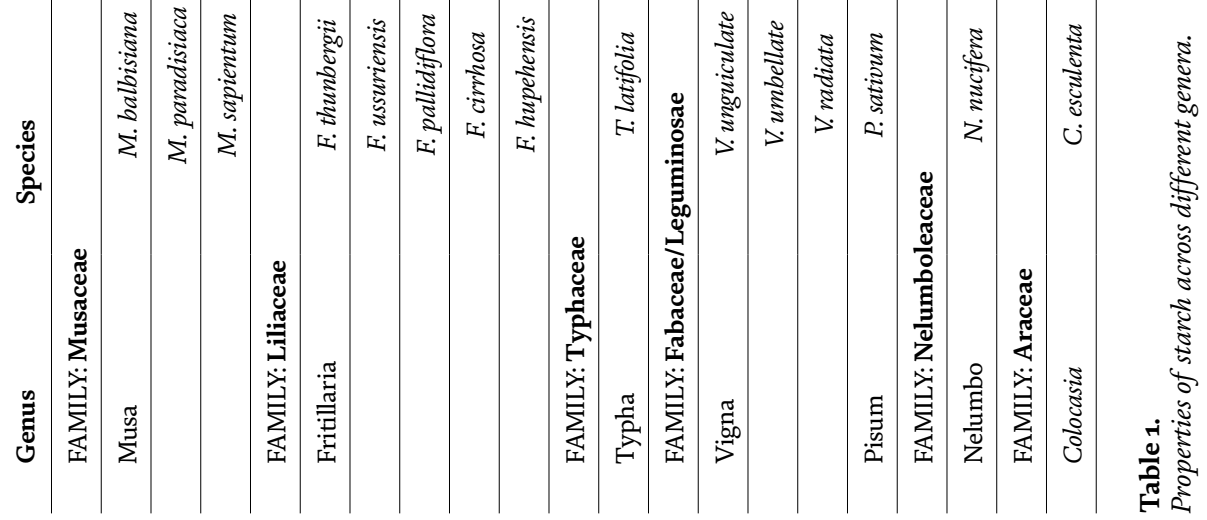



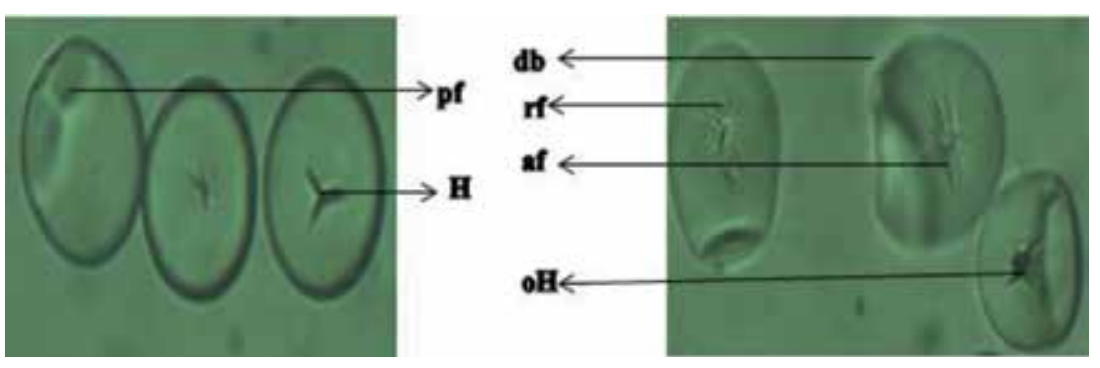

Figure 1.

Microscopy of starch grains from Cassia species (Leguminosae). H: hilum; oH: open hilum; af: asymmetric fissure; rf: reverse fissure; $p f$ : pressure facet; $d b$ : double border.

shape, surface characteristics, gene expression, reaction with iodine, X-ray diffraction pattern and gelatinization.

\subsubsection{Morphological and micrometric properties of starch granules}

These properties as described earlier from the qualitative and quantitative microscopic shape and size of starch grains. Studies carried out from four (4) Curcuma species (C. amada Roxb., C. aromatica Salisb., C. caesia Roxb and C. xanthorrhiza) showed great variability in shape and size (Table 1). Granules from C. aromatica were the largest in size, showed surface ornamentation and varied with the rest of the species [5]. Earlier Scanning electron microscope (SEM) studies in different Curcuma species also report wide difference in the shape and size of starch grains. The rhizomes of some Dioscorea species viz.: D. opposite Thumb, D. alata Linn, D. nipponica Makino, D. bulbifera Linn, and D. septemloba Thumb showed some defining properties along the lines of morphological, crystalline and physicochemical properties [6].

The physiology of the chloroplast and amyloplast of a plant greatly influences the morphology of starch granules thus causing the size and shape of a granule vary considerably with the morphological source of starch e.g. from root or tuber or endosperm of seed or from stem bark; geographical distribution or differences in climatic conditions wherein the plant was grown [7-9]. An extensive study centered on the classification of 23,100 granules and morphological features from 22 orders and 31 families drew out marker morphometric properties based on size, psilate texture, faceting and other quantitative microscopic properties, that could possibly identify species within each family. Examples of such morphotypes are Conoidcuneiforms or Obiculars, Pear Shaped-irregulars, Parabolic_Prism, Prism and Lobate Shell, Prismatic_-Polygonal, Globular-Orbicular, Globular Trapeziform, Hemisphere-Orbicular, etc. Granules from various species from families such as Zamiaceae, Araceae, Nymphaeaceae, Taccaceae, Orchidaceae, Fabaceae, Dioscoreacea, Iridaceae, Fabaceae, Sapotaceae, Apocynaceae, Arecaceae among others were screened. Major observations were the absence direct morphometric markers within 14 of the 31 screened families. The study concluded that morphological parameters were not concrete enough to establish taxonomic identification [4]. Properties of starch grains such as size, structure and shape extracted from various plant sources differ only to a certain extent, such that starches from some different biological sources can be identified. However, the range of shapes and sizes of starch grains are often wide and cut across different granules from even the same source (Figure 1 and Table 1). The variability is often as a result of differences in conditions such as climatic and/or geographic conditions, thus, features are not unique enough across all species in a family or genus. The degradative nature 
of starch within the tissues and storage organs at the point of seed germination, rhizome or tuber maturation, ripening of fruit or starch breakdown due to exposure to heat or chemical agents which causes it to loose textural, volumetric, and their morphometric properties, is another major factor that deters the use of micrometric parameters to classify species.

\subsubsection{Physicochemical properties of starch granules}

Starch grains vary in physicochemical properties. The variation in proportion of amylopectin and $\beta$-amylose present in starch granules contributes toward the slightly distinctive physical and chemical characters of starches from various biological sources. These characters often vary from species to species. In some species the amylose content increases as the granule develops or within different stages of granule formation for example the larger barley grains have higher amylose content than the smaller grains $[3,10,11]$. Pasting properties, reactions to stains, Thermal properties such as gelatinization temperatures and time and retrogradation differ between types of starch based on the amylopectin and amylose content. Increased amounts of amylose in starch, tends to raise gelatinization temperature of the starch $[12,13]$. The length and degree of branching of amylopectin, lipid and amylose content of the starch grossly affects pasting properties. The swelling and pasting properties of starch are enhanced by greater amylopectin content while swelling is inhibited by a higher lipid and amylose content [14]. The viscosity of pastes from starch is also determined by the chain length of amylopectin and molecular size of amylose [15]. There are complex interactions that result in the pasting properties of starches due to the differences in structural features. An increase in pasting temperature, resistance to shear thinning of starch pastes from sources such as Zea mays, Oryza sativa, Triticum aestivum and Hordeum vulgare was observed to be due to amylose lipid complexes [16]. Some starch grains react to iodine potassium iodide differently. For example, potato starch stains purple, indicating a relatively high amount of amylose, whereas starch with very high amylopectin content, such as waxy maize and the tubers of Australian terrestrial orchids, turn to more red color when stained with iodine.

\subsubsection{X-ray diffraction pattern}

Native starches show three main patterns of diffraction when exposed to X-rays called type A, type B and type $C$, which are caused by differences in the crystalline regions of the amylopectin molecules [17] and which relate to botanical differences [3]. In general, cereal starches usually give the A-type diffraction, while tuber starches generally show the B-type pattern (although some tropical tubers have A-type starches) and some root and seed starches give the C patterns [18]. According to a study [6] on different starches also from Dioscorea species, D. nipponica starches displayed A-type of diffraction while starches from D. opposite, D. alata, D. septemloba and $D$. bulbifera exhibited the C-type of diffraction. The following degrees of crystallinity viz.: $33.90,37.63,43.11,32.06$ and $53.35 \%$ were obtained from the five species, respectively. The pattern of X-ray diffraction along with other physicochemical properties can serve as a distinguishing factor for starches from different sources.

\section{Conclusions}

It is pertinent to involve data from morphological, physicochemical, chemical and genetic features of starch granules to classify and delinate species to avoid 
discrepancies. In the identification of some species, some morphometric features are specific enough and marker worthy to identify these species however this will be specie specific and might not cut across the genus or family of the botanical source. The qualitative and quantitative morphological and physicochemical properties can be harnessed in the selection of starches from different botanical sources for different uses.

\section{Acknowledgements}

Thank you to Mr. Agbaje Wale and Miss Esievo Benefit who served as a resource and a source of encouragement.

\section{Author details}

Omolola Temitope Fatokun

Department of Medicinal Plant Research and Traditional Medicine, National Institute for Pharmaceutical Research and Development, Idu, Indsutrial layout, F.C.T., Abuja, Nigeria

*Address all correspondence to: omololafatokun@gmail.com

\section{IntechOpen}

(C) 2019 The Author(s). Licensee IntechOpen. This chapter is distributed under the terms of the Creative Commons Attribution License (http://creativecommons.org/licenses/ by/3.0), which permits unrestricted use, distribution, and reproduction in any medium, provided the original work is properly cited. (cc) BY 


\section{References}

[1] Jane J, Kasemsuwan T, Leas S, Zobel H, Robyt JF. Anthology of starch granule morphology by scanning electron microscopy. Starch. 1994;46:121-129

[2] Sivak MN, Preiss J. Industrial applications of starch. In: Sivak MN, Preiss J, editors. Advances in Food Nutrition Research. Starch: Basic Science to Biotechnology. Cambridge, Massachusetts: Academic Press; 1998. pp. 163-170

[3] Buléon A, Colonna P, Planchot V, Ball S. Starch granules: Structure and biosynthesis. International Journal of Biological Macromolecules. 1998;23(2):85-112. DOI: $10.1016 /$ S0141-8130(98)00040-3

[4] Mercader J, Akeju T, Brown M, Bundala M, Collins MJ, Copeland L, et al. Exaggerated expectations in ancient starch research and the need for new taphonomic and authenticity criteria. FACETS. 2018;3:777-798

[5] Sajitha PK, Sasikumar B. Qualitative and quantitative variation in starch from four species of Curcuma. Cytologia. 2014;80(1):45-50

[6] Jiang Q, Gao W, Shi Y, Lia X, Wang H, Huang L, et al.

Physicochemical properties and in vitro digestion of starches from different Dioscorea plants. Food Hydrocolloids. 2013;32(2):432-439

[7] Singh J, McCarthy O, Singh H. Physico-chemical and morphological characteristics of new Zealand Taewa (Maori potato) starches. Carbohydrate Polymers. 2006;64:569-581

[8] Braga MEM, Moreschi SRM, Meireles MAA. Effects of supercritical fluid extraction on Curcuma longa L. and Zingiber officinale $\mathrm{R}$. starches. Carbohydrate Polymers.
2006;63(3):340-346. DOI: 10.1016/j. carbpol.2005.08.055

[9] Zhang H, Zhang W, Xu C, Zhou X. Morphological features and physicochemical properties of waxy wheat starch. International Journal of Biological Macromolecules. 2013;62:304-309. DOI: 10.1016/j. ijbiomac.2013.09.030

[10] Kang MY, Sugimoto Y, Kato I, Sakamoto S, Fuwa H. Some properties of large and small starch granules of barley (Hordeum julgare L.) ends sperm. Agricultural and Biological Chemistry. 1985;49:1291-1297

[11] Tester RF. Starch: The polysaccharide fractions. In: Frazier PJ, Donald AM, Richmond P, editors. Starch: Structure and Functionality. London, UK: The Royal Society of Chemistry; 1997. pp. 163-171

[12] Galliard T, Bowler P. Morphology and composition of starch. In: Galliard T, editor. Starch: Properties and Potential. New York: John Wiley \& Sons; 1987. p. 281

[13] Fredriksson H, Silverio J, Andersson R, Eliasson AC, Aman P. The influence of amylose and amylopectin characteristics on gelatinization and retrogradation properties of different starches. Carbohydrate Polymers. 1998;35:119-134

[14] Tester RF, Morrison WR. Swelling and gelatinization of cereal starches. Effects of amylopectins, amylose, and lipids. Cereal Chemistry. 1990;67:551-557

[15] Jane J, Chen JF. Effect of amylose molecular size and amylopectin branch chain length on paste properties of starch. Cereal Chemistry. 1992;69:60-65 
[16] Jane J, Chen YY, Lee LF, McPherson AE, Wong KS, Radosavljevic M, et al. Effects of amylopectin branch chain length and amylose content on the gelatinization and pasting properties of starch. Cereal Chemistry. 1999;76:629-637

[17] Perez S, Imberty A. Structural features of starch. Carbohydrates in Europe. 1996;15:17-21

[18] Zobel HF. Starch crystal transformation and their industrial importance. Starch/Staerke. 1998;40:1-5

[19] Bolanle O, Mpoko B, Robert A. Physicochemical properties of yam starch: Effect on textural quality of yam food product (pounded yam). Journal of Food, Agriculture and Environment. 2011;9(1):145-150

Otegbayo B, Lana O, Ibitoye W. Isolation and physicochemical characterization of starch isolated from plantain (Musa paradisiaca) and cooking banana (Musa sapientum). Journal of Food Biochemistry. 2009;34:1303-1318

[20] Shajun W, Jinglin Y, Wenyuan G, Jiping P, Yiugao Y, Peigen X.

Characterization of starch isolated from Fritillaria in traditional Chinese medicine. Journal of Food Engineering. 2007;80:727-734. DOI: 10.1016/j. jfoodeng.2006.01.086

[21] Kurzawska1 A, Gorecka D, Błaszczak W, Szwengiel A, Paukszta D, Lewandowicz D. The molecular and supermolecular structure of common cattail (Typha latifolia) starch. Starch/ Stärke. 2014;66:1-8. DOI: 10.1002/ star.201300283

[22] Chavan U, Momin A, Chavan JK, Ryszard A. Characteristics of starch from rice bean (Vigna umbellata L.) seeds-A short report. Polish Journal of Food and Nutrition Sciences. 2009;59:25-27
[23] Stute R. Properties and application of pea starches. Part 1: Properties. Starch-Starke. 1990;42:178-184

[24] Syed A, Singh S. Physicochemical, thermal, rheological and morphologhical characteristics of starch from three Indian Lotus root (Nelumbo nucifera Gaertn) cultivars. Journal of Food Processing \& Technology. 2013;S1:003. DOI: 10.4172/2157-7110. S1-00 


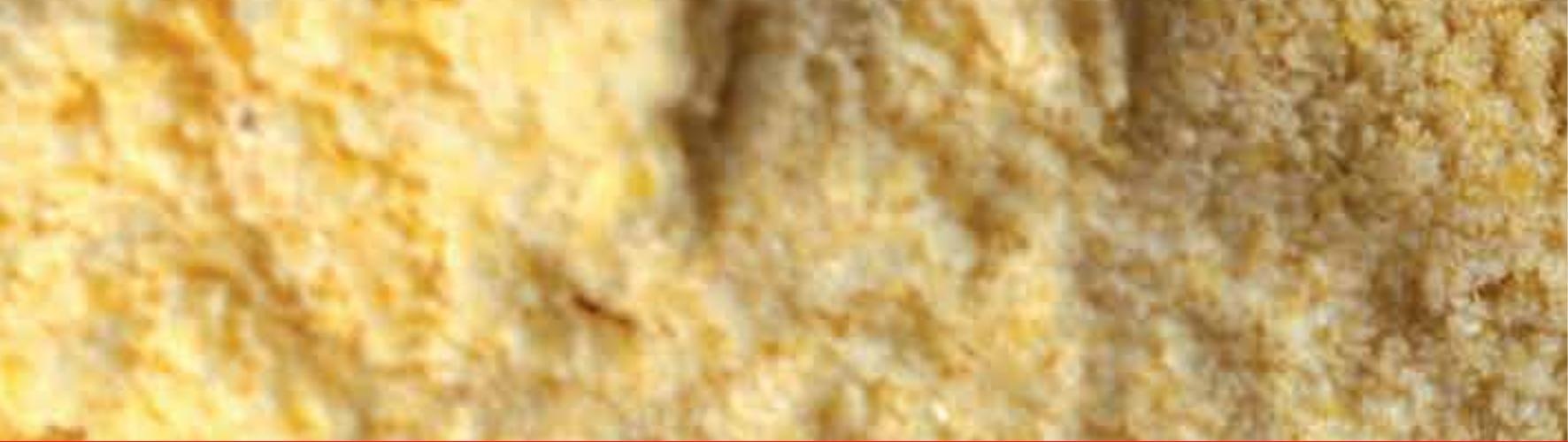

\section{Edited by Martins Emeje}

This book is about the chemical properties of starch. The book is a rich compendium driven by the desire to address the unmet needs of biomedical scientists to respond adequately to the controversy on the chemical properties and attendant reactivity of starch. It is a collective endeavor by a group of editors and authors with a wealth of experience and expertise on starch to aggregate the influence of qualitative and quantitative morphological, chemical, and genetic properties of starch on its functionalities, use, applications, and health benefits. The chemical properties of starch are conferred by the presence, amount and/or quality of amylose and amylopectin molecules, granule structure, and the nature and amounts of the lipid and protein molecules. The implication of this is comprehensively dealt with in this book. 